Florida International University FIU Digital Commons

6-18-2013

\title{
The Moderating Role of Personality on Workplace Conflict and Outcomes
}

John Wittgenstein

jwitt008@fiu.edu

DOI: $10.25148 /$ etd.FI14071163

Follow this and additional works at: https://digitalcommons.fiu.edu/etd

\section{Recommended Citation}

Wittgenstein, John, "The Moderating Role of Personality on Workplace Conflict and Outcomes" (2013). FIU Electronic Theses and Dissertations. 1548.

https://digitalcommons.fiu.edu/etd/1548

This work is brought to you for free and open access by the University Graduate School at FIU Digital Commons. It has been accepted for inclusion in FIU Electronic Theses and Dissertations by an authorized administrator of FIU Digital Commons. For more information, please contact dcc@fiu.edu. 


\section{FLORIDA INTERNATIONAL UNIVERSITY \\ Miami, Florida}

THE MODERATING ROLE OF PERSONALITY ON WORKPLACE CONFLICT AND OUTCOMES

A thesis submitted in partial fulfillment of the

requirements for the degree of

MASTER OF SCIENCE

in

PSYCHOLOGY

by

John P. Wittgenstein 
To: Dean Kenneth G. Furton

College of Arts and Sciences

This thesis, written by John P. Wittgenstein, and entitled The Moderating Role of Personality on Workplace Conflict and Outcomes, having been approved in respect to style and intellectual content, is referred to you for judgment.

We have read this thesis and recommend that it be approved.

$\begin{array}{r}\hline \text { Chockalingam Viswesvaran } \\ \hline \text { Jesse S. Michel } \\ \hline \text { Valentina Bruk-Lee, Major Professor }\end{array}$

Date of Defense: June 18, 2013

The thesis of John P. Wittgenstein is approved.

\begin{tabular}{r} 
Dean Kenneth G. Furton \\
College of Arts and Sciences \\
\hline Dean Lakshimi N. Reddi \\
University Graduate School
\end{tabular}

Florida International University, 2014 


\section{DEDICATION}

To Richard P. Wittgenstein (1952 - 2010). 


\section{ABSTRACT OF THE THESIS \\ THE MODERATING ROLE OF PERSONALITY ON WORKPLACE CONFLICT AND OUTCOMES}

by

John P. Wittgenstein

Florida International University, 2014

Miami, Florida

\section{Professor Valentina Bruk-Lee, Major Professor}

The purpose of this study was twofold. The first was to further clarify and expand or understanding of the relationship between interpersonal conflict, incivility, and their roles as stressors in the stressor-strain relationship. The second goal was to examine how neuroticism, extraversion, agreeableness, conscientiousness, trait anger, and sphere specific locus of control moderate the stressor-strain relationship between task conflict, relationship conflict, incivility and workplace and health outcomes. The results suggest that extraversion, neuroticism, conscientiousness, agreeableness, trait anger, and locus of control play significant roles in how workplace aggression affects individuals. These findings suggest that occupations that experience a high level of workplace aggression should consider incorporating these personality traits into their selection system as a way of limiting or reducing the effects workplace aggression can have on individual health, wellbeing, and job outcomes. 


\section{TABLE OF CONTENTS}

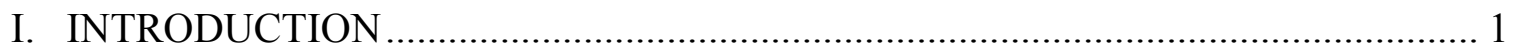

Defining and Conceptualizing Conflict and Incivility............................................. 2

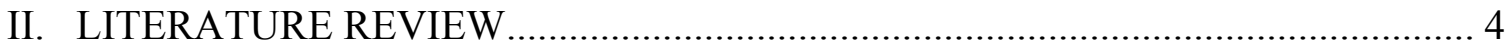

Historical Overview: Incivility and Workplace Conflict........................................... 4

Comparing Task Conflict, Relationship Conflict, and Incivility ................................ 9

Relationship Conflict, Task Conflict, Incivility, and the Job Stress Model ................. 11

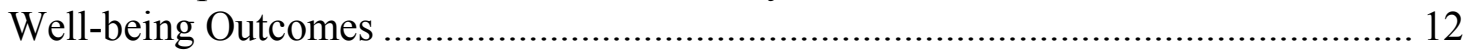

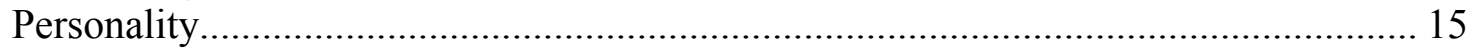

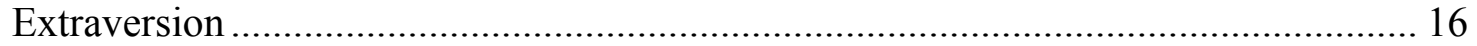

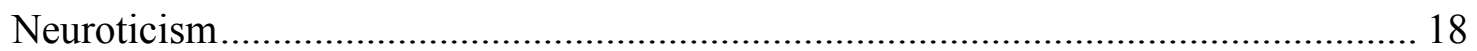

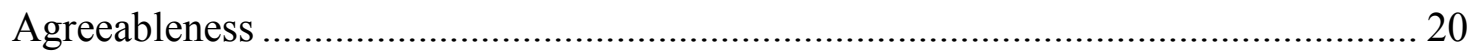

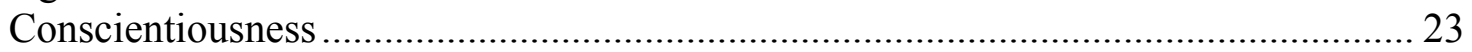

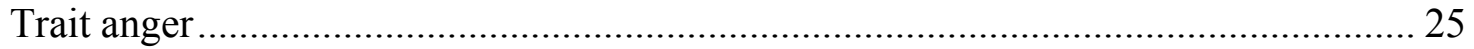

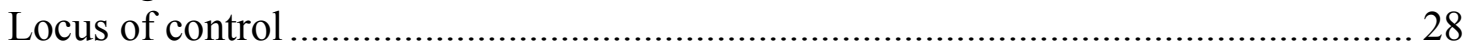

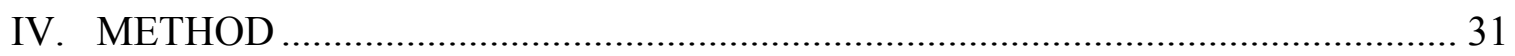

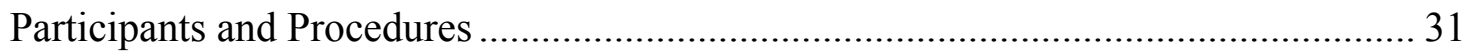

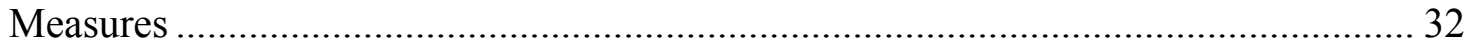

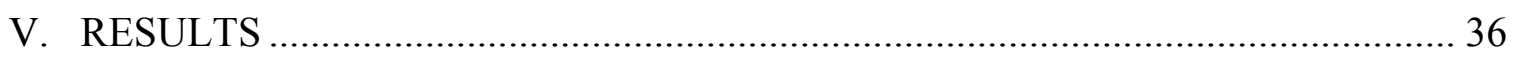

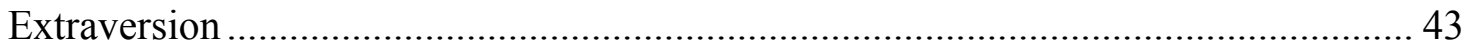

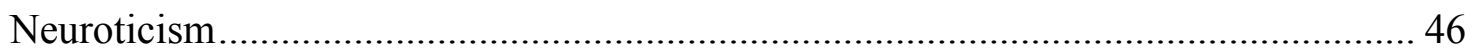

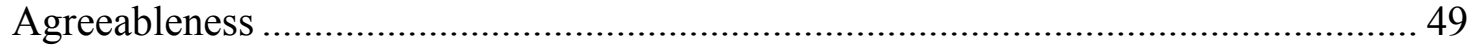

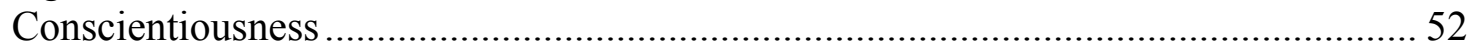

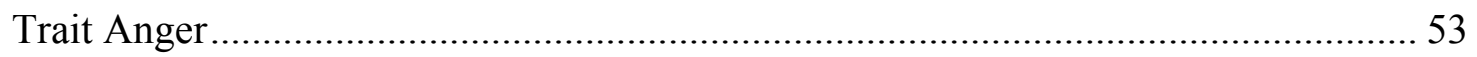

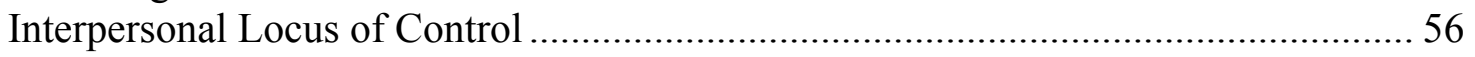

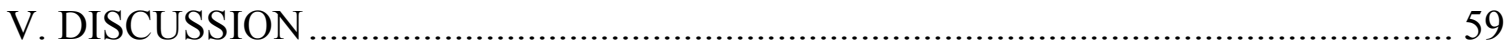

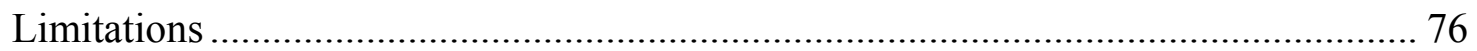

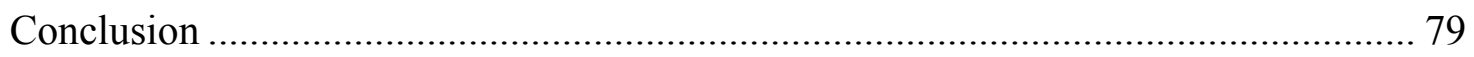

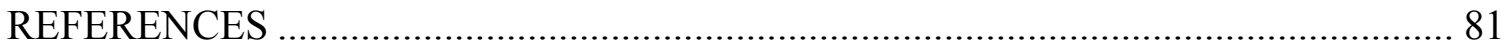

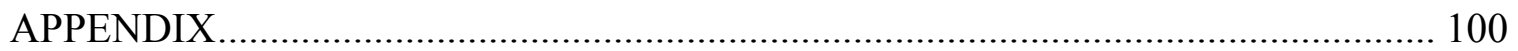




\section{LIST OF TABLES}

TABLE

PAGE

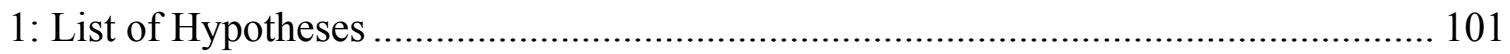

2: Means, Standard Deviations, and Correlations....................................................... 107

3: Hierarchical regression estimate for Incivility, Relationship Conflict, and Task

Conflict on Negative Emotions............................................................................... 109

4: Hierarchical regression estimates for Incivility, Relationship Conflict, and Task

Conflict on Depression

5: Hierarchical regression estimate for Incivility, Relationship Conflict, and Task

Conflict on Physical Symptoms

6: Hierarchical regression estimate for Incivility, Relationship Conflict, and Task

Conflict on Stress

7: Hierarchical regression estimate for Incivility, Relationship Conflict, and Task Conflict on Job Satisfaction

8: Hierarchical regression estimate for Incivility, Relationship Conflict, and Task Conflict on Life Satisfaction

9: Mediated regression of Negative Emotions on the Incivility to Strain relationship... 115

10: Mediated regression of Negative Emotions on the Relationship Conflict to Strain relationship

11: Mediated regression of Negative Emotions on the Task Conflict to Strain relationship

12: Extraversions moderating effects on Negative Emotions

13: The moderating role of Extraversion on the Incivility to strain relationship

14: The moderating role of Extraversion on the Relationship Conflict to strain relationship

15: The moderating role of Extraversion on the Task Conflict to strain relationship .... 126

16: Neuroticism moderating effects on Negative Emotions 128 
17: The moderating role of Neuroticism on the Incivility to strain relationship

18: The moderating role of Neuroticism on the Relationship Conflict to strain relationship

19: The moderating role of Neuroticism on the Task Conflict to strain relationship..... 133

20: Agreeableness moderating role on Negative Emotions

21: The moderating role of Agreeableness on the Incivility to strain relationship 136

22: The moderating role of Agreeableness on the Relationship Conflict to strain relationship..... 138

23: The moderating role of Agreeableness on the Task Conflict to strain relationship . 140

24: The moderating role of Conscientiousness on the Negative Emotions 142

25: The moderating role of Conscientiousness on the Incivility to strain relationship .. 143

26: The moderating role of Conscientiousness on the Relationship Conflict to strain relationship.

27: The moderating role of Conscientiousness on the Task Conflict to strain relationship.

28: The moderating role of Trait Anger between workplace aggression and Negative Emotions 149

29: The moderating role of Trait Anger on the Incivility to strain relationship 150

30: The moderating role of Trait Anger on the Relationship Conflict to strain relationship.....

31: The moderating role of Trait Anger on the Task Conflict to strain relationship...... 154

32: The moderating role of Locus of Control between workplace aggression and Negative Emotions 156

33: The moderating role of Locus of Control on the Incivility to strain relationship..... 157

34: The moderating role of Locus of Control on the Relationship Conflict to strain relationship. 
35: The moderating role of Locus of Control on the Task Conflict to strain

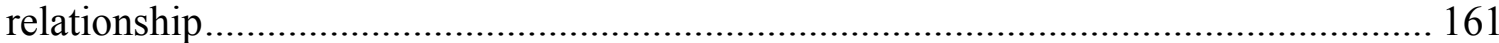




\section{LIST OF FIGURES}

FIGURE

PAGE

1: Emotion centered model of job stress .................................................................... 163

2: Extraversion moderating the incivility to depression relationship ............................ 164

3: Extraversion moderating the incivility to physical symptoms relationship................ 164

4: Extraversion moderating the incivility to job satisfaction relationship ...................... 165

5: Extraversion moderating the relationship conflict to depression relationship............ 165

6: Extraversion moderating the relationship conflict to physical symptoms

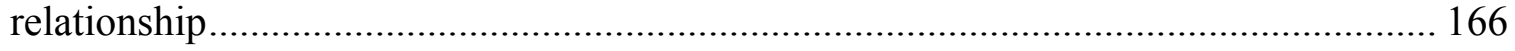

7: Extraversion moderating the relationship conflict to stress relationship .................... 166

8: Extraversion moderating the relationship conflict to life satisfaction relationship .... 167

9: Extraversion moderating the task conflict to depression relationship ........................ 167

10: Extraversion moderating the task conflict to physical symptoms relationship ........ 168

11: Neuroticism moderating the incivility to negative emotions relationship ................ 168

12: Neuroticism moderating the relationship conflict to negative emotions

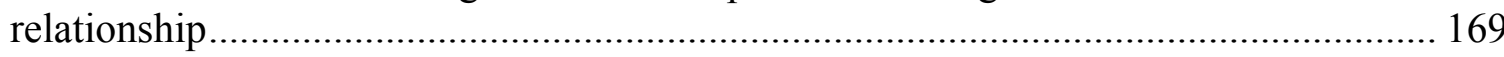

13: Neuroticism moderating the task conflict to negative emotions relationship........... 169

14: Neuroticism moderating the incivility to depression relationship ........................... 170

15: Neuroticism moderating the incivility to physical symptoms relationship .............. 170

16: Neuroticism moderating the incivility to stress relationship .................................. 171

17: Neuroticism moderating the incivility to life satisfaction relationship..................... 171

18: Neuroticism moderating the relationship conflict to depression relationship .......... 172

19: Neuroticism moderating the relationship conflict to physical symptoms relationship 
20: Neuroticism moderating the relationship conflict to stress relationship 173

21: Neuroticism moderating the relationship conflict to job satisfaction relationship ... 173

22: Neuroticism moderating the relationship conflict to life satisfaction relationship ... 174

23: Neuroticism moderating the task conflict to depression relationship....................... 174

24: Neuroticism moderating the task conflict to physical symptoms relationship ......... 175

25: Neuroticism moderating the task conflict to stress relationship .............................. 175

26: Neuroticism moderating the task conflict to job satisfaction relationship................ 176

27: Neuroticism moderating the task conflict to life satisfaction relationship ............... 176

28: Agreeableness moderating the incivility to negative emotions relationship ............ 177

29: Agreeableness moderating the relationship conflict to negative emotions relationship.

30: Agreeableness moderating the task conflict to negative emotions relationship ....... 178

31: Agreeableness moderating the incivility to depression relationship ....................... 178

32: Agreeableness moderating the incivility to physical symptoms relationship ........... 179

33: Agreeableness moderating the incivility to stress relationship................................ 179

34: Agreeableness moderating the incivility to life satisfaction relationship ................ 180

35: Agreeableness moderating the relationship conflict depression relationship ........... 180

36: Agreeableness moderating the relationship conflict to physical symptoms relationship.

37: Agreeableness moderating the relationship conflict to job satisfaction relationship 181

38: Agreeableness moderating the relationship conflict to life satisfaction relationship 182

39: Agreeableness moderating the task conflict to depression relationship .................. 182

40: Agreeableness moderating the task conflict to physical symptoms relationship...... 183

41: Agreeableness moderating the task conflict to life satisfaction relationship............ 183 
42: Conscientiousness moderating the incivility to physical symptoms relationship..... 184

43: Conscientiousness moderating the incivility to stress relationship ........................ 184

44: Conscientiousness moderating the incivility to job satisfaction relationship ........... 185

45: Conscientiousness moderating the task conflict to physical symptoms relationship 185

46: Trait anger moderating the incivility to negative emotions relationship ................. 186

47: Trait anger moderating the relationship conflict to negative emotions relationship 186

48: Trait anger moderating the incivility to depression relationship .......................... 187

49: Trait anger moderating the incivility to physical symptoms relationship ............... 187

50: Trait anger moderating the incivility to stress relationship ............................... 188

51: Trait anger moderating the incivility to job satisfaction relationship ..................... 188

52: Trait anger moderating the incivility to life satisfaction relationship..................... 189

53: Trait anger moderating the relationship conflict to depression relationship ........... 189

54: Trait anger moderating the relationship conflict to physical symptoms relationship190

55: Trait anger moderating the relationship conflict to stress relationship................... 190

56: Trait anger moderating the relationship conflict to job satisfaction relationship ..... 191

57: Trait anger moderating the relationship conflict to life satisfaction relationship ..... 191

58: Trait anger moderating the task conflict to depression relationship ...................... 192

59: Trait anger moderating the task conflict to physical symptoms relationship .......... 192

60: Trait anger moderating the task conflict to stress relationship ............................ 193

61: Trait anger moderating the task conflict to job satisfaction relationship................. 193

62: Trait anger moderating the task conflict to life satisfaction relationship ................ 194

63: Locus of control moderating the incivility to negative emotions relationship ......... 194 
64: Locus of control moderating the relationship conflict to negative emotions relationship 195

65: Locus of control moderating the task conflict to negative emotions relationship .... 195

66: Locus of control moderating the incivility to depression relationship ..................... 196

67: Locus of control moderating the incivility to physical symptoms relationship........ 196

68: Locus of control moderating the incivility to stress relationship............................. 197

69: Locus of control moderating the incivility to life satisfaction relationship.............. 197

70: Locus of control moderating the relationship conflict to depression relationship.... 198

71: Locus of control moderating the relationship conflict to physical symptoms relationship 198

72: Locus of control moderating the relationship conflict to job satisfaction relationship. 199

73: Locus of control moderating the relationship conflict to life satisfaction relationship 199

74: Locus of control moderating the task conflict to depression relationship 200 75: Locus of control moderating the task conflict to physical symptoms relationship .. 200 
The Moderating Role of Personality on Workplace Conflict and Outcomes

\section{Introduction}

The last 10 years has seen researchers eagerly pursue the concepts of conflict and incivility in the workplace. This can be seen through the publication of multiple metaanalyses examining the role that interpersonal conflict and incivility play, in both the work place and other spheres of daily life (De Dreu \& Weingart, 2003; Hershcovis, 2011). While there has been an increase of research examining the effects interpersonal conflict and incivility have, only a small segment of research has focused on the moderating roles personal characteristics play on both conflict and incivility. Traditionally, research has focused primarily on the relationship incivility and conflict have on workplace outcomes such as performance, satisfaction, counterproductive work behaviors, and health outcomes such as physical and physiological wellbeing, stress, and depression (De Dreu \& Weingart, 2003; Dijkstra, De Dreu, Evers, \& van Dierendonck, 2009; Frone, 2000; Heinisch \& Jex, 1997; Hershcovis, 2011; Penney \& Spector, 2005). While meta-analytical support for a relationship between interpersonal conflict types, incivility, and workplace and health outcomes has been established (De Dreu \& Weingart, 2003; Hershcovis, 2011; Nixon, Mazzola, Bauer, Krueger, \& Spector, 2011), the moderating role of individual differences is still largely unexplored. Thus, the purpose of this study is twofold. The first goal is to further clarify and understand the relationship between interpersonal conflict, incivility, and their roles as stressors in the stressor-strain relationship. The second goal of this study is to examine how neuroticism, extraversion, agreeableness, conscientiousness, trait anger, and sphere specific locus of control 
moderate the stressor-strain relationship between task conflict, relationship conflict, incivility and workplace and health outcomes.

\section{Defining and Conceptualizing Conflict and Incivility}

In order to understand and develop the moderating roles personality, trait anger, and locus of control may have on interpersonal conflict and incivility it is critical to define these constructs. Established conflict literature has shown that interpersonal conflict may be broken into smaller constructs to facilitate a greater understanding of how specific conflict interactions affect workplace outcomes (Jehn 1994; 1995). These two refined conflict constructs have been labeled task conflict and relationship conflict.

Task conflict is defined as occurring "when there are disagreements among group members about the content of the tasks being performed, including differences in viewpoints, ideas, and opinions" (Jehn, 1995, p. 258). Examples of task conflict in the workplace include incidents such as disagreements over the proper steps needed to complete a project, where an event should take place, or how resources should be utilized. Relationship conflict is defined as "interpersonal incompatibilities among group members, which typically includes tension, animosity, and annoyance among members within a group" (Jehn, 1995, p. 258). Incidents of relationship conflict involve a focus on disagreements and the friction that can occur when interacting with other people. Specifically it has been shown that relationship conflict often invokes feelings of “annoyance, frustration, and irritation” (Jehn \& Mannix, 2001, p. 238).

The differences between the two types of interpersonal conflict are important since the majority of occupational stress research has focused almost solely on the role relationship conflict plays, much to the detriment of our understanding of task conflict. 
Traditionally, relationship conflict has been found to be detrimental to individual and group performance, member satisfaction, wellbeing, and the likelihood of future group collaborations (Bruk-Lee \& Spector, 2006; Jehn, 1995; Shah \& Jehn, 1993). On the other hand, moderate levels of task conflict have been shown to be beneficial to group performance on certain types of tasks (Jehn, 1995; Jehn \& Shah, 1997; Shah \& Jehn, 1993). The counterintuitive directional nature of these previous findings highlight a gap in the social stressor literature which this study seeks to address through the exploration of both conflict types. Finally, unlike conflict, incivility is a much newer concept defined as "low intensity deviant behavior with ambiguous intent to harm the target in violation of workplace norms for mutual respect" (Andersson and Pearson, 1999 p. 457), and has been described colloquially as petty tyranny.

Traditionally, the occupational stress perspective views workplace interactions through two distinct variables labeled "stressors" and "strains" (Sonnentag \& Frese, 2003). Stressors are events or characteristics that may elicit a negative response from an employee. These negative responses, labeled strains, may affect the individual behaviorally, physically, or psychologically. This thesis conceptualizes both interpersonal conflict (task and relationship) and incivility as social stressors, which emerge from the social work environment including interpersonal relationships and interactions at work. Research examining the nature of stressors in the workplace reported that upwards of $74 \%$ of stressful incidents in the workplace were social in nature (e.g., interactions with colleagues, coworkers, and supervisors; Keenan \& Newton, 1985).

Support for the operationalization of incivility as a social stressor has recently been demonstrated (e.g., Cortina \& Magley, 2009; Kern \& Grandey, 2009). For example, 
Kern and Grandey (2009) found linkages between incivility and job burnout.

Furthermore, incivility has also been shown to act as a moderator of the stressor-strain relationship. Research by Oore, LeBlanc, Day, Leiter, Spence, \& Price (2010)

demonstrated how incivility could exacerbate the relationship between existing job role stressors and strains. However, Oore et al. (2010) did show that incivility did act as a stressor itself, but demonstrated a stronger effect when cast in the role of a moderating variable.

As workplace interactions and behaviors continue to be at the heart of the occupational stress research, the field's understanding and investigation of interpersonal conflict and incivility will continue to grow. Given that current research has begun to examine these stressors not just in relation to their outcomes, or strains, but to one another as well (e.g. Hershcovis, 2011), there is a growing body of evidence highlighting the need for better understanding of not only what these stressors are, but how their effects can influence their surrounding environments. Although interpersonal conflict and incivility do share some similarities, an examination of their historical background will show that they each examine different aspects of workplace aggression.

\section{Literature Review}

\section{Historical Overview: Incivility and Workplace Conflict}

Early stages of conflict research defined conflict as the perceptions of incompatibilities between individuals (e.g., Kahn \& Boulding, 1964). Conflict researchers have since moved away from these broad conceptual definitions in favor of breaking conflict into smaller and more precise constructs. Early conflict research by Guetzkow and Gyr (1954) distinguished between two types of conflict, one based on the 
interpersonal relations between individuals (also referred to as socio-affective type conflict) and the second based on the tasks and duties the individuals performed. Over time, research has strongly supported the notion that conflict may be distinguished into two major types, stemming either from the content of the task or from interpersonal interactions (Wall \& Nolan, 1986; Pinkly, 1990; Priem \& Price, 1991). Research by Jehn (1994, 1995) further supported the unique characteristics of these conflict types, showing task conflict to affect the routine standardized processes and distracting employees while interpersonal conflict was detrimental regardless of the type of task the group was performing or whether task conflict was present. These findings inspired Jehn's 1994 and 1995 task and relationship conflict measures, which were developed using on Rahim's (1983) intragroup conflict subscale.

Research examining task conflict has primarily focused on its negative impact on team performance (Jehn, Northcraft, \& Neale, 1999; Lovelace, Shapiro, \& Weingart, 2001; Pelled, Eisenhardt, Xin, 1999), job satisfaction (Guerra, Martinez, Munduate, \& Medina, 2005), organizational commitment (Lankau, Ward, Amason, Ng, Sonnenfeld, \& Agle, 2007; Jehn et al., 1999), and employee turnover intentions (Jehn et al., 1999). In addition, a meta-analysis conducted by De Dreu and Weingart (2003) supported these individual study's findings and reported that at the aggregate level task conflict has a negative relationship with both team satisfaction and performance.

Relationship conflict research has shown significant negative relationships with organizational and individual outcomes, including job satisfaction (Frone, 2000; Harvey, Blouin, \& Stout, 2006), performance (Jehn et al., 2001), team productivity (Van Vainen \& De Dreu, 2001; Jehn, 1995), turnover (Liu, Spector, \& Shi, 2008; Bayazit, \& Mannix 
2003; Jehn, Northcraft, \& Neale, 1999), commitment (Frone, 2000, Lankau et al, 2007), and well-being (Lazuras, Rodafinos, Matsiggos, \& Stamatoulakis, 2009; Bowling, \& Eschleman, 2010). Relationship conflict was also found to relate positively with workplace and health outcomes such as incidents of burnout (Giebels \& Janssen, 2005; Harvey et al, 2006; Dijkstra, De Dreu, Evers, van Dierendonck, 2009) and depression (Frone, 1998, 2000; Ogiwara, 2008). Furthermore, the 2003 meta-analysis by De Dreu and Weingart supported the established negative relationship between relationship conflict and team satisfaction and performance at the aggregate level.

A challenge of assessing task and relationship conflict is that they are positively correlated and generally occur simultaneously (De Dreu \& Weingart, 2003; Pearson, Ensley, \& Amason, 2002; Simon \& Peterson, 2000). A factor analysis demonstrated that although the conflict types are similar, people were able to distinguish between the two (Simon \& Peterson, 2000), thus supporting Jehn's (1995) conceptualization of task and relationship conflict as two separate constructs. The interrelation between task and relationship conflict can be explained by examining the role individual perception plays in the experience of task and relationship conflict. For example, an individual incident of task conflict can spill over into an interpersonal interaction sparking relationship conflict in relation to the original task conflict (Bono, Boles, Judge, \& Lauver, 2002). The inclusion of the individual's perception of the conflict event or interaction is essential to understanding that while task and relationship conflict are separate constructs, the divisional line between the two can be subjected to blurring by individual perceptions. In addition, task conflict has been hypothesized to have positive effects in decision or novel task situations and may be beneficial to creative problem solving (De Dreu \& Weingart, 
2003). Unlike task conflict, relationship conflict is considered to be a detriment in any situation where it may be present and should be minimized and controlled if possible.

Incivility was introduced as a psychological construct to capture lesser forms of mistreatment in organizations (Andersson \& Pearson, 1999). Incivility is currently studied through the incivility spiral model, which is unidirectional, beginning with the initial uncivil event and ending when one affected party stops the chain of incivility or once the interactions have past the tipping point of incivility and entered the domain of workplace aggression and violence (Andersson \& Pearson, 1999).

The incivility spiral model, created by Andersson and Pearson (1999), demonstrates the escalating nature of incivility and emphasizing its role in the workplace. The model is comprised of four key points. The first point is the perception of an initial act of incivility by the target. It is important to stress the influence of individual perception at this point, since uncivil acts that are not perceived as uncivil by the target will fail to initiate the incivility spiral. Inversely, the incivility spiral may also be started if an individual perceives incivility where none exists. The second point of the spiral is that, at any time, any individual involved may break the spiral, stopping the progression towards further aggression and violence. The third key point is that the spirals will illicit escalating retaliations based on perceived slights and violations of norms. This is represented both by the unidirectional pathway of the incivility model and that the only two apparent choices for someone who may be engaged in the spiral are to either retaliate or step away from the incivility all together. The fourth key point of the model is the tipping point where incivility crosses over and becomes aggressive antisocial behavior such as workplace violence. At this point, the individual's behavior has moved past the 
level of incivility and has crossed into the more serious manifestations of workplace violence and aggression.

Andersson and Pearson (1999) also proposed a model demonstrating how incivility may spread through an organization. This model postulates that additional members of the organization could be affected by incivility caused by others. This spillover from one incivility spiral to the creation of an additional spiral is called a secondary incivility spiral. Andersson and Pearson (1999) proposed that this could continue until the majority of the organization is engaged in an incivility spiral or has crossed the tipping point into more egregious workplace aggressions and violence, turning the organization into an uncivil entity.

Research examining workplace incivility began gaining momentum with the creation of Cortina, Magley, Williams and Langhout's (2001) workplace incivility scale. This seven-item survey assessed incivility by examining how often one experienced or perceived rudeness, disrespectful or condescending behaviors from coworkers or superiors over the previous five years. Since the introduction of incivility as a workplace construct, research has shown it to be significantly related with a host of negative workplace and health outcomes, including depression (Cortina, Magley, Williams \& Langhout, 2001; Lim, Cortina, Magley, 2008), anxiety (Cortina et al., 2001; Lim et al., 2008), work related time loss and slowdown (Skarlicke \& Folger, 1997; Pearson, Andersson \& Porath, 2000), supervisor misbehavior (Hornstein, 1996), counterproductive work behaviors (Penney \& Spector, 2005), job satisfaction (Penney \& Spector, 2005; Lim et al., 2008), and both mental and physical health (Lim et al., 2008). Incivility has also been found to have strong lasting direct and secondhand effects. Research has shown 
that $62 \%$ of survey respondents reported being bothered or feeling uncomfortable after witnessing an uncivil event (Farkas \& Johnson, 2002). An additional 52\% reported that they dwelt on uncivil events after they have occurred (Farkas \& Johnson, 2002) supporting Andersson and Pearson's (1999) conceptual model that incivility can spread.

\section{Comparing Task Conflict, Relationship Conflict, and Incivility}

Contemporary workplace aggression research has begun to debate whether there should be less of a distinction between the various forms of workplace aggression (Hershcovis, 2011). Hershcovis' research questioned the basic nature of the various forms of workplace aggression, highlighting the similarities between abusive supervision, bullying, incivility, social undermining, and interpersonal conflict. The analysis differentiated interpersonal conflict from the other constructs assessed, reporting that interpersonal conflict differences result from the mutually stressful nature of the interactions, and emphasizing its mutually shared experiences as being unique when compared to the one-sided nature of bullying or the tit for tat nature of the incivility spiral. However, the research further addressed the distinctions between incivility and the remaining workplace aggression constructs on the basis that incivility comprised of two characteristics unique only to incivility, the low intensity of the deviant acts and their ambiguous intent.

The low intensity of the deviant acts that comprise incivility is unique, as no other workplace aggression behaviors are defined in terms of their intensity. Specifically, researchers have argued that the minor forms of mistreatment that incivility represents could have a significant impact on employee attitudes toward the organization and should not be overlooked (Andersson \& Pearson, 1999). Aggressive workplace behaviors that go 
beyond the low intensity nature of incivility generally fall into the larger workplace aggression taxonomy (i.e., abusive supervision, bullying, and social undermining). Furthermore, researchers examining the effect of aggressive behaviors on conflict have shown that aggressive workplace behaviors generally escalate conflict levels (Glomb \& Liao, 2003; Jockin, Arvey \& McGue, 2001). This suggests that it may be simpler to escalate from incivility into a more severe form of workplace aggression than to regress from a more severe form of workplace aggression to incivility, demonstrating another conceptual difference between incivility and the more severe aggression constructs.

The second unique feature that distinguishes incivility from interpersonal conflict is the ambiguous nature of the actor's intent (Hershcovis, 2011). Researchers have argued that when defining mistreatment from the perspective of the perpetrator understanding intent is crucial. Furthermore, research has shown that perceived intent might be all that matters, as the victim will only react on the basis of their perceptions (Neuman \& Baron, 2005; Hershcovis, 2011). Specifically, incivility that is not perceived as incivility will fail to be assessed as incivility, and vice versa. Thus, the individual's perspective plays a crucial role since the effects of incivility only manifest themselves when they are perceived. This is in contrast to other aggressive workplace behaviors (e.g., bullying, supervisor abuse), which operate in a much more unilateral direction and with much less ambiguity (Hershcovis, 2011).

Research examining the overlapping nature of incivility and conflict is growing. As stated in Hershcovis' (2011) meta-analysis, incivility and interpersonal conflict share many overlapping characteristics. Studies examining the relationship between incivility and interpersonal conflict in the workplace have reported strong positive correlations 
ranging from .49 to .59 using both self-report and peer report, respectively (Penney \& Spector, 2005). Unfortunately, this research conceptualized interpersonal conflict as purely relationship based (ignoring the task type completely). To date there has been no research examining the relationship between task conflict and incivility. Thus, this research will also allow for a better understanding of how the types of interpersonal conflict relate to incivility. Given the similarities between conflict and incivility's characteristics and their effects on the individual, we believe these constructs to be positively related.

Hypothesis 1: Task and relationship conflict will be positively correlated with incivility.

\section{Relationship Conflict, Task Conflict, Incivility, and the Job Stress Model}

The emotion-centered model of job stress (see Figure 1) depicts the social stressor-strain relationship between stressors (task conflict, relationship conflict, incivility) and the various forms of strains (Spector \& Bruk-Lee, 2008). Framing workplace conflict and incivility through the stressor-strain perspective allows for the examination of the moderating effects of personality traits, trait anger, and sphere specific locus of control on workplace and health outcomes. Further, the emotion-centered model highlights the role of negative emotions in the stress process.

As seen in Figure 1, once an individual perceives a stressor in their environment, those stressors will then prompt an emotional response, which will mediate the relationship between the stressors and strains. Research examining the relationship between conflict and emotional states has shown that anger, anxiety, and frustration are the most frequently cited emotional responses when conflict is the salient stressor 
(Keenan \& Newton, 1985; Narayanana, Menon, \& Spector, 1999). This relationship has also been supported in the occupational stress research (e.g., Spector \& Jex, 1998). Furthermore, a cross-national study found that anger and frustration are the most frequent emotional reactions to interpersonal conflict (Narayanana et al., 1999). Research has also supported the positive relationship between conflict, anxiety and frustration (e.g., Spector, 1997; Spector \& Jex 1998; Fox, Spector \& Miles, 2001). Given the empirical and meta-analytical support for the positive relationship between conflict, incivility, and emotional responses, we believe this relationship to continue, creating a critical bridge in the job stress model.

Hypothesis $2 a, b$, c: Task conflict, relationship conflict, and incivility will be positively related to negative emotional responses such as anger, frustration, and anxiety.

\section{Well-being Outcomes}

Research examining incivility, relationship conflict, and task conflict has begun to demonstrate the serious negative consequences these workplace stressors have on individual wellbeing. Incivility has been shown to affect wellbeing as both a proximal and distal stressor. Specifically, research has shown incivility to have significant positive relationships with negative physical health, negative mental health, psychological distress, lower health satisfaction, stress, depression, emotional exhaustion, mental burnout, mood swings, sleep problems, feelings of shame, feelings of cynicism, feelings of guilt, feelings of embarrassment, less favorable life attitudes, and low self-esteem (Caza \& Cortina, 2007; Cortina, Magley, Williams, Langhout, 2001; Jaarveld, Walker, Skarlicki, 2010; Laschinger, Leiter, Day \& Gilin 2009; Lim and Lee, 2011; Kern \& Grandey, 2009; Lim \& Cortina 2005; Lim, Cortina \& Magley 2008; Tepper, 2000; 
Yamada, 2000). Recent meta-analytic research has reaffirmed these findings, supporting the relationship between incivility and physical and physiological health outcomes (Hershcovis, 2011).

Research has also begun to assess how relationship and task conflict can affect an individual's wellbeing. Relationship conflict has shown a positive relationship with a host of negative individual wellbeing outcomes. Specifically higher levels of relationship conflict has been shown to correlated positively with physiological strain (nausea, backache, headache, eye strain, and fatigue), emotional exhaustion, burnout, anxiety, and depression (Dijkstra, De Dreu, Evers, \& van Dierendonck, 2009; Frone, 1998; 2000; Friedman, Tidd, Currall, \& Tsai, 2000; Giebels \& Janssen, 2005; Lazuras, Rodafinos et al. 2009; Spector, Dwyer \& Jex, 1988; Spector \& O'Connell, 1994; Richardsen, Burke et al. 1992; Heinisch \& Jex 1997; Rainey 1999; Liu 2003; Nakata, Haratani et al. 2004; Bowling \& Beehr 2006; Bruk-Lee and Spector 2006; Harvey, Blouin et al. 2006; Liu, Spector et al. 2008; Ogiwara 2008; Newton \& Jimmieson, 2009). Task conflict has also been examined for its effects on individual wellbeing, and has demonstrated a positive relationship with reports of stress, lower mental health, burnout, and emotional exhaustion (Friedman et al. 2000; Giebels \& Janssen 2005; Dijkstra et al. 2009). Additionally, both conflict types have been shown to correlate negatively with measures of positive wellbeing, which assess areas such as life satisfaction, and overall mental health (Medina, Munduate, Dorado, Martinez, \& Guerra, 2005).

As with incivility, both task and relationship conflict have reached the point where meta-analysis techniques can be used to grasp a better understanding of how these variable relate with individual measures of wellbeing. These meta-analyses have 
reinforced the research and demonstrate the overwhelming support for the negative effects of conflict on individual wellbeing. Specifically, these studies have shown conflict to relate positively with negative psychological and physiological symptoms; such as backache, headache, eyestrain, sleep disturbances, fatigue, and gastrointestinal problems (e.g., Nixon, Mazzola, Bauer, Krueger, \& Spector, 2011). Furthermore, there has been an attempted shift in the conceptualization of conflict, moving it from its traditional classification as a stressful, disruptive event and re-branding it as a possibly functional and stimulating event which may allows for the introduction of new or unseen viewpoints (e.g., Jehn, 1995; Jehn \& Shah, 1997; Shah \& Jehn, 1993). However, this conceptualization of conflict found no support in De Dreu and Weingart's meta-analysis; in which they reported the opposite, that both task and relationship conflicts are equally disruptive to performance. Unfortunately as with incivility, there has not been any research demonstrating the positive effects of task or relationship conflicts may have on individual wellbeing. Finally, given that the only conceptualization of these social stressors having a positive influence is on a non-wellbeing outcome, we feel that this trend will continue and that task conflict, relationship conflict, and civility will all relate negatively to individual wellbeing across the board.

Hypothesis 3 a,b,c: Task conflict, relationship conflict, and incivility will be negatively related to individual measures of strain.

Hypothesis 3 d: Negative emotions will mediate the relationship between task conflict, relationship conflict, incivility and strain. 


\section{Personality}

The emotion-centered model of job stress proposes that an individual's personal characteristics will moderate their responses to their perceived stressors and shape how those responses are evaluated and experienced (Spector \& Bruk-Lee, 2008). While the role of personality as a moderator of individual behavior has been a topic of interest for

years (e.g., Eysenck \& Eysenck, 1985; Costa \& McCrea, 1992), only a handful of studies have examined their effects in the context of the social stressor-strain relationship (e.g., Bono, Boles, Judge, \& Lauver, 2002). The research that has been conducted has focused on conflict as either a broad non-domain specific construct (i.e., non-work conflict; Suls, Martin, \& David, 1998), as a non-work interpersonal form of conflict (i.e., spousal conflict; Bono et al., 2002), or used stand in constructs representing personality variables (e.g., control in lieu of conscientiousness; Jockin, Arvey, \& McGue, 2001). Therefore, an aim of this study will be to examine the potential moderating factors of personality in the stressor-strain relationship and assist in addressing current research gaps.

To frame personality, this study will be drawing from the established five factor model of personality. The five factor structural model has become a standard conceptual personality framework for addressing personality through five broad personality dimensions (Digman, 1990) which are extraversion, openness to experience, neuroticism, agreeableness, and conscientiousness (McCrae \& John, 1992). Previous research examining non-work based conflict involving roommates, dating couples, and married couples has demonstrated that personality does influence how conflict is viewed and acted upon (Fincham \& Beach, 1999; Geist \& Gilbert, 1996; Fuller \& Hall, 1996). 
An initial limitation when assessing task and relationship conflict is that they have rarely been examined in the context of the five-factor model. The majority of personality research in the conflict literature has either solely focused on relationship conflict (to the detriment of task conflict) or assessed conflict outside of the work environment entirely. Incivility research is just as lacking as it has focused heavily on the outcome side and only recently begun to assess the role that individual differences may play (e.g., Penney \& Spector, 2005). This study will examine the roles extraversion, neuroticism, agreeableness, and conscientiousness play in the stressor-strain relationship.

\section{Extraversion}

Extraversion describes someone who is active, energetic, enthusiastic, outgoing, and talkative (McCrae \& John, 1992). Individuals who score high in extraversion are believed to be more positive and have higher levels of energy. Extraverts also utilize more adaptable styles of coping when facing conflict (Hooker, Frazier \& Monahan, 1994) and have higher levels of positive thinking and restraint (McCrae \& Costa, 1986). These traits may allow individuals high in extraversion to draw from a greater pool of internal resources to deal with stressors or shield them from perceiving stressors. Research examining extraversion's moderating role on relationship conflict in the workplace has demonstrated that high levels of extraversion moderated the amount of conflict experienced and its effects on individual well-being (Dijkstra, Dierendonck, Evers, \& De Dreu, 2005). Specifically, Dijkstra et al. (2005) demonstrated that individuals low in extraversion experienced greater negative effects to their wellbeing when exposed to relationship conflict. Stepping outside of the workplace literature, extraversion has been shown to have a small negative moderating effect on task and relationship conflict in 
roommate scenarios, such that individuals high in extraversion reported less conflict (Bono et al, 2002).

Furthermore, researchers such as Eysenck, Gray, and others have hypothesized that individuals low in extraversion may be more susceptible to anxiety than individuals high in extraversion (Eysenck \& Eysenck, 1985; Eysenck, MacLeod, \& Mathews, 1987; Gray, 1981, 1987; Zinbarg \& Revelle, 1989). This research posited that people who are low in extraversion experience a greater level of susceptibility to punishment cues and are prone to greater arousal from those punishment cues. Rusting \& Larson (1997) supported the conceptualization of extraversion influencing the experience of negative emotions by demonstrating that extraversion has a significant negative moderating effect on how negative emotions are experienced. In addition, research by Larsen \& Ketelaar (1991) demonstrated how individuals low in extraversion have been shown to be more susceptible to negative emotions (e.g., anger frustration, anxiety).

Finally, research focusing on extraversion's relationship with task conflict and incivility is currently lacking. However, given the similarity in stressor behavior postulated in the job stress model (triggering emotional response which then lead to strains) and the similarities between relationship conflict and both incivility and task conflict, there is conceptual support that extraversion will moderate task conflict and incivility in the same manner as it has moderated relationship conflict.

Hypothesis 4a,b,c: Extraversion will moderate the relationship between task conflict, relationship conflict, and incivility and negative emotions such that individuals high in extraversion will experience fewer negative emotions. 
Hypothesis 4 d: Extraversion will moderate the relationship between task conflict, relationship conflict, and incivility and strains such that individuals high in extraversion will experience less strain.

\section{Neuroticism}

Neuroticism describes an individual who is prone to experiencing negative emotions such as fear, sadness, anger, guilt, depression, anxiety, and may be more impulsive or self-conscious (Costa \& McCrae, 1992). Research examining the moderating role of neuroticism on task and relationship conflict is rare and what has been done has focused on the non-work domains. Individuals scoring high in neuroticism have been shown to experience increased levels of task and relationship conflict in roommate studies (e.g., Bono et al, 2002). Dijkstra et al. (2005) reported similar findings when examining the role neuroticism plays on relationship conflict, showing that individuals high in neuroticism reported higher levels of relationship conflict. In addition, Milam et al. (2009) reported moderate positive correlations between the high levels of neuroticism and incivility.

Research into neuroticism and negative affectivity has demonstrated that negative affect corresponds with neuroticism (Tellegen, Watson \& Clark, 1988; Watson \& Tellegen, 1985; Watson \& Clark, 1984). Researchers examining the relationship between neuroticism and negative affect found significant positive correlations between the two constructs and have established that neuroticism is associated with a predisposition to experience negative affect (Watson \& Clark, 1984; Costa \& McCrae, 1980; Rusting \& Larsen, 1997; Meyer \& Shack, 1989; Larson \& Ketelaar, 1989). The consistency of the relationship between neuroticism and negative affectivity has been overwhelming, as the 
research strongly supports the theory that the assessment of negative affect is capturing some underlying characteristics of neuroticism (Watson \& Clark, 1984; Spector \& O’Connell, 1994; Lazurus, Rodafinos, Matsiggos, \& Stamatoulakis, 2009; Klainin, 2009; Heinisch \& Jex, 1997; Fortunato, LeBourgeois, \& Harsh, 2008; Ilies, Johnson, Judge \& Kenney, 2010; Bowling \& Eschleman, 2010).

Research examining the relationship between negative affect and conflict and incivility has shown high levels of negative affect to positively correlate with both conflict and incivility (e.g., Heinisch \& Jex, 1997; Spector \& Jex, 1998; Penney \& Spector, 2005; Bowling, Beehr, Bennett, \& Watson, 2010). Penney and Spector (2005) demonstrated that negative affect acts as a moderator between incivility and relationship conflict, and counterproductive work behaviors, demonstrating its potential role in the stressor-strain interaction. Additionally, Milam, Spitzmueller, and Penney (2009) showed that individuals high in neuroticism perceived more incivility, possibly since those individuals may be predisposed to worrying, nervousness, insecurity, self-pity, which may make them more likely to see otherwise seemingly innocuous events as uncivil. High negative affect has shown to be linked with incivility, correlating positively with reports of customer and employee incivility (Jaarsveld, Walker, \& Skarlicki, 2010). Higher levels of negative affect have also been shown to increase the occurrences of uncivil behaviors in the workplace (Reio \& Ghosh, 2009).

Longitudinal studies drawing from both nonclinical and clinical samples have reported a positive relationship between neuroticism and anxiety (Levenson et al., 1988; Noyes et al., 1980). This supports the hypothesis that individuals high in neuroticism would be more susceptible to anxiety than individuals low in neuroticism (e.g., Eysenck 
\& Eysenck, 1985; Eysenck, 1987; Gray, 1981, 1987; Zinbarg \& Revelle, 1989).

Furthermore, research examining neuroticism's relationship with negative emotions have shown high levels of neuroticism to be a significant predictor of future anxiety (Gershuny \& Sher, 1998), negative moods (Rusting \& Larson, 1997), a susceptibility to negative moods (Larsen \& Ketelaar, 1991), and a stronger association between daily stress and negative emotions (Mroczek \& Almeida, 2004). This research highlights how neuroticism influences the stressor strain relationship by moderating the level of experienced negative emotions elicited from the experienced stressor. Specifically, individuals high in neuroticism may be more susceptible to the strains caused by workplace conflict and incivility. These findings support the conceptualization that neuroticism will moderate the effects of task conflict, relationship conflict, and incivility. Individuals high in neuroticism will display a heightened sensitivity to stressors and those stressors will have a greater impact on the individual's reports of work and health outcomes.

Hypothesis 5a,b,c: Neuroticism will moderate the relationship between task conflict, relationship conflict, and incivility and negative emotions such that individuals high in neuroticism will experience more negative emotions.

Hypothesis 5 d: Neuroticism will moderate the relationship between task conflict, relationship conflict, and incivility and strains such that individuals high in neuroticism will experience more strain.

\section{Agreeableness}

Agreeableness is used to describe someone who is altruistic, trusting, cooperative, compliant, and motivated by the needs of others (Costa \& McCrae, 1992). It is 
considered to be the strongest personality predictor when assessing how people get along with one another (Organ, 1994). People high in agreeableness invest more energy and effort into protecting social relationships and avoiding coping strategies such as selfblame, avoidance, and wishful thinking (Hooker et al., 1994). Research has shown that individuals low in agreeableness generally experience more of conflict in general, with partners, and that they experience more negative emotions (Suls et al., 1998; Graziano, Jensen-Campbell, \& Hair; 1996; Graziano et al., 1996). When controlling for the influence of the additional four personality traits (extraversion, openness to experience, neuroticism, and conscientiousness), lower levels of agreeableness were found to be the most salient predictor of anger in couples (Buss, 1991).

Research examining the moderating effects of agreeableness on task and relationship conflict is currently scant. What research there is has been consistent, showing interpersonal conflict and agreeableness to correlate negatively at a moderate level (Ilies et al., 2010, Bowling \& Eschleman, 2010). Furthermore, this negative relationship has also been supported in research examining the relationship between nonwork relationship conflict (such as in a partner or roommate studies) and individual levels of agreeableness (Bono et al., 2002). Finally, research evaluating agreeableness's relationship with incivility is also limited, although it is consistent with agreeableness relationship with conflict (Milam et al., 2009). Specifically, Milam et al.'s research demonstrated that individuals low in agreeableness experience more incivility than those who are high in agreeableness. Although established research is rare, there is enough to highlight a negative relationship between interpersonal conflict, incivility, and high levels of agreeableness. 
Ilies et al. (2010) demonstrated agreeableness' role as a moderator between conflict and emotional responses, showing agreeableness to significantly moderate the affective implications of interpersonal conflict at work. Support for this relationship has been established, with research reporting agreeableness as acting as a strong predictor of negative workplace interactions, correlating negatively with both physical and psychological violent outcomes (Menard, Brunet, \& Savoie; 2011). These findings highlight agreeableness role as an important component of negative workplace behaviors (Glomb, 1998; Henle, 2005). Research focusing on the relationship between agreeableness and negative emotions such as anger, anxiety and frustration has shown agreeableness to play an important role in how emotions are experienced. Specifically, agreeableness has been shown to correlate negatively with anger and anxiety (Whiteman, Bedford, Grant, Fowkes \& Deary, 2001; Hastings \& O’Neill, 2009). Agreeableness has also been shown to be a direct predictor of anger, mistrust and confrontational attitudes in individuals low in agreeableness (Sanz, Garcia-Vera, \& Magan, 2010; Ode, Robinson, \& Wilkowski, 2008; Bresin, Hilmert, Wilkowski, \& Robinson, 2012). Moreover, agreeableness acts as a significant predictor of individual effort used to control individual emotions, such as anger, anxiety, and frustration (Tobin, Graziano, Vanman, \& Tassinary, 2000). In additional, the effects of agreeableness on individual emotions are amplified in the social setting, as individuals attach more importance to social relations (Kuppens, 2005). Finally, low levels of agreeableness have been shown to be predictive of angry, hostile and aggressive behaviors while individuals high in agreeableness have been shown to experience less anger (Ode, Robinson, \& Wilkowski, 2008; Egan \& 
Lewis, 2011). These findings support the hypothesis that agreeableness will moderate the effects of task conflict, relationship conflict, and incivility.

Hypothesis 6 a,b,c: Agreeableness will moderate the relationship between task conflict, relationship conflict, and incivility and negative emotions such that individuals high in agreeableness will experience fewer negative emotions.

Hypothesis 6 d: Agreeableness will moderate the relationship between task conflict, relationship conflict, and incivility and strains such that individuals high in agreeableness will experience less strain.

\section{Conscientiousness}

Conscientiousness describes someone who is dutiful, orderly, achievement focused, hardworking, and self-disciplined (Costa \& McCrae, 1992). Research by Mount, Barrick, and Strauss (1999) has shown that people high in conscientiousness tend to persistently work harder, increase their efforts to achieve their goals or objectives, and give more effort in negative situations than individuals low in conscientiousness (Colbert, Mount, Harter, Witt, \& Barrick, 2004). Research examining the relationship between conscientiousness and interpersonal conflict or incivility in the workplace is scant. What research there is has begun to demonstrate the moderating role conscientiousness plays on workplace incivility, showing conscientiousness to negatively moderate the relationship between incivility and both sharing knowledge and the intent to share knowledge (Shim, 2010). This suggests that conscientiousness may act as a key moderator on how workplace conflict and incivility are acted upon.

Stepping outside of the workplace focused literature, a study examining relationship conflict in the roommate environment found high levels of conscientiousness 
to be predictive of relationship conflict, while low levels of conscientiousness was associated with higher levels of task conflict (Bono, Boles, Judge, \& Lauver, 2002). Specifically, Bono et al. (2002) reported that relationship conflict was more prevalent when both individuals involved in the conflict experience had high levels of conscientiousness. This is thought to occur for two reasons, one is that high levels of conscientiousness have been shown to affect both criticality and inflexibility, and that conscientiousness has been associated with argumentativeness in men (Hogan \& Ones, 1997; Blickle, 1997). Researchers have also used the psychological construct of control as a proxy for conscientiousness (Tellegen $\&$ Waller, 2008). These findings, however, indicate that higher levels of control are negatively related to interpersonal conflict (Jockin et al., 2001; Bowling \& Eschleman, 2010).

Research examining conscientiousness' relationship with negative emotions such as anger, anxiety, and frustration is more established. Conscientiousness has been shown to relate negatively with self-reported anger and anger responses (Harmon, Jones \& Sigelman, 2001), the expression of anger (Martin et al., 1999), and has been shown to moderate the link between anger and aggression (Jensen-Campbell, Knack, Waldrip, \& Campbell, 2007). This last finding is especially interesting, as it reported no evidence of a relationship between anger and aggression in high conscientiousness individuals, suggesting that these individuals may be better able to control their behavior when they experience negative situations. Conversely, this research also suggests that individuals lower in conscientiousness may experience poorer interpersonal relationships, as they may be less capable of controlling their anger when confronted with a frustrating interpersonal situation. Specifically, the research has demonstrated that when individuals 
were low in conscientiousness other personality traits such as agreeableness became positively associated with anger. In addition, research has shown that conscientiousness plays a key role in individual self-regulation, suggesting that higher levels of conscientiousness are associated with higher levels of individual self-regulation, which is directly linked to stronger levels of emotional self-control (Barkley, 1998; Baumeister \& Vohs, 2004; Jensen-Campell, 2006). This research has conceptualized conscientiousness as an emotional and behavioral regulator, and this conceptualization has received support as the literature has shown conscientiousness to moderate social competence and peer conflicts in children, adolescents, and adults (Cavell, 1990; Barkley, 2001; JensenCampbell \& Malcolm, 2006; Jensen-Campbell, Knack, Waldrip, \& Campbell, 2007).

Although the Bono et al., (2002) findings raise the possibility that conscientiousness may play a different role in the emergence of conflict types, high levels of the trait are still expected to regulate the negative emotional reactions experienced and, consequently, the elicited strain. Hence, it is hypothesized that:

Hypothesis 7a,b,c: Conscientiousness will moderate the relationship between task conflict, relationship conflict, incivility and negative emotions such that individuals high in conscientiousness will experience fewer negative emotions.

Hypothesis $7 \mathrm{~d}$ : Conscientiousness will moderate the relationship between task conflict, relationship conflict, incivility and strains such that individuals high in conscientiousness will experience less strain.

\section{Trait anger}

Trait anger is conceptualized as the predisposition to perceive or experience situations in an anger provoking way (Spielberger, 1979). Individuals high in trait anger 
are more likely to be angered by the variety of daily situations they find themselves in or act on their anger through aggression and negative emotions. One of the greatest challenges when dealing with anger in the work place is the nature of anger itself. As demonstrated in the model of job stress (Figure 1; Spector \& Bruk-Lee, 2008) the experience of negative emotions is a key link in the stressor-strain relationship. One of the primary mechanisms of trait anger is anger rumination, which is the tendency to have repetitive thoughts dwelling on incidents that caused anger, even though there is no further environmental demand prompting these thoughts (Martin \& Tesser, 1996). These ruminations on anger help to maintain high level of psychological arousal and may act to preserve the original anger; even well after the incident causing it has passed (Brosschot, Gerin, \& Thayer, 2006). This is believed to be one of the key factors in individuals who are high in trait anger for experiencing greater prevalence of anger inducing events (Sukhodolsky, Golub, \& Cromwell, 2001).

Examining the links trait anger has with task conflict, relationship conflict, and incivility has shown trait anger to correlate strongly and positively with incidents of conflict between coworkers and customers (Sliter, Pui, Sliter, \& Jex, 2011; Fox, Spector, \& Miles, 2001). Trait anger has also shown positive correlations with counterproductive work behaviors (Fox et al., 2001), task performance (Sliter et al., 2011), and job dissatisfaction (Fox \& Spector, 1999). Sliter et al. (2011) examined trait anger's role as a moderator between interpersonal conflict and job-based outcomes. The research demonstrated that when dealing with external customers or clients, individuals high in trait anger were more likely to experience negative reactions than individuals with low levels of trait anger. In addition, research by Douglas and Martinko (2001) found that 
trait anger was strongly related $(r=.68)$ with a general assessment of workplace aggression. Finally, a meta-analysis examining workplace aggression demonstrated that at the aggregate level, trait anger is a significant contributor to both interpersonal and organizational aggression (Hershcovis, Turner, Barling, Arnold, Dupre, Inness, LeBlanc, \& Sivanathan, 2007).

Given that individuals high in trait anger report a greater frequency of incidents that lead to anger and that their anger remains a salient for longer time periods, it is important to understand how trait anger fits into the job stress model. Drawing from the previously established literature demonstrating the correlational relationship between trait anger and relationship conflict, task conflict, and incivility we believe trait anger will act as a moderator in the job stress model. Specifically, individuals high in trait anger will report more incidents of relationship conflict, task conflict, and incivility. In addition, trait anger will moderate the stressor strain relationship such that individuals with high levels of trait anger will report more negative emotions. Furthermore, the strains that individuals high in trait anger do report will be more impactful when compared to individuals low in trait anger.

Hypothesis 8 a,b,c: Trait anger will moderate the relationship between task conflict, relationship conflict, and incivility and negative emotions such that individuals high in trait anger will experience more negative emotions.

Hypothesis 8 d: Trait anger will moderate the relationship between task conflict, relationship conflict, and incivility and strains such that individuals high in trait anger will experience more strains. 


\section{Locus of control}

Locus of control (LOC) refers to the extent an individual believes that they can control the events that affect them, whether those events are grounded in the individual's own actions or from external forces (Rotter, 1966). Individual LOC is generally described in one of two ways, as an internal LOC or an external LOC. An internal locus of control refers to someone who believes that they are in control of their own actions and destiny while individuals with an external locus believe that powerful others, fate, or chance plays a large role in the outcome of events (Rotter, 1966). Research delving into the role that LOC plays on the task conflict, relationship conflict and incivility is currently limited in scope and often times contradictory. Longitudinal research has suggested that conflict situations would be more stressful to someone with an external locus of control due to their lack of perceived control. Spector and O'Connell (1994) demonstrated that individuals high in external locus of control reported more conflict than their internal locus of control counterparts. In addition, research examining LOC through the stressorstrain perspective has reported mixed findings, showing support that both an external and internal LOC can strengthen of the stressor-strain relationship (Kolb \& Aiello, 1996). However, a recent meta-analysis examining LOC in the work place found that individuals with an internal LOC showed positive correlations with individuals reported well-being, mental health, physical symptoms, and commitment while demonstrating a negative relationship with turnover intentions, job stress, and burnout $(\mathrm{Ng}$, Sorensen, \& Eby, 2006).

Although research has shown that Rotter's conceptualization of LOC correlates with work-related outcomes, researchers have argued that this conceptualization only 
serves as a rough measure of the construct (Phares, 1976). Research has since begun to develop and implement more domain-specific measures of LOC to better understand how specific situational factors may influence personal perspectives of control. The domainspecific measure of LOC relevant to this study of the stressor-strain relationship in the workplace is an individual's type of Interpersonal Locus of Control (ILOC).

The Interpersonal Locus of Control construct was presented by Paulhus (1983) and then revised in 1990. Paulhus (1983) conceptualized LOC in terms of how an individual partitioned their behavioral spheres, leading researchers to posit that an individual's locus of control can be partitioned into a variety of sub-spheres loci of control. Specifically, these sub-spheres of locus of control are an achievement LOC sphere, an interpersonal LOC (ILOC), and a socio-political LOC sphere. Of these three sphere specific locus of control, ILOC is the most relevant and related to interpersonal interactions, as it governs an individual's sense of control in their interpersonal relationships.

The ILOC sphere is defined as being salient when an individual interacts with others in a dyad and group situations. Examples of an interpersonal interaction include interactions such as defending one's interests in a meeting, or attempting to develop or enhance a social relationship (Paulhus, 1983). Unfortunately, only a handful of studies have examined the relationship between an individual's ILOC and wellbeing, with the majority being conducted outside of the workplace. What the workplace literature has shown is that both internal and external ILOC orientations can affect the stressor-strain process in different ways. Specifically, individuals with an external ILOC reported more self-reported negative general health symptoms on day they experienced conflict, while 
individuals with an internal ILOC reported higher levels of depression on days exposed to conflict (Hahn, 2000). Stepping outside of the workplace, research has reported that individuals with an external ILOC experienced greater levels of psychological distress (Charlton \& Thompson, 1996). Given that the research indicates that an external ILOC may be more susceptible to experiencing a greater level of negative wellbeing outcomes, it is believed that an external ILOC will have a larger impact on the stressor strain process.

Finally, research examining the relationship between LOC and the experience of negative emotions has reported somewhat mixed findings. Fox and Spector (1999) assessed the relationship between LOC and negative emotions such as anxiety and found that individuals with an external LOC reported higher associations with negative emotional responses. This relationship was also demonstrated by Hahn (2000) who reported that individuals with an external ILOC were more susceptible to anger and their internal ILOC counterparts. Furthermore, a study by Dengerlink, O'Leary, and Kasner's (1975) demonstrated that individuals with an external locus of control felt they were helpless to stop the aggressive behaviors. Hahn also demonstrated that an internal ILOC was more impactful toward individual's wellbeing outcomes such as depression. Given that the experience of negative emotions plays a crucial role in the job stress model and that the research indicates individuals with an external ILOC are more susceptible to negative emotions, we believe this trend will continue.

Hypothesis 9 a,b: ILOC will moderate the relationship between task conflict, relationship conflict, and incivility and negative emotions such that individuals with an external ILOC will experience more negative emotions. 
Hypothesis 9 c: ILOC will moderate the relationship between task conflict, relationship conflict, and incivility and strains such that individuals with an external ILOC will experience more strain.

\section{Method}

\section{Participants and Procedures}

Participants were recruited through an electronic invitation to complete an online survey using social media outlets (Facebook, LinkedIn, alumni and organizational based Listservs). Possible participants were presented with an opportunity to participate in a research project through electronic communication (email, social media; see appendix 1). The survey was made available through a link directing the participants to qualtrics.com, which directed the participants to further information about the study including the eligibility requirements, and the informed consent. To meet the edibility requirements participants had to be 18 years of age or older and work at least 20 hours per week. A ten dollar (\$10) gift card to Amazon.com was offered as compensation for the successful completion of a survey. The survey was accessed 753 times returning a final sample of 327 completed surveys reporting a completion rate of $43 \%$. The sample had an average age of 31.92 years old $(\mathrm{SD}=7.21)$, was $62.5 \%$ male $(37.5 \%$ female), and had 3.64 years $(\mathrm{SD}=3.68$ months) of tenure in their current job. The ethnic breakdown of this sample was: $71.2 \%$ White / Caucasian, $11.3 \%$ Hispanic 9.8\%, African American, $4.3 \%$ Asian, $2.1 \%$ Native American, $0.3 \%$ Pacific Islander, and $0.9 \%$ as "Other". The educational breakdown for this sample was: 4 year College Degree 53.9\%, Masters Degree 18.9\%, 2year College Degree 18.3\%, Some college 3.7\%, Doctoral Degree 2.5\%, High School / GED 1.5\%, and Professional Degree (JD, MD) 1.2\%. Finally, participants reported job 
levels were: Individual contributor $31.5 \%$, Senior level individual contributor $27 \%$, Manager level 21.2\%, Director level 14.5\%, Executive Level 5.8\%.

\section{Measures}

Task and relationship conflict: Task and relationship conflict was assessed using Jehn's (1995) interpersonal conflict measure. The interpersonal conflict measure consists of two subscales assessing task and relationship conflict. Each of these subscales consists of 4 items. Items measures the presence of conflict on a 5-point Likert scale ranging from $1=$ none to $5=$ always. Sample questions include "How much friction is there among members in your work unit" for the task subscale and "to what extent are there differences of opinion in your work unit“" for the relationship subscale. The coefficient alphas for both subscales were .80 .

Incivility: Incivility was measured using the Workplace Incivility Scale (WIS; Cortina et al., 2001). The WIS consists of seven items, each of which uses a 5-point Likert scale ranging from $1=$ never to $5=$ always. Sample questions ask "how often in the last month have you been in a situation where any of your superiors or coworkers..." “...put you down or was condescending to you?" and "...paid little attention to your statement or showed little interest in your opinion?". The coefficient alpha for this study was .91 .

Emotions: Negative emotional reactions were measured using a subscale of the 20-question version of the Job-Related Affective Well-being Scale (JAWS; Van Katwyk, Fox, Spector, \& Kelloway, 2000). This scale is comprise of 10 items and asks individuals to indicate how their job has made them feel across 10 negative emotional states. It uses a 5-point Likert scale with a 1 = "never" and a 5 = "very often" with a high score 
representing higher levels of negative emotion. Sample statements include "My job made me feel anxious" and "My job made me feel annoyed". The coefficient alpha for this study was .93 .

Extraversion: Individual levels of extraversion were assessed using the NEO-FFI 3 Personality Inventory, a shortened version of the NEO-PI developed by Costa and McCrea (1992). The NEO-FFI extraversion measure consists of 12 items. For each item, participants were asked to indicate their level of agreement about how each item represented them on a 5 -point Likert scale ranging from $1=$ strongly disagree to $5=$ strongly agree. A sample statement would be "I really like most people I meet". The coefficient alpha for this study was .69 .

Neuroticism: Individual levels of neuroticism were assessed using the NEO-FFI 3 Personality Inventory, a shortened version of the NEO-PI developed by Costa and McCrea (1992). The NEO-FFI neuroticism measure consists of 12 items. For each item, participants were asked to indicate their level of agreement about how much each item represented them on a 5-point Likert scale ranging from $1=$ strongly disagree to $5=$ strongly agree. A sample statement would be "I am easily frightened". The coefficient alpha for this study was .78.

Conscientiousness: Individual levels of conscientiousness were assessed using the NEO-FFI Personality Inventory, a shortened version of the NEO-PI developed by Costa and McCrea (1992). The NEO-FFI conscientiousness measure consists of 12 items. For each item, participants were asked to indicate their level of agreement about how much each item represented them on a 5-point Likert scale ranging from $1=$ strongly 
disagree to 5 = strongly agree. A sample statement would be "I am known for my prudence and common sense“. The coefficient alpha for this study was .82

Agreeableness: Individual levels of agreeableness were assessed using the NEOFFI Personality Inventory, a shortened version of the NEO-PI developed by Costa and McCrea (1992). The NEO-FFI agreeableness measure consists of 12 items. For each item, participants were asked to indicate their level of agreement about how much each item represented them on a 5-point Likert scale ranging from $1=$ strongly disagree to $5=$ strongly agree. The coefficient alpha for this study was .74 .

Trait anger: Trait anger was measured using Spielberger, Jacobs, Russell, and Crane's (1983) Trait Anger Scale (TAS). The TAS is comprised of 10 items designed to measure latent trait anger. Items are measured using a 4-point Likert scale with $1=$ "almost never" and 4 = "almost always" with higher scores representing higher levels of trait anger. Sample items include "I have a fiery temper" or "I am a hotheaded person". The coefficient alpha for this study was .85 .

Interpersonal Locus of Control Scale: Locus of control was assessed using the Interpersonal Locus of Control scale (ILOC, 10 items), which is a subscale of Paulhus (1983) 30 item spheres of control scale. The ILOC subscale specifically assesses an individual's sense of control in their interpersonal environment and is comprised of ten items which use a 7-point Likert scale, with a $1=$ strongly disagree and a $7=$ strongly agree. Sample statements include "I have no trouble making and keeping friends" and "If there is someone I want to meet I usually arrange it". A high score on this measure suggests an external locus of control. The coefficient alpha for this study was .62. 
Job satisfaction: Job satisfaction was measured using a modified version of the two-item measure developed by Cammann, Fichman, Jenkins, and Klesh (1979). The three items assess overall job satisfaction, as opposed to satisfaction with particular facets of the job (e.g., pay, workload) and uses a 5-point Likert scale, with a $1=$ strongly disagree and a $7=$ strongly agree. The coefficient alpha for this study was .72 .

Life satisfaction: Life satisfaction was measured using the Satisfaction With Life Scale (SWLS; Diener, Emmons, Larsen, \& Griffin, 1985). The SWLS is comprised of five items which use a 5 -point Likert scale, with a $1=$ strongly disagree and a $5=$ strongly agree. Sample statements include "In most ways my life is close to my ideal" and "The conditions of my life are excellent". The coefficient alpha for this study was .68 .

Depression: Depression was assessed using the Center for Epidemiologic Studies Depression Scale (CESD; Radloff, 1977). The CESD assesses depression as the frequency with which individuals experience symptoms such as a depressed mood, feelings of worthlessness, feelings of hopelessness, poor concentration, loss of appetite, and sleep disturbance. It contains 20 items and responses are assessed on a 4-point Likert scale with a $1=$ rarely or none of the time (less than once a day) and a $4=$ most or all of the time (five to seven days a week). Sample statements include "I felt fearful" and "I was happy". The coefficient alpha for this study was .88 .

Physical symptoms: Physical symptoms were measured using the Physical Symptom Inventory (PSI; Spector \& Jex, 1998). The PSI measures somatic health issues often related to stressors, such as backaches, heartburn, and trouble sleeping. It contains 18 items and asks participants to indicate whether they had experienced any of the 18 
health issues using one of five response options: $1=$ not at all, $2=$ once or twice, $3=$ once or twice per week, $4=$ once or twice per day, $5=$ several times per day. Physical symptoms include stomachaches, nausea, trouble sleeping, headache, digestive trouble, and backaches. Higher scores on the PSI indicate worse physical wellbeing or health. The coefficient alpha for this study was .97 .

Stress: Stress was measured using a modified version of the Perceived Stress Scale (PSS; Cohen, Kamarck, \& Mermelstein, 1983). This 13-item measure is designed to measure the experience of stress rather than just report stressful events. The scale was modified to focus on stress occurring in the workplace or as a consequence of the workplace and used a 5-point Likert scale with a $1=$ never and a $5=$ always. Sample statements include "In the last month, how often have you been upset because of something that happened unexpected" and "In the last month, how often have you felt nervous and stressed?" The coefficient alpha for this study was .73.

\section{Results}

All variables were assessed for skewness, kurtosis, and multicollinearity, no violations were found. Three types of analyses were conducted. The first type of analysis consisted of simple correlations to assess the bivariate relationships between variables. The second set of analysis consisted of hierarchal regressions, which examined the direct effects of the stressor variables on the strain outcomes. Finally, the third type of analysis used are a number of moderations examining the moderating effects of personality on the stressor strain relationship. All analyses were conducted using SPSS 20.0. All mediation and moderation analyses were conducted using the process macro (Hayes, 2012; Preacher \& Hayes, 2004) in SPSS 20.0. All analyses past correlations controlled for age, gender, 
and tenure. These variables were controlled for as research has shown that the experience of conflict or aggression can be interpreted differently depending on the individual's contextual variables. Specifically, research has highlighted the fact that males and females employ different defensive strategies (e.g. Bettencourt \& Miller, 1996; Canary, Cuningham \& Cody, 1988). In addition, both age and tenure have also been found to influence the experience of workplace aggression (e.g., Baron, Neuman \& Geddes, 1999; Aquino \& Thau, 2009; Schat, Frone \& Kelloway, 2006). Table 2 displays descriptive statistics and correlations for all variables.

Given the proposed similarities between relationship and task conflict and incivility it is important to show that each construct is distinct incivility, using the methods outlined by Hallberg and Schaufeli (2006). First, the initial correlations reveal that while relationship and task conflict are strongly related to incivility the relationship is not so strong as to immediately become cause for concern, reporting correlations of .68 and .66 respectively (see Table 2). A further investigation of the discriminant validity shows the discriminate validity between relationship and task conflict to be .79 and .77 between task conflict and incivility $\left(\mathrm{r}_{\mathrm{xy}} / \sqrt{ }\left(\mathrm{r}_{\mathrm{xx}}+\mathrm{r}_{\mathrm{yy}}\right)\right)$. Both of these results fall under the accepted level of .85 , which suggests that discriminate validity between these scales exists (Campbell \& Fiske, 1959; John \& Benet-Martinez, 2000). These findings support the conceptual concept of these constructs, showing that while they are related, they are investigating different aspect of workplace aggression.

As shown in Table 2, support was found for both hypotheses 1 and 2. Specifically, hypothesis 1 predicted a positive relationship between incivility, task, and relationship conflict. Incivility was significantly related to both relationship conflict $(r=$ 
$.68, p<.01)$ and task conflict $(r=.66, p<.01)$. Hypothesis 2 stated incivility, relationship conflict, and task conflict would be positively related to negative emotions. In support of hypotheses 2 incivility, relationship conflict, and task conflict all showed strong significant correlations with negative emotions $(r=.70, p<.01, r=.64, p<.01, r$ $=.64, p<.01$, respectively). Hierarchical regression analyses were used to examine the incremental variance explained by incivility, relationship conflict, and task conflict, in negative emotions, after controlling for the influences of age, gender, and job tenure. As shown in Table 3, all three predictors explained unique variance in negative emotions, $F$ $(1,303)=65.74, p<.001$, with the overall model accounting for $58 \%$ of the variance in negative emotions.

Correlational evidence showed support for hypotheses $3 a, 3 b$, and $3 c$ as incivility, relationship conflict, and task conflict all showed significant correlations with depression $(r=.75, p<.01, r=.61, p<.01, r=.62, p<.01)$, physical symptoms $(r=.73, p<.01, r$ $=.65, p<.01, r=.64, p<.01)$, stress $(r=.50, p<.01, r=.20, p<.01, r=.18, p<.01)$, job satisfaction $(r=-.28, p<.01, r=-.19, p<.01, r=-.17, p<.01)$, and life satisfaction $(r=.16, p<.01, r=.29, p<.01, r=.31, p<.01)$, respectively (see Table 2). Each of these relationships further were assessed through hierarchical multiple regression to assess workplace aggression's ability to predict levels of depression, physical symptoms, stress, job satisfaction, and life satisfaction.

All three types of workplace aggression effects on depression were assessed simultaneously through hierarchal repression techniques (see Table 4). This model explained $61 \%$ of the variance after controlling for age, gender, and tenure, $F(1,303)=$ $76.95, p<.001$. In this combined model, both incivility $(B=.60, p<.001)$ and task 
conflict $(B=.13, p<.05)$ were significant predictors of depression, while relationship conflict became non-significant. The hierarchal regression analysis for physical symptoms showed incivility, relationship conflict, and task conflict explained $59 \%$ of the variance in physical symptoms, $\mathrm{F}(1,303)=72.32, p<.001$ (see Table 5 ). In this combined model, incivility $(B=.48, p<.001)$, relationship conflict $(B=.19, p<.01)$, and task conflict $(B=.17, p<.01)$ all remained significant predictors of physical symptoms. In the hierarchal regression model for stress incivility, relationship conflict, task conflict, explained $37 \%$ of the variance, $F(1,303)=2.22, p<.001$ (see Table 6$)$. However, in this model only incivility $(B=.69, p<.001)$ and task conflict $(B=-.20, p<$ $.05)$ remain significant predictors of workplace stress while relationship conflict became non-significant. Furthermore, the effect of task conflict became negative, suggesting a suppression effect may be inflating the effect size of incivility on stress. For job satisfaction, the hierarchal model accounted for $14 \%$ of the variance in job satisfaction $F$ $(1,303)=8.37, p<.001$ (see Table 7). However, at step 2, only incivility remained a significant predictor of job satisfaction $(B=-.23, p<.01)$. For life satisfaction the hierarchal regression showed that the incremental variance explained by this model accounted for $20 \%$ of the variance in life satisfaction $F(4,303)=12.14, p<.001$ (see Table 8). However, at Step 2, only task conflict $(B=.34, p<.001)$ explained unique variance in the criterion.

Hypothesis $3 \mathrm{~d}$ stated that negative emotions would mediate the relationship between incivility, relationship conflict, and task conflict and the strain outcomes. For incivility support for hypothesis $3 \mathrm{~d}$ was shown in depression, physical symptoms, and job satisfaction (see Table 9). For depression there was a significant incivility to negative 
emotion direct effect $(a$ effect $=.72, p<.001)$, a significant negative emotions to depression direct effect $(b$ effect $=.31, p<.001)$, and a significant indirect effect through negative emotions (indirect effect $=.21, \mathrm{CI}^{95}=.16, .25$ ). Accounting for the mediating role of negative emotions, incivility continues to be a significant predictor of depression, suggesting negative emotions act as a partial mediator in the incivility to depression relationship.

For physical symptoms, there was a significant incivility to negative emotion direct effect $(a$ effect $=.72, p<.001)$, a significant negative emotions to physical symptom direct effect $(b$ effect $=.79, p<.001)$, and a significant indirect effect through negative emotions (indirect effect $=.54, \mathrm{CI}^{95}=.46, .63$ ). Accounting for negative emotion's mediating role, incivility continues to be a significant predictor of physical symptoms, suggestions negative emotions act as a partial mediator in the incivility to physical symptom relationship.

For job satisfactions there was a significant incivility to negative emotion direct effect $(a$ effect $=.72, p<.001)$, a significant negative emotions to job satisfaction direct effect $(b$ effect $=-.35, p<.001)$, and a significant indirect effect through negative emotions (indirect effect $=-24, \mathrm{CI}^{95}=-.33,-.15$ ). Accounting for negative emotions mediating role, incivility becomes a non-significant predictor of job satisfaction, suggesting negative emotions fully mediate the incivility to job satisfaction relationship. Hypothesis $3 \mathrm{~d}$ was not supported in stress and life satisfaction, suggesting that negative emotions do not play a mediating role in stress and life satisfaction relationship with incivility. 
Support for Hypothesis $3 \mathrm{~d}$ was found for relationship conflict in depression, physical symptoms, stress, and job satisfaction (see Table 10). For depression there was a significant relationship conflict to negative emotion direct effect $(a$ effect $=.64, p<.001)$, a significant negative emotions to depression direct effect ( $b$ effect $=.40, p<.001$ ), and a significant indirect effect through negative emotions (indirect effect $=.29, \mathrm{CI}^{95}=.23$, .36), when controlling for age, gender, and tenure. Once the mediating effects of negative emotions were included, relationship conflict remained a significant predictor of depression suggesting negative emotions partially mediate the relationship conflict to depression relationship.

For physical symptoms there was a significant relationship conflict to negative emotion direct effect ( $a$ effect $=.64, p<.001)$, a significant negative emotions to physical symptom direct effect $(b$ effect $=.86, p<.001)$, and a significant indirect effect through negative emotions (indirect effect $=.63, \mathrm{CI}^{95}=.53, .73$ ). Relationship conflict continued to be a significant predictor of physical symptoms with the inclusion of negative emotions as a mediator, suggesting negative emotions partially mediate the relationship conflict to physical symptom relationship.

For stress there was a significant relationship conflict to negative emotion direct effect $(a$ effect $=.64, p<.001)$, a significant negative emotions to stress direct effect $(b$ effect $=.17, p<.001)$, and a significant indirect effect through negative emotions (indirect effect $=.12, \mathrm{CI}^{95}=.07, .20$ ). Once negative emotions mediating effects were assessed, relationship conflict became a non-significant predictor of stress, suggesting that negative emotions fully mediate the relationship conflict to stress relationship. 
For job satisfaction there was a significant relationship conflict to negative emotion direct effect $(a$ effect $=.64, p<.001)$, a significant negative emotions to job satisfaction direct effect $(b$ effect $=-.38, p<.001)$, and a significant indirect effect through negative emotions (indirect effect $=-.27, \mathrm{CI}^{95}=-.38,-.18$ ). Once negative emotion's mediating effects were assessed, relationship conflict became a non-significant predictor of job satisfaction, suggesting that negative emotions fully mediate the relationship conflict to job satisfaction relationship.

Hypothesis 3d was supported with task conflict in depression, physical symptoms, stress, and job satisfaction (see Table 11). . In the depression outcome there was a significant task conflict to negative emotion direct effect $(a$ effect $=.64, p<.001)$, a significant negative emotions to depression direct effect ( $b$ effect $=.40, p<.001$ ), and a significant indirect effect through negative emotions (indirect effect $=.28, \mathrm{CI}^{95}=.22$, .34). After negative emotions were included as a mediator, task conflict remained a significant predictor of depression, demonstrating negative emotions role as a partial mediator of the task conflict to depression relationship.

For physical symptoms, there was a significant task conflict to negative emotion direct effect $(a$ effect $=.64, p<.001)$, a significant negative emotions to physical symptom direct effect $(b$ effect $=.87, p<.001)$, and a significant indirect effect through negative emotions (indirect effect $=.62, \mathrm{CI}^{95}=.52, .73$ ). Assessing negative emotions role as a mediator shows task conflict to continue to act as a significant predictor of physical symptoms once negative emotions mediating effects have been included, suggesting negative emotions only partially mediate the task conflict to physical symptom relationship. 
For stress there was a significant task conflict to negative emotion direct effect ( $a$ effect $=.64, p<.001)$, a significant negative emotions to stress direct effect $(b$ effect $=$ $.18, p<.001$ ), and a significant indirect effect through negative emotions (indirect effect $\left.=.13, \mathrm{CI}^{95}=.07, .18\right)$. Once negative emotions where included as a mediator, task conflict became a non-significant predictor of stress, suggesting negative emotions fully mediate the task conflict to stress relationship.

For job satisfaction there was a significant task conflict to negative emotion direct effect $(a$ effect $=.64, p<.001)$, a significant negative emotions to job satisfaction direct effect ( $b$ effect $=-.42, p<.001$ ), and a significant indirect effect through negative emotions (indirect effect $=-.30, \mathrm{CI}^{95}=-.40,-.21$ ). Once negative emotions were included as a mediator, task conflict became a non-significant predictor of job satisfaction, suggesting negative emotions fully mediate the task conflict to job satisfaction relationship. Overall, hypothesis $3 \mathrm{~d}$ was partially supported.

\section{Extraversion}

For moderation, all predictors and moderating variables were mean centered before analysis (Fields, 2009). At step 1 control and predictor variables were entered, at step 2 the interaction effect of the predictor variables were entered. Moderation was tested using the process model developed by Hayes and Preacher (2011; Hayes, 2012), which uses bootstrapping techniques to create confidence intervals for the moderation effect (Hayes, 2012; Preacher \& Hayes, 2004; Preacher, Rucker \& Hayes, 2007). In all cases where a significant moderation effect was observed, unstandardized simple slopes were created at one standard deviation above and below the mean as outlined by Aiken and West (1991). 
Hypothesis $4 a, 4 b$, and $4 c$ did not receive support as extraversion was found to be a non-significant moderator of the stressor to negative emption relationship, see Table 12. The interaction between incivility and extraversion was significant for depression $(b=$ $.10, \mathrm{p}<.05)$, physical symptoms $(b=-.38, \mathrm{p}<.001)$, and job satisfaction $(b=.28, \mathrm{p}<$ .01 ), suggesting that the effect of incivility on these outcomes is dependent on individual levels of extraversion (see Table 13).

For depression the simple slopes for individuals one standard deviation below and above the mean in extraversion were $b=.48, \mathrm{CI}^{95} .41, .55$, and $b=.38, \mathrm{CI}^{95} .33, .44$, respectively, see Figure 2. For physical symptoms both simple slopes were significantly different from zero with the lower slope reporting $b=1.03, \mathrm{CI}^{95} .89,1.17$ and the higher slope reporting $b=.66, \mathrm{CI}^{95} .54, .78$, see Figure 3. For job satisfaction an examination of the simple slopes revealed that only the low extraversion slope was significant $(b=-.31$, $\mathrm{CI}^{95}-.45,-.16$ ), while the high condition was not significantly different from zero, see Figure 4 . The interaction between incivility and extraversion accounted for $1 \%$ of the variance in depression, $2 \%$ of the variance in physical symptoms, and $2 \%$ of the variance in job satisfaction.

For relationship conflict, hypothesis $4 \mathrm{~d}$ was partially supported as the interaction between relationship conflict and extraversion was significant for depression $(b=-.22, \mathrm{p}$ $<.01)$, physical symptoms $(b=-.45, \mathrm{p}<.001)$, and stress $(b=-.17, \mathrm{p}<.05)$, see Table 14. This suggests that the effect of relationship conflict on these outcomes is dependent on individual levels of extraversion. For depression, both the low simple slope $(b=.53$, $\left.\mathrm{CI}^{95} .44 .63\right)$ and the high simple slope $\left(b=.32, \mathrm{CI}^{95} .24, .40\right)$ were significant, see Figure 5. This suggests that the effects of relationship conflict are stronger for depression in 
individuals with lower levels of extraversion. For physical symptoms both simple slopes were significantly different from zero (lower slope: $b=1.13, \mathrm{CI}^{95} .94,1.31$, higher slope: $\left.b=.69, \mathrm{CI}^{95} .54, .84\right)$, suggesting individuals low in extraversion may be prone to experiencing more physical symptoms, see Figure 6. The simple slopes for stress showed that only the low simple slope was significantly different from zero $\left(b=.19, \mathrm{CI}^{95} .09\right.$, .29), see Figure 7. These results suggest that lower levels of extraversion may increase the effect of incivility on stress. For life satisfaction both the low $\left(b=.42, \mathrm{CI}^{95} .26, .59\right)$ and high $\left(b=.18, \mathrm{CI}^{95} .05, .32\right)$ simple slopes were significantly different from zero. This suggests that lower levels of extraversion enhance the effects of relationship conflict on life satisfaction. The interaction between relationship conflict and extraversion accounted for $2 \%$ of the variance in depression, $2 \%$ of the variance in physical symptoms, $1 \%$ of the variance in stress, and $1 \%$ of the variance in life satisfaction.

The interaction between task conflict and extraversion was found significant for depression $(b=-.20, \mathrm{p}<.01)$ and physical symptoms $(b=-.42, \mathrm{p}<.01)$, suggesting that the effect of task conflict on these outcomes is dependent on individual levels of extraversion and providing partial support for hypothesis $4 \mathrm{~d}$ (see Table 15). An examination of the simple slopes for depression shows the lower simple slope to be $b=$ $.51, \mathrm{CI}^{95} .42 .59$, while the higher simple slope reported $b=.32 \mathrm{CI}^{95} .29, .39$, see Figure 9. These results suggest that task conflict has a stronger effect on depression in individuals who are low in extraversion. For physical symptoms the simple slopes reported and effect size of $\mathrm{b}=1.07, \mathrm{CI}^{95} .90,1.23$ for the lower slope and $\mathrm{b}=.67, \mathrm{CI}^{95}$ $.52, .82$ for the higher slope, suggesting the moderating effect of extraversion to be stronger in individuals with lower levels of extraversion, see Figure 10. The interaction 
between task conflict and extraversion accounted for $2 \%$ of the variance in depression and $2 \%$ of the variance in physical symptoms.

\section{Neuroticism}

Hypothesis $5 \mathrm{a}, 5 \mathrm{~b}$, and $5 \mathrm{c}$ were supported in that neuroticism moderated the relationships between incivility $(b=.29, \mathrm{p}<.001)$, relationship $(b=.33, \mathrm{p}<.001)$, and task conflict $(b=.26, \mathrm{p}<.001)$ with negative emotions, see Table 16. Across all cases, both slopes for high and low levels of neuroticism were significantly different from zero (see figures 11-13). Specifically, for incivility the high and low slopes were $b=.71, \mathrm{CI}^{95}$ $.61, .81$ and $b=.37, \mathrm{CI}^{95} .25, .48$. For relationship conflict the high slope was $b=.74$, $\mathrm{CI}^{95} .63, .86$ while the lower simple slope was $b=.36, \mathrm{CI}^{95} .22, .50$, and for task conflict the higher simple slope was $b=.71, \mathrm{CI}^{95} .60, .83$, while the lower simple slope was ( $b=$ $\left..40, \mathrm{CI}^{95} .27, .54\right)$. In all cases individuals high in neuroticism reported higher levels of negative emotions in response to more aggression.

The interaction between incivility and neuroticism was significant for depression $(b=.18, \mathrm{p}<.001)$, physical symptoms $(b=.49, \mathrm{p}<.001)$, and life satisfaction $(b=.43, \mathrm{p}$ $<.000$ ), suggesting that the effect of incivility on these outcomes is dependent on individual levels of neuroticism and lending partial support to hypothesis $5 \mathrm{~d}$ (see Table 17). For depression the higher simple slope reported an effect size of $b=.43, \mathrm{CI}^{95} .38$, .48 , while the lower condition reported an effect size of $b=.22, \mathrm{CI}^{95} .16, .29$, see Figure 14. Both simple slopes were significantly different from zero. For physical symptoms both the high slope $\left(b=.93, \mathrm{CI}^{95} .82,1.04\right)$ and the low slope $\left(b=.35, \mathrm{Cl}^{95} .22, .48\right)$ were significantly different from zero, see Figure 15. These results show that neuroticism enhances the effects of incivility on both depression and physical symptoms. The 
interaction for stress was also found to be significant $(b=-.21, \mathrm{p}=.001)$, but an examination of its simple slopes revealed only the lower simple slope was significantly different from zero $\left(b=.26, \mathrm{CI}^{95} .20, .33\right)$, see figure 16 . For life satisfaction only the higher simple slope reported a significant effect $\left(b=.40, \mathrm{CI}^{95} .29, .52\right)$, while the lower simple slope was non-significant, see Figure 17. These results show that even though the incivility to stress interaction is significant, it is not in a way that supports hypothesis $5 \mathrm{~d}$. The interaction between incivility and neuroticism accounted for $3 \%$ of the variance in depression, $7 \%$ of the variance in physical symptoms, $6 \%$ of the variance in stress, and $10 \%$ of the variance in life satisfaction.

The interaction between relationship conflict and neuroticism was significant for depression $(b=.22, \mathrm{p}<.001)$, physical symptoms $(b=.51, \mathrm{p}<.001)$, and life satisfaction $(b=.33, \mathrm{p}<.001)$, suggesting that the effect of relationship conflict on these outcomes is dependent on individual levels of neuroticism and partially supporting hypothesis $5 \mathrm{~d}$ (see Table 18). For depression both simple slopes were significantly different from zero (high slope $b=.42, \mathrm{CI}^{95} .35 .48$, low slope $b=.16, \mathrm{CI}^{95} .08, .24$ ), see Figure 18. For physical symptoms both of the simple slopes were significantly different from zero, with the high simple reporting $b=.96, \mathrm{CI}^{95} .83,1.09$, and the low simple slope reporting $\left(b=.36, \mathrm{CI}^{95}\right.$ $.20, .52)$, see Figure 19. For life satisfaction both simple slopes were significantly different from zero (high simple slope: $b=.47, \mathrm{CI}^{95} .34, .60$, low simple slope: $b=.08$, $\left.\mathrm{CI}^{95} .08, .24\right)$, see Figure 22 . These results suggest that individuals high in neuroticism may experience stronger effects from relationship conflict on depression, physical symptoms, and life satisfaction. 
The interaction between neuroticism and relationship conflict was significant for stress $(b=-.12, \mathrm{p}<.01)$ and job satisfaction $(b=.24, \mathrm{p}<.05)$, however the results did not manifest themselves as hypothesized. Specifically, an examination of the simple slopes for stress revealed that only the higher simple slope was significantly different from zero $\left(b=-.08, \mathrm{CI}^{95}-.15,-.01\right)$, see Figure 20 . For job satisfaction only the low simple slope was significantly different from zero $\left(b=-.29, \mathrm{CI}^{95}-.48,-.11\right)$, see Figure 21 . The interaction between relationship conflict and neuroticism accounted for $4 \%$ of the variance in depression, $5 \%$ of the variance in physical symptoms, $1 \%$ of the variance in stress, $2 \%$ of the variance in job satisfaction, and $4 \%$ of the variance in life satisfaction.

The interaction between task conflict and neuroticism was significant for depression $(b=.23, \mathrm{p}<.001)$, physical symptoms $(b=.51, \mathrm{p}<.001)$, and life satisfaction $(b=.19, \mathrm{p}<.05)$, suggesting that the effect of task conflict on these outcomes is dependent on individual levels of neuroticism, partially supporting hypothesis $5 \mathrm{~d}$, see Table 19. The simple slopes for depression revealed that both the high and low simple slopes were significantly different from zero $\left(b=.43, \mathrm{CI}^{95} .36 .49\right.$ and $b=.16, \mathrm{CI}^{95} .08$, .23 , respectively, see Figure 23). Similarly, for physical symptoms both simple slopes were significantly different from zero (high simple slope: $b=.96, \mathrm{CI}^{95} .82,1.09$, low simple slope: $b=.35, \mathrm{CI}^{95} .20, .51$, see Figure 24). For life satisfaction both simple slopes reported significant positive effects, with both the higher simple slope $\left(b=.45, \mathrm{CI}^{95} .32\right.$, $.58)$ and the lower slope $\left(b=.23, \mathrm{CI}^{95} .08, .38\right)$ being different from zero, see Figure 27. There was a significant interaction between task conflict and neuroticism for stress $(b=$ $.12, \mathrm{p}=.01)$ and job satisfaction $(b=.19, \mathrm{p}<.05)$. The findings however did not support the hypothesis $5 \mathrm{~d}$ as only the higher simple slope for stress was significantly different 
from zero $\left(b=-.09, \mathrm{CI}^{95}-.16,-.02\right)$, while the lower slope was non-significant, see Figure 25. For job satisfaction only the lower simple slope reported an effect significantly different from zero $\left(b=-.21, \mathrm{CI}^{95}-.38,-.04\right)$, while the higher simple slope was nonsignificant, see Figure 26. The interaction between task conflict and neuroticism accounted for $4 \%$ of the variance in depression, $5 \%$ of the variance in physical symptoms, $1 \%$ of the variance in stress, $1 \%$ of the variance in job satisfaction, and $1 \%$ of the variance in life satisfaction.

\section{Agreeableness}

The results indicate that the interaction of incivility $(b=-.49, \mathrm{p}<.001)$, relationship conflict $(b=-.40, \mathrm{p}<.001)$, and task conflict $(b=-.35, \mathrm{p}<.001)$ with agreeableness was significant, supporting hypothesis $6 a, 6 b$, and $6 \mathrm{c}$, see Table 20 . For all three stressors, agreeableness moderated their relationship with negative emotions in both the high and low conditions. For incivility the lower slope was $b=.91, \mathrm{CI}^{95} .80,1.02$ while the higher slope was $b=.40, \mathrm{CI}^{95} .28, .52$, see Figure 28. For relationship conflict the lower simple slope was $b=.81, \mathrm{CI}^{95} .69, .93$ and the higher slope was $b=.38, \mathrm{CI}^{95}$ $.25, .52$, see figure 29 . For task conflict the lower simple slope was $b=.78, \mathrm{CI}^{95} .66, .90$, while the higher simple slope was $b=.40, \mathrm{CI}^{95} .27, .54$, see figure 30 . Furthermore, the interaction between agreeableness and incivility, relationship conflict, and task conflict accounted for $7 \%, 5 \%$, and $3 \%$ of the variance explained in negative emotions, respectively. These results show agreeableness to moderate the aggression to negative emption relationship in both conditions. Specifically, as aggression increased individuals high in agreeableness reported less strain when compared to those who were low in agreeableness. 
The interaction between incivility and agreeableness was significant for depression $(b=-.30, \mathrm{p}<.001)$, physical symptoms $(b=-.68, \mathrm{p}<.001)$, stress $(b=.17, \mathrm{p}$ $=.001)$, and life satisfaction $(b=-.48, \mathrm{p}<.001)$, suggesting that the effect of incivility on these outcomes is dependent on individual levels of agreeableness and partially supporting hypothesis $6 \mathrm{~d}$, see Table 21 . For depression both slopes were significantly different from zero (lower slope: $b=.53, \mathrm{CI}^{95} .47, .59$, higher slope: $b=.21, \mathrm{CI}^{95} .15$, .27), see Figure 31. Similarly, for physical symptoms both slopes were significantly different from zero (lower slope: $b=1.08, \mathrm{CI}^{95} .96, .1 .21$, higher slope: $b=.36, \mathrm{CI}^{95} .23$, .50 ), see Figure 32. These results suggest that agreeableness moderates the relationship between incivility and depression and physical symptoms in both conditions. There was a significant interaction for stress $(b=.17, \mathrm{p}=.001)$, however the findings were unsupportive of hypothesis $6 \mathrm{~d}$. For stress both slopes were found to be significantly different from zero (higher slope: $b=.30, \mathrm{CI}^{95} .21, .38$, lower slope: $b=.12, \mathrm{CI}^{95} .05$, .20 ), see Figure 33. For life satisfaction only the lower slope was found to be significantly different from zero $\left(b=.40, \mathrm{CI}^{95} .27, .54\right)$, while the high condition was non-significant, see Figure 34. These results suggest that agreeableness only plays a significant moderating role on the incivility and life satisfaction relationship when its levels are low. The interaction between incivility and agreeableness accounted for $8 \%$ of the variance in depression, $10 \%$ of the variance in physical symptoms, $3 \%$ of the variance in stress, and $9 \%$ of the variance in life satisfaction.

For relationship conflict, partial support for hypothesis $6 \mathrm{~d}$ was found in the depression $(b=-.30, \mathrm{p}<.001)$, physical symptoms $(b=-.61, \mathrm{p}<.001)$, and life satisfaction $(b=-.46, \mathrm{p}<.001)$ (see Table 22). For depression both slopes were 
significantly different from zero with the lower slope reporting $b=.45, \mathrm{CI}^{95} .39, .52$ and the higher slope reporting $b=.13, \mathrm{CI}^{95} .06, .21$, see Figure 35 . For physical symptoms an examination of the simple slopes revealed that both slopes to be significantly different from zero (low slope: $b=.99, \mathrm{CI}^{95} .86,1.12$, high slope: $b=.35, \mathrm{CI}^{95} .20, .50$, see Figure 36). These results suggest that regardless of the level, agreeableness moderates the relationship between relationship conflict and depression and physical symptoms. The interaction for job satisfaction was significant $(b=-.23, \mathrm{p}<.05)$, however support for hypothesis $6 \mathrm{~d}$ was not supported as only higher simple slope was found to be significantly different form zero $\left(b=-.26, \mathrm{CI}^{95}-.43,-.09\right)$, while the low slope was nonsignificant, see Figure 37. Conversely, for life satisfaction only the lower simple slope was significantly different form zero $\left(b=.49, \mathrm{CI}^{95} .36, .62\right)$, while the higher simple slope was non-significant, see Figure 38. The interaction between relationship conflict and agreeableness accounted for $8 \%$ of the variance in depression, $7 \%$ of the variance in physical symptoms, $2 \%$ of the variance in job satisfaction, and $8 \%$ of the variance in life satisfaction.

The interaction between task conflict and agreeableness was significant for depression $(b=-.28, \mathrm{p}<.001)$, physical symptoms $(b=-.56, \mathrm{p}<.001)$, and life satisfaction $(b=-.42, \mathrm{p}<.001)$, partially supporting hypothesis $6 \mathrm{~d}$ and suggesting that the effect of task conflict on these outcomes is dependent on individual levels of agreeableness (see Table 23). For depression both slopes both the lower and higher slopes were significantly different from zero, $b=.44, \mathrm{CI}^{95} .38 .51$, and $b=.15, \mathrm{CI}^{95} .08, .23$, see Figure 39. For physical symptoms the lower slope was $b=.96, \mathrm{CI}^{95} .82,1.09$, and the higher slope was $b=.37, \mathrm{CI}^{95} .22, .52$, see Figure 40 . Both slopes were significantly 
different from zero. For life satisfaction only the lower simple slope was significantly different from zero $\left(b=.52, \mathrm{CI}^{95} .39, .65\right)$, while the higher simple slope was nonsignificant, see Figure 41. The interaction between task conflict and agreeableness accounted for $6 \%$ of the variance in depression, $6 \%$ of the variance in physical symptoms, and $6 \%$ of the variance in life satisfaction.

\section{Conscientiousness}

Hypotheses $7 \mathrm{a}, 7 \mathrm{~b}$, and $7 \mathrm{c}$ were unsupported as conscientiousness was found to be a non-significant in the incivility, relationship conflict, and task conflict to negative emotion relationship, as can be seen in Table 24 . The interaction between incivility and conscientiousness was significant for physical symptoms $(b=-.40, \mathrm{p}<.001)$, and job satisfaction $(b=.28, \mathrm{p}<.01)$, partially supporting hypothesis $7 \mathrm{~d}$ and suggesting that the effect of incivility on these outcomes is dependent on individual levels of conscientiousness (see Table 25). For physical symptoms both slopes were significantly different from zero, with the lower slope reporting $b=1.11, \mathrm{CI}^{95} .95,1.27$ and the higher slope reporting $b=.69, \mathrm{CI}^{95} .58, .81$, see Figure 42 . For job satisfaction only the low lower simple slope reported a significant moderating effect $\left(b=-.31, \mathrm{CI}^{95}-.47,-.15\right)$, while the higher slope was non-significant, see Figure 44. A significant interaction occurred for stress $(b=.12, \mathrm{p}=.05)$, however the findings were not supportive of hypothesis $7 \mathrm{~d}$ as the interaction for stress showed the higher slope to be $b=.22, \mathrm{CI}^{95} .16$, .27 while the lower slope reported $b=.09, \mathrm{CI}^{95} .01, .17$, see Figure 43 . The interaction between incivility and conscientiousness accounted for $3 \%$ of the variance in physical symptoms, $1 \%$ of the variance in stress, and $2 \%$ of the variance in job satisfaction. 
Hypothesis $7 \mathrm{~d}$ was unsupported for all five outcomes with relationship conflict (see Table 26).

For task conflict, only the interaction between task conflict and conscientiousness on physical symptoms was significant $(b=-.27, \mathrm{p}<.05)$, suggesting that the effect of task conflict on negative physical symptom is dependent on individual levels of conscientiousness, partially supporting hypothesis $7 \mathrm{~d}$, see Table 27 . Both slopes were found to be significantly different from zero, with the lower slope reporting $b=1.00 \mathrm{CI}^{95}$ $.83,1.17$ and the higher slope reporting $b=.72, \mathrm{CI}^{95} .58, .86$ see Figure 45 . The interaction between task conflict and conscientiousness accounted for $1 \%$ of the variance in physical symptoms.

\section{Trait Anger}

The interaction between incivility $(b=.25, \mathrm{p}<.001)$ relationship conflict $(b=.17$, $\mathrm{p}<.01)$ and trait anger was significant, supporting hypothesis $8 \mathrm{a}$ and $8 \mathrm{~b}$. However, hypothesis $8 \mathrm{c}$ was no supported as the interaction between task conflict and trait anger was non-significant (see Table 28). For both incivility and relationship conflict both slopes were significantly different form zero (incivility: high slope $b=.48, \mathrm{CI}^{95} .37, .59$, low slope $b=.21, \mathrm{CI}^{95} .12, .31$; relationship conflict: high slope $b=.39, \mathrm{CI}^{95} .27, .50$, low slope $b=.20, \mathrm{CI}^{95} .08, .32$ ), see figures 46 and 47 respectively. Furthermore, the interaction between incivility and trait anger accounted for $2 \%$ the variance explained in negative emotions while the interaction between relationship conflict and trait anger accounted for $1 \%$ of the variance in negative emotions. These results show trait anger to moderate the aggression to negative emption relationship in both conditions. 
The interaction between incivility and trait anger was significant for depression $(b$ $=.21, \mathrm{p}<.001)$, physical symptoms $(b=.45, \mathrm{p}<.001)$, and life satisfaction $(b=.41, \mathrm{p}<$ .001), suggesting that the effect of incivility on these outcomes is dependent on individual levels of trait anger and partially supporting hypothesis $8 d$, see Table 29 . For depression, both slopes were found to be significantly different form zero with the high slope reporting $b=.37, \mathrm{CI}^{95} .31, .43$ and the low slope reporting $b=.14, \mathrm{CI}^{95} .09, .19$, see Figure 48. For physical symptoms both the high slope $\left(b=.70, \mathrm{CI}^{95} .58, .82\right)$ and the lower slope $\left(b=.22, \mathrm{CI}^{95} .12, .33\right)$ were significantly different from zero, see Figure 49 . The interaction for stress was significant $(b=.22, p<.001)$. An examination if the simple slopes revealed that both slopes were significantly different form zero with the lower slope reporting $b=.34, \mathrm{CI}^{95} .27, .41$ and the higher slope reporting $b=.11, \mathrm{CI}^{95}$ $.02, .19$, see Figure 50. In addition the interaction for job satisfaction $(b=.21, \mathrm{p}<.01)$ was also significant. Contrary to the hypothesis only the lower simple slope for job satisfaction was significantly different form zero $\left(b=-.23, \mathrm{CI}^{95}-.38,-.08\right)$, while the higher slope was non-significant, see Figure 51. The findings for stress and job satisfaction did not support hypothesis $8 \mathrm{~d}$. For life satisfaction only the high slope was significant $\left(b=.35, \mathrm{CI}^{95} .20, .49\right)$, while the low slope was non-significant, see Figure 52 . The interaction between incivility and trait anger accounted for $5 \%$ of the variance in depression, $6 \%$ of the variance in physical symptoms, $6 \%$ of the variance in stress, $2 \%$ of the variance in job satisfaction, and $9 \%$ of the variance in life satisfaction.

For relationship conflict, partial support for hypothesis $8 \mathrm{~d}$ was found as the interaction between relationship conflict and trait anger was significant for depression ( $b$ $=.17, \mathrm{p}<.001)$, physical symptoms $(b=.34, \mathrm{p}<.001)$, and life satisfaction $(b=.44, \mathrm{p}<$ 
.001 ), (see Table 30). This suggests that the effect of relationship conflict on these outcomes is dependent on individual levels of trait anger. For depression only the higher simple slope reported a significant relationship between relationship conflict and depression, $\left(b=.23, \mathrm{CI}^{95} .16, .29\right)$, see Figure 53 . For physical symptoms both slopes were found to be significantly different from zero, with the high slope reporting $b=.55$, $\mathrm{CI}^{95} .41, .68$, and the low slope reporting $b=.19, \mathrm{CI}^{95} .04, .33$, see Figure 54 . For stress there was a significant interaction, but the results ran counter to the proposed hypothesis (lower slope: $b=.11, \mathrm{CI}^{95} .01 .21$ higher slope: $b=-.11, \mathrm{CI}^{95}-.20,-.02$, see Figure 55). The interaction for job satisfaction $(b=.38, \mathrm{p}<.001)$ reported a similar trend as stress, with only the lower simple slope was found to be significantly different from zero ( $b=$ $.31, \mathrm{Cl}^{95}-.49,-.13$ ), while the higher simple slope was non-significant, see Figure 56 . For life satisfaction only the high simple slope was found to be significant $\left(b=.47, \mathrm{CI}^{95} .32\right.$, $.62)$, while the lower condition was non-significant, see Figure 57. The interaction between relationship conflict and trait anger accounted for $8 \%$ of the variance in depression, $7 \%$ of the variance in physical symptoms, $4 \%$ of the variance in stress, $2 \%$ of the variance in job satisfaction, and $8 \%$ of the variance in life satisfaction.

The interaction between task conflict and trait anger was significant for depression $(b=.22, \mathrm{p}<.001)$, physical symptoms $(b=.41, \mathrm{p}<.001)$, and life satisfaction $(b=.41, \mathrm{p}<.001)$, partially supporting hypothesis $8 \mathrm{~d}$ (see Table 31$)$. These findings suggest that the effect of task conflict on these outcomes is dependent on individual levels of trait anger. For depression only the higher simple slope was significantly different from zero $\left(b=.29, \mathrm{CI}^{95} .23, .35\right)$, while the lower simple slope was nonsignificant, see Figure 58. For physical symptoms both slopes were significantly different 
form zero, with the higher slope reporting $b=.63, \mathrm{CI}^{95} .50, .76$, and the lower slope reporting $b=.19, \mathrm{CI}^{95} .06, .32$, see Figure 59 . . For stress the interaction between task conflict and trait anger were significant $(b=-.19, \mathrm{p}<.01)$, however they manifested themselves counter to the proposed hypothesis, with only the higher slope was significant $\left(b=-.12, \mathrm{CI}^{95}-.21,-.02\right)$, as the lower condition was non-significant, see Figure 60 . Similarly, the interaction with job satisfaction $(b=.41, \mathrm{p}<.001)$ was also significant. However, the results were counter to that of hypothesis 8 , as both slopes reported effects significantly different from zero, with the higher slope reporting a positive relationship $(b$ $\left.=.18, \mathrm{CI}^{95} .01, .35\right)$ and the lower slope reporting a negative relationship $\left(b=-.26, \mathrm{CI}^{95}\right.$ $.43,-.09)$, see Figure 61 . For life satisfaction only the higher simple slope was found to be significantly different from zero $\left(b=.54, \mathrm{CI}^{95} .39, .69\right)$, while the lower condition was non-significant, see Figure 62. The interaction between task conflict and trait anger accounted for $3 \%$ of the variance in depression, $3 \%$ of the variance in physical symptoms, $3 \%$ of the variance in stress, $5 \%$ of the variance in job satisfaction, and $6 \%$ of the variance in life satisfaction.

\section{Interpersonal Locus of Control}

Support was found for hypothesis $9 \mathrm{a}, 9 \mathrm{~b}$, and $9 \mathrm{c}$ as the interaction between incivility $(b=-.20, \mathrm{p}<.01)$, relationship conflict $(b=-.29, \mathrm{p}<.001)$, and task conflict $(b$ $=-.19, \mathrm{p}<.01)$ with locus of control were significant, see Table 32. Across all three stressors, both slopes were found to be significantly different form zero (incivility: lower slope: $b=.86, \mathrm{CI}^{95} .72,1.00$, higher slope: $b=.57, \mathrm{CI}^{95} .46, .69$; relationship conflict: lower slope $b=.93 \mathrm{CI}^{95} .78,1.08$, higher slope $b=.51, \mathrm{CI}^{95} .38, .64$ task conflict: lower slope: $b=.84 \mathrm{CI}^{95} .71, .97$, higher slope: $b=.56, \mathrm{CI}^{95} .43, .68$; see figures 63, 64, and 65, 
respectively). The interaction between incivility, relationship conflict, task conflict, and interpersonal locus of control respectively accounted for $1 \%, 3 \%$, and $2 \%$ of the variance explained in negative emotions.

The interaction between incivility and interpersonal locus of control was significant for depression $(b=-.20, \mathrm{p}<.001)$, physical symptoms $(b=-.49, \mathrm{p}<.001)$, and life satisfaction $(b=-.17, \mathrm{p}<.05)$, partially supporting hypothesis $9 \mathrm{~d}$ and suggesting that the effect of incivility on these outcomes is dependent on individual levels of interpersonal locus of control, see Table 33. For depression both slopes were significantly different from zero, with the lower slope reporting $b=.58, \mathrm{CI}^{95} .51, .65$ and the higher slope reporting $b=.28, \mathrm{CI}^{95} .22, .35$, see Figure 66 . For physical symptoms both the lower $\left(b=1.27, \mathrm{CI}^{95} 1.12,1.42\right)$ and higher simple slopes $\left(b=.55, \mathrm{CI}^{95} .42, .68\right)$ were significantly different from zero, see Figure 67. For life satisfaction only the lower slope reported a significant effect $\left(b=.37, \mathrm{CI}^{95} .22, .53\right)$, while the higher slope was nonsignificant, see Figure 69. For stress there was a significant interaction, however the results ran counter the proposed hypothesis as only the higher slope was significantly different from zero $\left(b=.22, \mathrm{CI}^{95} .15, .29\right)$, while the lower condition was non-significant, see Figure 68. The interaction between incivility and interpersonal locus of control accounted for $4 \%$ of the variance in depression, $6 \%$ of the variance in physical symptoms, $2 \%$ of the variance in stress, and $1 \%$ of the variance in life satisfaction.

Partial support was found for hypothesis $9 \mathrm{~d}$ as the interaction between relationship conflict and interpersonal locus of control was significant for depression $(b=$ $-.23, \mathrm{p}<.001)$, physical symptoms $(b=-.58, \mathrm{p}<.001)$, job satisfaction $(b=-.17, \mathrm{p}<$ $.05)$, and life satisfaction $(b=-.20, \mathrm{p}<.01)$, see Table 34 . These results suggest that the 
effect of relationship conflict on these outcomes is dependent on individual levels of interpersonal locus of control. For depression both simple slopes were found to be significantly different from zero (lower slope: $b=.58, \mathrm{CI}^{95} .49, .66$, higher slope: $b=.23$, $\mathrm{CI}^{95} .15, .30$ ), see Figure 70 . Similarly, for physical symptoms both simple slopes were significantly different from zero, with the lower slope reporting $b=1.32, \mathrm{CI}^{95} 1.16,1.49$ and the higher slope reporting $b=.47, \mathrm{CI}^{95} .33, .62$, see Figure 71. For job satisfaction only the higher simple slope was significantly different from zero $\left(b=-.30, \mathrm{CI}^{95}-.46,-\right.$ .14), while the lower slope was non-significant, see Figure 72. For life satisfaction both the lower and higher slopes were significant, $b=.46, \mathrm{CI}^{95} .30, .62$ and $b=.16, \mathrm{CI}^{95} .02$, .30 , respectively, see Figure 73 . The interaction between relationship conflict and interpersonal locus of control accounted for $5 \%$ of the variance in depression, $8 \%$ of the variance in physical symptoms, $1 \%$ of the variance in job satisfaction, and $2 \%$ of the variance in life satisfaction.

Finally, the interaction between task conflict and interpersonal locus of control was significant for depression $(b=-.22, \mathrm{p}<.001)$, and physical symptoms $(b=-.48, \mathrm{p}<$ .001 ), partially supporting hypothesis $9 \mathrm{~d}$ and suggesting that the effect of task conflict on these outcomes is dependent on individual levels of interpersonal locus of control (see table 35). For depression both slopes were found to be significantly different from zero (lower slope: $b=.55, \mathrm{CI}^{95} .48, .63$, higher slope: $b=.24, \mathrm{CI}^{95} .17, .31$ ), see Figure 74 . For physical symptoms both slopes were significantly different from zero, with the lower slope reporting $b=1.21, \mathrm{CI}^{95} 1.06,1.36$ while the higher slope reported $b=.50, \mathrm{CI}^{95} .36$, .64 , see Figure 75 . The interaction between task conflict and interpersonal locus of 
control accounted for $5 \%$ of the variance in depression and $7 \%$ of the variance in physical symptoms.

\section{Discussion}

The purpose of this study was twofold. The first was to further clarify and expand our understanding of the relationship between interpersonal conflict, incivility, and their roles as stressors in the stressor-strain relationship. The second was to examine how neuroticism, extraversion, agreeableness, conscientiousness, trait anger, and spherespecific locus of control moderate the stressor-strain relationship between task conflict, relationship conflict, incivility and workplace and health outcomes.

Hypothesis 1, 2, and 3 (a, b, c, and d) were aimed at addressing the first goal of this study. Specifically, hypothesis 1 stated that task and relationship conflict would be positively correlated with incivility. The results showed significant support for hypothesis 1, with both task and relationship conflict reporting strong correlations with incivility. These results are consistent with the limited body of research that has begun to examine the similarities and differences between the various sub forms of workplace aggression (e.g. Hershcovis, 2011; Penney \& Spector, 2005). However, while strongly related, conflict and incivility were shown to assess different underlying constructs, supporting the proposition that while conflict and incivility both examine components of workplace aggression, their contributions offer unique insights in understanding how aggression manifests itself in the workplace.

Hypothesis 2 stated that task conflict, relationship conflict, and incivility would all be positively related to negative emotional responses such as anger, frustration, and anxiety, and was supported across all three workplace aggression constructs. Our results 
support to the established model of emotion centered job stress (Spector, 1988, Spector \& Bruk-Lee, 2008) demonstrating that negative interpersonal interactions in the workplace can and will elicit negative emotional responses. Specifically, these emotional responses, prompted through the experience of negative interpersonal interactions are key in understanding how negative interactions can affect individuals (e.g. Narayanana, Menon, $\&$ Spector, 1999).

Hypothesis 3 (a, b, and c) stated that task conflict, relationship conflict, and incivility would be negatively related to individual measures of strain. This hypothesis was supported across four of the strain outcomes (depression, physical symptoms, stress, and job satisfaction), both through correlational and hierarchical regression evidence. The results were consistent with the current literature in the field for depression, physical symptoms, stress, and job satisfaction (e.g. Bruk-Lee, Nixon, Wittgenstein, \& Allen, 2013; Nixon, Mazzola, Bauer, Krueger, \& Spector, 2011; Wittgenstein, Allen, Bruk-Lee \& Nixon, 2013a; 2013b).

Across the majority of our hypotheses, the results for life satisfaction were counterintuitive to what the established literature would have suggested,. The results showed workplace aggression to be positively related with life satisfaction. However, research has shown workplace aggression to be negatively related to life satisfaction (e.g. Lim \& Cortina, 2005; Lim \& Lee, 2011) or to report no significant interaction at all (Cortina, Magley, Williams \& Langhout, 2001). A possible explanation for these results is offered through an examination of the current economic times and draws from the social psychology literature. Specifically, research has shown that that job mobility drops significantly during a recession, partially due to an overabundance of labor (Cascio \& 
Aguinis, 2011; Moscarini \& Thomsson, 2006; Oreopoulos, Wacher \& Heisz, 2006). This can create a situation where workers may feel unable to seek out alternate employment as a way to deal with the negative interactions in their workplace. This removal of the changeability in their employment and employer (the sources of their workplace aggression) could trigger an individual's psychological immune system (e.g. Frey, 1981; Frey, Kumpf, Irle, \& Gniech, 1998; Gilbert \& Ebert, 2002). Specifically, the psychological immune system refers to a set of biases and mental mechanisms employed by the individual to protect them from experiencing negative emotions from unchangeable circumstances. It occurs when negative outcomes threaten an individual's personal levels of satisfaction and works, without conscious awareness, by changing a person's interpretation of information or adjusts their subjective experiences in such a way to make their current negative experiences more bearable. Given that the current recession has drastically reduced job mobility, thereby making a person's job much less changeable, it is reasonable to believe that an individual's psychological immune system may have influenced how they conceptualize life satisfaction, shifting the influence of workplace interactions and onto other areas of their lives. Since each of the stressor-strain relationships in our model generally worked as intended except for life satisfaction, it is entirely possible that the current state of economic affairs has created a situation where individual's life satisfaction has been somewhat decoupled from their work experiences. If this is true, it suggests that while negative workplace interactions still have a significant effect on individual workplace outcomes such as health and job satisfaction, their influence on life satisfaction may be positive, as people may be grateful just to have a job in these turbulent economic times. This could override the negative effects that 
would be present if higher levels of job mobility existed, because the influence of their psychological immune system becomes less active as higher levels of changeability were available.

To further pull from the social psychology literature, research has also shown life satisfaction and happiness to be strongly related to social support (e.g. North, Holahan Moos \& Cronkite, 2008). Specifically, North et al.'s research demonstrated that when controlling for economic factors, such as income, an individual's social support structure, which was operationalized as family orientated social support, was strongly associated with life satisfaction and happiness. This research is consistent with research examining how workplace social support can function as a moderator or buffer for how workplace aggression is experienced and the reactions aggression can elicit (e.g. Schat \& Keeloway, 2003; van Emmerik, Euwema \& Bakker; 2007). The research suggests that an individual's psychological immunity may reduce the negative effects of workplace aggression on life satisfaction while an increase in social support received due to those stressors may inadvertently show a positive relationship between workplace aggression and life satisfaction. Specifically, both psychological immunity and social support may moderate the workplace aggression to life satisfaction relationship in such a way that they diminish the negative effects of workplace aggression while enhancing the positive effects social support can have. Future research examining life satisfaction should continue to clarify how work and non-work variables interact with one another to influence larger global life satisfaction outcomes.

Returning to hypothesis 3 ( $a, b$, and $c)$, the combined effect of all three of our stressors was also tested (see the combined model in tables 3 through 7). For each 
outcome besides life satisfaction, our results showed incivility remained significant and to be the strongest predictor. Furthermore, for stress, depression, and job satisfaction, relationship conflict became non-significant. This lends weight to the arguments presented by Hershcovis (2011) regarding the similarity of many of the workplace aggression constructs. It also suggests that for stress, depression, and job satisfaction that the unique contributions from relationship conflict may be accounted for by incivility. Conversely, for life satisfaction only task conflict was found to be a significant predictor, once all three were assessed simultaneously. A possible explanation for these results is that individuals who find themselves in conflict over how their work should be done may prompt greater (or more frequent) levels of social support, both from within the organization (e.g., coworkers) and from external relationships leading to higher life satisfaction. Future research should examine how these different workplace aggression constructs overlap, and where and when the distinctions should be made, and how the constructs should be differentiated, both between one another and within themselves (task and relationship conflict).

Hypothesis $3 \mathrm{~d}$, which stated that negative emotions would mediate the relationship between task conflict, relationship conflict, incivility, and strain, was generally supported. For incivility, hypothesis $3 \mathrm{~d}$ was supported in depression, physical symptoms, and job satisfaction outcomes. For relationship conflict, hypothesis $3 \mathrm{~d}$ was supported in depression, physical symptoms, stress, and job satisfaction. For task conflict hypothesis $3 \mathrm{~d}$ was supported in depression, physical symptoms, stress, and job satisfaction. These results are consistent with previous findings, both from a theoretical model perspective (Spector, 1988) and empirically (e.g. Nixon, Mazzola, Bauer, Krueger, 
$\&$ Spector, 2011). Given the overwhelming and consistent nature of these relationships, and the recent culmination of evidence through meta-analyses (e.g. Bruk-Lee, Nixon, Wittgenstein, \& Allen, 2013; Nixon, Mazzola, Bauer, Krueger, \& Spector, 2011; Wittgenstein, Allen, Bruk-Lee \& Nixon, 2013a; 2013b) there is a substantial amount of evidence suggesting the broad-reaching and pervasive effects of incivility, relationship conflict, and task conflict. Furthermore, the amount of variance explained by incivility, relationship, and task conflict and their impact through negative emotions was high. Given the growing concern of employee healthcare expenses both directly through medical costs and indirectly through decreased or lost productivity, workplace interventions focused on reducing lower levels of workplace aggression could have drastic results on these potential losses. As organizations look to react and adapt to the ever changing conditions of the global economy, an increased focus on workplace aggression interventions may present a low cost, high return strategy to addressing concerns about psychosomatic symptoms, stress, and depression.

Hypothesis 4 ( $a, b$, and $c)$ postulated that individuals high in extraversion would experience fewer negative emotions as a result of workplace aggression. The results suggest that extraversion did not play a significant role in the experience of negative emotions from workplace aggression. However, elements of hypothesis $4 \mathrm{~d}$ were supported, demonstrating that while extraversion may not have an effect on the experience of negative emotions, it was a significant moderator of the workplace aggression to workplace and wellbeing outcomes.

For hypothesis $4 \mathrm{~d}$ individuals scoring one standard deviation below the mean level of extraversion reported significantly stronger effects from workplace aggression 
for depression, physical symptoms, stress, job satisfaction and life satisfaction than those in the higher extraversion condition. The differences in how extraversion levels moderate the effects of workplace aggression support previous theories suggesting extraversion could affect the experience of workplace aggression. Specifically, individuals low in extraversion may be more susceptible to anxiety than individuals high in extraversion (e.g. Eysenck \& Eysenck, 1985) and that individuals high in extraversion may be more adaptable in their styles of coping when facing conflict and have higher levels of positive thinking (e.g. Hooker, Frazier \& Monahan, 1994; McCrae \& Costa, 1986). In addition, those individuals high in extraversion are more active, energetic, enthusiastic, outgoing, and talkative (McCrae \& John, 1992). Furthermore, extraversion's influence on these outcomes could also be triggered by a number of additional mechanisms, such as the level of the employee's performance, the organization's selection system, general levels of personal appraisal and perception of the job and or workplace, and even third variables such as mood or other situational differences (e.g. Bruk-Lee, Khoury, Nixon, Goh \& Spector, 2009). Examples of these mechanisms in action could be an employee's performance level and feedback influencing their levels of job and work satisfaction (Lawley \& Porter, 1967) or an introverted individual feeling overloaded due to their selection into a position that requires heavy interpersonal interactions, given that introverts find interpersonal interactions draining (McCrae \& John, 1992). Future research should continue to further investigate these mechanisms in concert with personality traits in order to clarify how the effects of workplace aggression are experienced across a variety of varying job settings and individual differences. 
Support was found for hypothesis 5 ( $a, b$, and $\mathrm{c}$ ), which stated neuroticism would moderate the relationship between task conflict, relationship conflict, and incivility with negative emotions such that individuals high in neuroticism would experience more negative emotions. As hypothesised, individuals high in neuroticism experienced significantly stronger negative emotions from their workplace aggression experiences. These results reflect the current state of neuroticism literature, which suggests that individuals high in neuroticism are prone to experiencing negative emotions such as fear, sadness, anger, guilt, depression, anxiety, and may be more impulsive or self-conscious (Costa \& McCrae, 1992). Furthermore, these findings highlight the role individual differences play in bolstering the strength of the workplace aggression on their outcomes.

Shifting from a focus from emotions to outcomes, hypothesis $5 \mathrm{~d}$ postulated neuroticism would moderate the relationship between task conflict, relationship conflict, and incivility and strains such that individuals high in neuroticism would experience more strain. Specifically, for depression and physical symptoms, individuals with higher neuroticism experienced stronger effects from workplace aggression than in those with lower neuroticism levels. These results are consistent with previous conceptualizations of how neuroticism may affect the experience of workplace aggression (e.g. Bono et al, 2002; Dijkstra et al., 2005) and research showing negative moods do effect the experience of strains (e.g., Mroczek \& Almeida, 2004). Specifically since being high in neuroticism describes an individual who is prone to experiencing negative emotions such as fear, sadness, anger, guilt, depression, anxiety, and may be more impulsive or selfconscious (Costa \& McCrae, 1992). Specifically, individuals high in neuroticism may create or exasperate the negative interactions, thereby magnifying the effects of 
workplace aggression (Bruk-Lee, Khoury, Nixon, Goh \& Spector, 2009; Depue \& Monroe, 1986)

The results for stress indicated that the effects of incivility were stronger in individuals low in extraversion. A potential reason for this may be that individuals high in neuroticism are prone to the experience of stress (e.g., Larsen \& Ketelaar, 1991). It is possible that individuals high in neuroticism already suffer from stress. Research has shown individuals high in neuroticism are more susceptible to anxiety than individuals low in neuroticism (e.g., Eysenck \& Eysenck, 1985). Given that high levels of neuroticism have shown to be significant predictor of future anxiety, negative moods, and a susceptibility to negative moods (Gershuny \& Sher, 1998; Larsen \& Ketelaar, 1991; Rusting \& Larson, 1997), it is possible that neurotic individuals may be experiencing enough stress from other aspects of their workplace (e.g., role stressors, time stressors) that the inclusion for workplace aggression becomes just another stressor. As the results show, individuals who are low in neuroticism reported stronger effects on their levels of stress from workplace aggression, suggesting that they may be more susceptible to an increase of stress due to workplace conflict as this increase may be more noticeable than for those already high in neuroticism.

In addition, the effects of task and relationship conflict on job satisfaction as moderated by neuroticism indicated that the effects of task and relationship conflict were stronger in those low in neuroticism. Similarly to the findings for stress, neuroticism has been shown to be negatively related to job satisfaction (Judge, Heller, \& Mount, 2002), suggesting that those high in neuroticism are less satisfied with their current jobs. This suggests that those individuals who are high in neuroticism may attribute less of their 
negative job satisfaction to workplace aggression, while workplace aggression elicits stronger negative job satisfaction reactions from those who are low in neuroticism. These results suggest that workplace aggression can have a significant impact on individuals of all neuroticism levels and is not as clear-cut as previously thought. Future research should examine the effects of different levels of neuroticism have on workplace outcomes, as our results suggest that even low levels of neuroticism can exacerbate the effects of negative workplace interactions.

The findings support the hypotheses $6 a, 6 b$, and $6 \mathrm{c}$ showing that individuals high in agreeableness report experiencing less negative emotions from workplace aggression than those who are low in agreeableness. These results are consistent with the literature as agreeableness has been shown to describe someone who is altruistic, trusting, cooperative, compliant, and motivated by the needs of others (Costa \& McCrae, 1992). Furthermore, research has demonstrated that individuals low in agreeableness experience more of conflict in general (e.g., Graziano, Jensen-Campbell, \& Hair; 1996; Graziano et al., 1996), and that when controlling for the influence of extraversion, openness to experience, neuroticism, and conscientiousness, lower levels of agreeableness were found to be the most salient predictor of anger (Buss, 1991).

Hypothesis $6 \mathrm{~d}$ was supported for incivility in depression, physical symptom, and life satisfaction outcomes, for relationship conflict in depression, physical symptom, job satisfaction, and life satisfaction, and for task conflict in depression, physical symptom, and life satisfaction. The results show that individuals high in agreeableness did experience weaker effects on the strain outcomes from the workplace aggression constructs. Given the current lack of research examining the role of agreeableness on the 
stressor strain relationship, these results begin to build our understanding of how agreeableness can moderate the effects of workplace aggression. However, the strength of the negative correlation shown between agreeableness and workplace aggression makes it unclear to whether high agreeableness is acting as a buffer between workplace aggression and their outcomes, or that individuals high in agreeableness experience less workplace aggression due to their ability to be cooperative and compliant.

In addition, the relationship between incivility and stress was counter to what our hypotheses predicted. Specifically, the results showed individuals high in agreeableness experienced stronger effects from workplace aggression regarding their experience of stress. Given that individuals high in agreeableness have been shown to be more cooperative and compliant, the experience of workplace aggression may cause individuals more stress as it is counter to their natural predisposition and therefore may cause greater levels of emotional dissonance. This may occur as workplace aggression causes individuals high in agreeableness greater levels of stress as it lessens their ability to cooperate and is congruent with previous emotional dissonance research, which shows agreeableness to mediate the relationship between job demands and strain outcomes such as emotional exhaustion (e.g., Lewig \& Dollard, 2003). Future research should continue to investigate the role of emotional dissonance in the stressor strain relationship and examine how individual's differences in personality can influence the experience of emotional dissonance in the stressor strain interaction.

Moving to conscientiousness, the results showed no support for hypothesis 7 (a, b, and c), suggesting that while workplace aggression is related to negative emotions, conscientiousness does not play a significant role in moderating workplace aggressions 
effects. Support for hypothesis $7 \mathrm{~d}$ was found for incivility in physical symptoms, and job satisfaction, and for task conflict in physical symptoms. Of all the personality variables assessed, conscientiousness played the smallest role as a moderator of the stressor strain relationship. The results indicate that individuals low in conscientiousness reported stronger effects from both incivility and task conflict when compared to those with high conscientious levels. These findings are consistent with previous research, which has shown conscientiousness to moderate the relationship between incivility and workplace outcomes (Shim, 2010). For the stress outcome, incivility reported a stronger effect at high levels of conscientiousness. This may occur as a component of conscientiousness is the feeling of individual control, which may be challenged when experiencing the ambiguity of workplace incivility. This lack of perceived control in an ambiguous situation may cause a person high in conscientiousness to experience greater levels of stress, as their sense of control could be threatened both by the uncivil acts and the ambiguous nature of the uncivil acts. Given that locus of control was also examined in this study, the role of control beliefs will be further discussed there.

Hypothesis 8 ( $a, b$, and $\mathrm{c}$ ) were supported, showing that individuals high in trait anger experienced stronger effects from workplace aggression on negative emotions. The findings are consistent with previous literature, which suggests that trait anger can be conceptualized as the predisposition to perceive or experience situations in an anger provoking way (Spielberger, 1979). Thus, individuals high in trait anger are more likely to be angered by the variety of daily situations they find themselves in and to focus or dwell on that anger for longer periods. These acts of rumination on feelings of 
mistreatment stemming from workplace aggression heighten the experience of the subsequent negative emotions experienced from workplace aggression.

Support was found for hypothesis $8 \mathrm{~d}$ for incivility, relationship conflict, and task conflict in depression, physical symptom, and life satisfaction. The results show that for the negative strains (depression, physical symptoms) individuals high in trait anger reported a stronger effect from the workplace aggression constructs. These results are consistent with the current research in the field. Trait anger has been linked to task conflict, relationship conflict, and incivility and has been shown to correlate strongly with incidents of conflict between coworkers and customers (Sliter, Pui, Sliter, \& Jex, 2011; Fox, Spector, \& Miles, 2001). Although the number of studies examining the processes through which trait anger can affect the stressor-strain relationship is limited, researchers have proposed two theoretical mechanisms for how trait anger influences individual' workplace outcomes (Bruk-Lee, Khoury, Nixon, Goh \& Spector, 2009; Spector, 2003). The first mechanism suggests that individuals high in trait anger perceive the world and their work place as more stressful and therefor causes them to be prone to lower levels of satisfaction and lower levels of wellbeing. The second mechanism postulates that individuals high in trait anger would be susceptible to over reacting to negative interactions or emotions than individuals low in trait anger.

For job satisfaction and stress, trait anger acted in such a way that individuals low in trait anger experienced higher levels of job satisfaction and lower levels of stress. These results are counter to what the established relationship between trait anger and job satisfaction, as the research has demonstrated that individuals high in trait anger generally reported lower levels of job satisfaction (e.g., Bruk-Lee, Khoury, Nixon, Goh \& Spector, 
2009; Glaso, Vie, Holmdal, \& Einarsen, 2010). This suggests that individuals high on trait anger may already be experiencing trait anger's negative effects on job satisfaction and the addition of a workplace aggression stressor does not affect job satisfaction over and above where it already is. Specifically an individual high in trait anger may be experiencing enough negative effects from other workplace sources outside of workplace aggression that the occurrence of workplace aggression may not be as salient of an experience as it may be to someone who is low in trait anger. On the other hand, research has also shown individuals low in trait anger to report higher levels of job satisfaction. This could strengthen the effects of workplace aggression as it creates negative situations and feelings of anger that the individual does not routinely have, thereby lowering job satisfaction levels.

Moving to stress, the results revealed that individuals low in trait anger experienced greater levels of stress when exposed to workplace aggression, while those in the high anger condition reported lower levels of stress. This too is counter to the established literature, which has shown stress and trait anger related positively to one another (Glaso et al., 2010). A possible explanation of these findings is that for individuals with high trait anger, the experience of workplace aggression may serve as rational cause of their stress, and therefore reduce the cognitive and emotional dissonance experienced by stress, which may not have as strongly defined origin point. Recall that individuals high in trait anger are more likely to be angered by the variety of daily situations they find themselves in and these anger-producing situations can compound, raising general stress levels (Spielberger, 1979). Conversely, individuals low in trait anger may be more susceptible to the experience of stress from workplace aggression 
given their propensity to shy away from anger or hostility. They may structure or see their view of the world in such a way that when something triggers the experience of negative emotions (and not in a routine, day-to-day type of way) it can cause more perceived stress. Given the counterintuitive nature of these trait anger findings, future research should further investigate how trait anger influences people's experiences of workplace aggression and how it shapes both their interpretation of the events and their experience of strains.

Hypothesis 9 ( $a, b$, and c) stated that interpersonal locus of control would moderate the relationship between task conflict, relationship conflict, and incivility and negative emotions such that individuals with an external locus of control will experience more negative emotions. As hypothesized Support was found for hypothesis 9 across all three aggression constructs. These results suggest that individuals who feel as if they have more control of their surroundings and their lives will experience fewer negative emotions from workplace aggression.

Support was found for hypothesis $9 \mathrm{~d}$ in incivility for depression, physical symptoms, and life satisfaction, for relationship conflict in depression, physical symptoms, job satisfaction, and life satisfaction, and for task conflict in depression and physical symptoms. The results show that individuals with an external locus of control were more susceptible to the effects of workplace aggression. Given that, individuals with an external locus of control believe in influence of powerful others, fate, or chance this can create a sense of inevitability or even feelings existential correctness in their experiences of workplace aggression, causing a sense of learned helplessness or acceptance of the aggression. Research has shown individuals with an external locus of 
control are more likely to respond to perceived job stressors (Storms \& Spector, 1987). Research examining the victim's responses to workplace aggression has shown them to report suffering from post-traumatic stress disorder, symptoms of low self-esteem, and feelings of self-hatred (Mikkelsen \& Einarsen, 2002, Felblinger, 2007). The psychological effects of workplace aggression can also elicit a shame response, as the victims attribute the workplace aggression as being their fault in some way and direct their response inwards (Felblinger, 2007). This sense of victimization and shame can lead to a self-blaming attitude, anger, and negative self-evaluations (Felblinger, 2007, Lewis, 1971; Pastor, 1995). Research has shown shame to have a highly toxic effect on individual's affect and leaves people feeling emotionally defeated (Tomkins, 1963). Given that the results of this study show individuals with an external locus of control were more susceptible to the effects of workplace aggression, it may be due to individuals placing the blame on themselves in the sense that they have brought these negative behaviors on themselves or are somehow responsible for the workplace aggression in the first place.

Research has also suggested that individuals with an internal locus of control may perceive rewards garnered by positive performance as more motivating than externals, leading to internal feels higher levels of workplace satisfaction (e.g. Bruk-Lee, Khoury, Nixon, Goh \& Spector, 2009). Studies have also shown individuals with an internal locus of control to report higher levels of satisfaction across a number of job related categories (Garson \& Stanwyck, 1997). A possible explanation for this may be found on the selection process, as research has shown people with an internal locus of control both performed better in interview settings and were more successful in the eyes 
of the interviewer. Furthermore, individuals whom are internally focused may also be more likely to take action when presented with workplace aggression due to their beliefs in their ability of control, through such possible avenues as attrition or confrontation (Bruk-Lee, Khoury, Nixon, Goh \& Spector, 2009; Harvey, Barnes, Sperry, and Harris, 1974).

However, the results were not consistent, and like many of the other hypotheses, the interaction between incivility and locus of control ran counter to our beliefs for the stress outcome. The findings indicated that individuals with an internal locus of control reported more stress from workplace aggression and were consistent with previous research (Hahn, 2000). This may be due to the an individual who has an internal locus of control experiencing greater levels of stress due to their perceived beliefs that they should be able to exact a degree of control over their experience of workplace aggression and are unable to. The research into the effects of locus of control in occupational health psychology literature is still young, and many of the findings can be contradictory. Future research should continue to build upon the established findings and further examine how the different manifestations of locus of control react to workplace aggression.

Finally, a brief discussion of the PROCESS macro for SPSS used for the analyses is in order. The process macro was developed Hayes and Preacher and is a "computational tool for path analysis-based moderation and mediation analysis as well as their combination as a "conditional process model" (Hayes, 2012, pg. 1). It is a combination of a number of their previous SPSS macros, which allows for the assessment and evaluation of two and three way interactions. Furthermore the process macro allows for the "estimating the coefficients of the model using OLS regression (for continuous 
outcomes) or maximum likelihood logistic regression (for dichotomous outcomes), PROCESS generates direct and indirect effects in mediation and mediated moderation models, conditional effects in moderation models, and conditional indirect effects in moderated mediation models with a single or multiple mediators. PROCESS offers various tools for probing 2 and 3 way interactions and can construct percentile based bootstrap confidence intervals for conditional and unconditional indirect effects." (Hayes, 2012, pg. 1).

\section{Limitations}

There are a number of limitations that should be considered when interpreting the results of this study. First, for two of our measures, extraversion and interpersonal locus of control reported alphas below .7, suggesting that their reliability may be below what is generally considered acceptable levels. However, both measures alphas were above .6, which is considered the minimum for adequate use (Field, 2009). Second, as outlined by Podsakoff, Mackenzie, Lee, and Podsakoff (2003) this study's results may be vulnerable to a number of common method biases. Specifically, there are elements from each of the four sources of common method bias, which may influence the results of this study. To begin with the first source, which are method effects produced by a common source (e.g., self-report biases). From this source, the two specific biases that could influence the results are the common method bias and differences in individual's positive and negative affectivity (how people see the world). Common source bias is thought to occur as the participant is providing the data for both the predictor and criterion variables, and in doing so may be motivated (through social desirability, consistency motif, or other cognitive process) to answer in a way that artificially influences the variables covariance 
(Podsakoff et al., 2003). However, research has suggested that the common method bias that may occur by using the same method of measurement (e.g. self-report) may not be as big of an issue as previously thought (Boswell, Boudreau, \& Dunford, 2004; Spector, 2006). To attempt to diminish any influences of this self-report bias, procedures outlined by Podsakoff et al. were used. Specifically, Podsakoff et al, suggest that implementing and assuring the participants that their answers would be anonymous and that they were free to answer the questions as well as they could. This is thought to help alleviate common method bias by reducing the participants evaluation anxiety, thereby making lessening the role that social desirability and a consistency motif may play (Podsakoff et al., 2003). Furthermore, this study's purpose was to assess how individuals react to negative interactions in the workplace, and serves as an initial investigation into the moderating effects of personality in that relationship. It was decided that a cross sectional research design using self-report data would be sufficient to begin to investigate personality's moderating role. Future research would be well served to revisit the questions asked in this study and address them through a longitudinal research design, pulling from a variety of sources in order to further clarify the moderating role of personality in the stressor strain relationship.

The second common method bias that could influence the results is the differences in individuals' positive and negative affectivity (Podsakoff et al., 2003). Positive and negative affectivity are mood-dispositional dimensions that reflect how individuals see the world through their emotions and self-concepts (Watson \& Clark, 1984). Given that this study measured both negative social interactions in the workplace and such negative outcomes as stress, depression, and physical symptoms there may be 
cause to believe that negative affectivity (and positive affectivity) could be biasing the results. Furthermore, researchers continue to debate the role of negative affectivity as a biasing variable (for review, see Podsakoff et al., 2003). However, while this study did not control for the effects of negative affectivity, one of its key hypothesis was the moderating role of neuroticism in the stressor strain relationship, which has been overwhelmingly shown to capture key elements of negative affectivity (Watson \& Clark, 1984; Spector \& O’Connell, 1994; Lazurus, Rodafinos, Matsiggos, \& Stamatoulakis, 2009; Klainin, 2009; Heinisch \& Jex, 1997; Fortunato, LeBourgeois, \& Harsh, 2008; Ilies, Johnson, Judge \& Kenney, 2010; Bowling \& Eschleman, 2010).

Moving from rating source limitations to item content limitations, there are two types of bias that could have influenced the results, priming and context-induced mood (Podsakoff et al., 2003). Priming has been shown to occur when certain questions are asked and those questions make other aspects related to those questions more salient (Salancik, 1984; Salancik \& Pfeffer, 1977). Given that roughly half of the measures used in this study focused on negative variables (e.g., incivility, depression, stress, anger), priming was a concern. Related to priming is the concept of context-induced mood, which suggests that the manner in which questions are phrased could produce transient mood states in the participants (Peterson, 2000; Podsakoff et al., 2003). In this survey, such items as the depression, physical symptoms, and workplace aggression scales could remind the participants of negative experiences in their lives and create a biasing effect. To address these potential biases, the survey was presented in such a way that the order in which the scales appeared was randomly determined (e.g. participant one may begin with incivility and the move on to extraversion, while participant may begin with measures of 
their locus of control and then to a measure of job satisfaction). This was implemented to minimize the potentially biasing effects of both priming and context-induced moods.

Finally, the limitations of cross sectional data should be discussed. Unlike a longitudinal study, a cross sectional approach cannot show causality due to the nature of the data collection and can be misleading if used as a proxy for longitudinal designs (Salthouse, 2011). This is due to the "snap shot" nature of how data is collected, with all relevant variables being collected during the same sampling or testing. Researchers criticizing the use of cross sectional data have shown it to prevent the proper identification of trends (Lubatkin \& Chatterjee, 1991), to misrepresent the nature of the relationship (Rumelt, 1991), or even fail to accurately report the true nature of the causal relationship (Hill \& Hansen, 1991). In this study, all of the variables including the stressors, the personality traits, and the strains were all collected at the same time, making the mediation analysis in this study susceptible to the limitations of a cross sectional data set. However, given that much of this research acting as an initial look in examining personality traits mediating role in the stressor strain relationship, the emphasis is not on whether there is direct causality so much that there is an interaction between workplace stressors and the individual's personality traits.

\section{Conclusion}

This study examines the moderating effects of personality on the stressor strain relationship and health and workplace outcome. The results suggest that extraversion, neuroticism, conscientiousness, agreeableness, trait anger, and locus of control play significant roles in how workplace aggression affects individuals. Building from the findings of this study, workplaces that experience high levels of workplace aggression 
may consider assessing these personality traits in their workforce as a way of identifying individuals who may be more susceptible to the effects of workplace aggression. As organizations continue to strive to adapt to new information and a changing society, these results will be crucial in understanding and preventing the negative effects of workplace aggression and ensuring targeted interventions and assistance can be directed towards the individuals who may be the most vulnerable. Recent research has begun to highlight the costs associated with depression, showing 1 in 10 Americans suffer from depression and that depression costs U.S. businesses over \$51 billion dollars a year from absenteeism and lost productivity (Gonzalez et al., 2010). Given that occupational health psychology and the study of workplace aggression is relatively new, the investigation of how personality can moderate the experience of aggression in the workplace is fundamental in furthering our understanding of the effects of workplace aggression. This study to build off of the previous research examining workplace aggression and investigated how personality differences in extraversion, neuroticism, agreeableness, conscientiousness, trait anger, and locus of control can influence the effects of workplace aggression. Understanding how personality can enhance or suppress these effects from workplace aggression will allow organizations to target individuals who may be more susceptible to the negative effects of workplace aggression and implement stronger preventative measures through employee training on how to deal with and minimize workplace aggressions effects. As research continues to expand, understanding the role of these established personality constructs play will be necessary in developing larger and more comprehensive models of workplace aggression and understanding he effects workplace aggression has on the individual. 


\section{REFERENCES}

Adams, G. A., \& Buck, J. (2010). Social stressors and strain among police officers: It's not just the bad guys. Criminal Justice and Behavior, 37(9), 1030-1040.

Aiken, L. S., \& West, S. G. (1991). Multiple regression: Testing and interpreting interactions. Sage Publications, Incorporated.

Amason, A. C., \& Schweiger, D. M. (1997). The Effects of Conflict on Strategic Decision Making Effectiveness and Organizational. Using conflict in organizations, 101.

Andersson, L. M., \& Pearson, C. M. (1999). Tit for tat? The spiraling effect of incivility in the workplace. Academy of Management Review, 452-471.

Aquino, K., \& Thau, S. (2009). Workplace victimization: Aggression from the target's perspective. Annual review of psychology, 60, 717-741.

Barkley, R. A. (1998). Attention-deficit/hyperactivity disorder. In E. J. Mash \& R. A.

Barkley (Eds.), Treatment of childhood disorders (2nd ed., pp. 55-110). New York: Guilford Press.

Barkley, R. A. (2001). The executive functions and self-regulation: An evolutionary neuropsychological perspective. Neuropsychology Review, 11(1), 1-29.

Baron, R. A., Neuman, J. H., \& Geddes, D. (1999). Social and personal determinants of workplace aggression: Evidence for the impact of perceived injustice and the Type A behavior pattern. Aggressive Behavior, 25(4), 281-296.

Barrick, M. R., \& Mount, M. K. (1991). The Big Five personality dimensions and job performance: A Meta-Analysis. Personnel Psychology, 44, 1-26.

Barrick, M. R., \& Mount, M. K. (1993). Autonomy as a moderator of the relationships between the Big Five personality dimensions and job performance. Journal of Applied Psychology, 78(1), 111.

Baumeister, R. F., \& Vohs, K. D. (2004). Handbook of self-regulation: Research, theory, and application. New York: Guilford Press.

Bayazit, M., \& Mannix, E. A. (2003). Should I stay or should I go? Small Group Research, 34(3), 290-321.

Bettencourt, B., \& Miller, N. (1996). Gender differences in aggression as a function of provocation: a meta-analysis. Psychological bulletin, 119(3), 422. 
Bono, J. E., Boles, T. L., Judge, T. A., \& Lauver, K. J. (2002). The role of personality in task and relationship conflict. Journal of Personality, 70(3), 311-344.

Boswell, W. R., Boudreau, J. W., \& Dunford, B. B. (2004). The outcomes and correlates of job search objectives: searching to leave or searching for leverage? The Journal of applied psychology, 89(6), 1083.

Bowling, N. A., \& Beehr, T. A. (2006). Workplace harassment from the victim's perspective: A theoretical model and meta-analysis. Journal of Applied Psychology, 91(5), 998.

Bowling, N. A., \& Eschleman, K. J. (2010). Employee personality as a moderator of the relationships between work stressors and counterproductive work behavior. Journal of Occupational Health Psychology, 15(1), 91-103.

Bresin, K., Hilmert, C. J., Wilkowski, B. M., \& Robinson, M. D. (2011). Response speed as an individual difference: Its role in moderating the agreeableness-anger relationship. Journal of Research in Personality. , 46, 79-86

Brosschot, J. F., Gerin, W., \& Thayer, J. F. (2006). The perseverative cognition hypothesis: a review of worry, prolonged stress-related physiological activation, and health. Journal of Psychosomatic Research, 60(2), 113-124.

Bruck, C. S., Allen, T. D., \& Spector, P. E. (2002). The relation between work-family conflict and job satisfaction: A finer-grained analysis. Journal of Vocational Behavior, 60(3), 336-353.

Bruk-Lee, V., Khoury, H. A., Nixon, A. E., Goh, A., \& Spector, P. E. (2009). Replicating and extending past personality/job satisfaction meta-analyses. Human Performance, 22(2), 156-189.

Bruk-Lee, V., \& Spector, P. E. (2006). The social stressors-counterproductive work behaviors link: Are conflicts with supervisors and coworkers the same? Journal of Occupational Health Psychology, 11(2), 145.

Bruk-Lee, V., Nixon, A. E., Wittgenstein, J. P., \& Allen, J. W. (2013, May). Task and relationship based conflict at work and psychological strain: A meta-analysis. Work, stress, and health 2013, Los Angeles, California.

Bruk-Lee, V., \& Spector, P. E. (2011). Interpersonal conflict and stress at work: Implications for employee health and well-being In A. M. Rossi, P. Perrewe \& J. A.

Meurs (Eds.), Stress and quality of working life (Vol. In Press). 
Buss, D. M. (1991). Conflict in married couples: Personality predictors of anger and upset. Journal of Personality, 59(4), 663-688.

Campbell, D. T., \& Fiske, D. W. (1959). Convergent and discriminant validation by the multitrait-multimethod matrix. Psychological bulletin, 56(2), 81.

Cammann, C., Fichman, M., Jenkins, D., \& Klesh, J. (1979). The Michigan organizational assessment questionnaire. University of Michigan. Ann Arbor, MI.

Canary, D. J., Cunningham, E. M., \& Cody, M. J. (1988). Goal types, gender, and locus of control in managing interpersonal conflict. Communication Research, 15(4), 426-446.

Cascio, W. F., \& Aguinis, H. (2005). Applied psychology in human resource management.

Cavell, T. A. (1990). Social adjustment, social performance, and social skills: A tricomponent model of social competence. Journal of Clinical Child Psychology, 19(2), 111-122.

Caza, B. B., \& Cortina, L. M. (2007). From insult to injury: Explaining the impact of incivility. Basic and Applied Social Psychology, 29(4), 335-350.

Charlton, P., \& Thompson, J. (1996). Ways of coping with psychological distress after trauma. British Journal of Clinical Psychology, 35(4), 517-530.

Chen, P. Y., \& Spector, P. E. (1991). Negative affectivity as the underlying cause of correlations between stressors and strains. Journal of Applied Social Psychology, 30, 867885 .

Cohen, S., Kamarck, T., \& Mermelstein, R. (1983). A global measure of perceived stress. Journal of Health and Social Behavior, 24(4), 385-396.

Colbert, A. E., Mount, M. K., Harter, J. K., Witt, L., \& Barrick, M. R. (2004). Interactive effects of personality and perceptions of the work situation on workplace deviance. Journal of Applied Psychology, 89(4), 599.

Cortina, L. M., \& Magley, V. J. (2009). Patterns and Profiles of response to incivility in the workplace. Journal of Occupational Health Psychology, 14(3), 272-288.

Cortina, L. M., Magley, V. J., Williams, J. H., \& Langhout, R. D. (2001). Incivility in the workplace: Incidence and impact. Journal of Occupational Health Psychology, 6(1), 6480 . 
Costa, P. T., \& McCrae, R. R. (1980). Influence of extraversion and neuroticism on subjective well-being: happy and unhappy people. Journal of Personality and Social Psychology, 38(4), 668.

Costa, P. T., \& McCrae, R. R. (1985). The NEO Personality inventory manual. Odessa, FL: Psychological Assessment Resources.

Costa, P. T., \& McCrae, R. R. (1989). The Neo PI/FFI manual supplement. Odessa, FL: Psychological Assessment Resources.

Costa, P. T., \& McCrae, R. R. (1992). Revised NEO personality inventory (NEO-PI and NEO five factor (NEO-FFI) Inventory professional manual. Odessa, FL: PAR.

De Dreu, C. K. W., Harinck, F., \& Van Vianen, A. E. M. (1999). Conflict and performance in groups and organizations. In C. L. Cooper \& I. Robertson (Eds.), International review of industrial and organizational psychology. Chinchester, UK: Wiley.

De Dreu, C. K. W., \& Weingart, L. R. (2003). Task versus relationship conflict, team performance, and team member satisfaction: A meta-analysis. Journal of Applied Psychology, 88(4), 741.

DeNeve, K. M., \& Cooper, H. (1998). The happy personality: a meta-analysis of 137 personality traits and subjective well-being. Psychological Bulletin, 124(2), 197.

Dengerink, H., O'Leary, M., \& Kasner, K. (1975). Individual differences in aggressive responses to attack: Internal-external locus of control and field dependenceindependence. Journal of Research in Personality, 9(3), 191-199.

Depue, R. A., \& Monroe, S. M. (1986). Conceptualization and measurement of human disorder in life stress research: The problem of chronic disturbance. Psychological Bulletin, 99(1), 36.

Diener, E., Emmons, R. A., Larsen, R. J., \& Griffin, S. (1985). The satisfaction with life scale. Journal of Personality Assessment, 49(1), 71-75.

Digman, J. M. (1990). Personality Structure: Emergence of the Five-Factor model. Annual Review Psychology, 41, 417-440.

Dijkstra, M. T. M., De Dreu, C. K. W., Evers, A., \& van Dierendonck, D. (2009). Passive responses to interpersonal conflict at work amplify employee strain. European Journal of Work and Organizational Psychology, 18(4), 405-423. 
Dijkstra, M. T. M., Dierendonck, D. V., Evers, A., \& de Dreu, C. K. W. (2005). Conflict and well-being at work: the moderating role of personality. Journal of Managerial Psychology, 20(2), 87-104.

Donnellan, M. B., Oswald, F. L., Baird, B. M., \& Lucas, R. E. (2006). The mini-IPIP scales: tiny-yet-effective measures of the Big Five factors of personality. Psychological Assessment, 18(2), 192.

Douglas, S. C., \& Martinko, M. J. (2001). Exploring the role of individual differences in the prediction of workplace aggression. Journal of Applied Psychology, 86(4), 547.

Edwards, J. R., \& Lambert, L. S. (2007). Methods for integrating moderation and mediation: A general analytical framework using moderated path analysis. Psychological Methods, 12(1), 1-22.

Egan, V., \& Lewis, M. (2011). Neuroticism and agreeableness differentiate emotional and narcissistic expressions of aggression. Personality and Individual Differences, 50(6), 845-850.

Ests, B., \& Wang, J. (2008). Integrative literature review: Workplace incivility: Impacts on individual and organizational performance. Human Resource Development Review, 7, 218-240.

Eysenck, H. J., \& Eysenck, M. W. (1985). Personality and individual differences: A natural science approach: Plenum Press New York.

Eysenck, M. W., MacLeod, C., \& Mathews, A. (1987). Cognitive functioning and anxiety. Psychological Research, 49(2), 189-195.

Farkas, S., \& Johnson, J. (2002). Aggravating Circumstances: A Status Report on Rudeness in America. A report from Public Agenda prepared for the Pew Charitable Trust.

Felblinger, D. M. (2008). Incivility and bullying in the workplace and nurses' shame responses. Journal of Obstetric, Gynecologic, \& Neonatal Nursing, 37(2), 234-242.

Field, A. (2009). Discovering statistics using SPSS. Sage Publications Limited.

Fincham, F. D., \& Beach, S. R. H. (1999). Conflict in marriage: Implications for working with couples. Annual Review of Psychology, 50(1), 47-77.

Fortunato, V. J., LeBourgeois, M. K., \& Harsh, J. (2008). Development of a fivedimensional measure of adult sleep quality. Educational and Psychological Measurement, 68(3), 488-514. 
Fox, S., \& Spector, P. E. (1999). A model of work frustration-aggression. Journal of Organizational Behavior, 20, 915-931.

Fox, S., Spector, P. E., \& Miles, D. (2001). Counterproductive work behavior (CWB) in response to job stressors and organizational justice: Some mediator and moderator tests for autonomy and emotions. Journal of Vocational Behavior, 59, 291-309.

Frey, D. (1981). Reversible and Irreversible Decisions Preference for Consonant Information as a Function of Attractiveness of Decision Alternatives. Personality and Social Psychology Bulletin, 7(4), 621-626.

Frey, D., Kumpf, M., Irle, M., \& Gniech, G. (1984). Re-evaluation of decision alternatives dependent upon the reversibility of a decision and the passage of time. European Journal of Social Psychology, 14(4), 447-450.

Friedman, R. A., Tidd, S. T., Currall, S. C., \& Tsai, J. C. (2000). What goes around comes around: The impact of personal conflict style on work conflict and stress. International Journal of Conflict Management, 11(1), 32-55.

Frone, M. R. (1998). Predictors of work injuries among employed adolescents. Journal of Applied Psychology, 83(4), 565-576.

Frone, M. R. (2000). Interpersonal conflict at work and psychological outcomes: Testing a model among young workers. Journal of Occupational Health Psychology, 5(2), 246255.

Fuller, B. E., \& Hall, F. J. (1996). Differences in personality type and roommate compatibility as predictors of roommate conflict. Journal of College Student Development, 37(5), 510-518.

Garson, B. E., \& Stanwyck, D. J. (1997). Locus of control and incentive in self-managing teams. Human Resource Development Quarterly, 8(3), 247-258.

Geist, R. L., \& Gilbert, D. G. (1996). Correlates of expressed and felt emotion during marital conflict: Satisfaction, personality, process, and outcome. Personality and Individual Differences, 21(1), 49-60.

Gemzøe Mikkelsen, E., \& Einarsen, S. (2002). Relationships between exposure to bullying at work and psychological and psychosomatic health complaints: the role of state negative affectivity and generalized self-efficacy. Scandinavian Journal of Psychology, 43(5), 397-405.

Gershuny, B. S., \& Sher, K. J. (1998). The relation between personality and anxiety: Findings from a 3-year prospective study. Journal of Abnormal Psychology, 107(2), 252. 
Gershuny, B. S., \& Sher, K. J. (1998). The relation between personality and anxiety: Findings from a 3-year prospective study. Journal of Abnormal Psychology, 107(2), 252.

Giebels, E., \& Janssen, O. (2005). Conflict stress and reduced well-being at work: The buffering effect of third-party help. European Journal of Work and Organizational Psychology, 14(2), 137.

Gilbert, D. T., \& Ebert, J. E. (2002). Decisions and revisions: The affective forecasting of changeable outcomes. Journal of personality and social psychology, 82(4), 503-514.

Glasø, L., Vie, T. L., Holmdal, G. R., \& Einarsen, S. (2011). An Application of Affective Events Theory to Workplace Bullying. European Psychologist, 16(3), 198-208.

Glomb, T. M., \& Liao, H. (2003). Interpersonal aggression in work groups: Social influence, reciprocal, and individual effects. Academy of Management Journal, 46(4), $486-496$.

Gonzalez, O., Berry, J., McKnight-Eily, L., Strine, T., Edwards, V., Lu, H., \& Croft, J. Center of Disease Control, Morbidity and Mortality Weekly Report. Current depression among adults --- united states, 2006 and 2008 (October 1, 2010 / 59(38);1229-1235)

Gouveia, V. V., Milfont, T. L., da Fonseca, P. N., \& Coelho, J. A. P. M. (2009). Life satisfaction in Brazil: Testing the psychometric properties of the satisfaction with life scale (SWLS) in five Brazilian samples. Social Indicators Research, 90(2), 267-277.

Gray, J. A. (1981). A critique of Eysenck's theory of personality. A model for personality, In H.J. Eysenck (Ed.), A model for personality (pp. 246-276). New York: Springer-Verlag.

Gray, J. A. (1987). The psychology of fear and stress (Vol. 5): Cambridge Univ. Pr.

Graziano, W. G., Jensen-Campbell, L. A., \& Hair, E. C. (1996). Perceiving interpersonal conflict and reacting to it: The case for agreeableness. Journal of Personality and Social Psychology, 70(4), 820.

Grzywacz, J. G., \& Marks, N. F. (2000). Reconceptualizing the work-family interface: An ecological perspective on the correlates of positive and negative spillover between work and family. Journal of Occupational Health Psychology, 5(1), 111-126.

Guerra, J. M., Martinez, I., Munduate, L., \& Medina, F. J. (2005). A contingency perspective on the study of the consequences of conflict types: The role of organizational culture. European Journal of Work and Organizational Psychology, 14(2), 157.

Guetzkow, H., \& Gyr, J. (1954). An analysis of conflict in decision-making groups. Human Relations. 7, 367-382 
Hahn, S. E. (2000). The effects of locus of control on daily exposure, coping and reactivity to work interpersonal stressors: A diary study. Personality and Individual Differences. 4(1), 729-748

Hallberg, U. E., \& Schaufeli, W. B. (2006). " Same Same" But Different? Can Work Engagement Be Discriminated from Job Involvement and Organizational

Commitment?. European Psychologist, 11(2), 119.

Harmon-Jones, E., \& Sigelman, J. (2001). State anger and prefrontal brain activity: evidence that insult-related relative left-prefrontal activation is associated with experienced anger and aggression. Journal of Personality and Social Psychology, 80(5), 797.

Harvey, S., Blouin, C., \& Stout, D. (2006). Proactive personality as a moderator of outcomes for young workers experiencing conflict at work. Personality and Individual Differences, 40(5), 1063-1074.

Harvey, J. H., Barnes, R. D., Sperry, D. L., \& Harris, B. (1974). Perceived choice as a function of internal-external locus of control. Journal of Personality, 42(3), 437-452.

Hastings, S. E., \& O'Neill, T. A. (2009). Predicting workplace deviance using broad versus narrow personality variables. Personality and Individual Differences, 47(4), 289293.

Hayes, A. F. (2012). PROCESS: A versatile computational tool for observed variable mediation, moderation, and conditional process modeling. Manuscript submitted for publication.

Hayes, A. F., \& Preacher, K. J. (2011). Indirect and direct effects of a multicategorical causal agent in statistical mediation analysis. Manuscript submitted for publication.

Heinisch, D. A., \& Jex, S. M. (1997). Negative affectivity and gender as moderators of the relationship between work-related stressors and depressed mood at work. Work \& Stress, 11(1), 46-57.

Henle, C. A. (2005). Predicting workplace deviance from the interaction between organizational justice and personality. Journal of Managerial Issues, 247-263.

Hershcovis, M. S. (2011). "Incivility, social undermining, bullying...oh my!": A call to reconcile constructs within workplace aggression research. Journal of Organizational Behavior, 32(3), 499-519.

Hershcovis, M. S., Turner, N., Barling, J., Arnold, K. A., Dupre, K. E., \& Inness, M.(2007). Predicting workplace aggression: A meta-analysis. Journal of Applied Psychology, 92(1), 228. 
Hill, C. W., \& Hansen, G. S. (1991). Are institutional investors myopic? A time-series study of four technology-driven industries. Strategic Management Journal, 12(1), 1-16.

Hogan, J., \& Ones, D. S. (1997). Conscientiousness and integrity at work. In R. Hogan, J. A. Johnson \& S. R. Briggs (Eds.), Handbook of Personality Psychology (pp. 849-870). San Diego, CA, US: Academic Press.

Hooker, K., Frazier, I. D., \& Monahan, D. J. (1994). Personality and coping among caregivers and spouses with dementia. The Gerontologist, 34, 386-392.

Hornstein, H. A. (1996). Brutal Bosses and their Prey. New York: Riverhead.

Ilies, R., Johnson, M. D., Judge, T. A., \& Keeney, J. (2010). A within-individual study of interpersonal conflict as a work stressor: Dispositional and situational moderators. Journal of Organizational Behavior, 32, 44-64.

Jehn, K. A. (1994). Enhancing effectiveness: An investigation of advantages and disadvantages of value-based intragroup conflict. International Journal of Conflict Management, 5(3), 223-238.

Jehn, K. A. (1995). A multimethod examination of the benefits and detriments of intragroup conflict. Administrative Science Quarterly, 40(2), 256-282.

Jehn, K. A., \& Mannix, E. A. (2001). The dynamic nature of conflict: A longitudinal study of intragroup conflict and group performance. The Academy of Management Journal, 44(2), 238-251.

Jehn, K. A., Northcraft, G.B., \& Neale, N.A. (1999). Why differences make a difference: a field study of diversity, conflict, and performance in workgroups. Administrative Science Quarterly, 44(4), 741-763.

Jehn, K. A., \& Shah, P. P. (1997). Interpersonal relationships and task performance: An examination of mediation processes in friendship and acquaintance groups. Journal of Personality and Social Psychology, 72(4), 775.

Jensen-Campbell, L. A., Knack, J. M., Waldrip, A. M., \& Campbell, S. D. (2007). Do Big Five personality traits associated with self-control influence the regulation of anger and aggression? Journal of Research in Personality, 41(2), 403-424.

Jensen-Campell, L. A., \& Graziano, W. G. (2001). Agreeableness as a moderator of interpersonal conflict. Journal of Personality, 69(2), 323-362.

Jockin, V., Arvey, R. D., \& McGue, M. (2001). Perceived Victimization Moderates SelfReports of Workplace Aggression and Conflict. Journal of Applied Psychology, 86(6), 1262-1269. 
John, O. P., \& Benet-Martinez, V. (2000). Measurement: Reliability, construct validation, and scale construction. Handbook of research methods in social and personality psychology.

Judge, T. A., Heller, D., \& Mount, M. K. (2002). Five-factor model of personality and job satisfaction: a meta-analysis. Journal of applied psychology, 87(3), 530.

Kahn, R. L., \& Boulding, E. (1964). Power and conflict in organizations: New York, Basic.

Keenan, A., \& Newton, T. J. (1985). Stressful events, stressors and psychological strains in young professional engineers. Journal of Organizational Behavior, 6(2), 151-156.

Kern, J. H., \& Grandey, A. A. (2009). Customer incivility as a social stressor: The role of race and racial identity for service employees. Journal of Occupational Health Psychology, 14(1), 46.

Klainin, P. (2009). Stress and health outcomes: The mediating role of negative affectivity in female health care workers. International Journal of Stress Management, 16(1), 45.

Kolb, K. J., \& Aiello, J. R. (1996). The effects of electronic performance monitoring on stress: Locus of control as a moderator variable. Computers in Human Behavior, 12(3), 407-423.

Kuppens, P. (2005). Interpersonal determinants of trait anger: Low agreeableness, perceived low social esteem, and the amplifying role of the importance attached to social relationships. Personality and Individual Differences, 38(1), 13-23.

Lankau, M. J., Ward, A., Amason, A., Ng, T., Sonnenfeld, J. A., \& Agle, B. R. (2007). Examining the impact of organizational value dissimilarity in top management teams. Journal of Managerial issues, 11-34.

Larsen, R. J., \& Ketelaar, T. (1991). Personality and susceptibility to positive and negative emotional states. Journal of Personality and Social Psychology, 61(1), 132.

Laschinger, H. K., Leiter, M., Day, A., \& Gilin, D. (2009). Workplace empowerment, incivility, and burnout: impact on staff nurse recruitment and retention outcomes. Journal of Nursing Management, 17(3), 302-311.

Lawler, E. E., \& Porter, L. W. (1967). The effect of performance on job satisfaction. Industrial relations: A journal of Economy and Society, 7(1), 20-28.

Lazuras, L., Rodafinos, A., Matsiggos, G., \& Stamatoulakis, A. (2009). Perceived occupational stress, affective, and physical well-being among telecommunication employees in Greece. Social Science \& Medicine, 68, 1075-1081. 
Lee-Baggley, D., Preece, M., \& DeLongis, A. (2005). Coping with interpersonal stress: Role of Big Five traits. Journal of Personality, 73(5), 1141-1180.

Levenson, M. R., Aldwin, C. M., Boss $\sqrt{ }$ C, R., \& Spiro, A. (1988). Emotionality and mental health: Longitudinal findings from the normative aging study. Journal of abnormal psychology, 97(1), 94.

Lewig, K. A., \& Dollard, M. F. (2003). Emotional dissonance, emotional exhaustion and job satisfaction in call center workers. European Journal of Work and Organizational Psychology, 12(4), 366-392.

Lewis, H. B. E. (1987). The role of shame in symptom formation. Lawrence Erlbaum Associates, Inc.

Lim, S., \& Cortina, L. M. (2005). Interpersonal mistreatment in the workplace: the interface and impact of general incivility and sexual harassment, Journal of Applied Psychology, 90(3), 483.

Lim, S., Cortina, L. M., \& Magley, V. J. (2008). Personal and workgroup incivility: Impact on work and health outcomes. Journal of Applied Psychology, 93(1), 95-107.

Lim, S., \& Lee, A. (2011). Work and non-work outcomes of workplace incivility: Does family support help? Journal of Occupational Health Psychology, 16(1), 95-111.

Liu. (2003). A comparison of job stressors and job strains among employees holding comparable jobs in western and eastern societies. Ph.D., University of South Florida, Tampa.

Liu, C., Spector, P. E., \& Shi, L. (2008). Use of Both Qualitative and Quantitative Approaches to Study Job Stress in Different Gender and Occupational Groups. Journal of Occupational Health Psychology, 13(4), 357-370.

Lovelace, K., Shapiro, D. L., \& Weingart, L. R. (2001). Maximizing cross-functional new product teams' innovativeness and constraint adherence: A conflict communications perspective. Academy of Management Journal, 779-793.

Lu, L., Kao, S. F., Siu, O.-1., \& Lu, C.-q. (2010). Work Stressors, Chinese coping strategies, and job performance in greater China. International Journal of Psychology, 45(4), 294-302.

Lubatkin, M., \& Chatterjee, S. (1991). The strategy-shareholder value relationship: Testing temporal stability across market cycles. Strategic Management Journal, 12(4), 251-270. 
Martin, L. L., \& Tesser, A. (1996). Some ruminative thoughts. Ruminative thoughts (pp. 1-47). Hillsdale, NJ, England: Lawrence Erlbaum Associates, Inc.

Matsuo, M. (2006). Customer orientation, conflict, and innovativeness in Japanese sales departments. Journal of Business Research, 59, 242-250.

McCrae, R. R., \& Costa, P. T. (1986). Personality, coping, and coping effectiveness in an adult sample. Journal of Personality, 54, 385-405.

McCrae, R. R., \& John, O. P. (1992). An introduction to the five-factor model and its applications. Journal of Personality, 60(2), 175-215.

McLaney, M. A., \& Hurrell, J. J. (1988). Control, stress, and job satisfaction in Canadian nurses. Work \& Stress, 2(3), 217-224.

Medina, F. J., Munduate, L., Dorado, M. A., Martinez, I., \& Guerra, J. M. (2005). Types of intragroup conflict and affective reactions. Journal of Managerial Psychology, 20(3/4), 219-230.

Menard, J., Brunet, L., \& Savoie, A. (2011). Interpersonal workplace deviance: Why do offenders act out? A comparative look on personality and organizational variables. Canadian Journal of Behavioral Science/Revue canadienne des sciences du comportement, 43(4), 309.

Meyer, G. J., \& Shack, J. R. (1989). Structural convergence of mood and personality: Evidence for old and new directions. Journal of Personality and Social Psychology, 57(4), 691.

Milam, A. C., Spitzmueller, C., \& Penney, L. M. (2009). Investigating individual differences among targets of workplace incivility. Journal of Occupational Health Psychology, 14(1), 58-69.

Mount, M. K., Barrick, M. R., \& Strauss, J. P. (1999). The joint relationship of conscientiousness and ability with performance: Test of the interaction hypothesis. Journal of Management, 25(5), 707-721.

Moscarini, G., \& Thomsson, K. (2007). Occupational and job mobility in the U.S. The Scandinavian Journal of Economics, 109(4), 807-836.

Mroczek, D. K., \& Almeida, D. M. (2004). The effect of daily stress, personality, and age on daily negative affect. Journal of Personality, 72(2), 355-378.

Nakata, A., Haratani, T., Takahashi, M., Kawakami, N., Arito, H., Kobayashi, F. (2004). Job stress, social support, and prevalence of insomnia in a population of Japanese daytime workers. Social Science \& Medicine, 59(8), 1719-1730. 
Narayanan, L., Menon, S., \& Spector, P. E. (1999). Stress in the workplace: A comparison of gender and occupations. Journal of Organizational Behavior, 20(1), 63 73.

Neuman, J. H., \& Baron, R. A. (2005). Aggression in the Workplace: A SocialPsychological Perspective. Investigations of actors and targets, Washington, DC, US: American Psychological Association

Newton, C. J., \& Jimmieson, N. L. (2009). Subjective fit with organizational culture: an investigation of moderating effects in the work stressor-employee adjustment relationship. The International Journal of Human Resource Management, 20(8), 17701789.

Ng, T. W. H., Sorensen, K. L., \& Eby, L. T. (2006). Locus of control at work: a metaanalysis. Journal of Organizational Behavior, 27(8), 1057-1087.

Nigg, J. T. (2000). On inhibition/disinhibition in developmental psychopathology: views from cognitive and personality psychology and a working inhibition taxonomy. Psychological Bulletin, 126(2), 220.

Nixon, A. E., Mazzola, J. J., Bauer, J., Krueger, J. R., \& Spector, P. E. (2011). Can work make you sick? A meta-analysis of the relationships between job stressors and physical symptoms. Work \& Stress, 25(1), 1-22.

Noor, N. M. (2002). Work-family conflict, locus of control, and women's well-being: Tests of alternative pathways. The Journal of Social Psychology, 142(5), 645-662.

North, R. J., Holahan, C. J., Moos, R. H., \& Cronkite, R. C. (2008). Family support, family income, and happiness: a 10-year perspective. Journal of Family Psychology, 22(3), 475-483.

Noyes Jr, R., Clancy, J., Hoenk, P. R., \& Slymen, D. J. (1980). The prognosis of anxiety neurosis. Archives of General Psychiatry, 37(2), 173.

Ode, S., Robinson, M. D., \& Wilkowski, B. M. (2008). Can one's temper be cooled? A role for agreeableness in moderating neuroticism's influence on anger and aggression. Journal of Research in Personality, 42(2), 295-311.

Ogiwara, C. (2008). Gender-related stress among Japanese working women. Transcultural Psychiatry, 45(3), 470.

Oore, G., LeBlanc, D., Day, A., Leiter, M. P., Spence, H. K., Price, S. L. (2010). When respect deteriorates: incivility as a moderator of the stressor-strain relationship among hospital workers. Journal of Nursing Management, 18(8), 878-888. 
Oreopoulos, P., Von Wachter, T., \& Heisz, A. (2006). The short-and long-term career effects of graduating in a recession: Hysteresis and heterogeneity in the market for college graduates (No. w12159). National Bureau of Economic Research.

Organ, D. W. (1988). A restatement of the satisfaction-performance hypothesis. Journal of Management, 14(4), 547-557.

Paulhus, D. (1983). Sphere-specific measures of perceived control. Journal of Personality and Social Psychology, 44(6), 1253.

Paulhus, D. L., \& Van Selst, M. (1990). The spheres of control scale: 10 years of research. Personality and Individual Differences, 11(10), 1029-1036.

Pastor, L. H. (1995). Initial assessment and intervention strategies to reduce workplace violence. American family physician, 52(4), 1169.

Pearson, A. W., Ensley, M. D., \& Amason, A. C. (2002). An assessment and refinement of Jehn's intragroup conflict scale. International Journal of Conflict Management, 13(2), 110-126.

Pearson, C. M., Andersson, L. M., \& Porath, C. L. (2000). Assessing and attacking workplace incivility. Organizational Dynamics, 29, 123-137.

Pelled, L. H., Eisenhardt, K. M., \& Xin, K. R. (1999). Exploring the black box: An analysis of work group diversity, conflict and performance. Administrative Science Quarterly, 44(1), 1-28.

Penney, L. M., \& Spector, P. E. (2005). Job stress, incivility, and counterproductive work behavior (CWB): The moderating role of negative affectivity. Journal of Organizational Behavior, 26(7), 777-796.

Peterson, C. (2000). The future of optimism. American psychologist, 55(1), 44-55.

Phares, E. J. (1976). Locus of control in personality: General Learning Press Morristown, NJ.

Pinkley, R. L. (1990). Dimensions of conflict frame: Disputant interpretations of conflict. Journal of Applied Psychology, 75(2), 117.

Podsakoff, P. M., MacKenzie, S. B., Lee, J. Y., \& Podsakoff, N. P. (2003). Common method biases in behavioral research: A critical review of the literature and recommended remedies. Journal of applied psychology, 88(5), 879-903. 
Preacher, K. J., \& Hayes, A. F. (2004). SPSS and SAS procedures for estimating indirect effects in simple mediation models. Behavior Research Methods, Instruments, \& Computers, 36(4), 717-731.

Preacher, K. J., Rucker, D. D., \& Hayes, A. F. (2007). Addressing moderated mediation hypotheses: Theory, methods, and prescriptions. Multivariate behavioral research, 42(1), 185-227.

Priem, R. L., \& Price, K. H. (1991). Process and outcome expectations for the dialectical inquiry, devil's advocacy, and consensus techniques of strategic decision making. Group \& Organization Management, 16(2), 206-225.

Radloff, L. S. (1977). The CES-D Scale. Applied Psychological Measurement, 1(3), $385-$ 401.

Rahim, M. A. (1983). A measure of styles of handling interpersonal conflict. The Academy of Management Journal, 26(2), 368-376.

Rainey, D. W. (1999). Sources of stress, burnout, and intention to terminate among basketball referees. Journal of Sport Behavior, 22(4), 578-590.

Rantanen, J., Pulkkinen, L., \& Kinnunen, U. (2005). The Big Five personality dimensions, work-family conflict, and psychological distress: A longitudinal view. Journal of Individual Differences, 26(3), 155.

Raz, N., \& Lindenberger, U. (2011). Only time will tell: Cross-sectional studies offer no solution to the age-brain-cognition triangle: Comment on Salthouse (2011).

Reio, T. G., \& Ghosh, R. (2009). Antecedents and outcomes of workplace incivility: Implications of human resource development research and practice. Human Resource Development Quarterly, 20(3), 237-264.

Richardsen, A., Burke, R.J. \& Leiter. M.P. (1992). Occupational demands, psychological burnout and anxiety among hospital personnel in Norway. Anxiety, Stress \& Coping, 5, $55-68$.

Rotter, J. B. (1966). Generalized expectations for internal versus external control of reinforcement. Psychological Monographs, 80(1), 609.

Rumelt, R. P. (1991). How much does industry matter? Strategic Management Journal, 12(3), 167-185.

Rusting, C. L., \& Larsen, R. J. (1997). Extraversion, neuroticism, and susceptibility to positive and negative affect: A test of two theoretical models. Personality and Individual Differences, 22(5), 607-612. 
Salancik, G. R. (1984). On priming, consistency, and order effects in job attitude assessment: With a note on current research.

Salancik, G. R., \& Pfeffer, J. (1977). An examination of need-satisfaction models of job attitudes. Administrative Science Quarterly, 427-456.

Salgado, J. F. (1997). The Five Factor model of personality and job performance in the European community. Journal of Applied Psychology, 82(1), 30.

Salthouse, T. A. (2011). Neuroanatomical substrates of age-related cognitive decline. Psychological bulletin, 137(5), 753.

Schat, A. C., Frone, M. R., \& Kelloway, E. K. (2006). Prevalence of Workplace Aggression in the US Workforce: Findings from a National Study.

Schat, A. C., \& Kelloway, E. K. (2003). Reducing the adverse consequences of workplace aggression and violence: The buffering effects of organizational support. Journal of Occupational Health Psychology, 8(2), 110-122.

Shah, P. P., \& Jehn, K. A. (1993). Do friends perform better than acquaintances? The interaction of friendship, conflict, and task. Group Decision and Negotiation, 2(2), 149165.

Shim, J. H. (2010). The Relationship Between Workplace Incivility and the Intention to Share Knowledge: The Moderating Effects of Collaborative Climate and Personality Traits. University of Minnesota.

Simons, T. L., \& Peterson, R. S. (2000). Task conflict and relationship conflict in top management teams: The pivotal role of intragroup trust. Journal of Applied Psychology, 85(1), 102.

Skarlicki, D. P., \& Folger, R. (1997). Retaliation in the workplace: The roles of distributive, procedural, and interactional justice. Journal of Applied Psychology, 82, 434-443.

Sliter, M. T., Pui, S. Y., Sliter, K. A., \& Jex, S. M. (2011). The differential effects of interpersonal conflict from customers and coworkers: Trait anger as a moderator. Journal of Occupational Health Psychology, 16(4), 424.

Sonnentag, S., \& Frese, M. (2003). Stress in Organizations Handbook of Psychology: John Wiley \& Sons, Inc.

Spector, P. E. (1982). Behavior in organizations as a function of employee's locus of control. Psychological Bulletin, 91(3), 482. 
Spector, P. E. (1988). Development of the work locus of control scale. Journal of Occupational Psychology, 61(4), 335-340.

Spector, P. E. (1997). The role of frustration in antisocial behavior at work. In R. A. Giacalone \& J. Greenberg (Eds.), Antisocial behavior in organizations. (pp. 1-17): Thousand Oaks, CA, US: Sage Publications, Inc.

Spector, P. E. (2003). Individual differences in health and well-being in organizations. Health and safety in organizations: A multilevel perspective, 29-55.

Spector, P. E. (2006). Method variance in organizational research truth or urban legend?. Organizational research methods, 9(2), 221-232.

Spector, P. E., \& Bruk-Lee, V. (2008). Conflict, health, and well-being. In C.K.W. De Dreu \& M.J. Gelfand (Eds.), The psychology of conflict and conflict management in organizations. (pp. 267-288) CRC Press

Spector, P. E., Dwyer, D. J., \& Jex, S., M. (1998). Relation of job stressors to affective, health, and performance outcomes: A comparison of multiple data sources. Journal of Applied Psychology, 73(1), 11-19.

Spector, P. E., \& Jex, S., M. (1998). Development of four self-report measures of job stressors and strain: Interpersonal conflict at work scale, organizational constraints scale, quantitative workload inventory, and physical symptoms inventory. Journal of Occupational Health Psychology, 3(4), 356-367.

Spector, P. E., \& O'Connell, B. J. (1994). The contribution of personality traits, negative affectivity, locus of control and Type A to the subsequent reports of job stressors and job strains. Journal of Occupational and Organizational Psychology, 67(1), 1-12.

Spector, P. E., Sanchez, J. I., Siu, O. L., Salgado, J., \& Ma, J. (2004). Eastern versus western control beliefs at work: An investigation of secondary control, socio-instrumental control, and work locus of control in China and the US. Applied Psychology, 53(1), 3860 .

Spielberger, C., Gorush, R., Lushene, R., Vagg, P., \& Jacobs, G. (1983). STAI: Manual for the State-Trait Personality Inventory (STPI): Palo Alto: Consulting Psychologists Press.

Spielberger, C. D., Jacobs, G., Russell, S., \& Crane, R. S. (1983). Assessment of anger: The state-trait anger scale. Advances in Personality Assessment, 2, 159-187.

Sukhodolsky, D. G., Golub, A., \& Cromwell, E. N. (2001). Development and validation of the anger rumination scale. Personality and Individual Differences, 31(5), 689-700. 
Suls, J., Martin, R., \& David, J. P. (1998). Person-environment fit and its limits: Agreeableness, neuroticism, and emotional reactivity to interpersonal conflict. Personality and Social Psychology Bulletin, 24(1), 88-98.

Tai, K., \& Lim, S. (2011). Core self-evaluation and neuroticism: Moderating the Incivility-Psychological health relationship. Paper presented at the SIOP, Chicago.

Tepper, B. J. (2000). Consequences of abusive supervision. Academy of Management Journal, 43, 178-191.

Tobin, R. M., Graziano, W. G., Vanman, E. J., \& Tassinary, L. G. (2000). Personality, emotional experience, and efforts to control emotions. Journal of Personality and Social Psychology, 79(4), 656.

Tomkins, S. S. (1962). Affect, imagery, consciousness: Vol. I. The positive affects.

Van de Vliert, E., \& De Dreu, C. K. W. (1994). Optimizing performance by conflict stimulation. International Journal of Conflict Management, 5(3), 211-222.

van Emmerik, I. H., Euwema, M. C., \& Bakker, A. B. (2007). Threats of workplace violence and the buffering effect of social support. Group \& Organization Management, 32(2), 152-175.

van Jaarsveld, D. D., Walker, D. D., \& Skarlicki, D. P. (2010). The role of job demands and emotional exhaustion in the relationship between customer and employee incivility. Journal of Management, 36(6), 1486-1504.

Van Katwyk, P. T., Fox, S., Spector, P. E., \& Kelloway, E. K. (2000). Using the JobRelated Affective Well-Being Scale (JAWS) to investigate affective responses to work stressors. Journal of Occupational Health Psychology, 5(2), 219.

Van Vianen, A. E. M., \& De Dreu, C. K. W. (2001). Personality in teams: Its relationship to social cohesion, task cohesion, and team performance. European Journal of Work and Organizational Psychology, 10(2), 97-120.

Van Woerkom, M., \& Engen, M. L. (2009). Learning from conflicts? The relationship between task and relationship conflicts, team learning, and team performance. European Journal of Work and Organizational Psychology, 18(4), 381-404.

Vankataramani, V., \& Dalal, R. S. (2007). Who helps and harms whom? Relational antecedents of interpersonal helping and harming in organizations. Journal of Applied Psychology, 92, 952-966.

Vodosek, M. (2007). Intragroup conflict as a mediator between cultural diversity and work group outcomes. International Journal of Conflict Management, 18(4), 345-375. 
Wall Jr, V. D., \& Nolan, L. L. (1986). Perceptions of inequity, satisfaction, and conflict in task-oriented groups. Human Relations, 39(11), 1033-1051.

Watson, D., \& Clark, L. A. (1984). Negative affectivity: the disposition to experience aversive emotional states. Psychological Bulletin, 96(3), 465.

Watson, D., Clark, L. A., \& Tellegen, A. (1988). Development and validation of brief measures of positive and negative affect: the PANAS scales. Journal of Personality and Social Psychology, 54(6), 1063.

Watson, D., \& Friend, R. (1969). Measurement of social-evaluative anxiety. Journal of Consulting and Clinical Psychology, 33(4), 448-457.

Watson, D., \& Tellegen, A. (1985). Toward a consensual structure of mood.

Psychological Bulletin, 98(2), 219.

Wayne, J. H., Musisca, N., \& Fleeson, W. (2004). Considering the role of personality in the work-family experience: Relationships of the Big Five to work-family conflict and facilitation. Journal of Vocational Behavior, 64, 108-130.

Whiteman, M., Bedford, A., Grant, E., Fowkes, F., \& Deary, I. (2001). The five-factor model (NEO-FFI) and The Personality Deviance Scales-Revised (PDS-R): Going around in interpersonal circles. Personality and Individual Differences, 31(2), 259-267.

Wittgenstein, J. P., Allen, J. W. Bruk-Lee, V., \& Nixon, A. E., (2013, May). Clowns to the left, conflict to the right: Stuck with relationship conflict. Work, stress, and health 2013, Los Angeles, California.

Wittgenstein, J. P., Allen, J. W. Bruk-Lee, V., \& Nixon, A. E., (2013, May). What's task conflict got to do with it: A meta-analysis. Work, stress, and health 2013, Los Angeles, California.

Zinbarg, R., \& Revelle, W. (1989). Personality and conditioning: A test of four models. Journal of Personality and Social Psychology, 57(2), 301. 


\section{Appendix 1}

Participant email recruitment letter:

Dear Participant,

Thank you for your participation in research here at Florida International University.

Your participation in this research will help us to gain a better understanding of how social interactions in the workplace affect individual's health and work outcomes. By completing the survey you are eligible for a $10 \$$ amazon.com gift card

Your $10 \$$ amazon gift card code is:

Please go to www.amazon.com/redeemgift to redeem your gift card

If there are any difficulties or concerns regarding your gift card please contact me at $\underline{\text { XXXXXXXX@fiu.edu }}$

In addition, a colleague of mine is running a similar research project and offering an additional $10 \$$ amazon.com gift card for participation. More information can be found at:

https://fiu.qualtrics.com/SE/?SID=SV_a9Q1oqMnndgKqpbT

Thank you for your time and participation,

John Wittgenstein 
1: Task and relationship conflict will be positively correlated with incivility.

Relationship conflict

Yes

Task conflict

Yes

Hypothesis 2 a, b, c: Task conflict, relationship conflict, and incivility will be positively related to negative emotional responses such as anger, frustration, and anxiety.

Incivility

Relationship conflict

Yes

Task conflict

Yes

Yes

Hypothesis 3 a,b,c: Task conflict, relationship conflict, and incivility will be negatively related to individual measures of strain.

Incivility with depression

Yes

Incivility with Physical Symptoms

Yes

Incivility with Stress

Yes

Incivility with Job Satisfaction

Yes

Incivility with Life Satisfaction

Yes

Relationship Conflict with depression

Yes

Relationship Conflict with Physical Symptoms

Yes

Relationship Conflict with Stress

Yes

Relationship Conflict with Job Satisfaction

Yes

Relationship Conflict with Life Satisfaction

Yes

Task Conflict with depression

Yes

Task Conflict with Physical Symptoms

Yes

Task Conflict with Stress

Yes

Task Conflict with Job Satisfaction

Yes

Task Conflict with Life Satisfaction

Yes 


\begin{tabular}{lc}
\hline \multicolumn{1}{c}{ Hypothesis } & Suppor \\
\hline Hypothesis $\mathbf{3}$ d: Negative emotions will mediate the & \\
relationship between task conflict, relationship conflict, & \\
incivility and strain. & \\
& \\
Incivility with depression & Yes \\
Incivility with Physical Symptoms & Yes \\
Incivility with Stress & No \\
Incivility with Job Satisfaction & Yes \\
Incivility with Life Satisfaction & No \\
Relationship Conflict with depression & Yes \\
Relationship Conflict with Physical Symptoms & Yes \\
Relationship Conflict with Stress & Yes \\
Relationship Conflict with Job Satisfaction & Yes \\
Relationship Conflict with Life Satisfaction & No \\
Task Conflict with depression & Yes \\
Task Conflict with Physical Symptoms & Yes \\
Task Conflict with Stress & Yes \\
Task Conflict with Job Satisfaction & Yes \\
Task Conflict with Life Satisfaction & No
\end{tabular}

Hypothesis 4a,b,c: Extraversion will moderate the relationship between task conflict, relationship conflict, and incivility and negative emotions such that individuals high in extraversion will experience fewer negative emotions.

Incivility

No

Relationship conflict $\quad$ No

Task conflict $\quad$ No

Hypothesis $4 \mathrm{~d}$ : Extraversion will moderate the relationship between task conflict, relationship conflict, and incivility and strains such that individuals high in extraversion will experience less strain.

Incivility with depression

Incivility with Physical Symptoms $\quad$ Yes

Incivility with Stress $\quad$ No

Incivility with Job Satisfaction $\quad$ Yes

Incivility with Life Satisfaction $\quad$ No

Relationship Conflict with depression $\quad$ Yes

Relationship Conflict with Physical Symptoms Yes

Relationship Conflict with Stress $\quad$ Yes

Relationship Conflict with Job Satisfaction No

Relationship Conflict with Life Satisfaction No 
Task Conflict with depression

Yes

Task Conflict with Physical Symptoms

Yes

Task Conflict with Stress

No

Task Conflict with Job Satisfaction

No

Task Conflict with Life Satisfaction

No

Hypothesis 5a,b,c: Neuroticism will moderate the relationship between task conflict, relationship conflict, and incivility and negative emotions such that individuals high in neuroticism will experience more negative emotions.

Incivility

Yes

Relationship conflict

Yes

Task conflict

Yes

Hypothesis $\mathbf{5} \mathrm{d}$ : Neuroticism will moderate the relationship between task conflict, relationship conflict, and incivility and strains such that individuals high in neuroticism will experience more strain.

Incivility with depression

Yes

Incivility with Physical Symptoms

Yes

Incivility with Stress

No

Incivility with Job Satisfaction

No

Incivility with Life Satisfaction

Yes

Relationship Conflict with depression

Yes

Relationship Conflict with Physical Symptoms

Yes

Relationship Conflict with Stress

No

Relationship Conflict with Job Satisfaction

No

Relationship Conflict with Life Satisfaction

Yes

Task Conflict with depression

Yes

Task Conflict with Physical Symptoms

Yes

Task Conflict with Stress

No

Task Conflict with Job Satisfaction

No

Task Conflict with Life Satisfaction

Yes 
Table 1 cont.

Hypothesis

Supported

Hypothesis 6 a,b,c: Agreeableness will moderate the relationship between task conflict, relationship conflict, and incivility and negative emotions such that individuals high in agreeableness will experience fewer negative emotions.

Incivility

Yes

Relationship conflict

Yes

Task conflict

Yes

Hypothesis $6 \mathrm{~d}$ : Agreeableness will moderate the relationship between task conflict, relationship conflict, and incivility and strains such that individuals high in agreeableness will experience less strain.

Incivility with depression

Yes

Incivility with Physical Symptoms

Incivility with Stress

Yes

Incivility with Job Satisfaction

Yes

Incivility with Life Satisfaction

No

Relationship Conflict with depression

Yes

Relationship Conflict with Physical Symptoms

Yes

Relationship Conflict with Stress

Yes

Relationship Conflict with Job Satisfaction

No

Relationship Conflict with Life Satisfaction

No

Task Conflict with depression

Yes

Task Conflict with Physical Symptoms

Yes

Task Conflict with Stress

Yes

Task Conflict with Job Satisfaction

No

Task Conflict with Life Satisfaction

No

Yes

Hypothesis 7a,b,c: Conscientiousness will moderate the relationship between task conflict, relationship conflict, incivility and negative emotions such that individuals high in conscientiousness will experience fewer negative emotions.

Incivility

No

Relationship conflict

No

Task conflict

No 
Hypothesis $7 \mathrm{~d}$ : Conscientiousness will moderate the relationship between task conflict, relationship conflict, incivility and strains such that individuals high in conscientiousness will experience less strain.

Incivility with depression

No

Incivility with Physical Symptoms

Yes

Incivility with Stress

No

Incivility with Job Satisfaction

Yes

Incivility with Life Satisfaction

No

Relationship Conflict with depression

No

Relationship Conflict with Physical Symptoms

No

Relationship Conflict with Stress

No

Relationship Conflict with Job Satisfaction

No

Relationship Conflict with Life Satisfaction

No

Task Conflict with depression

No

Task Conflict with Physical Symptoms

Yes

Task Conflict with Stress

No

Task Conflict with Job Satisfaction

No

Task Conflict with Life Satisfaction

No

Hypothesis 8 a,b,c: Trait anger will moderate the relationship between task conflict, relationship conflict, and incivility and negative emotions such that individuals high in trait anger will experience more negative emotions.

Incivility

Relationship conflict

Yes

Task conflict

Yes

No

Hypothesis $8 \mathrm{~d}$ : Trait anger will moderate the relationship between task conflict, relationship conflict, and incivility and strains such that individuals high in trait anger will experience more strains.

Incivility with depression

Yes

Incivility with Physical Symptoms

Yes

Incivility with Stress

No

Incivility with Job Satisfaction

No

Incivility with Life Satisfaction

Yes 
Table 1 cont.

\begin{tabular}{l} 
Hypothesis \\
\hline Relationship Conflict with depression \\
Relationship Conflict with Physical Symptoms \\
Relationship Conflict with Stress \\
Relationship Conflict with Job Satisfaction \\
Relationship Conflict with Life Satisfaction \\
Task Conflict with depression \\
Task Conflict with Physical Symptoms \\
Task Conflict with Stress \\
Task Conflict with Job Satisfaction \\
Task Conflict with Life Satisfaction \\
Hypothesis 9 a,b: ILOC will moderate the relationship \\
between task conflict, relationship conflict, and incivility \\
and negative emotions such that individuals with an \\
external ILOC will experience more negative emotions.
\end{tabular}

Incivility

Yes

Relationship conflict $\quad$ Yes

Task conflict

Yes

Hypothesis 9 c: ILOC will moderate the relationship between task conflict, relationship conflict, and incivility and strains such that individuals with an external ILOC will experience more strain.

Incivility with depression

Yes Incivility with Physical Symptoms $\quad$ Yes Incivility with Stress $\quad$ No

Incivility with Job Satisfaction $\quad$ No

Incivility with Life Satisfaction $\quad$ Yes

Relationship Conflict with depression $\quad$ Yes

Relationship Conflict with Physical Symptoms $\quad$ Yes

Relationship Conflict with Stress No

Relationship Conflict with Job Satisfaction Yes

Relationship Conflict with Life Satisfaction $\quad$ Yes

Task Conflict with depression $\quad$ Yes

Task Conflict with Physical Symptoms $\quad$ Yes

Task Conflict with Stress $\quad$ No

Task Conflict with Job Satisfaction No

Task Conflict with Life Satisfaction No 
Table 2: Means, Standard Deviations, and Correlations

\begin{tabular}{|c|c|c|c|c|c|c|c|c|c|c|}
\hline Variables & $M$ & $S D$ & 1 & 2 & 3 & 4 & 5 & 6 & 7 & 8 \\
\hline 1. Age & 31.92 & 7.21 & - & & & & & & & \\
\hline 2. Gender & 1.38 & 0.48 & -.079 & - & & & & & & \\
\hline 3. Tenure & 43.68 & 44.11 & $.216^{* *}$ & -.060 & - & & & & & \\
\hline 4. Relationship Conflict & 2.85 & 0.72 & .046 & -.066 & -.054 & - & & & & \\
\hline 5. Task Conflict & 2.85 & 0.73 & -.027 & -.083 & -.017 & $.810^{* *}$ & - & & & \\
\hline 6. Incivility & 2.65 & 0.86 & -.012 & $-.215^{* *}$ & -.038 & $.681^{* *}$ & $.664^{* *}$ & - & & \\
\hline 7. Negative Emotions & 2.54 & 0.81 & -.088 & -.087 & -.029 & $.636^{* *}$ & $.641^{* *}$ & $.700^{* *}$ & - & \\
\hline 8. Neuroticism & 2.82 & 0.59 & $-.269^{* *}$ & -.054 & -.073 & $.344^{* *}$ & $.326^{* *}$ & $.522^{* *}$ & $.527^{* *}$ & - \\
\hline 9. Extraversion & 3.31 & 0.48 & $.141^{*}$ & $.158^{* *}$ & -.038 & -.078 & -.002 & $-.273^{* *}$ & $-.279^{* *}$ & $-.392^{* *}$ \\
\hline 10. Agreeableness & 3.17 & 0.53 & .052 & $.284^{* *}$ & .023 & $-.407^{* *}$ & $-.378^{* *}$ & $-.649^{* *}$ & $-.444^{* *}$ & $-.390^{* *}$ \\
\hline 11. Conscientiousness & 3.39 & 0.52 & $.157^{* *}$ & $.198^{* *}$ & -.036 & $-.139^{*}$ & -.087 & $-.370^{* *}$ & $-.267^{* *}$ & $-.395^{* *}$ \\
\hline 12. Locus of Control & 4.41 & 0.73 & $.112^{*}$ & $.204^{* *}$ & .018 & $-.156^{* *}$ & -.074 & $-.476^{* *}$ & $-.286^{* *}$ & $-.453^{* *}$ \\
\hline 13. Trait Anger & 2.21 & 0.53 & -.058 & $-.139^{*}$ & -.070 & $.626^{* *}$ & $.576^{* *}$ & $.705^{* *}$ & $.769^{* *}$ & $.536^{* *}$ \\
\hline 14. Stress & 2.78 & 0.45 & $-.258^{* *}$ & $-.135^{*}$ & $-.199^{* *}$ & $.196^{* *}$ & $.183^{* *}$ & $.498^{* *}$ & $.334^{* *}$ & $.643^{* *}$ \\
\hline 15. Physical Symptoms & 2.21 & 0.97 & -.054 & $-.133^{*}$ & .025 & $.645^{* *}$ & $.643^{* *}$ & $.728^{* *}$ & $.844^{* *}$ & $.533^{* *}$ \\
\hline 16. Depression & 2.19 & 0.47 & -.035 & $-.122^{*}$ & -.027 & $.614^{* *}$ & $.616^{* *}$ & $.753^{* *}$ & $.794^{* *}$ & $.572^{* *}$ \\
\hline 17. Job Satisfaction & 3.65 & 0.77 & $.186^{* *}$ & $.158^{* *}$ & -.089 & $-.192^{* *}$ & $-.171^{* *}$ & $-.284^{* *}$ & $-.393^{* *}$ & $-.337^{* *}$ \\
\hline 18. Life Satisfaction & 3.42 & 0.69 & $.224^{* *}$ & .071 & $-.126^{*}$ & $.290^{* *}$ & $.311^{* *}$ & $.161^{* *}$ & $.126^{*}$ & -.074 \\
\hline
\end{tabular}


Table 2 continued: Means, Standard Deviations, and Correlations

\begin{tabular}{|c|c|c|c|c|c|c|c|c|c|c|c|}
\hline Variables & $M$ & $S D$ & 9 & 10 & 11 & 12 & 13 & 14 & 15 & 16 & 17 \\
\hline 1. Age & 31.92 & 7.21 & & & & & & & & & \\
\hline 2. Gender & 1.38 & 0.48 & & & & & & & & & \\
\hline 3. Tenure & 43.68 & 44.11 & & & & & & & & & \\
\hline 4. Relationship Conflict & 2.85 & 0.72 & & & & & & & & & \\
\hline 5. Task Conflict & 2.85 & 0.73 & & & & & & & & & \\
\hline 6. Incivility & 2.65 & 0.86 & & & & & & & & & \\
\hline 7. Negative Emotions & 2.54 & 0.81 & & & & & & & & & \\
\hline 8. Neuroticism & 2.82 & 0.59 & & & & & & & & & \\
\hline 9. Extraversion & 3.31 & 0.48 & - & & & & & & & & \\
\hline 10. Agreeableness & 3.17 & 0.53 & $.335^{* *}$ & - & & & & & & & \\
\hline 11. Conscientiousness & 3.39 & 0.52 & $.502^{* *}$ & $.455^{* *}$ & - & & & & & & \\
\hline 12. Locus of Control & 4.41 & 0.73 & $.557^{* *}$ & $.489^{* *}$ & $.499^{* *}$ & - & & & & & \\
\hline 13. Trait Anger & 2.21 & 0.53 & $-.233^{* *}$ & $-.610^{* *}$ & $-.279^{* *}$ & $-.388^{* *}$ & - & & & & \\
\hline 14. Stress & 2.78 & 0.45 & $-.370^{* *}$ & $-.423^{* *}$ & $-.533^{* *}$ & $-.554^{* *}$ & $.366^{* *}$ & - & & & \\
\hline 15. Physical Symptoms & 2.21 & 0.97 & $-.232^{* *}$ & $-.510^{* *}$ & $-.251^{* *}$ & $-.285^{* *}$ & $.771^{* *}$ & $.308^{* *}$ & - & & \\
\hline 16. Depression & 2.19 & 0.47 & $-.217^{* *}$ & $-.548^{* *}$ & $-.268^{* *}$ & $-.384^{* *}$ & $.781^{* *}$ & $.410^{* *}$ & $.864^{* *}$ & - & \\
\hline 17. Job Satisfaction & 3.65 & 0.77 & $.444^{* *}$ & $.309^{* *}$ & $.467^{* *}$ & $.252^{* *}$ & $-.275^{* *}$ & $-.279^{* *}$ & $-.341^{* *}$ & $-.222^{* *}$ & - \\
\hline 18. Life Satisfaction & 3.42 & 0.69 & $.254^{* *}$ & -.034 & $.301^{* *}$ & $.170^{* *}$ & $.143^{* *}$ & $-.135^{*}$ & $.144^{* *}$ & $.169^{* *}$ & $.361^{* *}$ \\
\hline
\end{tabular}


Table 3: Hierarchical regression estimate for Incivility, Relationship Conflict, and Task Conflict on Negative Emotions

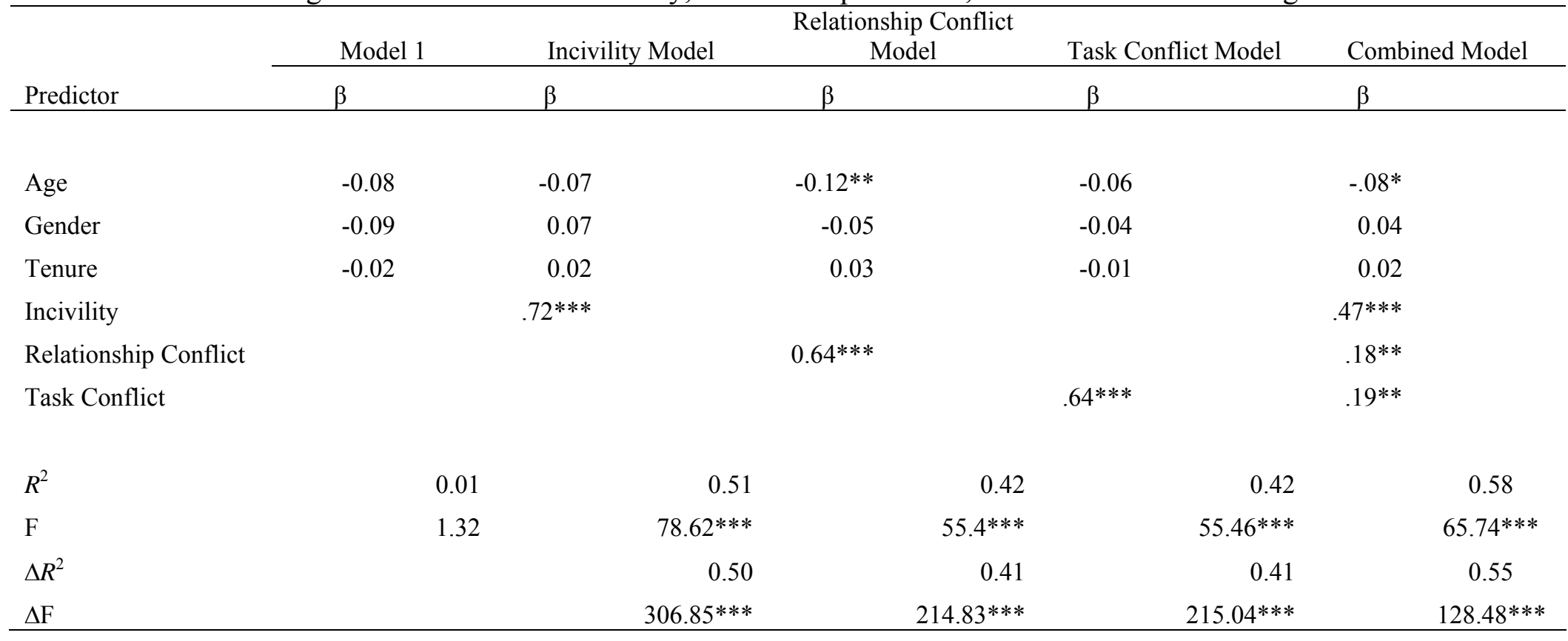

Note. $N=308 . \beta=$ Standardized coefficients. ${ }^{*}=p<.05,{ }^{* *}=p<.01, * * *=p<.001$ 
Table 4: Hierarchical regression estimates for Incivility, Relationship Conflict, and Task Conflict on Depression

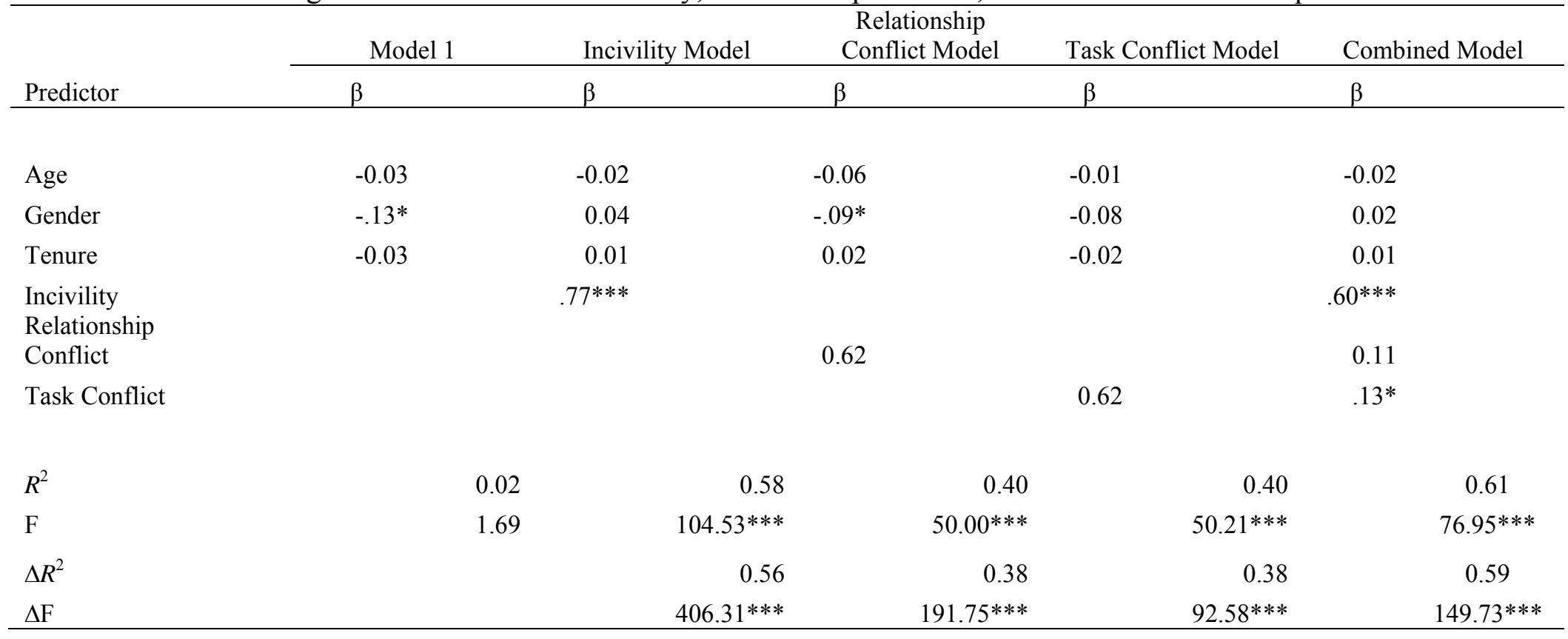

Note. $N=308 . \beta=$ Standardized coefficients. ${ }^{*}=p<.05, * *=p<.01, * * *=p<.001$ 
Table 5: Hierarchical regression estimate for Incivility, Relationship Conflict, and Task Conflict on Physical Symptoms

\begin{tabular}{|c|c|c|c|c|c|c|c|c|c|c|}
\hline & $\begin{array}{l}\text { Mod } \\
\text { el } 1\end{array}$ & & $\begin{array}{l}\text { Incivility } \\
\text { Model }\end{array}$ & & $\begin{array}{c}\text { Relationship } \\
\text { Conflict Model }\end{array}$ & & $\begin{array}{c}\text { Task } \\
\text { Conflict } \\
\text { Model } \\
\end{array}$ & & $\begin{array}{l}\text { Combine } \\
\mathrm{d} \text { Model }\end{array}$ & \\
\hline Predictor & $\beta$ & & $\beta$ & & $\beta$ & & $\beta$ & & $\beta$ & \\
\hline Age & -0.06 & & -0.05 & & $-.10^{*}$ & & -0.04 & & -0.06 & \\
\hline Gender & $-.13^{*}$ & & 0.03 & & $-.10^{*}$ & & $-.09^{*}$ & & -0.01 & \\
\hline Tenure & 0.03 & & 0.07 & & 0.08 & & 0.04 & & 0.07 & \\
\hline $\begin{array}{l}\text { Incivility } \\
\text { Relationship } \\
\text { Conflict } \\
\text { Task } \\
\text { Conflict }\end{array}$ & & & $.73 * * *$ & & $.65 * * *$ & & $.65 * * *$ & & $\begin{array}{l}.48^{* * *} \\
.19^{* *} \\
.17^{* *}\end{array}$ & \\
\hline$R^{2}$ & & 0.02 & & 0.53 & & 0.44 & & 0.43 & & 0.59 \\
\hline $\mathrm{F}$ & & 2.03 & & $86.75 * * *$ & & $59.99 * * *$ & & $58.06^{* * *}$ & & $72.32 * * *$ \\
\hline$\Delta R^{2}$ & & & & 0.51 & & 0.42 & & 0.41 & & 0.57 \\
\hline$\Delta \mathrm{F}$ & & & & $334.20 * * *$ & & $229.28 * * *$ & & $221.73 * * *$ & & $139.82 * * *$ \\
\hline
\end{tabular}

Note. $N=308 . \beta=$ Standardized coefficients. $*=p<.05, * *=p<.01, * * *=p<.001$ 
Table 6: Hierarchical regression estimate for Incivility, Relationship Conflict, and Task Conflict on Stress

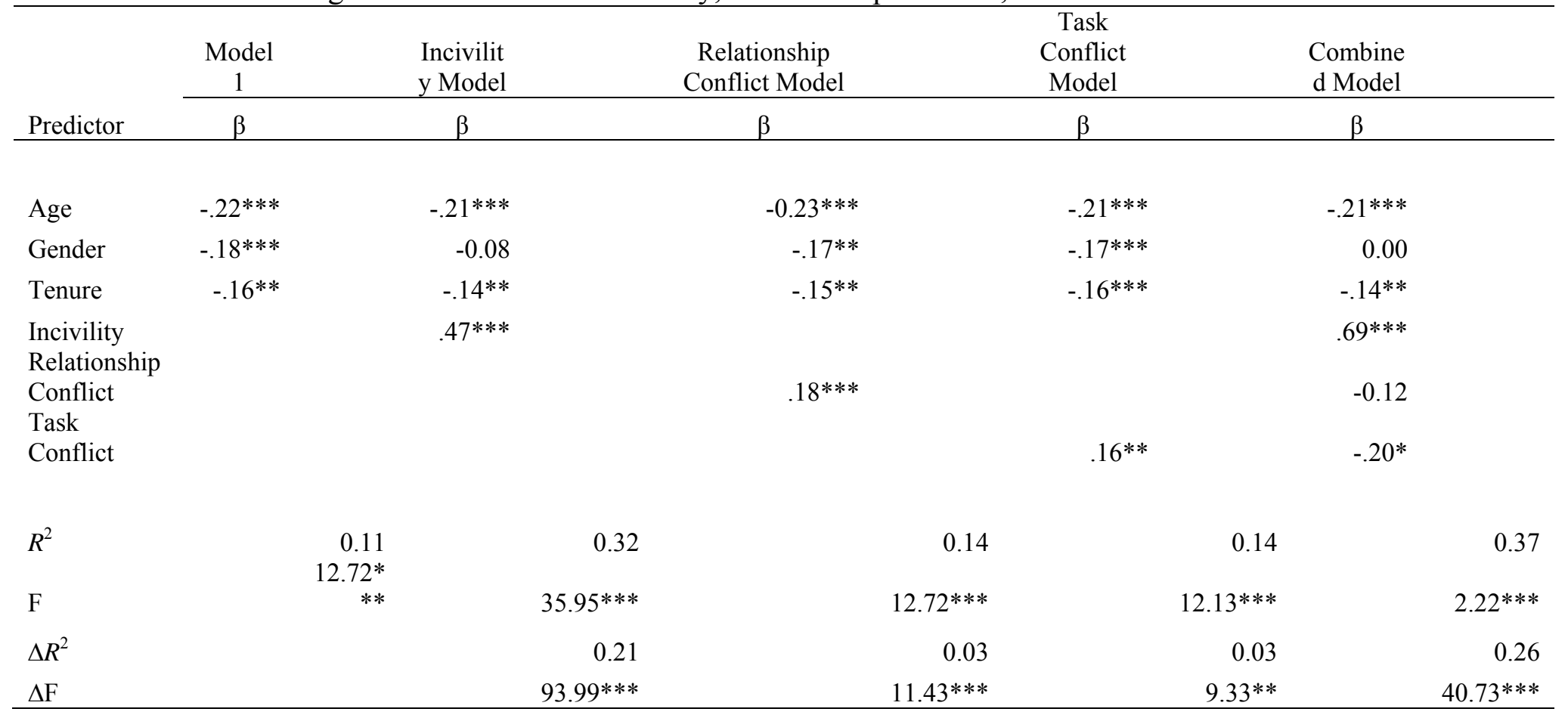

Note. $N=308 . \beta=$ Standardized coefficients. $*=p<.05, * *=p<.01, * * *=p<.001$ 
Table 7: Hierarchical regression estimate for Incivility, Relationship Conflict, and Task Conflict on Job Satisfaction

\begin{tabular}{|c|c|c|c|c|c|c|c|c|c|c|}
\hline & $\begin{array}{c}\text { Model } \\
1 \\
\end{array}$ & & $\begin{array}{c}\text { Incivili } \\
\text { ty } \\
\text { Model }\end{array}$ & & $\begin{array}{c}\text { Relationship } \\
\text { Conflict Model }\end{array}$ & & $\begin{array}{c}\text { Task Conflict } \\
\text { Model }\end{array}$ & & $\begin{array}{c}\text { Combi } \\
\text { ned } \\
\text { Model }\end{array}$ & \\
\hline Predictor & $\beta$ & & $\beta$ & & $\beta$ & & $\beta$ & & $\beta$ & \\
\hline Age & $.22 * * *$ & & $.22 * * *$ & & $.23 * * *$ & & $.21 * * *$ & & $.23 * * *$ & \\
\hline Gender & $.17^{* *}$ & & $.12 *$ & & $.16^{* *}$ & & $.16^{* *}$ & & $.12 *$ & \\
\hline Tenure & $-.13^{*}$ & & $-.14 * *$ & & $-.14^{*}$ & & $-.13^{*}$ & & $-.14 * *$ & \\
\hline $\begin{array}{l}\text { Incivility } \\
\text { Relationship }\end{array}$ & & & $-.25 * * *$ & & & & & & $-.23 * *$ & \\
\hline $\begin{array}{l}\text { Conflict } \\
\text { Task }\end{array}$ & & & & & $-.20 * * *$ & & & & -.12 & \\
\hline Conflict & & & & & & & $-.16^{* *}$ & & 0.09 & \\
\hline$R^{2}$ & & $\begin{array}{c}0.08 \\
8.51^{* *}\end{array}$ & & 0.14 & & 0.12 & & 0.10 & & 0.14 \\
\hline $\mathrm{F}$ & & $*$ & & 12.1 & & $10.16^{* * *}$ & & $8.77^{* * *}$ & & $8.37 * * *$ \\
\hline$\Delta R^{2}$ & & & & 0.06 & & 0.04 & & 0.03 & & 0.07 \\
\hline$\Delta \mathrm{F}$ & & & & $21.51 * * *$ & & $14.01 * * *$ & & $8.89 * *$ & & $7.67 * * *$ \\
\hline
\end{tabular}

Note. $N=308 . \beta=$ Standardized coefficients. ${ }^{*}=p<.05, * *=p<.01, * * *=p<.001$ 
Table 8: Hierarchical regression estimate for Incivility, Relationship Conflict, and Task Conflict on Life Satisfaction

\begin{tabular}{|c|c|c|c|c|c|c|c|c|c|c|}
\hline & Model 1 & & $\begin{array}{c}\text { Incivility } \\
\text { Model } \\
\end{array}$ & & $\begin{array}{c}\text { Relationship } \\
\text { Conflict } \\
\text { Model } \\
\end{array}$ & & $\begin{array}{c}\text { Task } \\
\text { Conflict } \\
\text { Model } \\
\end{array}$ & & $\begin{array}{c}\text { Combined } \\
\text { Model }\end{array}$ & \\
\hline Predictor & $\beta$ & & $\beta$ & & $\beta$ & & $\beta$ & & $\beta$ & \\
\hline Age & $.28 * * *$ & & $.28 * * *$ & & $.26^{* * *}$ & & $.29 * * *$ & & $.28 * * *$ & \\
\hline Gender & 0.08 & & $.11 *$ & & 0.09 & & 0.1 & & 0.08 & \\
\hline Tenure & $.18^{* *}$ & & $-.17 * *$ & & $-.16^{* *}$ & & $-.18^{* * *}$ & & $-.18^{* * *}$ & \\
\hline $\begin{array}{l}\text { Incivility } \\
\text { Relationship }\end{array}$ & & & $.17 * *$ & & & & & & -0.12 & \\
\hline $\begin{array}{l}\text { Conflict } \\
\text { Task }\end{array}$ & & & & & $.26 * * *$ & & & & 0.07 & \\
\hline Conflict & & & & & & & $.31 * * *$ & & $.34 * * *$ & \\
\hline$R^{2}$ & & 0.09 & & 0.12 & & 0.16 & & 0.19 & & $\begin{array}{r}0.20 \\
12.14 * *\end{array}$ \\
\hline $\mathrm{F}$ & & $10.16^{* * *}$ & & $10.04 * * *$ & & $14.31 * * *$ & & $17.60 * * *$ & & * \\
\hline$\Delta R^{2}$ & & & & 0.03 & & 0.07 & & 0.10 & & $\begin{array}{r}0.10 \\
12.91 * *\end{array}$ \\
\hline$\Delta \mathrm{F}$ & & & & $8.88^{* *}$ & & $24.41 * * *$ & & $36.35 * * *$ & & $*$ \\
\hline
\end{tabular}

Note. $N=308 . \beta=$ Standardized coefficients. $*=p<.05, * *=p<.01, * * *=p<.001$ 
Table 9: Mediated regression of Negative Emotions on the Incivility to Strain relationship

\begin{tabular}{lccccc}
\hline Incivility & Coefficient & $S E$ & $t$ & $p$ & Model R $^{2}$ \\
\hline Direct effects & & & & & \\
$\quad$ Depression as DV & & & & & \\
Age & 0.00 & 0.00 & 0.55 & 0.583 & \\
Gender & 0.00 & 0.03 & 0.07 & 0.420 & \\
Tenure & 0.00 & 0.00 & 0.01 & 0.994 & \\
$\quad$ Negative emotions & 0.31 & 0.03 & 11.77 & 0.000 & \\
$\quad$ Incivility & 0.22 & 0.03 & 8.79 & 0.000 & $0.71^{* * *}$ \\
Indirect effect $^{\text {a }}$ & Effect & $S E$ & $L L C I$ & $U L C I$ & \\
$\quad$ Incivility on Depression & 0.21 & 0.02 & 0.17 & 0.28 & \\
\hline & Coefficient & $S E$ & $t$ & $p$ & Model R $^{2}$ \\
\hline
\end{tabular}

\section{Direct effects}

Physical Symptoms as DV

\begin{tabular}{|c|c|c|c|c|c|}
\hline Age & 0.00 & 0.00 & -0.16 & 0.869 & \\
\hline Gender & -0.04 & 0.06 & -0.64 & 0.522 & \\
\hline Tenure & 0.00 & 0.00 & 1.96 & 0.051 & \\
\hline Negative emotions & 0.79 & 0.05 & 16.17 & 0.000 & \\
\hline Incivility & 0.29 & 0.05 & 6.11 & 0.000 & $.75 * * *$ \\
\hline rect effect ${ }^{a}$ & Effect & $S E$ & $L L C I$ & $U L C I$ & \\
\hline civility on Physical Symptoms & 0.54 & 0.04 & 0.46 & 0.63 & \\
\hline & Coefficient & $S E$ & $t$ & $p$ & Model R ${ }^{2}$ \\
\hline
\end{tabular}

\section{Direct effects}

Stress as DV

Age

Gender

$\begin{array}{llll}-0.01 & 0.00 & -4.48 & 0.000\end{array}$

Tenure

Negative emotions

Incivility

Indirect effect ${ }^{a}$

Incivility on Stress

$\begin{array}{llll}-0.07 & 0.04 & -1.54 & 0.125\end{array}$

$\begin{array}{llll}0.00 & 0.00 & -2.86 & 0.005\end{array}$

$\begin{array}{llll}-0.04 & 0.04 & -0.99 & 0.325\end{array}$

$\begin{array}{llll}0.27 & 0.04 & 7.53 & 0.000\end{array}$

$.32 * * *$

Direct effects

Job Satisfaction as DV

Age

Gender

Tenure

Negative emotions

Incivility

Indirect effect ${ }^{a}$

\begin{tabular}{cccc} 
Effect & SE & LLCI & ULCI \\
\hline-0.02 & -0.03 & -0.07 & 0.03
\end{tabular}

Coefficient $S E \quad t$

$t \quad p$

p Model $\mathrm{R}^{2}$

Incivility on Job Satisfaction

$\begin{array}{rrrr}0.02 & 0.01 & 3.59 & 0.000 \\ 0.23 & 0.08 & 2.69 & 0.008 \\ 0.00 & 0.00 & -2.51 & 0.013 \\ -0.35 & 0.07 & -5.05 & 0.000 \\ 0.01 & 0.07 & 0.18 & 0.854\end{array}$

\begin{tabular}{cccc} 
Effect & SE & LLCI & ULCI \\
\hline-0.24 & 0.05 & -0.33 & -0.15
\end{tabular}

Note. $N=308 \mathrm{DV}=$ dependent variable. $\mathrm{SE}=$ standard error. $^{\mathrm{a}}=1,000$ bootstrap samples. $\mathrm{LLCI}=$ bias corrected lower limit confidence interval. ULCI $=$ bias corrected upper limit confidence interval. Effect size estimates are unstandardized coefficients. $*=p<.05, * *=p<.01, * * *=p<.001$ 
Table 9 continued: Mediated regression of Negative Emotions on the Relationship Conflict to Strain relationship

\begin{tabular}{|c|c|c|c|c|c|}
\hline & Coefficient & $S E$ & $t$ & $p$ & Model $\mathrm{R}^{2}$ \\
\hline \multicolumn{6}{|l|}{ Direct effects } \\
\hline \multicolumn{6}{|l|}{ Life Satisfaction as DV } \\
\hline Age & 0.03 & 0.01 & 5.07 & 0.000 & \\
\hline Gender & 0.16 & 0.08 & 1.97 & 0.050 & \\
\hline Tenure & 0.00 & 0.00 & -3.10 & 0.002 & \\
\hline Negative emotions & 0.06 & 0.07 & 0.91 & 0.366 & \\
\hline Incivility & 0.09 & 0.06 & 1.46 & 0.146 & $.12 * * *$ \\
\hline Indirect effect $^{a}$ & Effect & $S E$ & $L L C I$ & $U L C I$ & \\
\hline Incivility on Life Satisfaction & 0.04 & 0.05 & -0.06 & 0.13 & \\
\hline
\end{tabular}

Note. $N=308 \mathrm{DV}=$ dependent variable. $\mathrm{SE}=$ standard error. $^{\mathrm{a}}=1,000$ bootstrap samples. $\mathrm{LLCI}=$ bias corrected lower limit confidence interval. ULCI $=$ bias corrected upper limit confidence interval. Effect size estimates are unstandardized coefficients. $*=p<.05, * *=p<.01, * * *=p<.001$ 
Table 10: Mediated regression of Negative Emotions on the Relationship Conflict to Strain relationship

\begin{tabular}{|c|c|c|c|c|c|}
\hline Relationship Conflict & Coefficient & $S E$ & $t$ & $p$ & Model $\mathrm{R}^{2}$ \\
\hline \multicolumn{6}{|l|}{ Direct effects } \\
\hline \multicolumn{6}{|l|}{ Depression as DV } \\
\hline Age & 0.00 & 0.00 & 0.43 & 0.668 & \multirow{7}{*}{$.66^{* * *}$} \\
\hline Gender & -0.06 & 0.03 & -1.71 & 0.088 & \\
\hline Tenure & 0.00 & 0.00 & -0.07 & 0.941 & \\
\hline Negative emotions & 0.40 & 0.03 & 15.20 & 0.000 & \\
\hline Relationship Conflict & 0.13 & 0.03 & 4.26 & 0.000 & \\
\hline Indirect effect $^{\mathrm{a}}$ & Effect & $S E$ & $L L C I$ & $U L C I$ & \\
\hline $\begin{array}{l}\text { Relationship Conflict on } \\
\text { Depression }\end{array}$ & 0.29 & 0.03 & 0.23 & 0.36 & \\
\hline & Coefficient & $S E$ & $t$ & $p$ & Model $\mathrm{R}^{2}$ \\
\hline
\end{tabular}

\section{Direct effects}

Physical Symptoms as DV

$\begin{array}{lrrrrr}\text { Age } & 0.00 & 0.00 & -0.46 & 0.640 & \\ \text { Gender } & -0.12 & 0.06 & -1.98 & 0.050 & \\ \text { Tenure } & 0.00 & 0.00 & 1.99 & 0.050 & \\ \text { Negative emotions } & 0.86 & 0.05 & 18.63 & 0.000 & \\ \text { Relationship Conflict }_{\text {irect effect }^{\mathrm{a}}} & 0.26 & 0.05 & 4.95 & 0.000 & .74 * * * \\ \text { Reffect } & \text { SE } & \text { LLCI } & \text { ULCI } & \end{array}$

Relationship Conflict on Physical

\begin{tabular}{llllll} 
Symptoms & 0.63 & 0.05 & 0.53 & 0.73 & \\
\hline & Coefficient & SE & $t$ & $p$ & Model R $^{2}$ \\
\hline
\end{tabular}

\section{Direct effects}

Stress as DV

Age

Gender

$\begin{array}{llll}-0.01 & 0.00 & -3.60 & 0.000\end{array}$

Tenure

$\begin{array}{llll}-0.13 & 0.05 & -2.95 & 0.004\end{array}$

Negative emotions

$\begin{array}{llll}0.00 & 0.00 & -2.97 & 0.003\end{array}$

Relationship Conflict

$\begin{array}{llll}0.17 & 0.04 & 4.48 & 0.000\end{array}$

$\begin{array}{llll}-0.01 & 0.04 & -0.22 & 0.827\end{array}$

$.20 * * *$

Indirect effect ${ }^{\mathrm{a}}$ Effect

Relationship Conflict on Stress

$\begin{array}{llll}0.12 & 0.03 & 0.07 & 0.20\end{array}$

Note. $N=308 \mathrm{DV}=$ dependent variable. $\mathrm{SE}=$ standard error. $^{\mathrm{a}}=1,000$ bootstrap samples. $\mathrm{LLCI}=$ bias corrected lower limit confidence interval. ULCI $=$ bias corrected upper limit confidence interval. Effect size estimates are unstandardized coefficients. $*=p<.05, * *=p<.01, * * *=p<.001$ 
Table 10 continued: Mediated regression of Negative Emotions on the Relationship Conflict to Strain relationship

\begin{tabular}{|c|c|c|c|c|c|}
\hline & Coefficient & $S E$ & $t$ & $p$ & Model R ${ }^{2}$ \\
\hline \multicolumn{6}{|l|}{ Direct effects } \\
\hline \multicolumn{6}{|l|}{ Job Satisfaction as DV } \\
\hline Age & 0.02 & 0.01 & 3.48 & 0.000 & \multirow{7}{*}{$.20 * * *$} \\
\hline Gender & 0.22 & 0.08 & 2.71 & 0.007 & \\
\hline Tenure & 0.00 & 0.00 & -2.46 & 0.014 & \\
\hline Negative emotions & -0.38 & 0.06 & -5.82 & 0.000 & \\
\hline Relationship Conflict & 0.05 & 0.07 & 0.73 & 0.464 & \\
\hline Indirect effect ${ }^{\mathrm{a}}$ & Effect & $S E$ & $L L C I$ & ULCI & \\
\hline \multirow[t]{2}{*}{$\begin{array}{l}\text { Relationship Conflict c } \\
\text { Satisfaction }\end{array}$} & -0.27 & 0.05 & -0.38 & -0.18 & \\
\hline & Coefficient & $S E$ & $t$ & $p$ & Model $\mathrm{R}^{2}$ \\
\hline
\end{tabular}

Direct effects

Life Satisfaction as DV

$\begin{array}{lccccc}\text { Age } & 0.02 & 0.01 & 4.68 & 0.000 & \\ \text { Gender } & 0.13 & 0.08 & 1.71 & 0.088 & \\ \text { Tenure } & 0.00 & 0.00 & -2.95 & 0.003 & \\ \text { Negative emotions } & -0.03 & 0.06 & -0.47 & 0.637 & \\ \text { Relationship Conflict }^{\text {a }} & 0.28 & 0.07 & 4.08 & 0.000 & .16^{* * *} \\ \text { Effect } & \text { SE } & \text { LLCI } & \text { ULCI } & \end{array}$

Relationship Conflict on Life

Satisfaction

$\begin{array}{llll}-0.02 & 0.05 & -0.11 & 0.07\end{array}$

Note. $N=308 \mathrm{DV}=$ dependent variable. $\mathrm{SE}=$ standard error. $^{\mathrm{a}}=1,000$ bootstrap samples. $\mathrm{LLCI}=$ bias corrected lower limit confidence interval. ULCI $=$ bias corrected upper limit confidence interval. Effect size estimates are unstandardized coefficients. $*=p<.05, * *=p<.01, * * *=p<.001$ 
Table 11: Mediated regression of Negative Emotions on the Task Conflict to Strain relationship

\begin{tabular}{|c|c|c|c|c|c|}
\hline Task Conflict & Coefficient & $S E$ & $t$ & $p$ & Model $\mathrm{R}^{2}$ \\
\hline \multicolumn{6}{|l|}{ Direct effects } \\
\hline \multicolumn{6}{|l|}{ Depression as DV } \\
\hline Age & 0.00 & 0.00 & 0.93 & 0.354 & \multirow{7}{*}{$.66^{* * *}$} \\
\hline Gender & -0.05 & 0.03 & -1.62 & 0.106 & \\
\hline Tenure & 0.00 & 0.00 & -0.38 & 0.702 & \\
\hline Negative emotions & 0.40 & 0.03 & 15.18 & 0.000 & \\
\hline Task Conflict & 0.12 & 0.03 & 4.29 & 0.000 & \\
\hline Indirect effect ${ }^{\mathrm{a}}$ & Effect & $S E$ & $L L C I$ & $U L C I$ & \\
\hline \multirow[t]{2}{*}{ Task Conflict on Depression } & 0.28 & 0.03 & 0.22 & 0.34 & \\
\hline & Coefficient & $S E$ & $t$ & $p$ & Model $\mathrm{R}^{2}$ \\
\hline \multicolumn{6}{|l|}{ Direct effects } \\
\hline \multicolumn{6}{|l|}{ Physical Symptoms as DV } \\
\hline Age & 0.00 & 0.00 & 0.12 & 0.910 & \multirow{7}{*}{$.74 * * *$} \\
\hline Gender & -0.11 & 0.06 & -1.87 & 0.060 & \\
\hline Tenure & 0.00 & 0.00 & 1.63 & 0.100 & \\
\hline Negative emotions & 0.87 & 0.05 & 18.72 & 0.000 & \\
\hline Task Conflict & 0.24 & 0.05 & 4.65 & 0.000 & \\
\hline Indirect effect ${ }^{a}$ & Effect & $S E$ & $L L C I$ & $U L C I$ & \\
\hline \multirow[t]{2}{*}{$\begin{array}{l}\text { Task Conflict on Physical } \\
\text { Symptoms }\end{array}$} & 0.62 & 0.05 & 0.52 & 0.73 & \\
\hline & Coefficient & $S E$ & $t$ & $p$ & Model $\mathrm{R}^{2}$ \\
\hline \multicolumn{6}{|l|}{ Direct effects } \\
\hline \multicolumn{6}{|l|}{ Stress as DV } \\
\hline Age & -0.01 & 0.00 & -3.65 & 0.000 & \multirow{6}{*}{$.20 * * *$} \\
\hline Gender & -0.14 & 0.05 & -2.96 & 0.003 & \\
\hline Tenure & 0.00 & 0.00 & -2.97 & 0.003 & \\
\hline Negative emotions & 0.18 & 0.04 & 4.76 & 0.000 & \\
\hline Task Conflict & -0.03 & 0.04 & -0.65 & 0.518 & \\
\hline Indirect effect ${ }^{a}$ & Effect & $S E$ & $L L C I$ & $U L C I$ & \\
\hline Task Conflict on Stress & 0.13 & 0.03 & 0.07 & 0.18 & \\
\hline
\end{tabular}

Note. $N=308 \mathrm{DV}=$ dependent variable. $\mathrm{SE}=$ standard error. $^{\mathrm{a}}=1,000$ bootstrap samples. $\mathrm{LLCI}=$ bias corrected lower limit confidence interval. ULCI $=$ bias corrected upper limit confidence interval. Effect size estimates are unstandardized coefficients. $*=p<.05, * *=p<.01, * * *=p<.001$ 
Table 11 continued: Mediated regression of Negative Emotions on the Task Conflict to Strain relationship

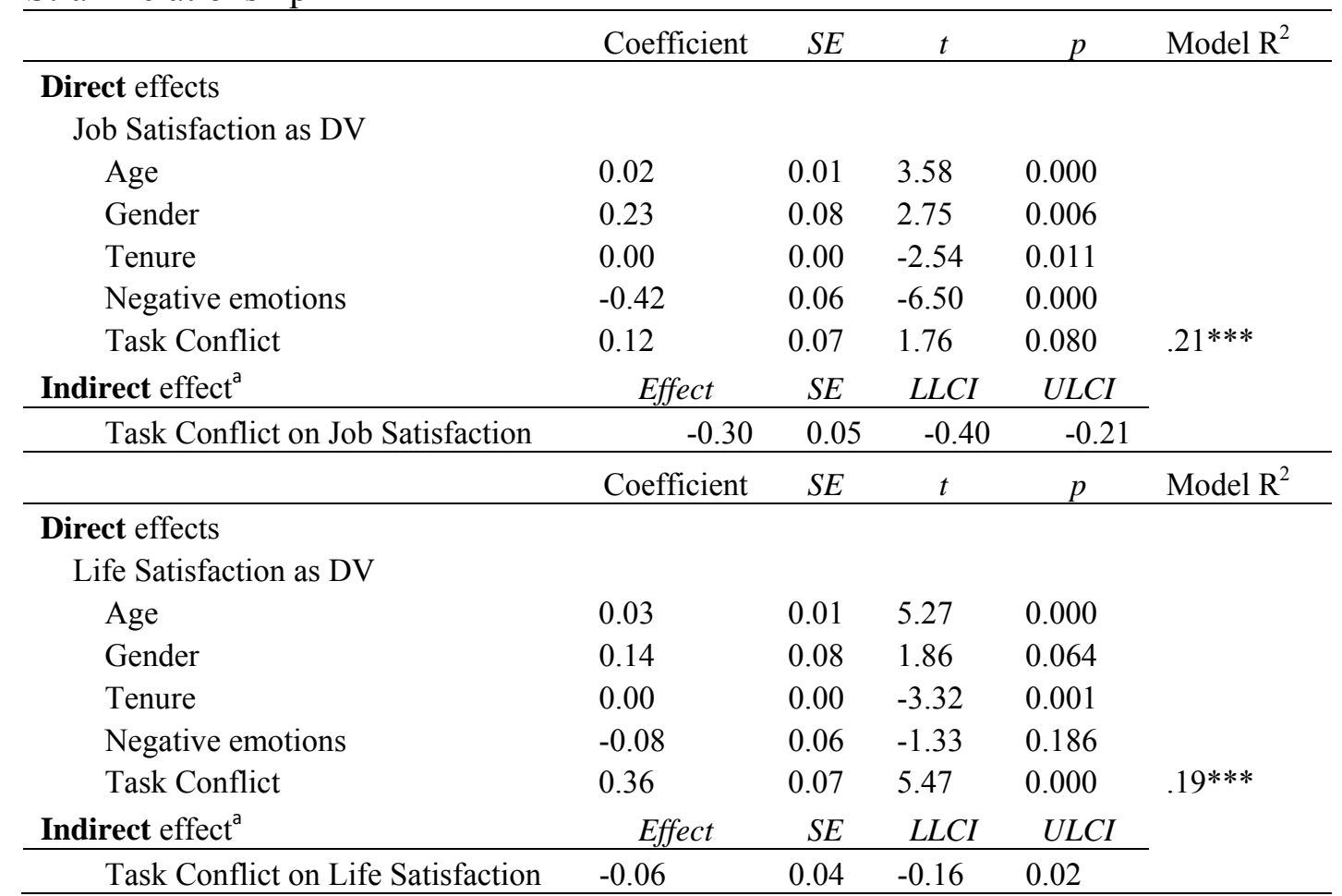

Note. $N=308 \mathrm{DV}=$ dependent variable. $\mathrm{SE}=$ standard error. $^{\mathrm{a}}=1,000$ bootstrap samples. $\mathrm{LLCI}=$ bias corrected lower limit confidence interval. ULCI $=$ bias corrected upper limit confidence interval. Effect size estimates are unstandardized coefficients. $*=p<.05, * *=p<.01$, $* * *=p<.001$ 
Table 12: Extraversions moderating effects on Negative Emotions

\begin{tabular}{|c|c|c|c|c|c|}
\hline Incivility & Coefficient & SE & $t$ & $p$ & Model $\mathrm{R}^{2}$ \\
\hline \multicolumn{6}{|l|}{ Direct effects } \\
\hline \multicolumn{6}{|l|}{ Negative Emotions as DV } \\
\hline Age & -0.01 & 0.00 & -1.43 & 0.154 & \\
\hline Gender & 0.13 & 0.07 & 1.96 & 0.051 & \\
\hline Tenure & 0.00 & 0.00 & 0.10 & 0.922 & \\
\hline Extraversion & -0.24 & 0.08 & -2.92 & 0.004 & \\
\hline Incivility & 0.67 & 0.04 & 16.70 & 0.000 & \\
\hline Incivility $*$ Extraversion & -0.15 & 0.09 & -1.76 & 0.079 & $.52 * * *$ \\
\hline Relationship Conflict & Coefficient & SE & $t$ & $p$ & Model R ${ }^{2}$ \\
\hline \multicolumn{6}{|l|}{ Direct effects } \\
\hline \multicolumn{6}{|l|}{ Negative Emotions as DV } \\
\hline Age & -0.01 & 0.00 & -1.97 & 0.049 & \\
\hline Gender & -0.03 & 0.07 & -0.41 & 0.683 & \\
\hline Tenure & 0.00 & 0.00 & 0.26 & 0.798 & \\
\hline Extraversion & -0.38 & 0.08 & -4.76 & 0.000 & \\
\hline Relationship Conflict & 0.72 & 0.05 & 14.61 & 0.000 & \\
\hline Relationship Conflict $*$ & & & & & \\
\hline Extraversion & -0.13 & 0.11 & -1.16 & 0.249 & $.46^{* * *}$ \\
\hline Task Conflict & Coefficient & $S E$ & $t$ & $p$ & Model R ${ }^{2}$ \\
\hline \multicolumn{6}{|l|}{ Direct effects } \\
\hline \multicolumn{6}{|l|}{ Negative Emotions as DV } \\
\hline Age & 0.00 & 0.00 & -0.46 & 0.643 & \\
\hline Gender & 0.00 & 0.07 & 0.02 & 0.987 & \\
\hline Tenure & 0.00 & 0.00 & -0.61 & 0.545 & \\
\hline Extraversion & -0.45 & 0.08 & -5.86 & 0.000 & \\
\hline Task Conflict & 0.71 & 0.05 & 15.43 & 0.000 & \\
\hline Task Conflict $*$ Extraversion & 0.04 & 0.10 & -0.40 & 0.690 & $.49 * * *$ \\
\hline
\end{tabular}

Note. $N=308 \mathrm{DV}=$ dependent variable. $\mathrm{SE}=$ standard error. Conditional effect sizes are $+/-1 \mathrm{SD}$. Effect size estimates are unstandardized coefficients. $*=p<.05, * *=p<.01, * * *=p<.001$ 
Table 13: The moderating role of Extraversion on the Incivility to strain relationship

\begin{tabular}{|c|c|c|c|c|c|}
\hline Incivility & Coefficient & $S E$ & $t$ & $p$ & Model R ${ }^{2}$ \\
\hline \multicolumn{6}{|l|}{ Direct effects } \\
\hline \multicolumn{6}{|l|}{ Depression as DV } \\
\hline Age & 0.00 & 0.00 & -0.49 & 0.626 & \\
\hline Gender & 0.04 & 0.04 & 1.12 & 0.263 & \\
\hline Tenure & 0.00 & 0.00 & 0.03 & 0.978 & \\
\hline Extraversion & -0.08 & 0.05 & -1.60 & 0.111 & \\
\hline Incivility & 0.43 & 0.02 & 19.60 & 0.000 & \\
\hline Incivility * Extraversion & -0.10 & 0.05 & -2.10 & 0.037 & $.59 * * *$ \\
\hline \multicolumn{6}{|l|}{ Physical Symptoms as DV } \\
\hline Age & -0.01 & 0.01 & -1.30 & 0.193 & \\
\hline Gender & 0.07 & 0.08 & 0.90 & 0.367 & \\
\hline Tenure & 0.00 & 0.00 & 1.39 & 0.167 & \\
\hline Extraversion & -0.26 & 0.10 & -2.75 & 0.006 & \\
\hline Incivility & 0.85 & 0.05 & 18.30 & 0.000 & \\
\hline Incivility * Extraversion & -0.38 & 0.10 & -3.83 & 0.000 & $.56^{* * *}$ \\
\hline \multicolumn{6}{|l|}{ Stress as DV } \\
\hline Age & -0.01 & 0.00 & -3.78 & 0.000 & \\
\hline Gender & -0.05 & 0.04 & -1.11 & 0.270 & \\
\hline Tenure & 0.00 & 0.00 & -3.36 & 0.001 & \\
\hline Extraversion & -0.24 & 0.05 & -4.57 & 0.000 & \\
\hline Incivility & 0.22 & 0.03 & 8.57 & 0.000 & \\
\hline Incivility $*$ Extraversion & -0.04 & 0.05 & -0.68 & 0.496 & $.37 * * *$ \\
\hline \multicolumn{6}{|l|}{ Job Satisfaction as DV } \\
\hline Age & 0.02 & 0.01 & 0.01 & 0.001 & \\
\hline Gender & 0.12 & 0.08 & 0.08 & 0.155 & \\
\hline Tenure & 0.00 & 0.00 & 0.00 & 0.041 & \\
\hline Extraversion & 0.72 & 0.10 & 7.3 & 0.000 & \\
\hline Incivility & -0.70 & 0.50 & -3.62 & 0.000 & \\
\hline Incivility * Extraversion & 0.28 & 10.00 & 2.87 & 0.006 & $.27 * * *$ \\
\hline
\end{tabular}

Note. $N=308 \mathrm{DV}=$ dependent variable. $\mathrm{SE}=$ standard error. 1,000 bootstrap samples. $\mathrm{LLCI}=$ bias corrected lower limit confidence interval. ULCI $=$ bias corrected upper limit confidence interval.

Conditional effect sizes are $+/-1 \mathrm{SD}$. Effect size estimates are unstandardized coefficients. $*=p<.05, * *$ $=p<.01, * * *=p<.001$ 
Table 13 continued: The moderating role of Extraversion on the Incivility to strain relationship

$\begin{array}{lllll}\text { Coefficient } & S E & t & p & \text { Model R }^{2}\end{array}$

Direct effects

Life Satisfaction as DV

Age

$\begin{array}{llll}0.02 & 0.00 & 4.38 & 0.000\end{array}$

Gender

$\begin{array}{llll}0.12 & 0.08 & 1.59 & 0.113\end{array}$

Tenure

$\begin{array}{llll}0.00 & 0.00 & -2.86 & 0.005\end{array}$

Extraversion

$\begin{array}{llll}0.38 & 0.09 & 4.00 & 0.000\end{array}$

Incivility

$\begin{array}{llll}0.19 & 0.05 & 4.12 & 0.000\end{array}$

Incivility * Extraversion

$\begin{array}{llll}-0.02 & 0.10 & -1.59 & 0.861\end{array}$

Note. $N=308 \mathrm{DV}=$ dependent variable. $\mathrm{SE}=$ standard error. 1,000 bootstrap samples. LLCI $=$ bias corrected lower limit confidence interval. ULCI = bias corrected upper limit confidence interval.

Conditional effect sizes are $+/-1$ SD. Effect size estimates are unstandardized coefficients. $*=p<.05, * *$

$=p<.01, * * *=p<.001$ 
Table 14: The moderating role of Extraversion on the Relationship Conflict to strain relationship

\begin{tabular}{|c|c|c|c|c|c|}
\hline Relationship Conflict & Coefficient & $S E$ & $t$ & $p$ & Model $\mathrm{R}^{2}$ \\
\hline \multicolumn{6}{|l|}{ Direct effects } \\
\hline \multicolumn{6}{|l|}{ Depression as DV } \\
\hline Age & 0.00 & 0.00 & -1.08 & 0.280 & \\
\hline Gender & -0.06 & 0.04 & -1.38 & 0.168 & \\
\hline Tenure & 0.00 & 0.00 & -0.03 & 0.979 & \\
\hline Extraversion & -0.21 & 0.05 & -4.29 & 0.000 & \\
\hline Relationship Conflict & 0.43 & 0.03 & 14.28 & 0.000 & \\
\hline Relationship Conflict* & & & & & \\
\hline Extraversion & -0.22 & 0.07 & -3.30 & 0.001 & $.44 * * *$ \\
\hline \multicolumn{6}{|l|}{ Physical Symptoms as DV } \\
\hline Age & -0.01 & 0.01 & -1.20 & 0.055 & \\
\hline Gender & -0.13 & 0.08 & -1.50 & 0.133 & \\
\hline Tenure & 0.00 & 0.00 & 1.46 & 0.144 & \\
\hline Extraversion & -0.42 & 0.09 & -4.49 & 0.000 & \\
\hline Relationship Conflict & 0.91 & 0.06 & 15.65 & 0.000 & \\
\hline Relationship Conflict * & & & & & \\
\hline Extraversion & -0.45 & 0.13 & -3.46 & 0.000 & $.48 * * *$ \\
\hline \multicolumn{6}{|l|}{ Stress as DV } \\
\hline Age & -0.01 & 0.00 & -3.57 & 0.000 & \\
\hline Gender & -0.10 & 0.05 & -2.19 & 0.029 & \\
\hline Tenure & 0.00 & 0.00 & -3.43 & 0.000 & \\
\hline Extraversion & -0.34 & 0.05 & -6.74 & 0.000 & \\
\hline Relationship Conflict & 0.11 & 0.03 & 3.40 & 0.000 & \\
\hline Relationship Conflict * & & & & & \\
\hline Extraversion & -0.17 & 0.07 & -2.41 & 0.017 & $.26 * * *$ \\
\hline \multicolumn{6}{|l|}{ Job Satisfaction as DV } \\
\hline Age & 0.02 & 0.01 & 3.21 & 0.002 & \\
\hline Gender & 0.17 & 0.08 & 2.13 & 0.034 & \\
\hline Tenure & 0.00 & 0.00 & -2.36 & 0.019 & \\
\hline Extraversion & 0.56 & 0.09 & 6.27 & 0.000 & \\
\hline Relationship Conflict & -0.16 & 0.06 & -2.92 & 0.004 & \\
\hline Relationship Conflict* & & & & & \\
\hline Extraversion & -0.21 & 0.13 & -1.66 & 0.100 & $.26^{* * *}$ \\
\hline
\end{tabular}


Table 14 continued: The moderating role of Extraversion on the Relationship Conflict to strain relationship

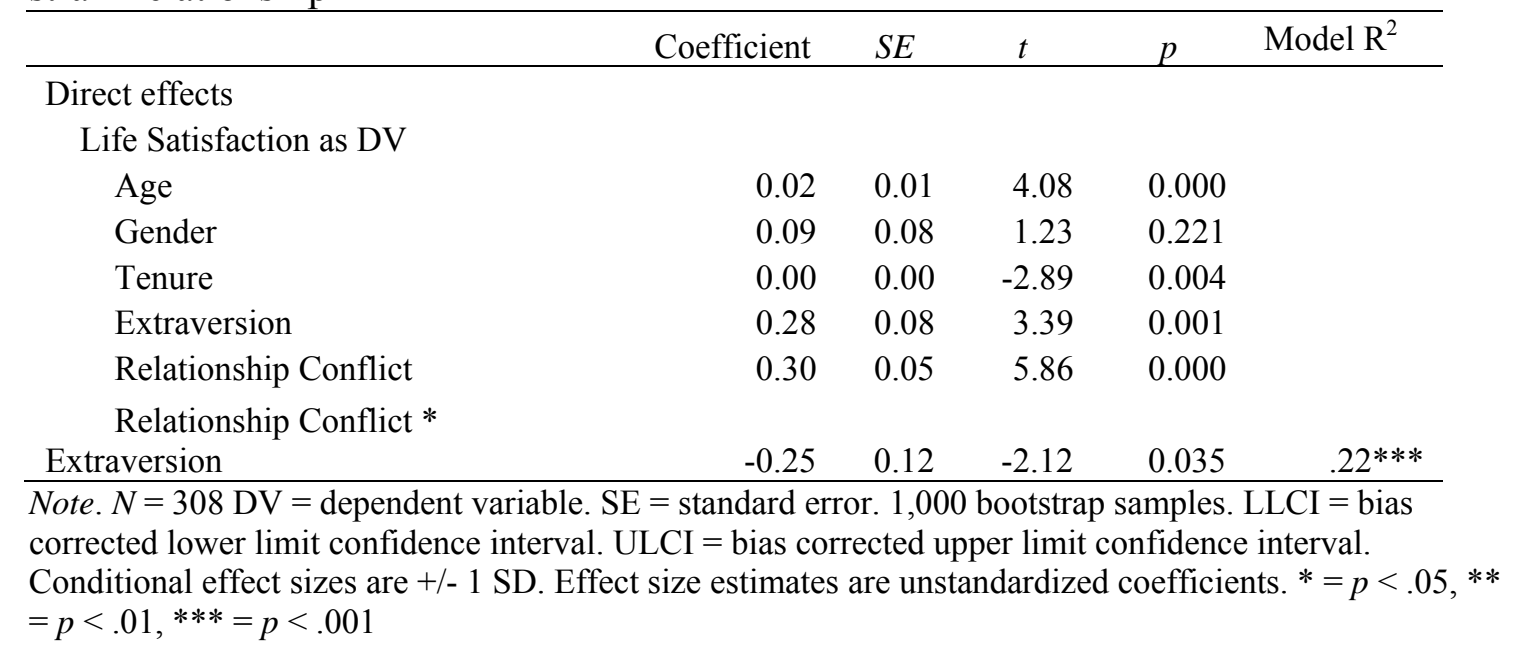


Table 15: The moderating role of Extraversion on the Task Conflict to strain relationship

\begin{tabular}{|c|c|c|c|c|c|}
\hline Task Conflict & Coefficient & $S E$ & $t$ & $p$ & Model $\mathrm{R}^{2}$ \\
\hline \multicolumn{6}{|l|}{ Direct effects } \\
\hline \multicolumn{6}{|l|}{ Depression as DV } \\
\hline Age & 0.00 & 0.02 & 0.16 & 0.872 & \\
\hline Gender & -0.04 & 0.04 & -0.80 & 0.376 & \\
\hline Tenure & 0.00 & 0.00 & -0.94 & 0.346 & \\
\hline Extraversion & -0.25 & 0.05 & -5.38 & 0.000 & \\
\hline Task Conflict & 0.41 & 0.03 & 14.69 & 0.000 & \\
\hline Task Conflict * Extraversion & -0.20 & 0.06 & -3.18 & 0.002 & $.46^{* * *}$ \\
\hline \multicolumn{6}{|l|}{ Physical Symptoms as DV } \\
\hline Age & 0.00 & 0.01 & -0.57 & 0.568 & \\
\hline Gender & -0.08 & 0.08 & -0.96 & 0.337 & \\
\hline Tenure & 0.00 & 0.00 & 0.47 & 0.636 & \\
\hline Extraversion & -0.51 & 0.09 & -5.69 & 0.000 & \\
\hline Task Conflict & 0.87 & 0.05 & 15.85 & 0.000 & \\
\hline Task Conflict * Extraversion & -0.42 & 0.12 & -3.40 & 0.001 & $.49 * * *$ \\
\hline \multicolumn{6}{|l|}{ Stress as DV } \\
\hline Age & -0.01 & 0.00 & -3.29 & 0.001 & \\
\hline Gender & -0.10 & 0.05 & -2.08 & 0.038 & \\
\hline Tenure & 0.00 & 0.00 & -3.4 & 0.000 & \\
\hline Extraversion & -0.34 & 0.05 & -6.73 & 0.000 & \\
\hline Task Conflict & 0.10 & 0.03 & 3.32 & 0.001 & \\
\hline Task Conflict * Extraversion & -0.11 & 0.07 & -1.62 & 0.105 & $.25 * * *$ \\
\hline \multicolumn{6}{|l|}{ Job Satisfaction } \\
\hline Age & 0.02 & 0.01 & 2.85 & 0.005 & \\
\hline Gender & 0.16 & 0.08 & 1.99 & 0.047 & \\
\hline Tenure & 0.00 & 0.00 & -2.14 & 0.034 & \\
\hline Extraversion & 0.61 & 0.09 & 7.03 & 0.000 & \\
\hline Task Conflict & -0.16 & 0.05 & -3.09 & 0.002 & \\
\hline Task Conflict * Extraversion & -0.10 & 0.12 & -0.84 & 0.399 & $.25 * * *$ \\
\hline
\end{tabular}

Note. $N=308 \mathrm{DV}=$ dependent variable. $\mathrm{SE}=$ standard error. 1,000 bootstrap samples. $\mathrm{LLCI}=$ bias corrected lower limit confidence interval. ULCI $=$ bias corrected upper limit confidence interval.

Conditional effect sizes are $+/-1$ SD. Effect size estimates are unstandardized coefficients. $*=p<.05, * *$ $=p<.01, * * *=p<.001$ 
Table 15 continued: The moderating role of Extraversion on the Task Conflict to strain relationship

$\begin{array}{lllll}\text { Coefficient } & S E & t & p & \text { Model } \mathrm{R}^{2}\end{array}$

Direct effects

Life Satisfaction as DV

$\begin{array}{lrrrr}\text { Age } & 0.02 & 0.01 & 4.64 & 0.000 \\ \text { Gender } & 0.11 & 0.07 & 1.43 & 0.154 \\ \text { Tenure } & 0.00 & 0.00 & -3.25 & 0.001 \\ \text { Extraversion } & 0.24 & 0.08 & 3.40 & 0.001 \\ \text { Task Conflict } & 0.31 & 0.05 & 6.34 & 0.000 \\ \text { Task Conflict * Extraversion } & -0.16 & 0.11 & -1.44 & 0.150\end{array}$

$.24 * * *$

Note. $N=308 \mathrm{DV}=$ dependent variable. $\mathrm{SE}=$ standard error. 1,000 bootstrap samples. $\mathrm{LLCI}=$ bias corrected lower limit confidence interval. ULCI = bias corrected upper limit confidence interval.

Conditional effect sizes are $+/-1 \mathrm{SD}$. Effect size estimates are unstandardized coefficients. $*=p<.05, * *$ $=p<.01,{ }^{* * *}=p<.001$ 
Table 16: Neuroticism moderating effects on Negative Emotions

\begin{tabular}{lrrrrr}
\hline Incivility & Coefficient & \multicolumn{1}{l}{$S E$} & \multicolumn{1}{c}{$t$} & $p$ & Model R $^{2}$ \\
\hline Direct effects & & & & & \\
$\quad$ Negative Emotions as DV & & & & & \\
$\quad$ Age & -0.01 & 0.00 & -1.16 & 0.249 & \\
Gender & 0.08 & 0.06 & 1.23 & 0.219 & \\
Tenure & 0.00 & 0.00 & 0.77 & 0.441 & \\
Neuroticism & 0.45 & 0.07 & 6.44 & 0.000 & \\
Incivility & 0.54 & 0.04 & 12.49 & 0.000 & \\
Incivility * Neuroticism & 0.29 & 0.06 & 4.84 & 0.000 & $.58^{* * *}$
\end{tabular}

\begin{tabular}{|c|c|c|c|c|c|}
\hline Relationship Conflict & Coefficient & $S E$ & $t$ & $p$ & Model R ${ }^{2}$ \\
\hline \multicolumn{6}{|l|}{ Direct effects } \\
\hline \multicolumn{6}{|l|}{ Negative Emotions as DV } \\
\hline Age & 0.00 & 0.00 & -0.89 & 0.375 & \\
\hline Gender & -0.04 & 0.07 & -0.67 & 0.503 & \\
\hline Tenure & 0.00 & 0.00 & 1.30 & 0.195 & \\
\hline Neuroticism & 0.53 & 0.06 & 8.60 & 0.000 & \\
\hline $\begin{array}{l}\text { Relationship Conflict } \\
\text { Relationship Conflict * }\end{array}$ & 0.55 & 0.05 & 11.34 & 0.000 & \\
\hline Neuroticism & 0.33 & 0.07 & 4.36 & 0.000 & $.55^{* * *}$ \\
\hline Task Conflict & Coefficient & $S E$ & $t$ & $p$ & Model $\mathrm{R}^{2}$ \\
\hline \multicolumn{6}{|l|}{ Direct effects } \\
\hline \multicolumn{6}{|l|}{ Negative Emotions as DV } \\
\hline Age & 0.00 & 0.00 & 0.05 & 0.961 & \\
\hline Gender & -0.03 & 0.07 & -0.45 & 0.651 & \\
\hline Tenure & 0.00 & 0.00 & 0.55 & 0.581 & \\
\hline Neuroticism & 0.52 & 0.05 & 8.62 & 0.000 & \\
\hline Task Conflict & 0.56 & 0.05 & 12.00 & 0.000 & \\
\hline Task Conflict $*$ Neuroticism & 0.26 & 0.07 & 3.57 & 0.000 & $.54 * * *$ \\
\hline
\end{tabular}

Note. $N=308 \mathrm{DV}=$ dependent variable. $\mathrm{SE}=$ standard error. Conditional effect sizes are $+/-1 \mathrm{SD}$. Effect size estimates are unstandardized coefficients. $*=p<.05, * *=p<.01, * * *=p<.001$ 
Table 17: The moderating role of Neuroticism on the Incivility to strain relationship

\begin{tabular}{|c|c|c|c|c|c|}
\hline Incivility & Coefficient & $S E$ & $t$ & $p$ & Model $\mathrm{R}^{2}$ \\
\hline \multicolumn{6}{|l|}{ Direct effects } \\
\hline \multicolumn{6}{|l|}{ Depression as DV } \\
\hline Age & 0.00 & 0.00 & 0.46 & 0.645 & \\
\hline Gender & 0.02 & 0.03 & 0.47 & 0.637 & \\
\hline Tenure & 0.00 & 0.00 & 0.66 & 0.511 & \\
\hline Neuroticism & 0.30 & 0.04 & 8.38 & 0.000 & \\
\hline Incivility & 0.33 & 0.02 & 14.55 & 0.000 & \\
\hline Incivility $*$ Neuroticism & 0.18 & 0.03 & 5.56 & 0.000 & $.66^{* * *}$ \\
\hline \multicolumn{6}{|l|}{ Physical Symptoms as DV } \\
\hline Age & -0.01 & 0.01 & -1.10 & 0.271 & \\
\hline Gender & 0.00 & 0.07 & 0.01 & 0.989 & \\
\hline Tenure & 0.00 & 0.00 & 2.45 & 0.015 & \\
\hline Neuroticism & 0.60 & 0.08 & 7.80 & 0.000 & \\
\hline Incivility & 0.64 & 0.05 & 13.37 & 0.000 & \\
\hline Incivility $*$ Neuroticism & 0.49 & 0.07 & 7.39 & 0.000 & $.63 * * *$ \\
\hline \multicolumn{6}{|l|}{ Stress as DV } \\
\hline Age & 0.00 & 0.00 & -1.13 & 0.259 & \\
\hline Gender & -0.07 & 0.04 & -1.82 & 0.070 & \\
\hline Tenure & 0.00 & 0.00 & -3.94 & 0.000 & \\
\hline Neuroticism & 0.26 & 0.04 & 6.62 & 0.000 & \\
\hline Incivility & 0.14 & 0.02 & 5.74 & 0.000 & \\
\hline Incivility $*$ Neuroticism & -0.21 & 0.03 & -6.08 & 0.000 & $.54 * * *$ \\
\hline \multicolumn{6}{|l|}{ Job Satisfaction as DV } \\
\hline Age & 0.02 & 0.01 & 2.57 & 0.011 & \\
\hline Gender & 0.18 & 0.90 & 2.15 & 0.033 & \\
\hline Tenure & 0.00 & 0.00 & -2.43 & 0.016 & \\
\hline Neuroticism & -0.20 & 0.09 & -2.22 & 0.027 & \\
\hline Incivility & -0.15 & 0.06 & -2.62 & 0.010 & \\
\hline Incivility $*$ Neuroticism & 0.15 & 0.08 & 1.84 & 0.067 & $.18^{* * *}$ \\
\hline
\end{tabular}

Note. $N=308 \mathrm{DV}=$ dependent variable. $\mathrm{SE}=$ standard error. 1,000 bootstrap samples. $\mathrm{LLCI}=$ bias corrected lower limit confidence interval. ULCI $=$ bias corrected upper limit confidence interval.

Conditional effect sizes are $+/-1 \mathrm{SD}$. Effect size estimates are unstandardized coefficients. $*=p<.05, * *$ $=p<.01, * * *=p<.001$ 
Table 17 continued: The moderating role of Neuroticism on the Incivility to strain relationship

\begin{tabular}{lccccc}
\hline & Coefficient & $S E$ & $t$ & $p$ & Model R $^{2}$ \\
\hline Direct effects & & & & & \\
$\quad$ Life Satisfaction as DV & & & & & \\
Age & 0.02 & 0.01 & 3.28 & 0.001 & \\
Gender & 0.14 & 0.08 & 1.82 & 0.069 & \\
Tenure & 0.00 & 0.00 & -2.82 & 0.005 & \\
Neuroticism & 0.01 & 0.08 & 0.16 & 0.872 & \\
Incivility & 0.15 & 0.05 & 2.98 & 0.003 & \\
Incivility * Neuroticism & 0.43 & 0.07 & 6.16 & 0.000 & $.23^{* * *}$ \\
\hline
\end{tabular}

Note. $N=308 \mathrm{DV}=$ dependent variable. $\mathrm{SE}=$ standard error. 1,000 bootstrap samples. $\mathrm{LLCI}=$ bias corrected lower limit confidence interval. ULCI = bias corrected upper limit confidence interval.

Conditional effect sizes are $+/-1 \mathrm{SD}$. Effect size estimates are unstandardized coefficients. $*=p<.05, * *$

$=p<.01, * * *=p<.001$ 
Table 18: The moderating role of Neuroticism on the Relationship Conflict to strain relationship

\begin{tabular}{|c|c|c|c|c|c|}
\hline Relationship Conflict & Coefficient & $S E$ & $t$ & $p$ & Model $\mathrm{R}^{2}$ \\
\hline \multicolumn{6}{|l|}{ Direct effects } \\
\hline \multicolumn{6}{|l|}{ Depression as DV } \\
\hline Age & 0.00 & 0.00 & 0.89 & 0.377 & \\
\hline Gender & -0.06 & 0.04 & -1.63 & 0.105 & \\
\hline Tenure & 0.00 & 0.00 & 0.15 & 0.249 & \\
\hline Neuroticism & 0.38 & 0.03 & 11.00 & 0.000 & \\
\hline Relationship Conflict & 0.29 & 0.03 & 10.41 & 0.000 & \\
\hline Relationship Conflict * & & & & & \\
\hline Neuroticism & 0.22 & 0.04 & 5.17 & 0.000 & $.58 * * *$ \\
\hline \multicolumn{6}{|l|}{ Physical Symptoms as DV } \\
\hline Age & 0.00 & 0.01 & -0.59 & 0.554 & \\
\hline Gender & -0.14 & 0.07 & -1.83 & 0.068 & \\
\hline Tenure & 0.00 & 0.00 & 2.94 & 0.004 & \\
\hline Neuroticism & 0.66 & 0.07 & 0.43 & 0.000 & \\
\hline $\begin{array}{l}\text { Relationship Conflict } \\
\text { Relationship Conflict* }\end{array}$ & 0.66 & 0.06 & 11.85 & 0.000 & \\
\hline Neuroticism & 0.51 & 0.09 & 5.98 & 0.000 & $.59 * * *$ \\
\hline \multicolumn{6}{|l|}{ Stress as DV } \\
\hline Age & 0.00 & 0.00 & -0.95 & 0.345 & \\
\hline Gender & -0.12 & 0.04 & -3.09 & 0.002 & \\
\hline Tenure & 0.00 & 0.00 & -3.83 & 0.000 & \\
\hline Neuroticism & 0.44 & 0.04 & 12.03 & 0.000 & \\
\hline Relationship Conflict & -0.01 & 0.03 & -0.33 & 0.745 & \\
\hline $\begin{array}{l}\text { Relationship Conflict * } \\
\text { Neuroticism }\end{array}$ & -0.12 & 0.04 & -2.73 & 0.007 & $.46^{* * *}$ \\
\hline \multicolumn{6}{|l|}{ Job Satisfaction as DV } \\
\hline Age & 0.02 & 0.01 & 2.65 & 0.009 & \\
\hline Gender & 0.24 & 0.08 & 2.82 & 0.005 & \\
\hline Tenure & 0.00 & 0.00 & -2.21 & 0.028 & \\
\hline Neuroticism & -0.27 & 0.08 & -3.48 & 0.000 & \\
\hline $\begin{array}{l}\text { Relationship Conflict } \\
\text { Relationship Conflict } *\end{array}$ & -0.16 & 0.06 & -2.49 & 0.013 & \\
\hline Neuroticism & 0.24 & 0.10 & 2.47 & 0.014 & $.18^{* * *}$ \\
\hline
\end{tabular}


Table 18 continued: The moderating role of Neuroticism on the Relationship Conflict to strain relationship

\begin{tabular}{lrrrrr}
\hline & Coefficient & $S E$ & $t$ & $p$ & Model R $^{2}$ \\
\hline Direct effects & & & & & \\
$\quad$ Life Satisfaction as DV & & & & & \\
$\quad$ Age & 0.02 & 0.01 & 3.56 & 0.000 & \\
$\quad$ Gender & 0.13 & 0.07 & 0.70 & 0.090 & \\
$\quad$ Tenure & 0.00 & 0.00 & -2.43 & 0.016 & \\
$\quad$ Neuroticism & -0.12 & 0.07 & -1.76 & 0.079 & \\
$\quad$ Relationship Conflict & 0.27 & 0.06 & 4.91 & 0.000 & \\
$\quad$ Relationship Conflict & & & & & \\
Neuroticism & 0.33 & 0.08 & 3.91 & 0.000 & $.22 * * *$ \\
\hline Note. $N=308$ DV $=$ dependent variable. SE $=$ standard error. 1,000 bootstrap samples. LLCI $=$ bias \\
corrected lower limit confidence interval. ULCI = bias corrected upper limit confidence interval. \\
Conditional effect sizes are $+/-$ 1 SD. Effect size estimates are unstandardized coefficients. * $=p<.05, * *$ \\
$=p<.01, * * *=p<.001$
\end{tabular}


Table 19: The moderating role of Neuroticism on the Task Conflict to strain relationship

\begin{tabular}{|c|c|c|c|c|c|}
\hline Task Conflict & Coefficient & $S E$ & $t$ & $p$ & Model $\mathrm{R}^{2}$ \\
\hline \multicolumn{6}{|l|}{ Direct effects } \\
\hline \multicolumn{6}{|l|}{ Depression as DV } \\
\hline Age & 0.00 & 0.00 & 1.48 & 0.139 & \\
\hline Gender & -0.05 & 0.04 & -1.42 & 0.156 & \\
\hline Tenure & 0.00 & 0.00 & 0.68 & 0.498 & \\
\hline Neuroticism & 0.38 & 0.03 & 11.29 & 0.000 & \\
\hline Task Conflict & 0.29 & 0.03 & 11.25 & 0.000 & \\
\hline Task Conflict $*$ Neuroticism & 0.23 & 0.04 & 5.55 & 0.000 & $.59 * * *$ \\
\hline \multicolumn{6}{|l|}{ Physical Symptoms as DV } \\
\hline Age & 0.00 & 0.01 & 0.12 & 0.906 & \\
\hline Gender & -0.12 & 0.07 & -1.60 & 0.112 & \\
\hline Tenure & 0.00 & 0.00 & 2.35 & 0.019 & \\
\hline Neuroticism & 0.65 & 0.07 & 9.57 & 0.000 & \\
\hline Task Conflict & 0.65 & 0.05 & 12.39 & 0.000 & \\
\hline Task Conflict $*$ Neuroticism & 0.51 & 0.08 & 6.11 & 0.000 & $.59 * * *$ \\
\hline \multicolumn{6}{|l|}{ Stress as DV } \\
\hline Age & 0.00 & 0.00 & -0.77 & 0.443 & \\
\hline Gender & -0.12 & 0.04 & -3.11 & 0.002 & \\
\hline Tenure & 0.00 & 0.00 & -3.85 & 0.000 & \\
\hline Neuroticism & 0.45 & 0.04 & 12.53 & 0.000 & \\
\hline Task Conflict & -0.02 & 0.03 & -0.59 & 0.558 & \\
\hline Task Conflict $*$ Neuroticism & -0.12 & 0.04 & -2.72 & 0.007 & $.46^{* * *}$ \\
\hline \multicolumn{6}{|l|}{ Job Satisfaction as DV } \\
\hline Age & 0.01 & 0.01 & 2.23 & 0.026 & \\
\hline Gender & 0.23 & 0.08 & 2.77 & 0.006 & \\
\hline Tenure & 0.00 & 0.00 & -2.08 & 0.039 & \\
\hline Neuroticism & -0.32 & 0.08 & -4.08 & 0.000 & \\
\hline Task Conflict & -0.10 & 0.06 & -1.6 & 0.111 & \\
\hline Task Conflict * Neuroticism & 0.19 & 0.10 & 2.00 & 0.046 & $.17 * * *$ \\
\hline
\end{tabular}

Note. $N=308 \mathrm{DV}=$ dependent variable. $\mathrm{SE}=$ standard error. 1,000 bootstrap samples. $\mathrm{LLCI}=$ bias corrected lower limit confidence interval. ULCI = bias corrected upper limit confidence interval. Conditional effect sizes are $+/-1$ SD. Effect size estimates are unstandardized coefficients. $*=p<.05, * *$ $=p<.01, * * *=p<.001$ 
Table 19 continued: The moderating role of Neuroticism on the Task Conflict to strain relationship

\begin{tabular}{lllll} 
Coefficient & $S E$ & $t$ & $p$ & Model R $^{2}$ \\
\hline
\end{tabular}

Direct effects

Life Satisfaction as DV

$\begin{array}{lrrrr}\text { Age } & 0.02 & 0.01 & 4.02 & 0.000 \\ \text { Gender } & 0.13 & 0.07 & 1.81 & 0.071 \\ \text { Tenure } & 0.00 & 0.00 & -2.97 & 0.003 \\ \text { Neuroticism } & -0.18 & 0.07 & -2.58 & 0.010 \\ \text { Task Conflict } & 0.34 & 0.05 & 6.45 & 0.000 \\ \text { Task Conflict* Neuroticism } & 0.19 & 0.08 & 2.22 & 0.027\end{array}$

Note. $N=308 \mathrm{DV}=$ dependent variable. $\mathrm{SE}=$ standard error. 1,000 bootstrap samples. LLCI = bias corrected lower limit confidence interval. ULCI $=$ bias corrected upper limit confidence interval.

Conditional effect sizes are $+/-1 \mathrm{SD}$. Effect size estimates are unstandardized coefficients. $*=p<.05, * *$ $=p<.01,{ }^{* * *}=p<.001$ 
Table 20: Agreeableness moderating role on Negative Emotions

\begin{tabular}{lrrrrr}
\hline Incivility & Coefficient & $S E$ & $t$ & $p$ & Model R $^{2}$ \\
\hline Direct effects & & & & & \\
$\quad$ Negative Emotions as DV & & & & & \\
$\quad$ Age & -0.01 & 0.00 & -2.85 & 0.005 & \\
Gender & 0.04 & 0.07 & 0.57 & 0.568 & \\
Tenure & 0.00 & 0.00 & 1.49 & 0.138 & \\
Agreeableness & -0.18 & 0.08 & -2.19 & 0.000 & \\
Incivility & 0.66 & 0.05 & 14.06 & 0.029 & \\
$\quad$ Incivility * Agreeableness & -0.49 & 0.07 & -7.05 & 0.000 & $.58^{* * *}$ \\
Relationship Conflict & Coefficient & $S E$ & $t$ & $p$ & Model R $^{2}$ \\
\hline
\end{tabular}

Direct effects

Negative Emotions as DV

$\begin{array}{lrrrrr}\text { Age } & -0.01 & 0.00 & -2.73 & 0.007 & \\ \text { Gender } & -0.01 & 0.07 & -0.15 & 0.878 & \\ \text { Tenure } & 0.00 & 0.00 & 1.67 & 0.096 & \\ \text { Agreeableness } & -0.43 & 0.07 & -5.85 & 0.000 & \\ \quad \text { Relationship Conflict } & 0.59 & 0.05 & 11.63 & 0.000 & \\ \quad \text { Relationship Conflict * } & & & & & \\ \text { Agreeableness } & -0.40 & 0.08 & -5.35 & 0.000 & .51^{* * *}\end{array}$

\begin{tabular}{lllllll} 
Task Conflict & Coefficient & $S E$ & $t$ & $p$ & Model $^{2}$ \\
\hline
\end{tabular}

Direct effects

Negative Emotions as DV

$\begin{array}{lrrrrr}\text { Age } & -0.01 & 0.00 & -1.88 & 0.062 & \\ \text { Gender } & 0.00 & 0.07 & 0.00 & 0.997 & \\ \text { Tenure } & 0.00 & 0.00 & 0.87 & 0.387 & \\ \text { Agreeableness } & -0.40 & 0.07 & -5.63 & 0.000 & \\ \text { Task Conflict } & 0.59 & 0.05 & 11.96 & 0.000 & \\ \text { Task Conflict * Agreeableness } & -0.35 & 0.08 & -4.39 & 0.000 & .50^{* * *}\end{array}$

Note. $N=308 \mathrm{DV}=$ dependent variable. $\mathrm{SE}=$ standard error. Conditional effect sizes are $+/-1$ SD. Effect size estimates are unstandardized coefficients. $*=p<.05, * *=p<.01, * * *=p<.001$ 
Table 21: The moderating role of Agreeableness on the Incivility to strain relationship

\begin{tabular}{|c|c|c|c|c|c|}
\hline Incivility & Coefficient & $S E$ & $t$ & $p$ & Model $\mathrm{R}^{2}$ \\
\hline \multicolumn{6}{|l|}{ Direct effects } \\
\hline \multicolumn{6}{|l|}{ Depression as DV } \\
\hline Age & 0.00 & 0.00 & -1.61 & 0.109 & \\
\hline Gender & 0.01 & 0.03 & 0.24 & 0.807 & \\
\hline Tenure & 0.00 & 0.00 & 1.57 & 0.116 & \\
\hline Agreeableness & -0.22 & 0.04 & -5.21 & 0.000 & \\
\hline Incivility & 0.37 & 0.02 & 15.12 & 0.000 & \\
\hline Incivility * Agreeableness & -0.30 & 0.04 & -8.44 & 0.000 & $.67 * * *$ \\
\hline \multicolumn{6}{|l|}{ Physical Symptoms as DV } \\
\hline Age & -0.01 & 0.01 & -2.60 & 0.010 & \\
\hline Gender & -0.02 & 0.07 & -0.31 & 0.754 & \\
\hline Tenure & 0.00 & 0.00 & 3.29 & 0.001 & \\
\hline Agreeableness & -0.43 & 0.09 & -4.70 & 0.000 & \\
\hline Incivility & 0.72 & 0.05 & 13.96 & 0.000 & \\
\hline Incivility * Agreeableness & -0.68 & 0.08 & -8.95 & 0.000 & $.64 * * *$ \\
\hline \multicolumn{6}{|l|}{ Stress as DV } \\
\hline Age & -0.01 & 0.00 & -3.82 & 0.000 & \\
\hline Gender & -0.03 & 0.04 & -0.65 & 0.519 & \\
\hline Tenure & 0.00 & 0.00 & -3.44 & 0.000 & \\
\hline Agreeableness & -0.05 & 0.06 & -0.92 & 0.358 & \\
\hline Incivility & 0.21 & 0.03 & 6.62 & 0.000 & \\
\hline Incivility * Agreeableness & 0.17 & 0.05 & 3.59 & 0.000 & $.36 * * *$ \\
\hline \multicolumn{6}{|l|}{ Job Satisfaction as DV } \\
\hline Age & 0.02 & 0.01 & 3.68 & 0.000 & \\
\hline Gender & 0.13 & 0.09 & 1.45 & 0.148 & \\
\hline Tenure & 0.00 & 0.00 & -2.46 & 0.014 & \\
\hline Agreeableness & 0.27 & 0.11 & 2.4 & 0.014 & \\
\hline Incivility & -0.12 & 0.06 & -1.9 & 0.059 & \\
\hline Incivility * Agreeableness & -0.06 & 0.09 & -0.67 & 0.505 & $.16^{* * *}$ \\
\hline
\end{tabular}

Note. $N=308 \mathrm{DV}=$ dependent variable. $\mathrm{SE}=$ standard error. 1,000 bootstrap samples. $\mathrm{LLCI}=$ bias corrected lower limit confidence interval. ULCI $=$ bias corrected upper limit confidence interval.

Conditional effect sizes are $+/-1 \mathrm{SD}$. Effect size estimates are unstandardized coefficients. $*=p<.05, * *$ $=p<.01, * * *=p<.001$ 
Table 21 continued: The moderating role of Agreeableness on the Incivility to strain relationship

\begin{tabular}{lccccc}
\hline & Coefficient & $S E$ & $t$ & $p$ & Model $^{2}$ \\
\hline Direct effects & & & & & \\
$\quad$ Life Satisfaction as DV & & & & & \\
Age & 0.02 & 0.01 & 4.31 & 0.000 & \\
Gender & 0.07 & 0.08 & 0.95 & 0.343 & \\
Tenure & 0.00 & 0.00 & -2.34 & 0.020 & \\
Agreeableness & -0.06 & 0.10 & -0.64 & 0.524 & \\
Incivility & 0.15 & 0.06 & 2.77 & 0.006 & \\
Incivility * Agreeableness & -0.48 & 0.08 & -5.82 & 0.000 & $.21^{* * *}$ \\
\hline Note. $N=308$ DV $=$ dependent variable. SE $=$ standard error. 1,000 bootstrap samples. LLCI $=$ bias \\
corrected lower limit confidence interval. ULCI = bias corrected upper limit confidence interval. \\
Conditional effect sizes are $+/-1$ SD. Effect size estimates are unstandardized coefficients. $*=p<.05, * *$ \\
$=p<.01, * * *=p<.001$
\end{tabular}


Table 22: The moderating role of Agreeableness on the Relationship Conflict to strain relationship

\begin{tabular}{|c|c|c|c|c|c|}
\hline Relationship Conflict & Coefficient & $S E$ & $t$ & $p$ & Model $\mathrm{R}^{2}$ \\
\hline \multicolumn{6}{|l|}{ Direct effects } \\
\hline \multicolumn{6}{|l|}{ Depression as DV } \\
\hline Age & 0.00 & 0.00 & -1.41 & 0.159 & \\
\hline Gender & -0.01 & 0.04 & -0.38 & 0.707 & \\
\hline Tenure & 0.00 & 0.00 & -1.83 & 0.068 & \\
\hline Agreeableness & -0.39 & 0.04 & -0.7 & 0.000 & \\
\hline Relationship Conflict & 0.29 & 0.03 & 10.44 & 0.000 & \\
\hline $\begin{array}{l}\text { Relationship Conflict* } \\
\text { Agreeableness }\end{array}$ & -0.30 & 0.04 & -7.28 & 0.000 & $.57 * * *$ \\
\hline \multicolumn{6}{|l|}{ Physical Symptoms as DV } \\
\hline Age & -0.01 & 0.01 & -2.44 & 0.015 & \\
\hline Gender & -0.07 & 0.08 & -0.86 & 0.393 & \\
\hline Tenure & 0.00 & 0.00 & 3.47 & 0.000 & \\
\hline Agreeableness & -0.68 & 0.08 & -8.45 & 0.000 & \\
\hline Relationship Conflict & 0.67 & 0.06 & 11.97 & 0.000 & \\
\hline $\begin{array}{l}\text { Relationship Conflict * } \\
\text { Agreeableness }\end{array}$ & -0.61 & 0.08 & -7.34 & 0.000 & $.58 * * *$ \\
\hline \multicolumn{6}{|l|}{ Stress as DV } \\
\hline Age & -0.01 & 0.00 & -3.90 & 0.000 & \\
\hline Gender & -0.07 & 0.05 & -1.40 & 0.164 & \\
\hline Tenure & 0.00 & 0.00 & -2.73 & 0.007 & \\
\hline Agreeableness & -0.31 & 0.05 & -6.33 & 0.000 & \\
\hline Relationship Conflict & 0.02 & 0.03 & 0.59 & 0.554 & \\
\hline $\begin{array}{l}\text { Relationship Conflict * } \\
\text { Agreeableness }\end{array}$ & -0.01 & 0.05 & -0.23 & 0.821 & $.25^{* * *}$ \\
\hline \multicolumn{6}{|l|}{ Job Satisfaction as DV } \\
\hline Age & 0.02 & 0.01 & 3.77 & 0.000 & \\
\hline Gender & 0.15 & 0.09 & 1.65 & 0.099 & \\
\hline Tenure & 0.00 & 0.00 & -2.17 & 0.031 & \\
\hline Agreeableness & 0.30 & 0.09 & 3.35 & 0.001 & \\
\hline Relationship Conflict & -0.14 & 0.06 & -2.19 & 0.029 & \\
\hline $\begin{array}{l}\text { Relationship Conflict * } \\
\text { Agreeableness }\end{array}$ & -0.23 & 0.09 & -2.50 & 0.013 & $.18^{* * *}$ \\
\hline
\end{tabular}

Note. $N=308 \mathrm{DV}=$ dependent variable. $\mathrm{SE}=$ standard error. 1,000 bootstrap samples. $\mathrm{LLCI}=$ bias corrected lower limit confidence interval. ULCI $=$ bias corrected upper limit confidence interval.

Conditional effect sizes are $+/-1 \mathrm{SD}$. Effect size estimates are unstandardized coefficients. $*=p<.05, * *$ $=p<.01, * * *=p<.001$ 
Table 22 continued: The moderating role of Agreeableness on the Relationship Conflict to strain relationship

\begin{tabular}{lllll} 
Coefficient & $S E$ & $t$ & $p$ & Model R $^{2}$ \\
\hline
\end{tabular}

Direct effects

Life Satisfaction as DV

Age

$\begin{array}{rrrr}0.02 & 0.01 & 0.54 & 0.000 \\ 0.08 & 0.08 & 1.09 & 0.278 \\ 0.00 & 0.00 & -2.04 & 0.042 \\ 0.00 & 0.08 & 0.00 & 0.996 \\ 0.25 & 0.06 & 4.47 & 0.000\end{array}$

Relationship Conflict

$\begin{array}{llll}-0.46 & 0.08 & -5.73 & 0.000\end{array}$ $.25^{* * *}$

Agreeableness

$\begin{array}{llll}-0.46 & 0.08 & -5.73 & 0.000\end{array}$

Note. $N=308 \mathrm{DV}=$ dependent variable. $\mathrm{SE}=$ standard error. 1,000 bootstrap samples. LLCI $=$ bias corrected lower limit confidence interval. ULCI = bias corrected upper limit confidence interval.

Conditional effect sizes are $+/-1 \mathrm{SD}$. Effect size estimates are unstandardized coefficients. $*=p<.05, * *$ $=p<.01, * * *=p<.001$ 
Table 23: The moderating role of Agreeableness on the Task Conflict to strain relationship

\begin{tabular}{|c|c|c|c|c|c|}
\hline Relationship Conflict & Coefficient & $S E$ & $t$ & $p$ & Model R ${ }^{2}$ \\
\hline \multicolumn{6}{|l|}{ Direct effects } \\
\hline \multicolumn{6}{|l|}{ Depression as DV } \\
\hline Age & 0.00 & 0.00 & -0.86 & 0.391 & \\
\hline Gender & -0.01 & 0.04 & -0.33 & 0.738 & \\
\hline Tenure & 0.00 & 0.00 & 1.11 & 0.269 & \\
\hline Agreeableness & -0.36 & 0.04 & -9.23 & 0.000 & \\
\hline Relationship Conflict & 0.30 & 0.03 & 0.94 & 0.000 & \\
\hline $\begin{array}{l}\text { Relationship Conflict* } \\
\text { Agreeableness }\end{array}$ & -0.28 & 0.04 & -6.23 & 0.000 & $.56^{* * *}$ \\
\hline \multicolumn{6}{|l|}{ Physical Symptoms as DV } \\
\hline Age & -0.01 & 0.01 & -1.72 & 0.087 & \\
\hline Gender & -0.06 & 0.08 & -0.75 & 0.452 & \\
\hline Tenure & 0.00 & 0.00 & 2.62 & 0.009 & \\
\hline Agreeableness & -0.63 & 0.08 & -8.02 & 0.000 & \\
\hline Relationship Conflict & 0.66 & 0.05 & 12.11 & 0.000 & \\
\hline $\begin{array}{l}\text { Relationship Conflict * } \\
\text { Agreeableness }\end{array}$ & -0.56 & 0.09 & -6.24 & 0.000 & $.57 * * *$ \\
\hline \multicolumn{6}{|l|}{ Stress as DV } \\
\hline Age & -0.01 & 0.00 & -3.77 & 0.000 & \\
\hline Gender & -0.06 & 0.05 & -1.34 & 0.180 & \\
\hline Tenure & 0.00 & 0.00 & -2.82 & 0.005 & \\
\hline Agreeableness & -0.31 & 0.05 & -6.55 & 0.000 & \\
\hline Relationship Conflict & 0.02 & 0.03 & 0.5 & 0.616 & \\
\hline $\begin{array}{l}\text { Relationship Conflict * } \\
\text { Agreeableness }\end{array}$ & 0.01 & 0.05 & 0.11 & 0.913 & $.25^{* * *}$ \\
\hline \multicolumn{6}{|l|}{ Job Satisfaction as DV } \\
\hline Age & 0.02 & 0.01 & 3.45 & 0.001 & \\
\hline Gender & 0.14 & 0.09 & 1.54 & 0.124 & \\
\hline Tenure & 0.00 & 0.00 & -2.20 & 0.029 & \\
\hline Agreeableness & 0.37 & 0.09 & 4.16 & 0.000 & \\
\hline Relationship Conflict & -0.08 & 0.06 & -1.34 & 0.181 & \\
\hline $\begin{array}{l}\text { Relationship Conflict* } \\
\text { Agreeableness }\end{array}$ & -0.14 & 0.10 & -1.39 & 0.165 & $.16^{* * *}$ \\
\hline
\end{tabular}

Note. $N=308 \mathrm{DV}=$ dependent variable. $\mathrm{SE}=$ standard error. 1,000 bootstrap samples. $\mathrm{LLCI}=$ bias corrected lower limit confidence interval. ULCI = bias corrected upper limit confidence interval.

Conditional effect sizes are $+/-1 \mathrm{SD}$. Effect size estimates are unstandardized coefficients. $*=p<.05, * *$ $=p<.01, * * *=p<.001$ 
Table 23 continued: The moderating role of Agreeableness on the Task Conflict to strain relationship

$\begin{array}{lllll}\text { Coefficient } & S E & t & p & \text { Model R }^{2}\end{array}$

Direct effects

Life Satisfaction as DV

Age

$\begin{array}{rrrr}0.02 & 0.01 & 4.60 & 0.000 \\ 0.08 & 0.08 & 0.99 & 0.322 \\ 0.00 & 0.00 & -2.41 & 0.017 \\ 0.08 & 0.08 & 1.03 & 0.306 \\ 0.30 & 0.05 & 5.79 & 0.000\end{array}$

Relationship Conflict

Relationship Conflict *

$\begin{array}{llll}-0.42 & 0.09 & -4.86 & 0.000\end{array}$

$.25 * * *$

Agreeableness

$\begin{array}{llll}-0.42 & 0.09 & -4.86 & 0.000\end{array}$

Note. $N=308 \mathrm{DV}=$ dependent variable. $\mathrm{SE}=$ standard error. 1,000 bootstrap samples. $\mathrm{LLCI}=$ bias corrected lower limit confidence interval. ULCI $=$ bias corrected upper limit confidence interval.

Conditional effect sizes are $+/-1$ SD. Effect size estimates are unstandardized coefficients. $*=p<.05, * *$ $=p<.01, * * *=p<.001$ 
Table 24: The moderating role of Conscientiousness on the Negative Emotions

\begin{tabular}{lrrrrr}
\hline Incivility & Coefficient & $S E$ & $t$ & $p$ & Model R $^{2}$ \\
\hline Direct effects & & & & & \\
$\quad$ Negative Emotions as DV & & & & & \\
$\quad$ Age & -0.01 & 0.00 & -1.87 & 0.063 & \\
Gender & 0.10 & 0.07 & 1.45 & 0.149 & \\
Tenure & 0.00 & 0.00 & 0.16 & 0.873 & \\
Conscientiousness & -0.05 & 0.07 & -0.63 & 0.528 & \\
Incivility & 0.71 & 0.04 & 16.18 & 0.000 & \\
Incivility * Conscientiousness & -0.15 & 0.08 & -1.81 & 0.071 & $.52^{* * *}$ \\
Relationship Conflict & Coefficient & $S E$ & $t$ & $p$ & Model R $^{2}$ \\
\hline
\end{tabular}

Negative Emotions as DV

$\begin{array}{lrrrrr}\text { Age } & -0.01 & 0.01 & -1.89 & 0.059 & \\ \text { Gender } & -0.04 & 0.07 & -0.48 & 0.629 & \\ \text { Tenure } & 0.00 & 0.00 & 0.38 & 0.704 & \\ \text { Conscientiousness } & -0.24 & 0.07 & -3.32 & 0.000 & \\ \text { Relationship Conflict } & 0.70 & 0.05 & 13.10 & 0.000 & \\ \begin{array}{l}\text { Relationship Conflict * } \\ \text { nscientiousness }\end{array} & 0.05 & 0.10 & 0.52 & 0.602 & .45^{* * *}\end{array}$

Conscientiousness

\begin{tabular}{lccccc} 
Task Conflict & Coefficient & $S E$ & $t$ & $p$ & Model R $^{2}$ \\
\hline Direct effects & & & & & \\
$\quad$ Negative Emotions as DV & & & & & \\
$\quad$ Age & 0.00 & 0.01 & -0.40 & 0.687 & \\
Gender & 0.00 & 0.07 & -0.03 & 0.973 & \\
Tenure & 0.00 & 0.00 & -0.46 & 0.643 & \\
Conscientiousness & -0.31 & 0.07 & -4.36 & 0.000 & \\
Task Conflict & 0.69 & 0.05 & 14.55 & 0.000 & \\
Task Conflict * Conscientiousness & 0.04 & 0.09 & 0.43 & 0.667 & $.46^{* * *}$ \\
\hline
\end{tabular}

Note. $N=308 \mathrm{DV}=$ dependent variable. $\mathrm{SE}=$ standard error. Conditional effect sizes are $+/-1 \mathrm{SD}$. Effect size estimates are unstandardized coefficients. $*=p<.05, * *=p<.01, * * *=p<.001$ 
Table 25: The moderating role of Conscientiousness on the Incivility to strain relationship

\begin{tabular}{|c|c|c|c|c|c|}
\hline Incivility & Coefficient & $S E$ & $t$ & $p$ & Model $\mathrm{R}^{2}$ \\
\hline \multicolumn{6}{|l|}{ Direct effects } \\
\hline \multicolumn{6}{|l|}{ Depression as DV } \\
\hline Age & 0.00 & 0.00 & -0.61 & 0.541 & \\
\hline Gender & 0.03 & 0.04 & 0.86 & 0.393 & \\
\hline Tenure & 0.00 & 0.00 & 0.10 & 0.924 & \\
\hline Conscientiousness & -0.01 & 0.04 & -0.31 & 0.757 & \\
\hline Incivility & 0.43 & 0.02 & 8.26 & 0.000 & \\
\hline Incivility * Conscientiousness & -0.05 & 0.05 & -1.05 & 0.294 & $.58 * * *$ \\
\hline \multicolumn{6}{|l|}{ Physical Symptoms as DV } \\
\hline Age & -0.01 & 0.01 & -1.82 & 0.070 & \\
\hline Gender & 0.02 & 0.08 & 0.21 & 0.837 & \\
\hline Tenure & 0.00 & 0.00 & 1.26 & 0.208 & \\
\hline Conscientiousness & -0.07 & 0.08 & -0.87 & 0.387 & \\
\hline Incivility & 0.90 & 0.05 & 18.20 & 0.000 & \\
\hline Incivility $*$ Conscientiousness & -0.40 & 0.10 & -4.17 & 0.000 & $.56 * * *$ \\
\hline \multicolumn{6}{|l|}{ Stress as DV } \\
\hline Age & -0.01 & 0.00 & -2.97 & 0.003 & \\
\hline Gender & -0.02 & 0.04 & -0.40 & 0.691 & \\
\hline Tenure & 0.00 & 0.00 & -3.54 & 0.001 & \\
\hline Conscientiousness & -0.30 & 0.04 & -7.30 & 0.000 & \\
\hline Incivility & 0.15 & 0.03 & 6.1 & 0.000 & \\
\hline Incivility * Conscientiousness & 0.12 & 0.05 & 2.56 & 0.011 & $.46^{* * *}$ \\
\hline \multicolumn{6}{|l|}{ Job Satisfaction as DV } \\
\hline Age & 0.02 & 0.01 & 3.18 & 0.002 & \\
\hline Gender & 0.13 & 0.08 & 1.57 & -0.032 & \\
\hline Tenure & 0.00 & 0.00 & -1.83 & -0.003 & \\
\hline Conscientiousness & 0.65 & 0.08 & 7.65 & 0.000 & \\
\hline Incivility & -0.16 & 0.05 & -3.18 & 0.002 & \\
\hline Incivility $*$ Conscientiousness & 0.28 & 0.10 & 2.91 & 0.004 & $.28 * * *$ \\
\hline
\end{tabular}

Note. $N=308 \mathrm{DV}=$ dependent variable. $\mathrm{SE}=$ standard error. 1,000 bootstrap samples. $\mathrm{LLCI}=$ bias corrected lower limit confidence interval. ULCI = bias corrected upper limit confidence interval. Conditional effect sizes are $+/-1 \mathrm{SD}$. Effect size estimates are unstandardized coefficients. ${ }^{*}=p<.05, * *$ $=p<.01, * * *=p<.001$ 
Table 25 continued: The moderating role of Conscientiousness on the Incivility to strain relationship

\begin{tabular}{lllll} 
Coefficient & $S E$ & $t$ & $p$ & Model $\mathrm{R}^{2}$ \\
\hline
\end{tabular}

Direct effects

Life Satisfaction as DV

Age

$\begin{array}{llll}0.02 & 0.01 & 3.89 & 0.000\end{array}$

Gender

$\begin{array}{llll}0.09 & 0.08 & 1.17 & 0.245\end{array}$

Tenure

$\begin{array}{llll}0.00 & 0.00 & -2.87 & 0.004\end{array}$

Conscientiousness

$\begin{array}{llll}0.48 & 0.08 & 6.02 & 0.000\end{array}$

Incivility

$\begin{array}{llll}0.25 & 0.05 & 5.27 & 0.000\end{array}$

Incivility * Conscientiousness

$\begin{array}{llll}-0.09 & 0.09 & -0.93 & 0.353\end{array}$

Note. $N=308 \mathrm{DV}=$ dependent variable. $\mathrm{SE}=$ standard error. 1,000 bootstrap samples. $\mathrm{LLCI}=$ bias corrected lower limit confidence interval. ULCI = bias corrected upper limit confidence interval.

Conditional effect sizes are $+/-1 \mathrm{SD}$. Effect size estimates are unstandardized coefficients. $*=p<.05, * *$

$=p<.01, * * *=p<.001$ 
Table 26: The moderating role of Conscientiousness on the Relationship Conflict to strain relationship

\begin{tabular}{|c|c|c|c|c|c|}
\hline Relationship Conflict & Coefficient & $S E$ & $t$ & $p$ & Model $\mathrm{R}^{2}$ \\
\hline \multicolumn{6}{|l|}{ Direct effects } \\
\hline \multicolumn{6}{|l|}{ Depression as DV } \\
\hline Age & 0.00 & 0.00 & -0.63 & 0.527 & \\
\hline Gender & -0.06 & 0.04 & -1.30 & 0.194 & \\
\hline Tenure & 0.00 & 0.00 & 0.08 & 0.935 & \\
\hline Conscientiousness & -0.16 & 0.04 & -3.73 & 0.000 & \\
\hline Relationship Conflict & 0.40 & 0.03 & 13.20 & 0.000 & \\
\hline $\begin{array}{l}\text { Relationship Conflict * } \\
\text { Conscientiousness }\end{array}$ & 0.01 & 0.06 & 0.12 & 0.907 & $.43^{* * *}$ \\
\hline \multicolumn{6}{|l|}{ Physical Symptoms as DV } \\
\hline Age & -0.01 & 0.01 & -1.58 & 0.114 & \\
\hline Gender & -0.13 & 0.09 & -1.52 & 0.129 & \\
\hline Tenure & 0.00 & 0.00 & 1.54 & 0.124 & \\
\hline Conscientiousness & -0.30 & 0.09 & -3.46 & 0.001 & \\
\hline Relationship Conflict & 0.87 & 0.06 & 14.71 & 0.000 & \\
\hline $\begin{array}{l}\text { Relationship Conflict * } \\
\text { Conscientiousness }\end{array}$ & -0.13 & 0.12 & -1.02 & 0.307 & $.46^{* * *}$ \\
\hline \multicolumn{6}{|l|}{ Stress as DV } \\
\hline Age & -0.01 & 0.00 & -2.81 & 0.005 & \\
\hline Gender & -0.07 & 0.04 & -1.54 & 0.126 & \\
\hline Tenure & 0.00 & 0.00 & -3.86 & 0.000 & \\
\hline Conscientiousness & -0.42 & 0.04 & -9.00 & 0.000 & \\
\hline Relationship Conflict & 0.07 & 0.03 & 2.46 & 0.014 & \\
\hline $\begin{array}{l}\text { Relationship Conflict * } \\
\text { Conscientiousness }\end{array}$ & 0.00 & 0.06 & 0.01 & 0.988 & $.37 * * *$ \\
\hline \multicolumn{6}{|l|}{ Job Satisfaction as DV } \\
\hline Age & 0.02 & 0.01 & 2.99 & 0.003 & \\
\hline Gender & 0.13 & 0.08 & 1.61 & 0.109 & \\
\hline Tenure & 0.00 & 0.00 & -2.23 & 0.026 & \\
\hline Conscientiousness & 0.6 & 0.08 & 7.52 & 0.000 & \\
\hline Relationship Conflict & -0.17 & 0.06 & -3.00 & 0.000 & \\
\hline $\begin{array}{l}\text { Relationship Conflict * } \\
\text { Conscientiousness }\end{array}$ & 0.02 & 0.12 & 0.19 & 0.847 & $.27 * * *$ \\
\hline
\end{tabular}

Note. $N=308 \mathrm{DV}=$ dependent variable. $\mathrm{SE}=$ standard error. 1,000 bootstrap samples. $\mathrm{LLCI}=$ bias corrected lower limit confidence interval. ULCI = bias corrected upper limit confidence interval.

Conditional effect sizes are $+/-1 \mathrm{SD}$. Effect size estimates are unstandardized coefficients. $*=p<.05, * *$ $=p<.01, * * *=p<.001$ 
Table 26 continued: The moderating role of Conscientiousness on the Relationship Conflict to strain relationship

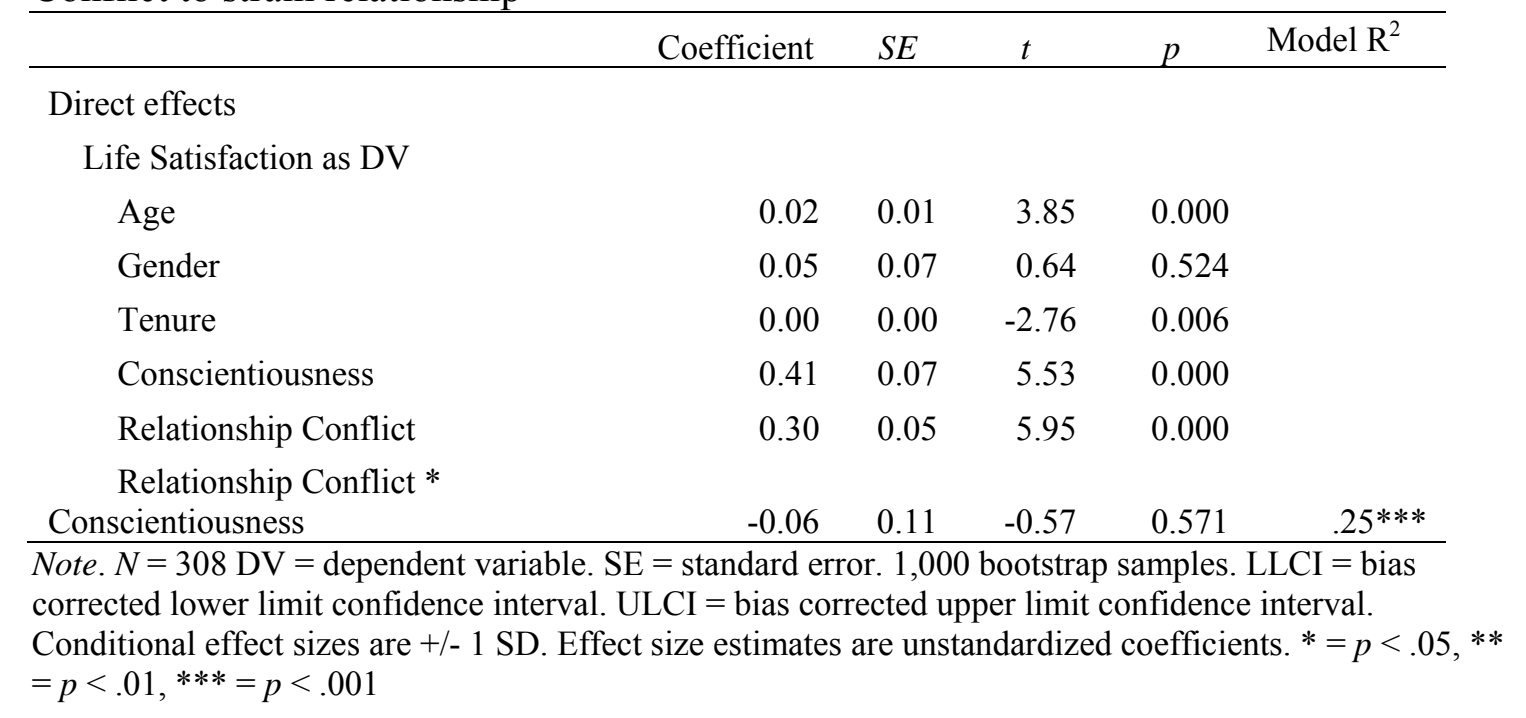


Table 27: The moderating role of Conscientiousness on the Task Conflict to strain relationship

\begin{tabular}{|c|c|c|c|c|c|}
\hline Task Conflict & Coefficient & $S E$ & $t$ & $p$ & Model $\mathrm{R}^{2}$ \\
\hline \multicolumn{6}{|l|}{ Direct effects } \\
\hline \multicolumn{6}{|l|}{ Depression as DV } \\
\hline Age & 0.00 & 0.00 & 0.61 & 0.543 & \\
\hline Gender & -0.04 & 0.04 & -0.89 & 0.373 & \\
\hline Tenure & 0.00 & 0.00 & -0.81 & 0.417 & \\
\hline Conscientiousness & -0.10 & 0.04 & -5.01 & 0.000 & \\
\hline Task Conflict & 0.40 & 0.03 & 14.02 & 0.000 & \\
\hline Task Conflict * Conscientiousness & -0.05 & 0.06 & -0.95 & 0.341 & $.45 * * *$ \\
\hline \multicolumn{6}{|l|}{ Physical Symptoms as DV } \\
\hline Age & 0.00 & 0.01 & -0.42 & 0.677 & \\
\hline Gender & -0.10 & 0.09 & -1.12 & 0.266 & \\
\hline Tenure & 0.00 & 0.00 & 0.52 & 0.602 & \\
\hline Conscientiousness & -0.41 & 0.09 & -4.92 & 0.000 & \\
\hline Task Conflict & 0.86 & 0.06 & 15.34 & 0.000 & \\
\hline Task Conflict $*$ Conscientiousness & -0.27 & 0.11 & -2.50 & 0.013 & $.48 * * *$ \\
\hline \multicolumn{6}{|l|}{ Stress as DV } \\
\hline Age & -0.01 & 0.00 & -2.43 & 0.016 & \\
\hline Gender & -0.06 & 0.04 & -1.46 & 0.147 & \\
\hline Tenure & 0.00 & 0.00 & -3.95 & 0.000 & \\
\hline Conscientiousness & -0.42 & 0.04 & -9.92 & 0.000 & \\
\hline Task Conflict & 0.08 & 0.03 & 2.69 & 0.008 & \\
\hline Task Conflict * Conscientiousness & 0.05 & 0.05 & 0.92 & 0.361 & $.38 * * *$ \\
\hline \multicolumn{6}{|l|}{ Job Satisfaction as DV } \\
\hline Age & 0.02 & 0.01 & 2.72 & 0.007 & \\
\hline Gender & 0.12 & 0.08 & 1.53 & 0.126 & \\
\hline Tenure & 0.00 & 0.00 & -2.02 & 0.043 & \\
\hline Conscientiousness & 0.63 & 0.08 & 7.85 & 0.000 & \\
\hline Task Conflict & -0.15 & 0.05 & -2.77 & 0.006 & \\
\hline Task Conflict $*$ Conscientiousness & 0.04 & 0.10 & 0.38 & 0.706 & $.26^{* * *}$ \\
\hline
\end{tabular}

Note. $N=308 \mathrm{DV}=$ dependent variable. $\mathrm{SE}=$ standard error. 1,000 bootstrap samples. $\mathrm{LLCI}=$ bias corrected lower limit confidence interval. ULCI = bias corrected upper limit confidence interval. Conditional effect sizes are $+/-1 \mathrm{SD}$. Effect size estimates are unstandardized coefficients. ${ }^{*}=p<.05, * *$ $=p<.01, * * *=p<.001$ 
Table 27 continued: The moderating role of Conscientiousness on the Task Conflict to strain relationship

\begin{tabular}{lllll} 
Coefficient & $S E$ & $t$ & $p$ & Model R $^{2}$ \\
\hline
\end{tabular}

Direct effects

Life Satisfaction as DV

$\begin{array}{lrrrr}\text { Age } & 0.02 & 0.01 & 4.49 & 0.000 \\ \text { Gender } & 0.06 & 0.07 & 0.84 & 0.403 \\ \text { Tenure } & 0.00 & 0.00 & -3.11 & 0.002 \\ \text { Conscientiousness } & 0.40 & 0.07 & 5.40 & 0.000 \\ \text { Task Conflict } & 0.32 & 0.05 & 6.61 & 0.000\end{array}$

Note. $N=308 \mathrm{DV}=$ dependent variable. $\mathrm{SE}=$ standard error. 1,000 bootstrap samples. $\mathrm{LLCI}=$ bias corrected lower limit confidence interval. ULCI $=$ bias corrected upper limit confidence interval.

Conditional effect sizes are $+/-1$ SD. Effect size estimates are unstandardized coefficients. $*=p<.05, * *$ $=p<.01, * * *=p<.001$ 
Table 28: The moderating role of Trait Anger between workplace aggression and Negative Emotions

\begin{tabular}{|c|c|c|c|c|c|}
\hline Incivility & Coefficient & $S E$ & $t$ & $p$ & Model $\mathrm{R}^{2}$ \\
\hline \multicolumn{6}{|l|}{ Direct effects } \\
\hline \multicolumn{6}{|l|}{ Negative Emotions as DV } \\
\hline Age & -0.01 & 0.00 & -2.54 & 0.012 & \\
\hline Gender & 0.05 & 0.06 & 0.00 & 0.369 & \\
\hline Tenure & 0.00 & 0.00 & 1.59 & 0.113 & \\
\hline Trait Anger & 0.72 & 0.07 & 9.97 & 0.000 & \\
\hline Incivility & 0.35 & 0.04 & 7.92 & 0.000 & \\
\hline Incivility * Trait Anger & 0.25 & 0.05 & 4.84 & 0.000 & $.68 * * *$ \\
\hline Relationship Conflict & Coefficient & $S E$ & $t$ & $p$ & Model R ${ }^{2}$ \\
\hline \multicolumn{6}{|l|}{ Direct effects } \\
\hline \multicolumn{6}{|l|}{ Negative Emotions as DV } \\
\hline Age & -0.01 & 0.00 & -2.19 & 0.029 & \\
\hline Gender & -0.01 & 0.06 & -0.18 & 0.861 & \\
\hline Tenure & 0.00 & 0.00 & 1.76 & 0.080 & \\
\hline Trait Anger & 0.88 & 0.07 & 12.62 & 0.000 & \\
\hline Relationship Conflict & 0.29 & 0.05 & 5.87 & 0.000 & \\
\hline Relationship Conflict * Trait Anger & 0.17 & 0.06 & 2.72 & 0.007 & $.65^{* * *}$ \\
\hline Task Conflict & Coefficient & $S E$ & $t$ & $p$ & Model R ${ }^{2}$ \\
\hline \multicolumn{6}{|l|}{ Direct effects } \\
\hline \multicolumn{6}{|l|}{ Negative Emotions as DV } \\
\hline Age & -0.01 & 0.00 & -1.52 & 0.131 & \\
\hline Gender & 0.01 & 0.06 & 0.12 & 0.908 & \\
\hline Tenure & 0.00 & 0.00 & 1.15 & 0.249 & \\
\hline Trait Anger & 0.87 & 0.07 & 13.11 & 0.000 & \\
\hline Task Conflict & 0.34 & 0.05 & 7.44 & 0.000 & \\
\hline Task Conflict * Trait Anger & 0.12 & 0.07 & 1.80 & 0.073 & $.66 * * *$ \\
\hline
\end{tabular}

Note. $N=308 \mathrm{DV}=$ dependent variable. $\mathrm{SE}=$ standard error. Conditional effect sizes are $+/-1 \mathrm{SD}$. Effect size estimates are unstandardized coefficients. $*=p<.05,{ }^{*}=p<.01, * * *=p<.001$ 
Table 29: The moderating role of Trait Anger on the Incivility to strain relationship

\begin{tabular}{|c|c|c|c|c|c|}
\hline Incivility & Coefficient & $S E$ & $t$ & $p$ & Model R ${ }^{2}$ \\
\hline \multicolumn{6}{|l|}{ Direct effects } \\
\hline \multicolumn{6}{|l|}{ Depression as DV } \\
\hline Age & 0.00 & 0.00 & -1.88 & 0.061 & \\
\hline Gender & -0.01 & 0.03 & -0.38 & 0.701 & \\
\hline Tenure & 0.00 & 0.00 & 1.80 & 0.073 & \\
\hline Trait Anger & 0.36 & 0.04 & 9.48 & 0.000 & \\
\hline Incivility & 0.26 & 0.02 & 11.30 & 0.000 & \\
\hline Incivility $*$ Trait Anger & 0.21 & 0.03 & 8.02 & 0.000 & $.75 * * *$ \\
\hline \multicolumn{6}{|l|}{ Physical Symptoms as DV } \\
\hline Age & -0.01 & 0.00 & -2.80 & 0.005 & \\
\hline Gender & -0.05 & 0.06 & -0.78 & 0.438 & \\
\hline Tenure & 0.00 & 0.00 & 3.67 & 0.000 & \\
\hline Trait Anger & 0.77 & 0.08 & 9.54 & 0.000 & \\
\hline Incivility & 0.46 & 0.05 & 9.46 & 0.000 & \\
\hline Incivility * Trait Anger & 0.45 & 0.06 & 7.76 & 0.000 & $.73 * * *$ \\
\hline \multicolumn{6}{|l|}{ Stress as DV } \\
\hline Age & -0.01 & 0.00 & -3.06 & 0.002 & \\
\hline Gender & -0.03 & 0.04 & -0.71 & 0.476 & \\
\hline Tenure & 0.00 & 0.00 & -3.68 & 0.000 & \\
\hline Trait Anger & 0.08 & 0.06 & 1.40 & 0.136 & \\
\hline Incivility & 0.22 & 0.03 & 6.69 & 0.000 & \\
\hline Incivility * Trait Anger & -0.22 & 0.04 & -5.63 & 0.000 & $.39 * * *$ \\
\hline \multicolumn{6}{|l|}{ Job Satisfaction as DV } \\
\hline Age & 0.02 & 0.01 & 3.09 & 0.002 & \\
\hline Gender & 0.15 & 0.09 & 1.73 & 0.085 & \\
\hline Tenure & 0.00 & 0.00 & -2.32 & 0.021 & \\
\hline Trait Anger & -0.30 & 0.11 & -2.66 & 0.008 & \\
\hline Incivility & -0.11 & 0.07 & -1.69 & 0.092 & \\
\hline Incivility $*$ Trait Anger & 0.21 & 0.08 & 2.63 & 0.009 & $.17 * * *$ \\
\hline
\end{tabular}

Note. $N=308 \mathrm{DV}=$ dependent variable. $\mathrm{SE}=$ standard error. 1,000 bootstrap samples. LLCI = bias corrected lower limit confidence interval. ULCI = bias corrected upper limit confidence interval.

Conditional effect sizes are $+/-1$ SD. Effect size estimates are unstandardized coefficients. $*=p<.05, * *$ $=p<.01, * * *=p<.001$ 
Table 29 continued: The moderating role of Trait Anger on the Incivility to strain relationship

\begin{tabular}{lrrrrr}
\hline & Coefficient & $S E$ & $t$ & $p$ & Model $^{2}$ \\
\hline Direct effects & & & & & \\
$\quad$ Life Satisfaction as DV & 0.02 & 0.01 & 3.72 & 0.000 & \\
$\quad$ Age & 0.09 & 0.08 & 1.13 & 0.261 & \\
Gender & 0.00 & 0.00 & -2.48 & 0.014 & \\
Tenure & -0.06 & 0.10 & -0.62 & 0.538 & \\
Trait Anger & 0.13 & 0.06 & 2.19 & 0.029 & \\
Incivility & 0.41 & 0.07 & 5.70 & 0.000 & $.21^{* * *}$ \\
$\quad$ Incivility * Trait Anger & & & & \\
Note. $N=308$ DV $=$ dependent variable. SE $=$ standard error. 1,000 bootstrap samples. LLCI $=$ bias \\
corrected lower limit confidence interval. ULCI = bias corrected upper limit confidence interval. \\
Conditional effect sizes are $+/$ - 1 SD. Effect size estimates are unstandardized coefficients. $*=p<.05, * *$ \\
$=p<.01, * * *=p<.001$
\end{tabular}


Table 30: The moderating role of Trait Anger on the Relationship Conflict to strain relationship

\begin{tabular}{|c|c|c|c|c|c|}
\hline Relationship Conflict & Coefficient & $S E$ & $t$ & $p$ & Model $\mathrm{R}^{2}$ \\
\hline \multicolumn{6}{|l|}{ Direct effects } \\
\hline \multicolumn{6}{|l|}{ Depression as DV } \\
\hline Age & 0.00 & 0.00 & -0.95 & 0.343 & \\
\hline Gender & -0.05 & 0.03 & -1.56 & 0.119 & \\
\hline Tenure & 0.00 & 0.00 & 1.91 & 0.057 & \\
\hline Trait Anger & 0.53 & 0.04 & 13.22 & 0.000 & \\
\hline Relationship Conflict & 0.14 & 0.03 & 4.82 & 0.000 & \\
\hline Relationship Conflict * Trait Anger & 0.17 & 0.04 & 4.56 & 0.000 & $.67 * * *$ \\
\hline \multicolumn{6}{|l|}{ Physical Symptoms as DV } \\
\hline Age & -0.01 & 0.00 & -2.07 & 0.039 & \\
\hline Gender & -0.12 & 0.07 & -1.79 & 0.074 & \\
\hline Tenure & 0.00 & 0.00 & 3.72 & 0.000 & \\
\hline Trait Anger & 0.99 & 0.08 & 12.31 & 0.000 & \\
\hline Relationship Conflict & 0.37 & 0.06 & 6.35 & 0.000 & \\
\hline Relationship Conflict * Trait Anger & 0.34 & 0.07 & 4.54 & 0.000 & $0.67 * * *$ \\
\hline \multicolumn{6}{|l|}{ Stress as DV } \\
\hline Age & -0.01 & 0.00 & -3.08 & 0.002 & \\
\hline Gender & -0.09 & 0.05 & -1.99 & 0.048 & \\
\hline Tenure & 0.00 & 0.00 & -3.6 & 0.000 & \\
\hline Trait Anger & 0.34 & 0.06 & 6.05 & 0.000 & \\
\hline Relationship Conflict & 0.00 & 0.04 & -0.04 & 0.967 & \\
\hline \multicolumn{6}{|l|}{ Job Satisfaction as DV } \\
\hline Age & 0.02 & 0.01 & 3.19 & 0.002 & \\
\hline Gender & 0.17 & 0.09 & 1.97 & 0.049 & \\
\hline Tenure & 0.00 & 0.00 & -1.72 & 0.086 & \\
\hline Trait Anger & -0.40 & 0.10 & -3.91 & 0.000 & \\
\hline Relationship Conflict & -0.11 & 0.07 & -1.55 & 0.121 & \\
\hline Relationship Conflict * Trait Anger & 0.38 & 0.09 & 3.99 & 0.000 & $.19^{* * *}$ \\
\hline
\end{tabular}

Note. $N=308 \mathrm{DV}=$ dependent variable. $\mathrm{SE}=$ standard error. 1,000 bootstrap samples. $\mathrm{LLCI}=$ bias corrected lower limit confidence interval. ULCI = bias corrected upper limit confidence interval.

Conditional effect sizes are $+/-1 \mathrm{SD}$. Effect size estimates are unstandardized coefficients. $*=p<.05, * *$ $=p<.01, * * *=p<.001$ 
Table 30 continued: The moderating role of Trait Anger on the Relationship Conflict to strain relationship

\begin{tabular}{lllll} 
Coefficient & $S E$ & $t$ & $p$ & Model R $^{2}$ \\
\hline
\end{tabular}

Direct effects

Life Satisfaction as DV

Age

$\begin{array}{llll}0.02 & 0.01 & 3.94 & 0.000\end{array}$

Gender

$\begin{array}{llll}0.07 & 0.08 & 0.89 & 0.374\end{array}$

Tenure

$\begin{array}{llll}0.00 & 0.00 & -1.81 & 0.072\end{array}$

Trait Anger

$\begin{array}{llll}-0.15 & 0.09 & -1.65 & 0.090\end{array}$

Relationship Conflict

$\begin{array}{llll}0.24 & 0.06 & 3.71 & 0.000\end{array}$

Relationship Conflict * Trait Anger

$\begin{array}{llll}0.44 & 0.08 & 5.26 & 0.000\end{array}$

$.23 * * *$

Note. $N=308 \mathrm{DV}=$ dependent variable. $\mathrm{SE}=$ standard error. 1,000 bootstrap samples. $\mathrm{LLCI}=$ bias corrected lower limit confidence interval. ULCI $=$ bias corrected upper limit confidence interval.

Conditional effect sizes are $+/-1$ SD. Effect size estimates are unstandardized coefficients. $*=p<.05$, ** $=p<.01, * * *=p<.001$ 
Table 31: The moderating role of Trait Anger on the Task Conflict to strain relationship

\begin{tabular}{|c|c|c|c|c|c|}
\hline Task Conflict & Coefficient & $S E$ & $t$ & $p$ & Model R ${ }^{2}$ \\
\hline \multicolumn{6}{|l|}{ Direct effects } \\
\hline \multicolumn{6}{|l|}{ Depression as DV } \\
\hline Age & 0.00 & 0.00 & -1.18 & 0.238 & \\
\hline Gender & -0.06 & 0.03 & -1.77 & 0.077 & \\
\hline Tenure & 0.00 & 0.00 & 1.92 & 0.056 & \\
\hline Trait Anger & 0.49 & 0.04 & 13.07 & 0.000 & \\
\hline Task Conflict & 0.17 & 0.03 & 6.76 & 0.000 & \\
\hline Task Conflict * Trait Anger & 0.22 & 0.04 & 5.85 & 0.000 & $.69 * *$ \\
\hline \multicolumn{6}{|l|}{ Physical Symptoms as DV } \\
\hline Age & -0.01 & 0.00 & -2.01 & 0.045 & \\
\hline Gender & -0.12 & 0.07 & -1.87 & 0.063 & \\
\hline Tenure & 0.00 & 0.00 & 3.58 & 0.000 & \\
\hline Trait Anger & 0.94 & 0.08 & 12.43 & 0.000 & \\
\hline Task Conflict & 0.41 & 0.05 & 7.95 & 0.000 & \\
\hline Task Conflict* Trait Anger & 0.41 & 0.08 & 5.36 & 0.000 & $.69 * * *$ \\
\hline \multicolumn{6}{|l|}{ Stress as DV } \\
\hline Age & -0.01 & 0.00 & -2.74 & 0.006 & \\
\hline Gender & -0.09 & 0.05 & -1.99 & 0.048 & \\
\hline Tenure & 0.00 & 0.00 & -3.48 & 0.001 & \\
\hline Trait Anger & 0.34 & 0.05 & 6.26 & 0.000 & \\
\hline Task Conflict & -0.01 & 0.04 & -0.34 & 0.732 & \\
\hline Task Conflict* Trait Anger & -0.19 & 0.06 & -3.49 & 0.001 & $.24 * * *$ \\
\hline \multicolumn{6}{|l|}{ Job Satisfaction as DV } \\
\hline Age & 0.02 & 0.01 & 2.53 & 0.012 & \\
\hline Gender & 0.16 & 0.09 & 1.83 & 0.069 & \\
\hline Tenure & 0.00 & 0.00 & -1.60 & 0.111 & \\
\hline Trait Anger & -0.48 & 0.10 & -4.80 & 0.000 & \\
\hline Task Conflict & -0.04 & 0.07 & -0.57 & 0.572 & \\
\hline Task Conflict* Trait Anger & 0.41 & 0.10 & 4.08 & 0.000 & $.18^{* * * *}$ \\
\hline
\end{tabular}

Note. $N=308 \mathrm{DV}=$ dependent variable. $\mathrm{SE}=$ standard error. 1,000 bootstrap samples. $\mathrm{LLCI}=$ bias corrected lower limit confidence interval. ULCI = bias corrected upper limit confidence interval.

Conditional effect sizes are $+/-1$ SD. Effect size estimates are unstandardized coefficients. $*=p<.05, * *$ $=p<.01, * * *=p<.001$ 
Table 31 continued: The moderating role of Trait Anger on the Task Conflict to strain relationship

$\begin{array}{lllll}\text { Coefficient } & S E & t & p & \text { Model R }^{2}\end{array}$

Direct effects

Life Satisfaction as DV

\begin{tabular}{lrrrrr} 
Age & 0.02 & 0.01 & 3.97 & 0.000 & \\
Gender & 0.08 & 0.07 & 1.01 & 0.311 & \\
Tenure & 0.00 & 0.00 & -2.22 & 0.027 & \\
Trait Anger & -0.20 & 0.09 & -2.25 & 0.025 & \\
Task Conflict & 0.32 & 0.06 & 5.44 & 0.000 & \\
Task Conflict* Trait Anger & 0.41 & 0.09 & 4.70 & 0.000 & $.25^{* * *}$ \\
\hline
\end{tabular}

Note. $N=308 \mathrm{DV}=$ dependent variable. $\mathrm{SE}=$ standard error. 1,000 bootstrap samples. $\mathrm{LLCI}=$ bias corrected lower limit confidence interval. ULCI = bias corrected upper limit confidence interval.

Conditional effect sizes are $+/-1$ SD. Effect size estimates are unstandardized coefficients. $*=p<.05, * *$

$=p<.01, * * *=p<.001$ 
Table 32: The moderating role of Locus of Control between workplace aggression and Negative Emotions

\begin{tabular}{|c|c|c|c|c|c|}
\hline Incivility & Coefficient & $S E$ & $t$ & $p$ & Model $\mathrm{R}^{2}$ \\
\hline \multicolumn{6}{|l|}{ Direct effects } \\
\hline \multicolumn{6}{|l|}{ Negative Emotions as DV } \\
\hline Age & -0.01 & 0.05 & -2.67 & 0.011 & \\
\hline Gender & 0.11 & 0.07 & 1.55 & 0.122 & \\
\hline Tenure & 0.00 & 0.00 & 0.51 & 0.613 & \\
\hline Locus of Control & -0.06 & 0.06 & -1.01 & 0.313 & \\
\hline Incivility & 0.72 & 0.04 & 16.48 & 0.000 & \\
\hline Incivility * Locus of Control & -0.20 & 0.07 & -2.98 & 0.003 & $.52 * * *$ \\
\hline Relationship Conflict & Coefficient & $S E$ & $t$ & $p$ & Model $\mathrm{R}^{2}$ \\
\hline \multicolumn{6}{|l|}{ Direct effects } \\
\hline \multicolumn{6}{|l|}{ Negative Emotions as DV } \\
\hline Age & -0.01 & 0.00 & -2.66 & 0.008 & \\
\hline Gender & -0.01 & 0.07 & -0.16 & 0.873 & \\
\hline Tenure & 0.00 & 0.00 & 0.73 & 0.464 & \\
\hline Locus of Control & -0.27 & 0.05 & -5.38 & 0.000 & \\
\hline Relationship Conflict & 0.72 & 0.05 & 14.82 & 0.000 & \\
\hline $\begin{array}{l}\text { Relationship Conflict * Locus of } \\
\text { Control }\end{array}$ & -0.29 & 0.07 & -3.97 & 0.000 & $.48 * * *$ \\
\hline Task Conflict & Coefficient & $S E$ & $t$ & $p$ & Model $\mathrm{R}^{2}$ \\
\hline \multicolumn{6}{|l|}{ Direct effects } \\
\hline \multicolumn{6}{|l|}{ Negative Emotions as DV } \\
\hline Age & -0.01 & 0.00 & -1.34 & 0.181 & \\
\hline Gender & 0.02 & 0.07 & 0.23 & 0.817 & \\
\hline Tenure & 0.00 & 0.00 & 0.09 & 0.931 & \\
\hline Locus of Control & -0.30 & 0.05 & -6.15 & 0.000 & \\
\hline Task Conflict & 0.70 & 0.05 & 15.20 & 0.000 & \\
\hline Task Conflict * Locus of Control & -0.19 & 0.06 & -2.98 & 0.003 & $.49 * * *$ \\
\hline
\end{tabular}

Note. $N=308 \mathrm{DV}=$ dependent variable. $\mathrm{SE}=$ standard error. Conditional effect sizes are $+/-1 \mathrm{SD}$. Effect size estimates are unstandardized coefficients. $*=p<.05, * *=p<.01, * * *=p<.001$ 
Table 33: The moderating role of Locus of Control on the Incivility to strain relationship

\begin{tabular}{|c|c|c|c|c|c|}
\hline Incivility & Coefficient & $S E$ & $t$ & $p$ & Model $\mathrm{R}^{2}$ \\
\hline \multicolumn{6}{|l|}{ Direct effects } \\
\hline \multicolumn{6}{|l|}{ Depression as DV } \\
\hline Age & 0.00 & 0.00 & -1.83 & 0.068 & \\
\hline Gender & 0.05 & 0.04 & 1.28 & 0.202 & \\
\hline Tenure & 0.00 & 0.00 & 0.40 & 0.689 & \\
\hline Locus of Control & -0.15 & 0.03 & -4.54 & 0.000 & \\
\hline Incivility & 0.43 & 0.02 & 19.00 & 0.000 & \\
\hline Incivility * Locus of Control & -0.20 & 0.03 & -5.83 & 0.000 & $.62 * * *$ \\
\hline \multicolumn{6}{|l|}{ Physical Symptoms as DV } \\
\hline Age & -0.02 & 0.01 & -3.30 & 0.001 & \\
\hline Gender & 0.04 & 0.08 & 0.57 & 0.571 & \\
\hline Tenure & 0.00 & 0.00 & 2.08 & 0.039 & \\
\hline Locus of Control & -0.18 & 0.07 & -2.65 & 0.008 & \\
\hline Incivility & 0.91 & 0.05 & 19.06 & 0.000 & \\
\hline Incivility * Locus of Control & -0.49 & 0.07 & -6.79 & 0.000 & $.60 * * *$ \\
\hline \multicolumn{6}{|l|}{ Stress as DV } \\
\hline Age & -0.01 & 0.00 & -2.83 & 0.005 & \\
\hline Gender & -0.03 & 0.04 & -0.78 & 0.438 & \\
\hline Tenure & 0.00 & 0.00 & -3.49 & 0.001 & \\
\hline Locus of Control & -0.19 & 0.04 & -5.18 & 0.000 & \\
\hline Incivility & 0.13 & 0.03 & 5.34 & 0.000 & \\
\hline Incivility * Locus of Control & 0.11 & 0.04 & 2.96 & 0.003 & $.47 * * *$ \\
\hline \multicolumn{6}{|l|}{ Job Satisfaction as DV } \\
\hline Age & 0.02 & 0.01 & 3.47 & 0.001 & \\
\hline Gender & 0.17 & 0.09 & 1.89 & 0.059 & \\
\hline Tenure & 0.00 & 0.00 & -2.49 & 0.010 & \\
\hline Locus of Control & 0.11 & 0.08 & 1.40 & 0.161 & \\
\hline Incivility & -0.18 & 0.06 & -3.20 & 0.002 & \\
\hline Incivility * Locus of Control & -0.02 & 0.08 & -0.26 & 0.794 & $.15 * * *$ \\
\hline
\end{tabular}

Note. $N=308 \mathrm{DV}=$ dependent variable. $\mathrm{SE}=$ standard error. 1,000 bootstrap samples. $\mathrm{LLCI}=$ bias corrected lower limit confidence interval. ULCI = bias corrected upper limit confidence interval.

Conditional effect sizes are $+/-1$ SD. Effect size estimates are unstandardized coefficients. $*=p<.05, * *$ $=p<.01, * * *=p<.001$ 
Table 33 continued: The moderating role of Locus of Control on the Incivility to strain relationship

\begin{tabular}{lrrrrr}
\hline & Coefficient & $S E$ & $t$ & $p$ & Model $^{2}$ \\
\hline Direct effects & & & & & \\
$\quad$ Life Satisfaction as DV & & & & & \\
Age & 0.02 & 0.01 & 3.79 & 0.000 & \\
Gender & 0.12 & 0.08 & 1.57 & 0.116 & \\
Tenure & 0.00 & 0.00 & -3.04 & 0.003 & \\
Locus of Control & 0.17 & 0.07 & 2.36 & 0.019 & \\
Incivility & 0.25 & 0.05 & 5.07 & 0.000 & $.18^{* * *}$ \\
Incivility * Locus of Control & -0.17 & 0.08 & -2.21 & 0.028 & bias \\
Note. $N=308$ DV $=$ dependent variable. SE $=$ standard error. 1,000 bootstrap samples. LLCI $=$ bial \\
corrected lower limit confidence interval. ULCI = bias corrected upper limit confidence interval. \\
Conditional effect sizes are $+/-1$ SD. Effect size estimates are unstandardized coefficients. $*=p<.05, * *$ \\
$=p<.01, * * *=p<.001$
\end{tabular}


Table 34: The moderating role of Locus of Control on the Relationship Conflict to strain relationship

\begin{tabular}{|c|c|c|c|c|c|}
\hline Relationship Conflict & Coefficient & $S E$ & $t$ & $p$ & Model $\mathrm{R}^{2}$ \\
\hline \multicolumn{6}{|l|}{ Direct effects } \\
\hline \multicolumn{6}{|l|}{ Depression as DV } \\
\hline Age & 0.00 & 0.00 & -1.41 & 0.156 & \\
\hline Gender & -0.02 & 0.04 & -0.56 & 0.573 & \\
\hline Tenure & 0.00 & 0.00 & 0.54 & 0.590 & \\
\hline Locus of Control & -0.25 & 0.03 & -8.66 & 0.000 & \\
\hline Relationship Conflict & 0.40 & 0.03 & 14.70 & 0.000 & \\
\hline $\begin{array}{l}\text { Relationship Conflict * Locus of } \\
\text { Control }\end{array}$ & -0.23 & 0.04 & -5.88 & 0.000 & $0.53^{* * *}$ \\
\hline \multicolumn{6}{|l|}{ Physical Symptoms as DV } \\
\hline Age & -0.02 & 0.01 & -2.89 & 0.004 & \\
\hline Gender & -0.10 & 0.08 & -1.21 & 0.227 & \\
\hline Tenure & 0.00 & 0.00 & 2.22 & 0.027 & \\
\hline Locus of Control & -0.36 & 0.06 & -6.34 & 0.000 & \\
\hline Relationship Conflict & 0.90 & 0.05 & 16.56 & 0.000 & \\
\hline $\begin{array}{l}\text { Relationship Conflict * Locus of } \\
\text { Control }\end{array}$ & -0.58 & 0.08 & -7.22 & 0.000 & $.55^{* * *}$ \\
\hline \multicolumn{6}{|l|}{ Stress as DV } \\
\hline Age & -0.01 & 0.00 & -3.31 & 0.001 & \\
\hline Gender & -0.06 & 0.04 & -1.38 & 0.170 & \\
\hline Tenure & 0.00 & 0.00 & -3.33 & 0.001 & \\
\hline Locus of Control & -0.32 & 0.03 & -10.60 & 0.000 & \\
\hline Relationship Conflict & 0.06 & 0.03 & 1.99 & 0.048 & \\
\hline $\begin{array}{l}\text { Relationship Conflict * Locus of } \\
\text { Control }\end{array}$ & 0.00 & 0.04 & -0.01 & 0.991 & $.40 * * *$ \\
\hline \multicolumn{6}{|l|}{ Job Satisfaction as DV } \\
\hline Age & 0.02 & 0.01 & 3.41 & 0.000 & \\
\hline Gender & 0.21 & 0.09 & 2.39 & 0.018 & \\
\hline Tenure & 0.00 & 0.00 & -2.48 & 0.014 & \\
\hline Locus of Control & 0.15 & 0.06 & 2.38 & 0.018 & \\
\hline Relationship Conflict & -0.17 & 0.06 & -2.93 & 0.004 & \\
\hline $\begin{array}{l}\text { Relationship Conflict* Locus of } \\
\text { Control }\end{array}$ & -0.17 & 0.09 & -1.98 & 0.049 & $.16^{* * *}$ \\
\hline
\end{tabular}

Note. $N=308 \mathrm{DV}=$ dependent variable. $\mathrm{SE}=$ standard error. 1,000 bootstrap samples. $\mathrm{LLCI}=$ bias corrected lower limit confidence interval. ULCI = bias corrected upper limit confidence interval.

Conditional effect sizes are $+/-1 \mathrm{SD}$. Effect size estimates are unstandardized coefficients. $*=p<.05, * *$ $=p<.01, * * *=p<.001$ 
Table 34 continued: The moderating role of Locus of Control on the Relationship Conflict to strain relationship

\begin{tabular}{lrrrrr}
\hline & Coefficient & $S E$ & \multicolumn{1}{c}{$t$} & $p$ & Model R $^{2}$ \\
\hline Direct effects & & & & & \\
$\quad$ Life Satisfaction as DV & & & & & \\
$\quad$ Age & 0.02 & 0.01 & 3.95 & 0.000 & \\
$\quad$ Gender & 0.09 & 0.08 & 1.16 & 0.248 & \\
$\quad$ Tenure & 0.00 & 0.00 & -2.93 & 0.004 & \\
$\quad$ Locus of Control & 0.14 & 0.05 & 2.49 & 0.013 & \\
$\quad$ Relationship Conflict & 0.31 & 0.05 & 5.92 & 0.000 & \\
$\quad$ Relationship Conflict * Locus of & & & & & \\
Control & -0.20 & 0.08 & -2.66 & 0.008 & $.21^{* * *}$ \\
\hline
\end{tabular}

Note. $N=308 \mathrm{DV}=$ dependent variable. $\mathrm{SE}=$ standard error. 1,000 bootstrap samples. $\mathrm{LLCI}=$ bias corrected lower limit confidence interval. ULCI $=$ bias corrected upper limit confidence interval.

Conditional effect sizes are $+/-1 \mathrm{SD}$. Effect size estimates are unstandardized coefficients. $*=p<.05, * *$ $=p<.01, * * *=p<.001$ 
Table 35: The moderating role of Locus of Control on the Task Conflict to strain relationship

\begin{tabular}{|c|c|c|c|c|c|}
\hline Task Conflict & Coefficient & $S E$ & $t$ & $p$ & Model $\mathrm{R}^{2}$ \\
\hline \multicolumn{6}{|l|}{ Direct effects } \\
\hline \multicolumn{6}{|l|}{ Depression as DV } \\
\hline Age & 0.00 & 0.00 & -0.59 & 0.558 & \\
\hline Gender & -0.01 & 0.04 & -0.21 & 0.836 & \\
\hline Tenure & 0.00 & 0.00 & -0.21 & 0.834 & \\
\hline Locus of Control & -0.26 & 0.03 & -9.78 & 0.000 & \\
\hline Task Conflict & 0.40 & 0.03 & 15.81 & 0.000 & \\
\hline Task Conflict * Locus of Control & -0.22 & 0.04 & -6.13 & 0.000 & $.56^{* * *}$ \\
\hline \multicolumn{6}{|l|}{ Direct effects } \\
\hline \multicolumn{6}{|l|}{ Physical Symptoms as DV } \\
\hline Age & -0.01 & 0.01 & -1.85 & 0.066 & \\
\hline Gender & -0.07 & 0.08 & -0.86 & 0.390 & \\
\hline Tenure & 0.00 & 0.00 & 1.37 & 0.173 & \\
\hline Locus of Control & -0.37 & 0.05 & -6.85 & 0.000 & \\
\hline Task Conflict & 0.85 & 0.05 & 16.47 & 0.000 & \\
\hline Task Conflict * Locus of Control & -0.48 & 0.07 & -6.62 & 0.000 & $.55^{* * *}$ \\
\hline \multicolumn{6}{|l|}{ Stress as DV } \\
\hline Age & -0.01 & 0.00 & -2.79 & 0.006 & \\
\hline Gender & -0.05 & 0.04 & -1.31 & 0.191 & \\
\hline Tenure & 0.00 & 0.00 & -3.52 & 0.001 & \\
\hline Locus of Control & -0.31 & 0.03 & -11.09 & 0.000 & \\
\hline Task Conflict & 0.07 & 0.03 & 2.57 & 0.011 & \\
\hline Task Conflict * Locus of Control & 0.04 & 0.04 & 1.14 & 0.255 & $.41 * * *$ \\
\hline \multicolumn{6}{|l|}{ Job Satisfaction as DV } \\
\hline Age & 0.02 & 0.01 & 3.27 & 0.001 & \\
\hline Gender & 0.19 & 0.09 & 2.19 & 0.030 & \\
\hline Tenure & 0.00 & 0.00 & -2.34 & 0.020 & \\
\hline Locus of Control & 0.20 & 0.06 & 3.43 & 0.001 & \\
\hline Task Conflict & -0.15 & 0.06 & -2.70 & 0.007 & \\
\hline Task Conflict * Locus of Control & -0.01 & 0.08 & -0.17 & 0.867 & $.14^{* * *}$ \\
\hline
\end{tabular}

Note. $N=308 \mathrm{DV}=$ dependent variable. $\mathrm{SE}=$ standard error. 1,000 bootstrap samples. $\mathrm{LLCI}=$ bias corrected lower limit confidence interval. ULCI $=$ bias corrected upper limit confidence interval. Conditional effect sizes are $+/-1$ SD. Effect size estimates are unstandardized coefficients. $*=p<.05, * *$ $=p<.01, * * *=p<.001$ 
Table 35 continued: The moderating role of Locus of Control on the Task Conflict to strain relationship

\begin{tabular}{lllll} 
Coefficient & $S E$ & $t$ & $p$ & Model R $^{2}$ \\
\hline
\end{tabular}

Direct effects

Life Satisfaction as DV

$\begin{array}{lrrrr}\text { Age } & 0.02 & 0.01 & 4.49 & 0.000 \\ \text { Gender } & 0.10 & 0.08 & 1.30 & 0.195 \\ \text { Tenure } & 0.00 & 0.00 & -3.29 & 0.001 \\ \text { Locus of Control } & 0.14 & 0.05 & 2.81 & 0.005 \\ \text { Task Conflict } & 0.32 & 0.05 & 6.48 & 0.000 \\ \text { Task Conflict * Locus of Control } & -0.11 & 0.07 & -1.58 & 0.115\end{array}$

Note. $N=308 \mathrm{DV}=$ dependent variable. $\mathrm{SE}=$ standard error. 1,000 bootstrap samples. $\mathrm{LLCI}=$ bias corrected lower limit confidence interval. ULCI = bias corrected upper limit confidence interval.

Conditional effect sizes are $+/-1 \mathrm{SD}$. Effect size estimates are unstandardized coefficients. $*=p<.05, * *$ $=p<.01,{ }^{* * *}=p<.001$ 
Figure 1: Emotion centered model of job stress (Spector \& Bruk-Lee, 2008)

\begin{tabular}{|c|c|}
\hline $\begin{array}{c}\text { Stressors: } \\
\text { Incivility, } \\
\text { Relationship } \\
\text { Conflict } \\
\text { Task }\end{array} \longrightarrow \begin{array}{c}\text { Emotion: } \\
\text { Anxiety } \\
\text { Anger } \\
\text { Frustration }\end{array} \longrightarrow \begin{array}{c}\text { Strains: } \\
\text { Behavioral } \\
\text { Physical } \\
\text { Psychological }\end{array}$ \\
\hline
\end{tabular}

Figure 1a: Proposed models

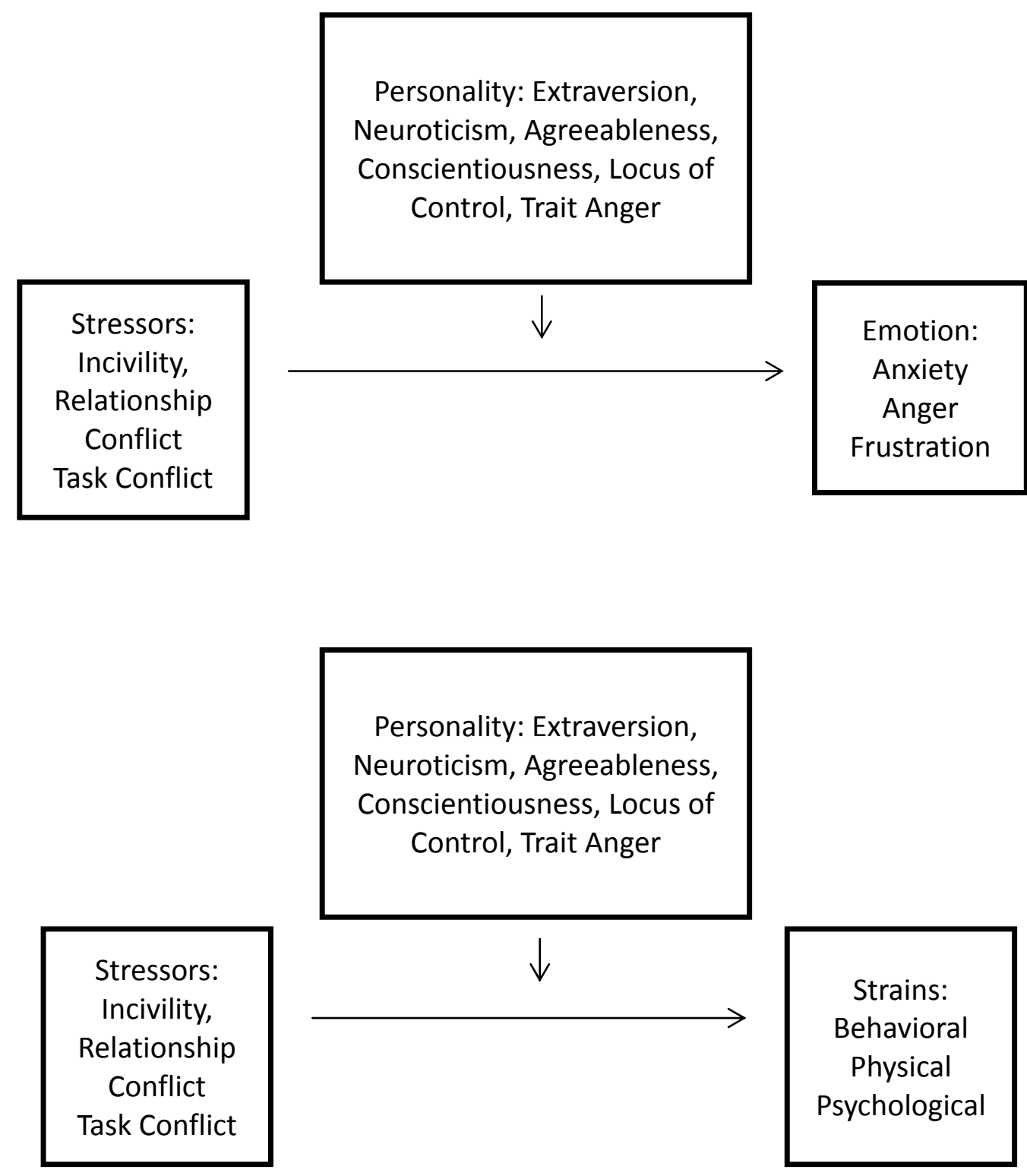


Figure 2: Extraversion moderating the incivility to depression relationship

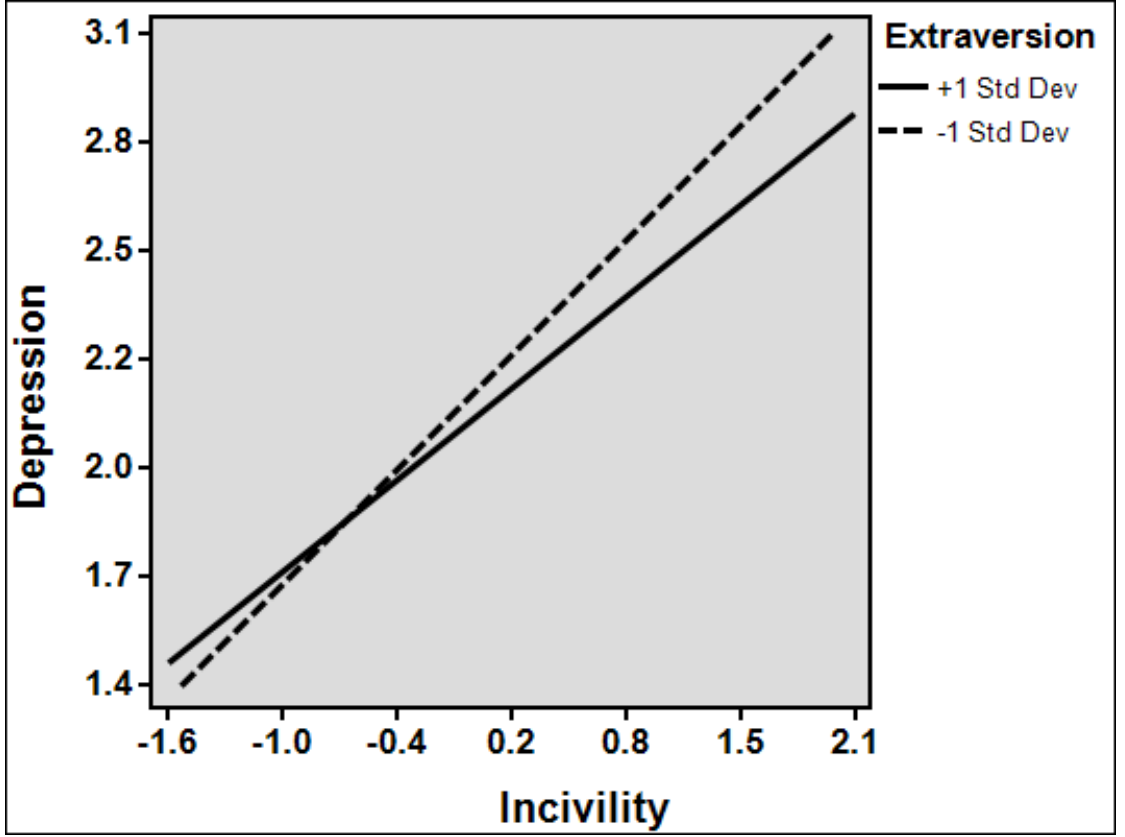

Note: -1 Std Dev effect size $=0.48, L L I C=0.41, U L C I=0.55,+1$ Std Dev effect size $=0.38, L L C I=0.33$, $U L C I=0.44$. $L L C I=$ lower limit confidence interval. $\mathrm{ULCI}=$ upper limit confidence interval.

Figure 3: Extraversion moderating the incivility to physical symptoms relationship

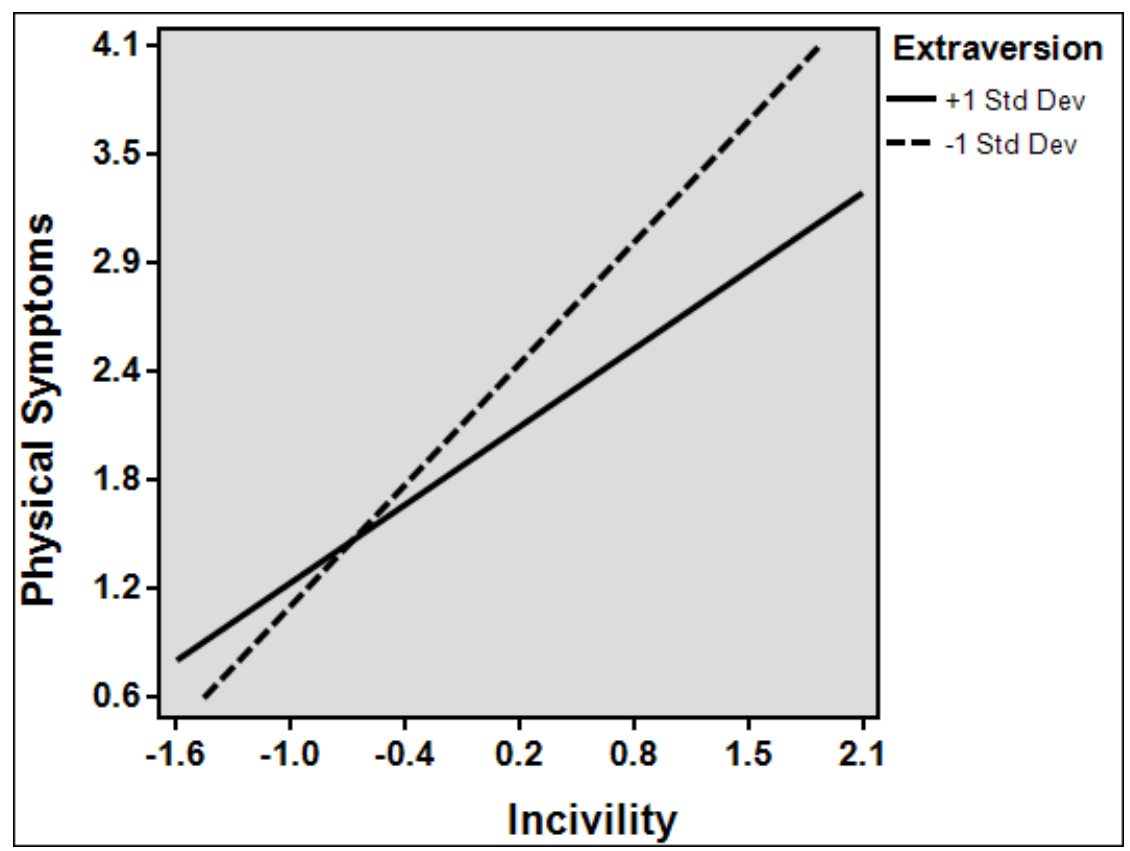

Note: -1 Std Dev effect size $=1.03, L L I C=0.89, U L C I=1.17,+1$ Std Dev effect size $=0.66, L L C I=0.54$, $U L C I=0.78 . \mathrm{LLCI}=$ lower limit confidence interval. $\mathrm{ULCI}=$ upper limit confidence interval. 
Figure 4: Extraversion moderating the incivility to job satisfaction relationship

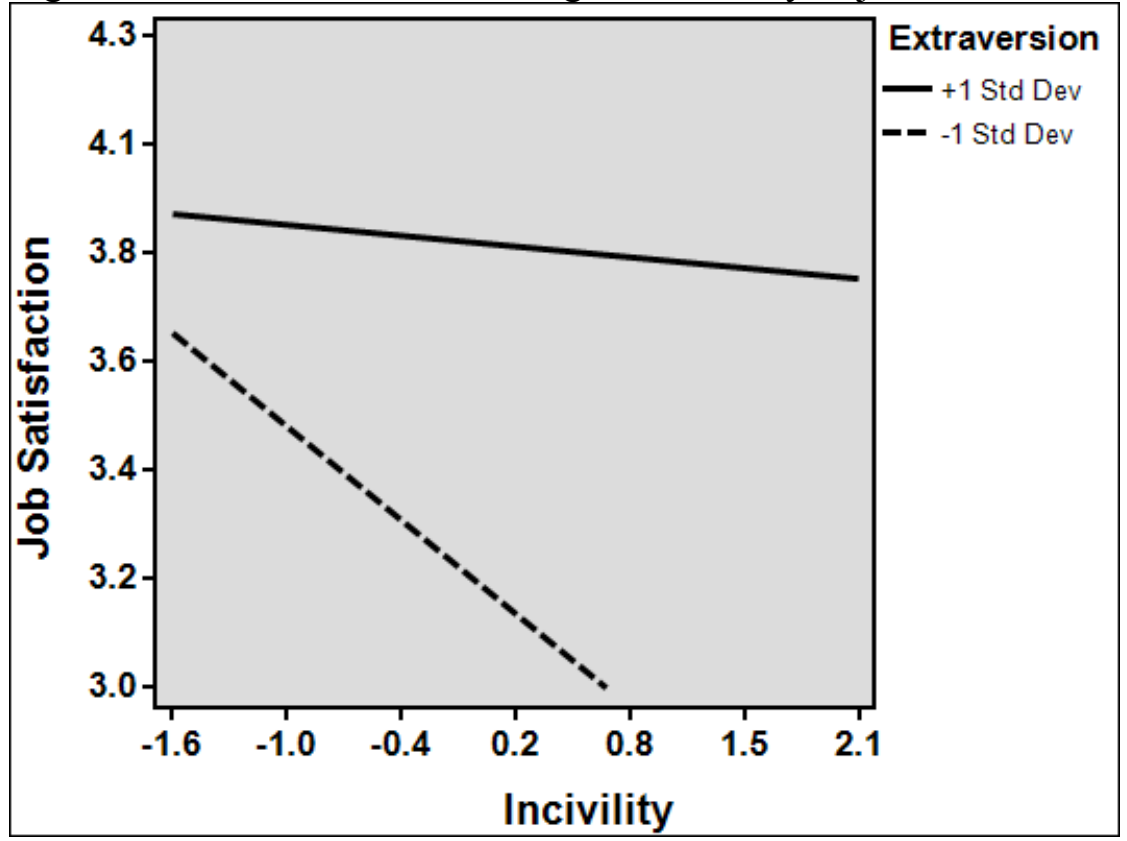

Note: -1 Std Dev effect size $=-0.31, L L I C=-0.45, U L C I=-0.16,+1$ Std Dev effect size $=-0.04, L L C I=-$ $0.16, U L C I=0.09 . \mathrm{LLCI}=$ lower limit confidence interval. $\mathrm{ULCI}=$ upper limit confidence interval.

Figure 5: Extraversion moderating the relationship conflict to depression relationship

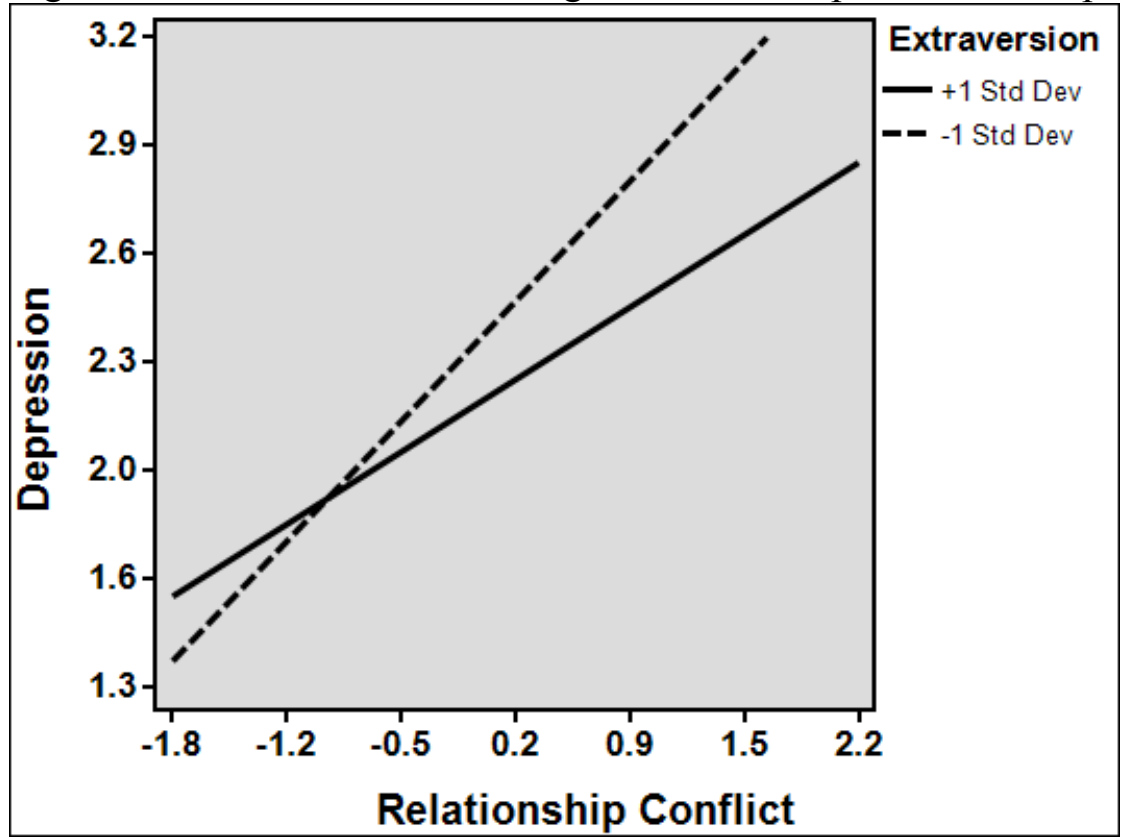

Note: -1 Std Dev effect size $=0.53, L L I C=0.44, U L C I=0.63,+1$ Std Dev effect size $=0.32, L L C I=0.24$, $U L C I=0.40 . \mathrm{LLCI}=$ lower limit confidence interval. $\mathrm{ULCI}=$ upper limit confidence interval. 
Figure 6: Extraversion moderating the relationship conflict to physical symptoms relationship

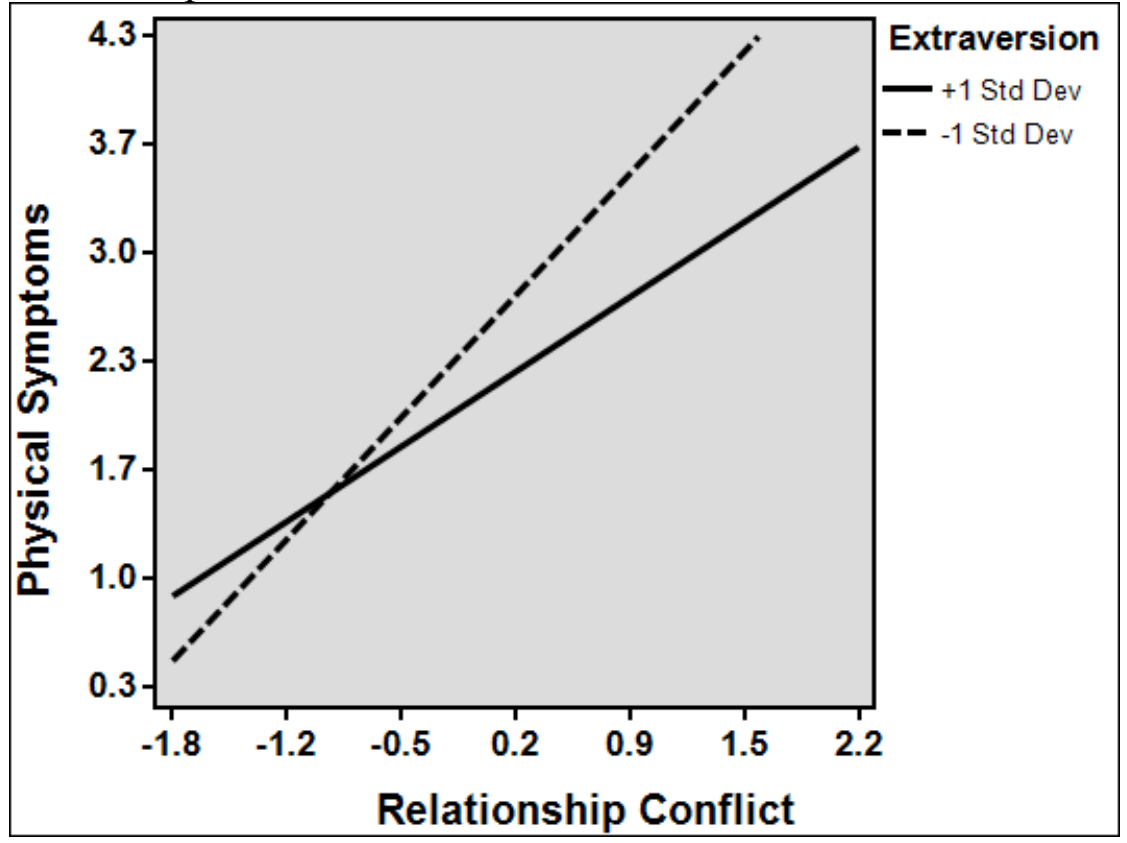

Note: -1 Std Dev effect size $=1.13, L L I C=0.94 U L C I=1.31,+1$ Std Dev effect size $=0.69, L L C I=0.54$, $U L C I=0.84 . \mathrm{LLCI}=$ lower limit confidence interval. $\mathrm{ULCI}=$ upper limit confidence interval.

Figure 7: Extraversion moderating the relationship conflict to stress relationship

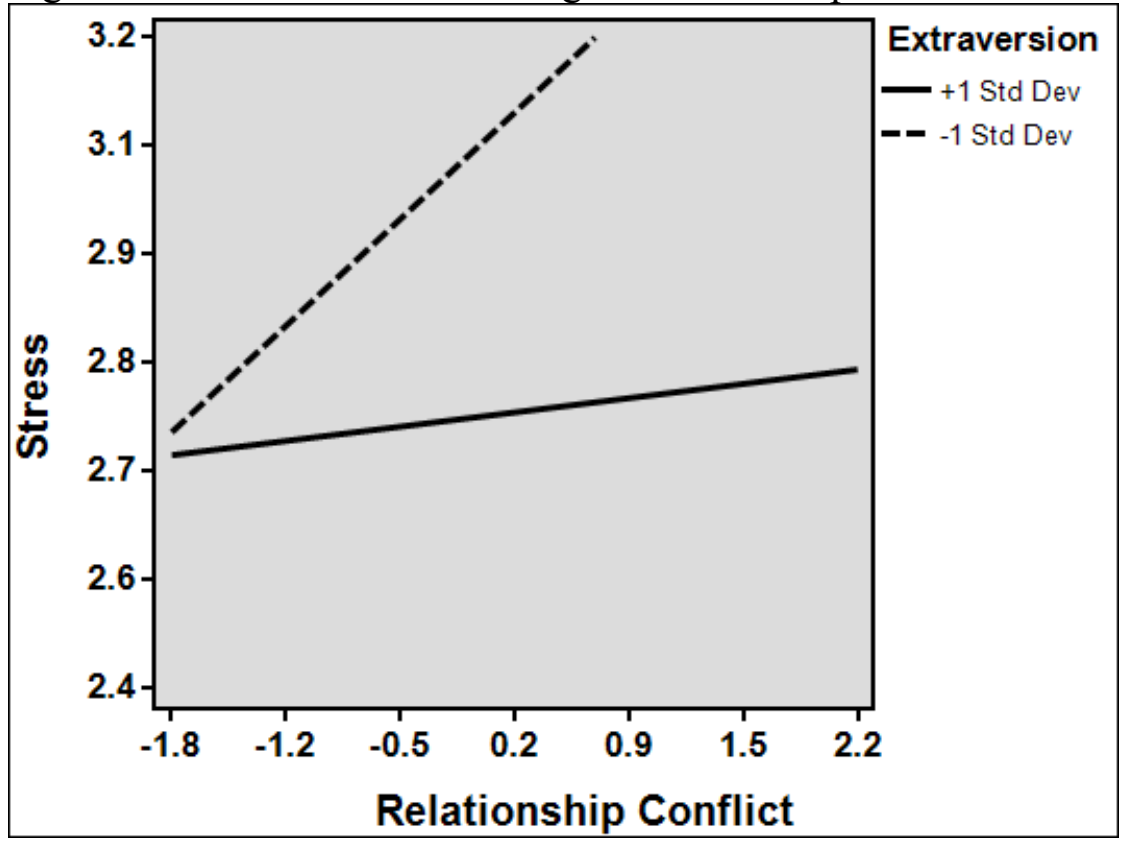

Note: -1 Std Dev effect size $=0.19, L L I C=0.09, U L C I=0.29,+1$ Std Dev effect size $=0.03, L L C I=$ $-0.06, U L C I=0.11$. LLCI $=$ lower limit confidence interval. $\mathrm{ULCI}=$ upper limit confidence interval. 
Figure 8: Extraversion moderating the relationship conflict to life satisfaction relationship

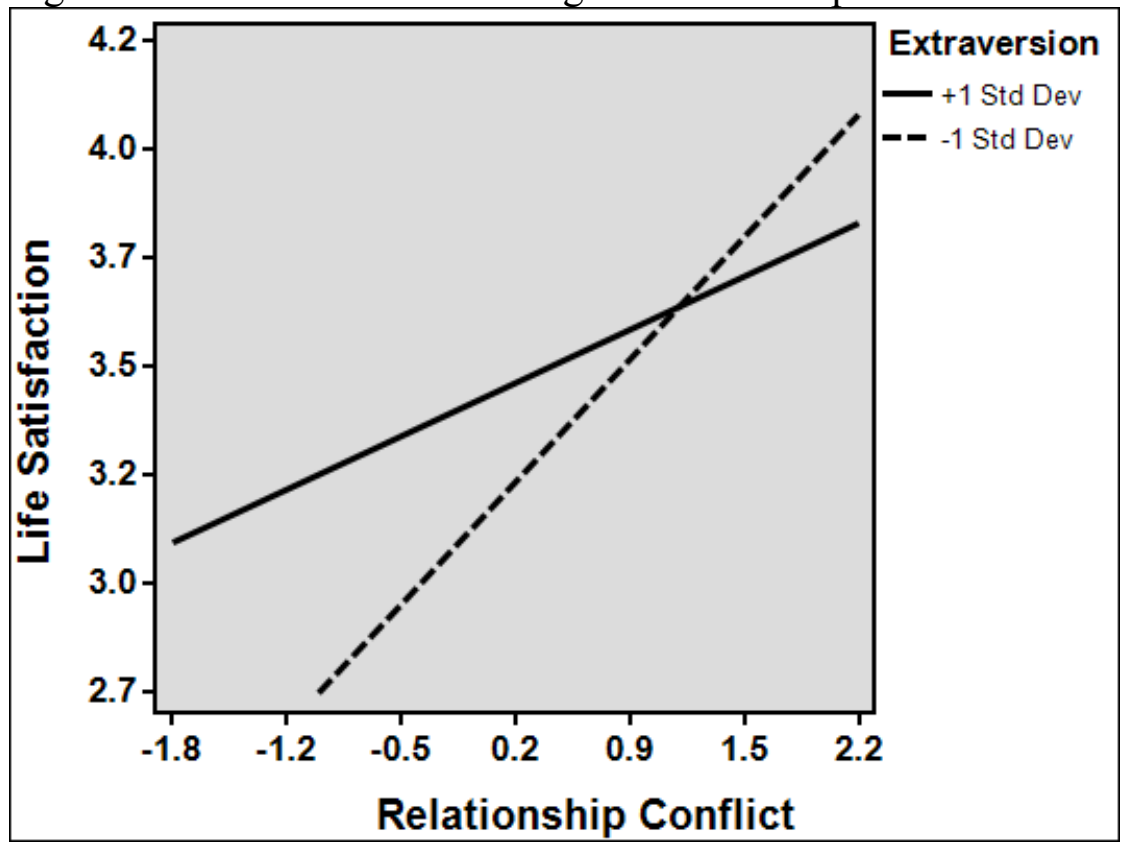

Note: -1 Std Dev effect size $=0.42, L L I C=0.26, U L C I=0.59,+1$ Std Dev effect size $=0.18, L L C I=0.05$, $U L C I=0.32$. LLCI $=$ lower limit confidence interval. $\mathrm{ULCI}=$ upper limit confidence interval.

Figure 9: Extraversion moderating the task conflict to depression relationship

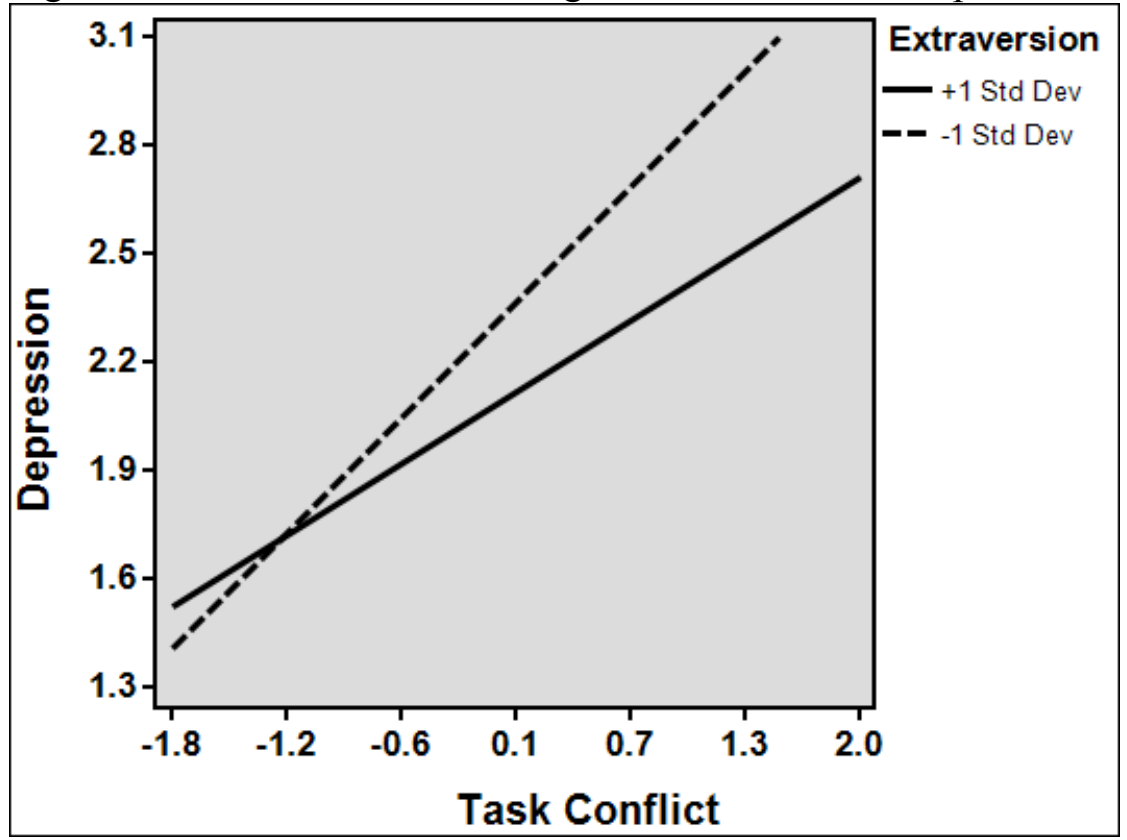

Note: -1 Std Dev effect size $=0.51, L L I C=0.42, U L C I=0.59,+1$ Std Dev effect size $=0.32, L L C I=0.29$, $U L C I=0.39$. LLCI $=$ lower limit confidence interval. ULCI $=$ upper limit confidence interval. 
Figure 10: Extraversion moderating the task conflict to physical symptoms relationship

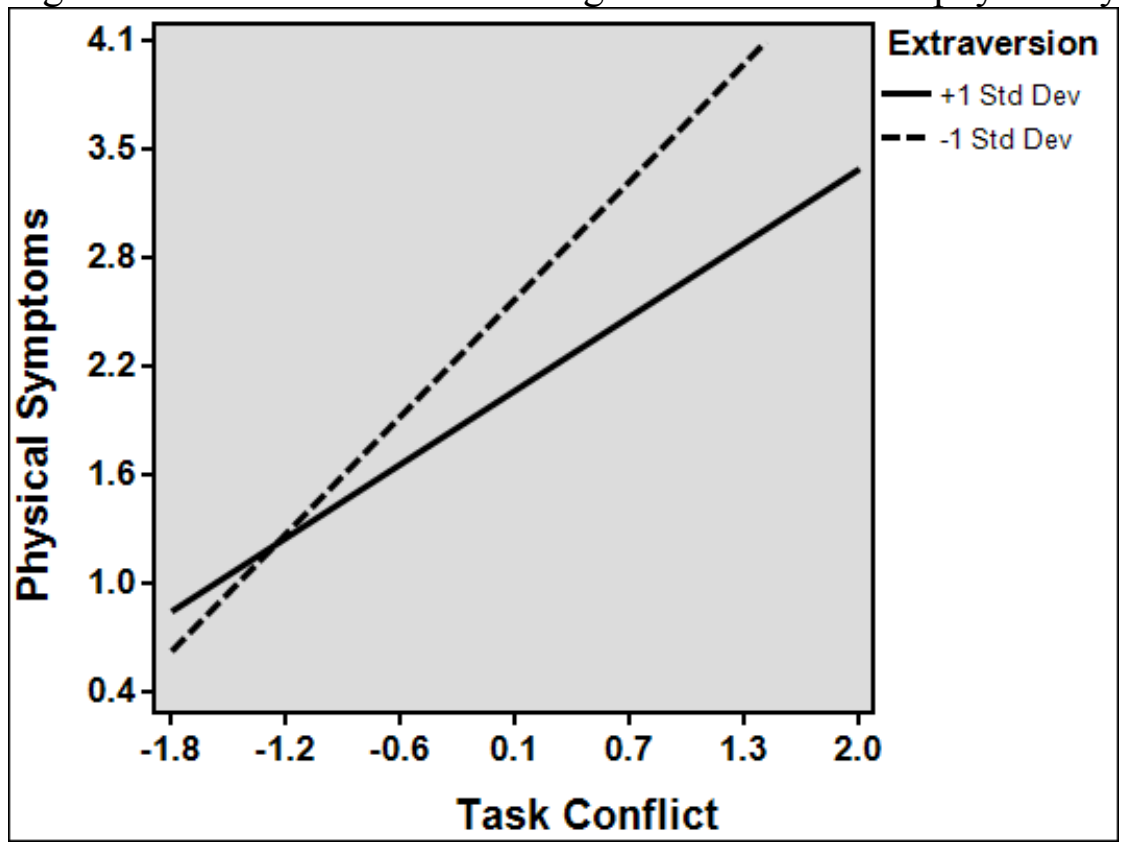

Note: -1 Std Dev effect size $=1.07, L L I C=0.90, U L C I=1.23,+1$ Std Dev effect size $=0.67, L L C I=0.52$, $U L C I=0.82 . \mathrm{LLCI}=$ lower limit confidence interval. $\mathrm{ULCI}=$ upper limit confidence interval.

Figure 11: Neuroticism moderating the incivility to negative emotions relationship

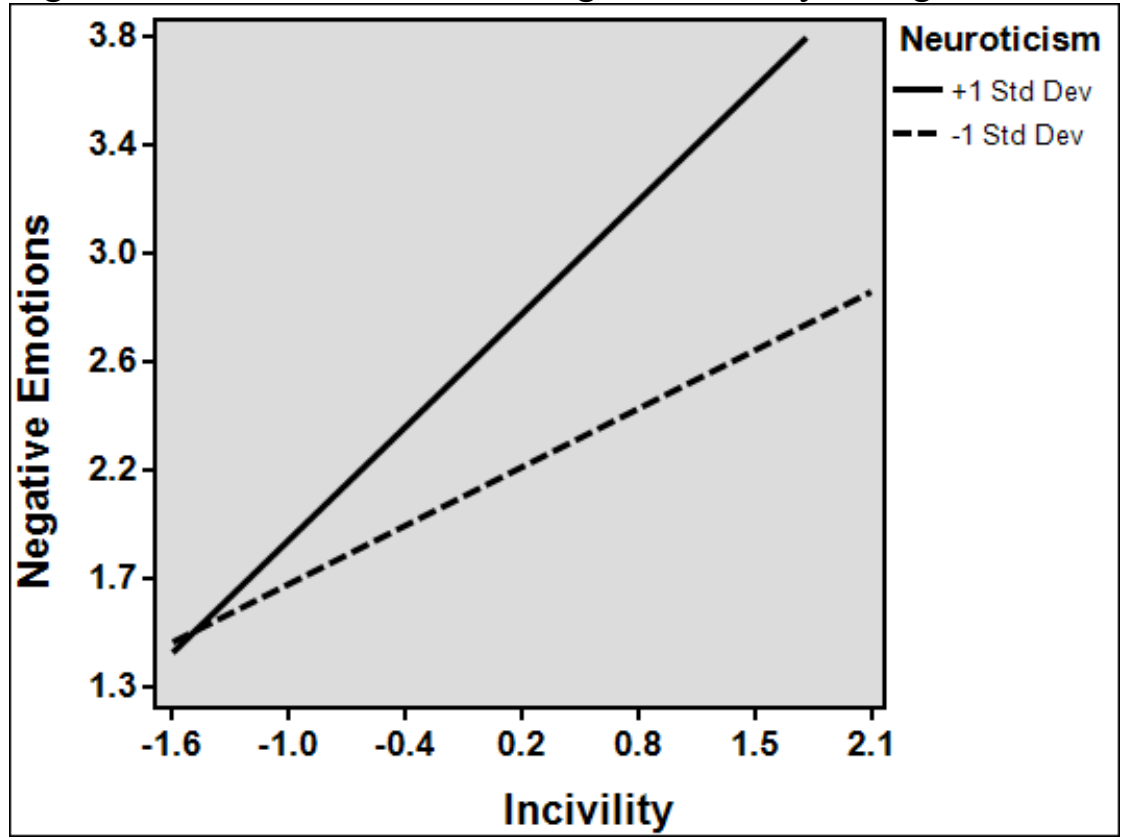

Note: -1 Std Dev effect size $=0.37, L L I C=0.25, U L C I=0.48,+1$ Std Dev effect size $=0.71, L L C I=0.61$, $U L C I=0.81$. LLCI $=$ lower limit confidence interval. ULCI $=$ upper limit confidence interval. 
Figure 12: Neuroticism moderating the relationship conflict to negative emotions relationship

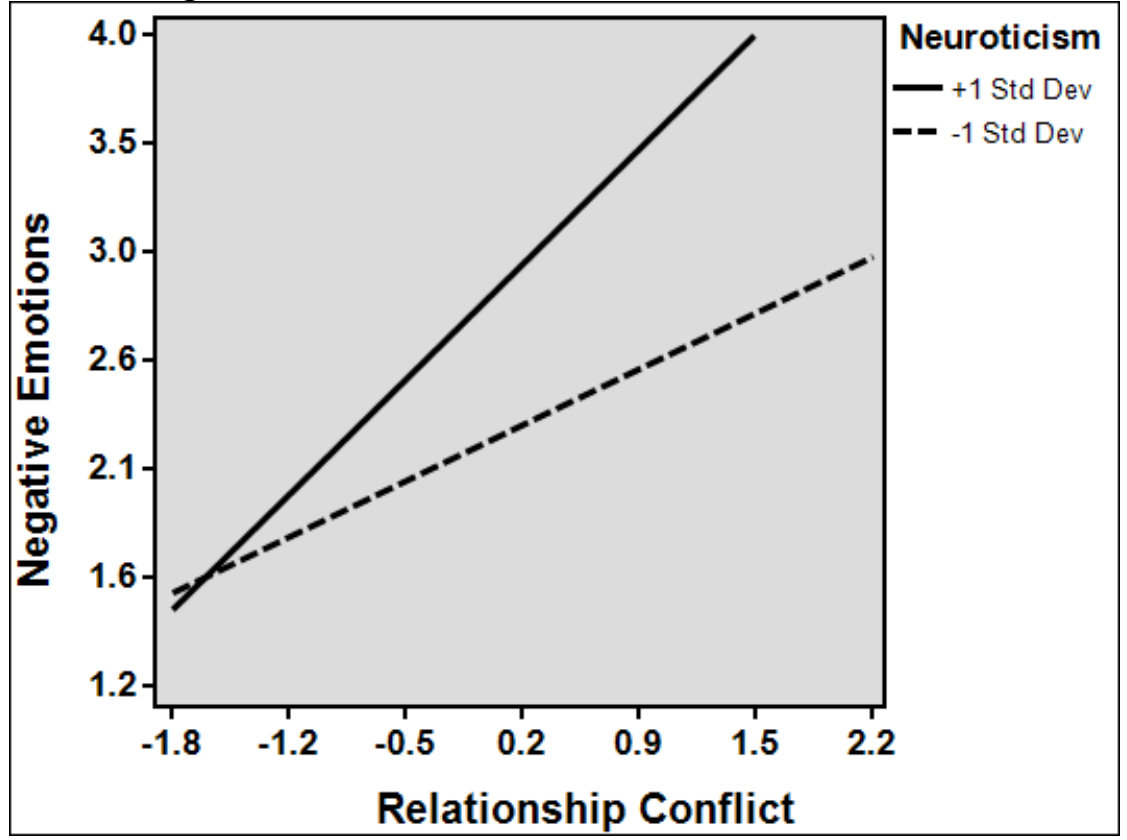

Note: -1 Std Dev effect size $=0.36, L L I C=0.22, U L C I=0.50,+1$ Std Dev effect size $=0.74, L L C I=0.63$, $U L C I=0.86 . \mathrm{LLCI}=$ lower limit confidence interval. $\mathrm{ULCI}=$ upper limit confidence interval.

Figure 13: Neuroticism moderating the task conflict to negative emotions relationship

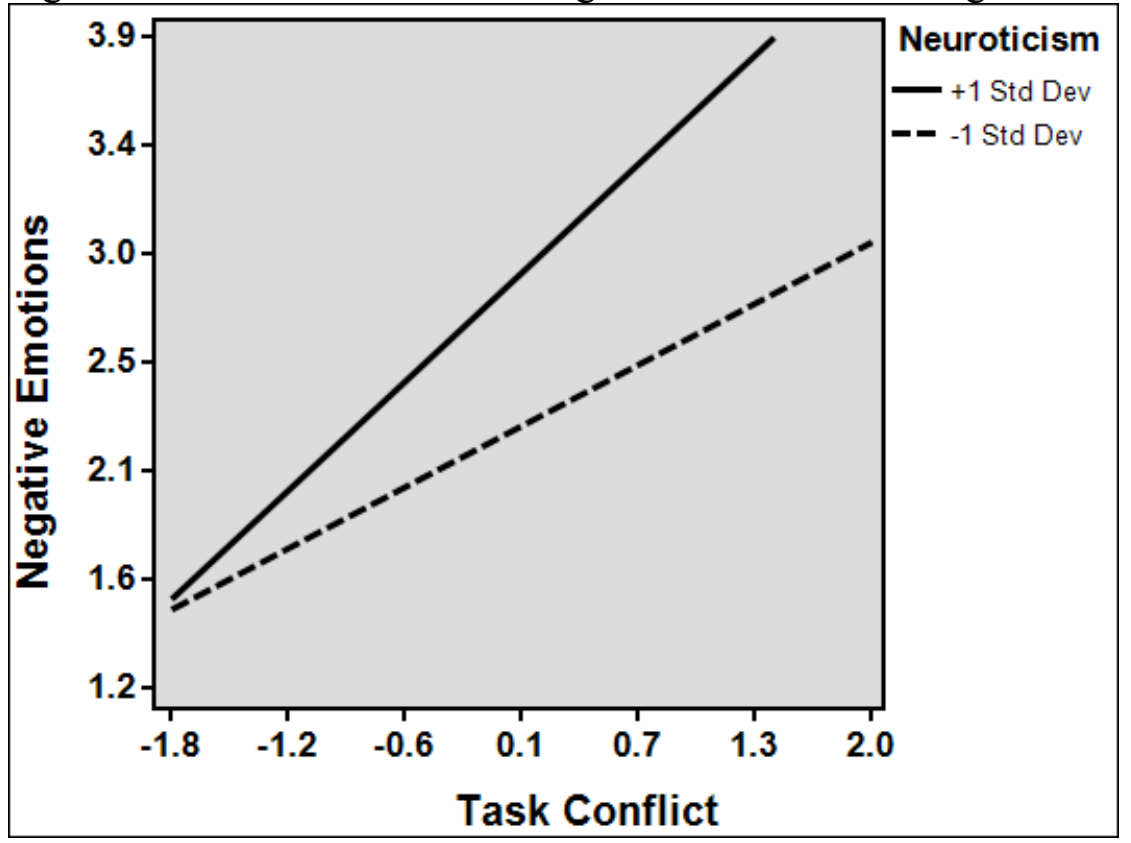

Note: -1 Std Dev effect size $=0.40, L L I C=0.27, U L C I=0.54,+1$ Std Dev effect size $=0.71, L L C I=0.60$, $U L C I=0.83 . \mathrm{LLCI}=$ lower limit confidence interval. $\mathrm{ULCI}=$ upper limit confidence interval. 
Figure 14: Neuroticism moderating the incivility to depression relationship

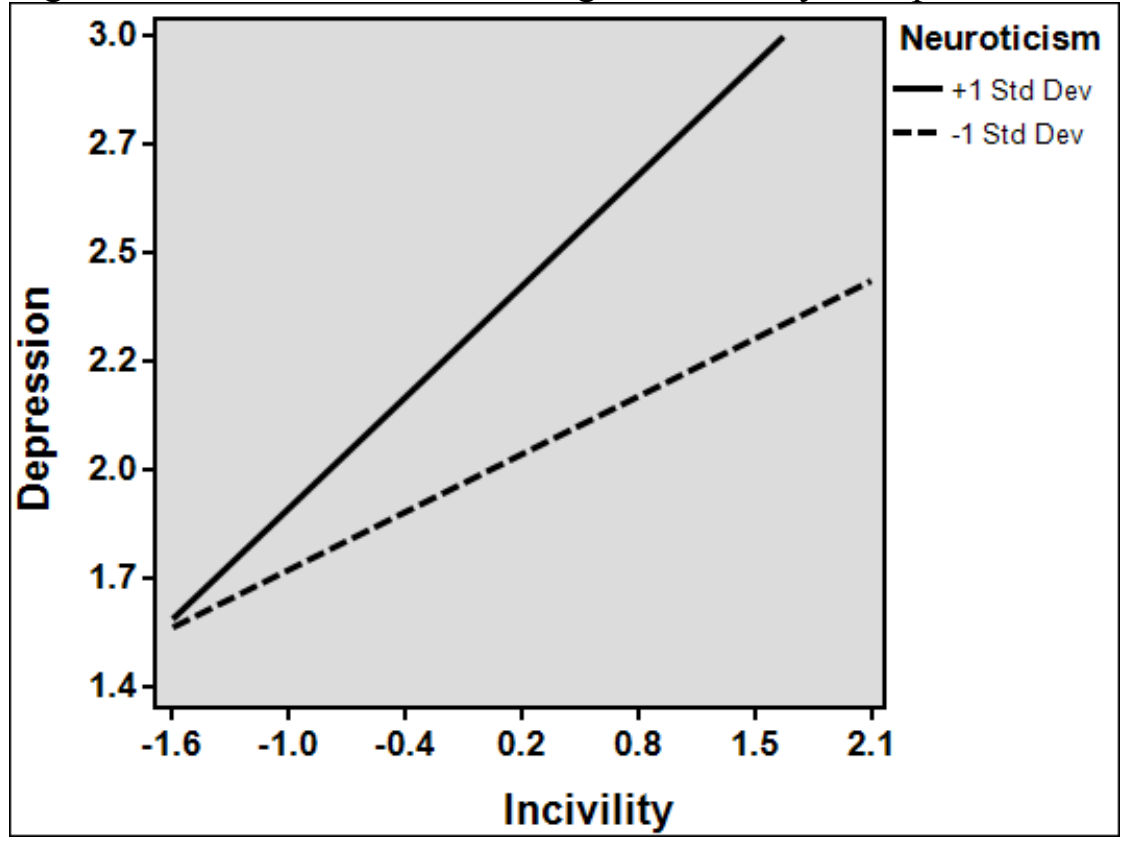

Note: -1 Std Dev effect size $=0.22, L L I C=0.16, U L C I=0.29,+1$ Std Dev effect size $=0.43, L L C I=0.38$, $U L C I=0.48$. LLCI $=$ lower limit confidence interval. ULCI $=$ upper limit confidence interval.

Figure 15: Neuroticism moderating the incivility to physical symptoms relationship

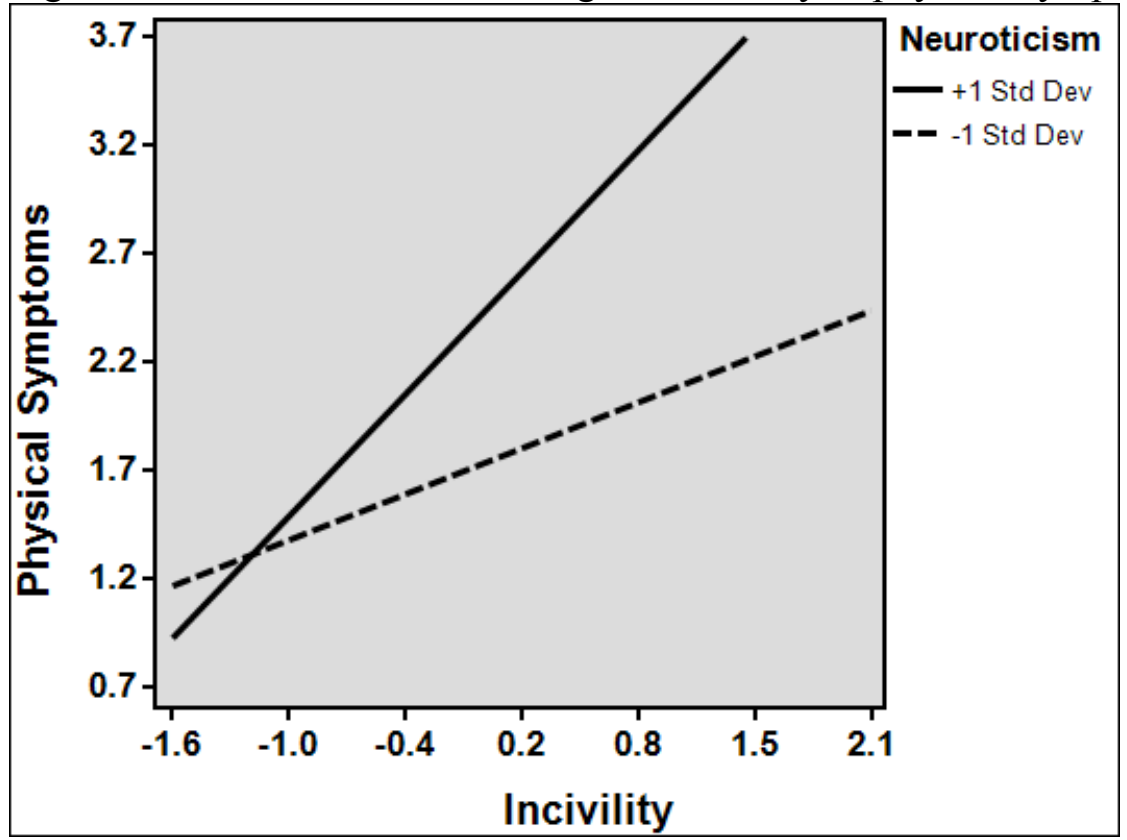

Note: -1 Std Dev effect size $=0.35, L L I C=0.22, U L C I=0.48,+1$ Std Dev effect size $=0.9 ., L L C I=0.82$, $U L C I=1.04 . \mathrm{LLCI}=$ lower limit confidence interval. ULCI $=$ upper limit confidence interval. 
Figure 16: Neuroticism moderating the incivility to stress relationship

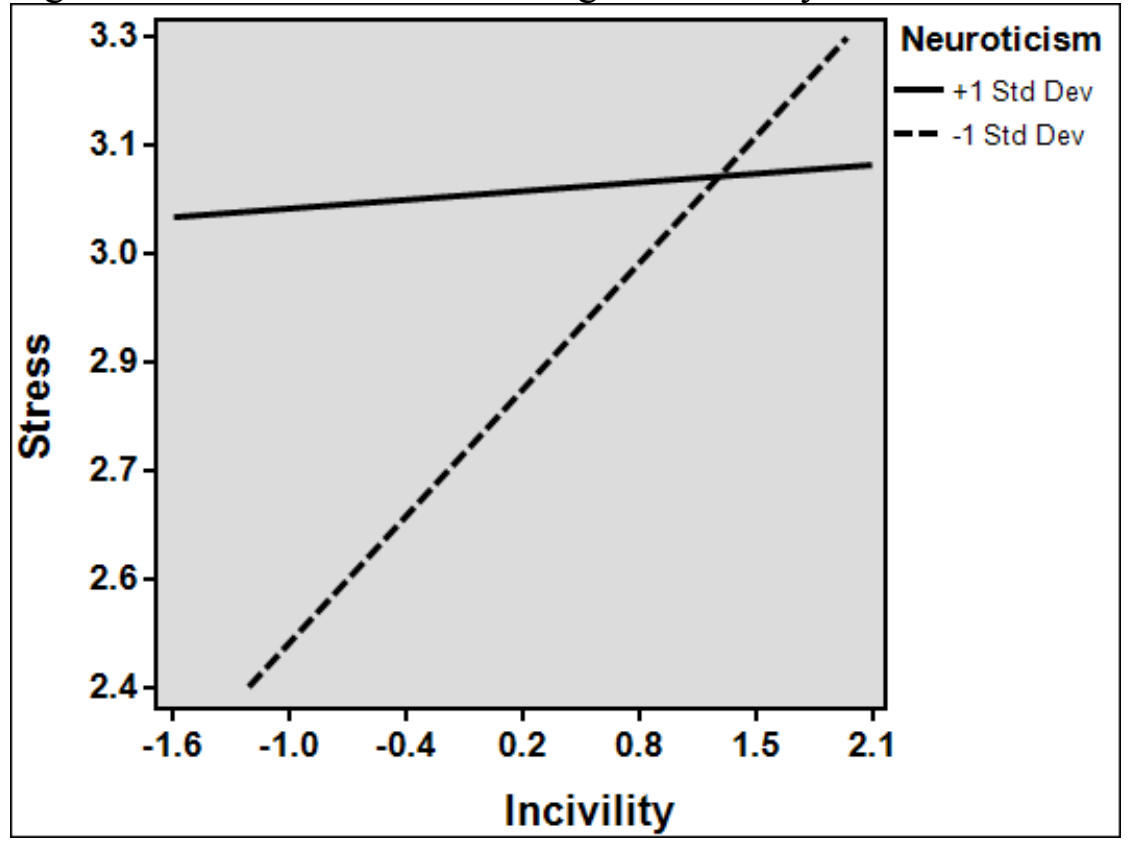

Note: -1 Std Dev effect size $=0.26, L L I C=0.20, U L C I=0.33,+1$ Std Dev effect size $=0.02, L L C I=$ $0.04, U L C I=0.08$. LLCI $=$ lower limit confidence interval. ULCI $=$ upper limit confidence interval.

Figure 17: Neuroticism moderating the incivility to life satisfaction relationship

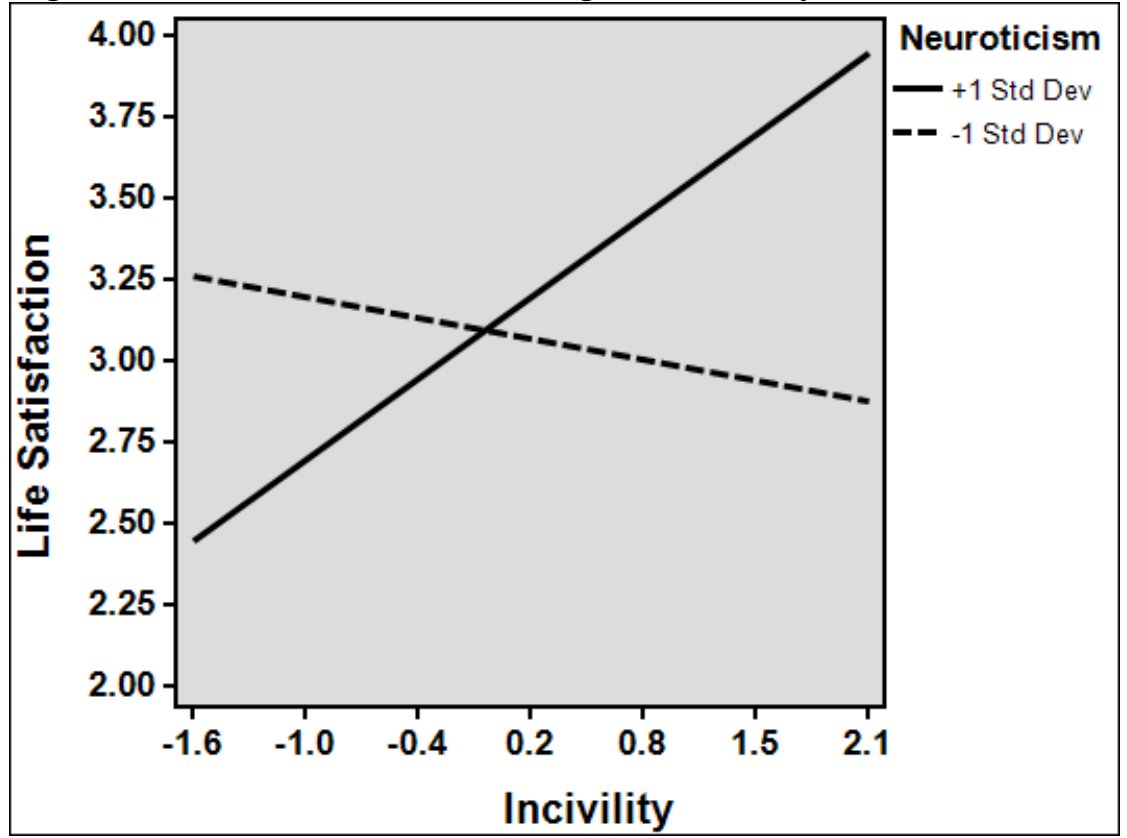

Note: -1 Std Dev effect size $=-0.10, L L I C=-0.24, U L C I=0.03,+1$ Std Dev effect size $=0.40, L L C I=$ $0.29, U L C I=0.52 . \mathrm{LLCI}=$ lower limit confidence interval. ULCI $=$ upper limit confidence interval. 
Figure 18: Neuroticism moderating the relationship conflict to depression relationship

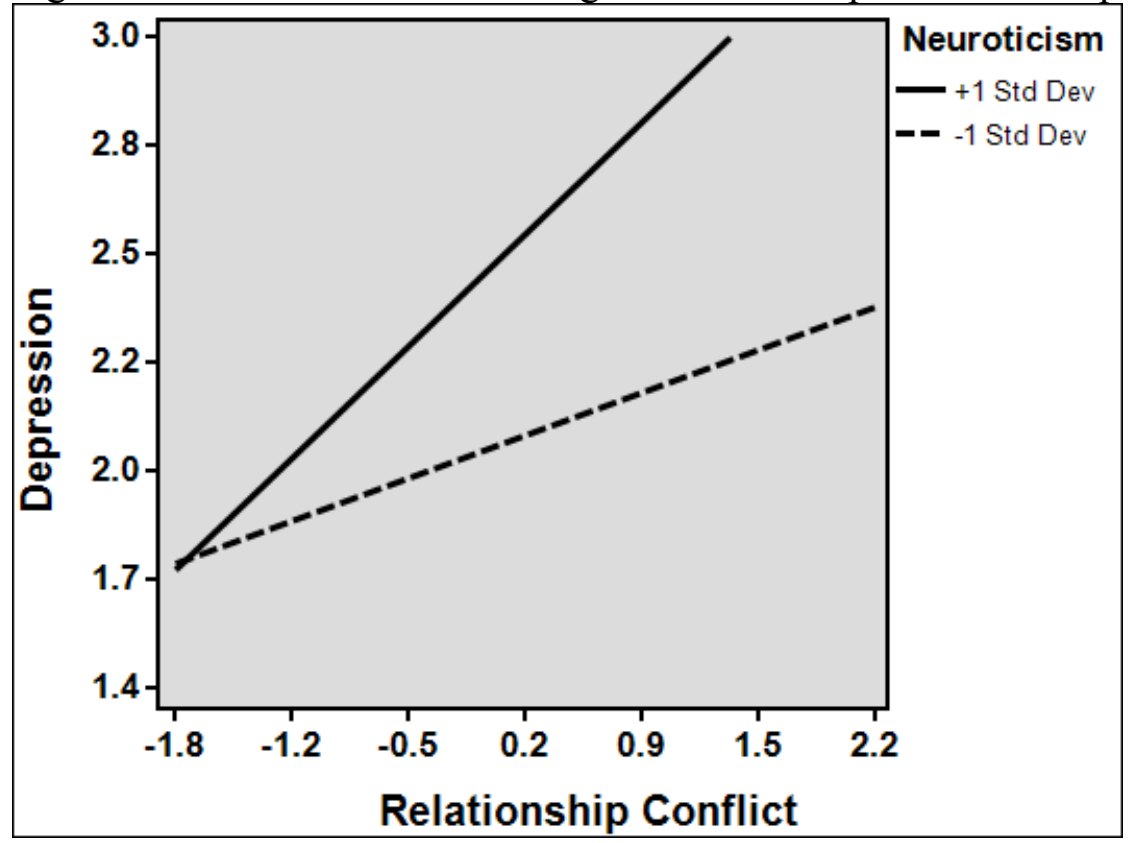

Note: -1 Std Dev effect size $=0.16, L L I C=0.08, U L C I=0.24,+1$ Std Dev effect size $=0.42, L L C I=0.35$, $U L C I=0.48$. LLCI $=$ lower limit confidence interval. $\mathrm{ULCI}=$ upper limit confidence interval.

Figure 19: Neuroticism moderating the relationship conflict to physical symptoms relationship

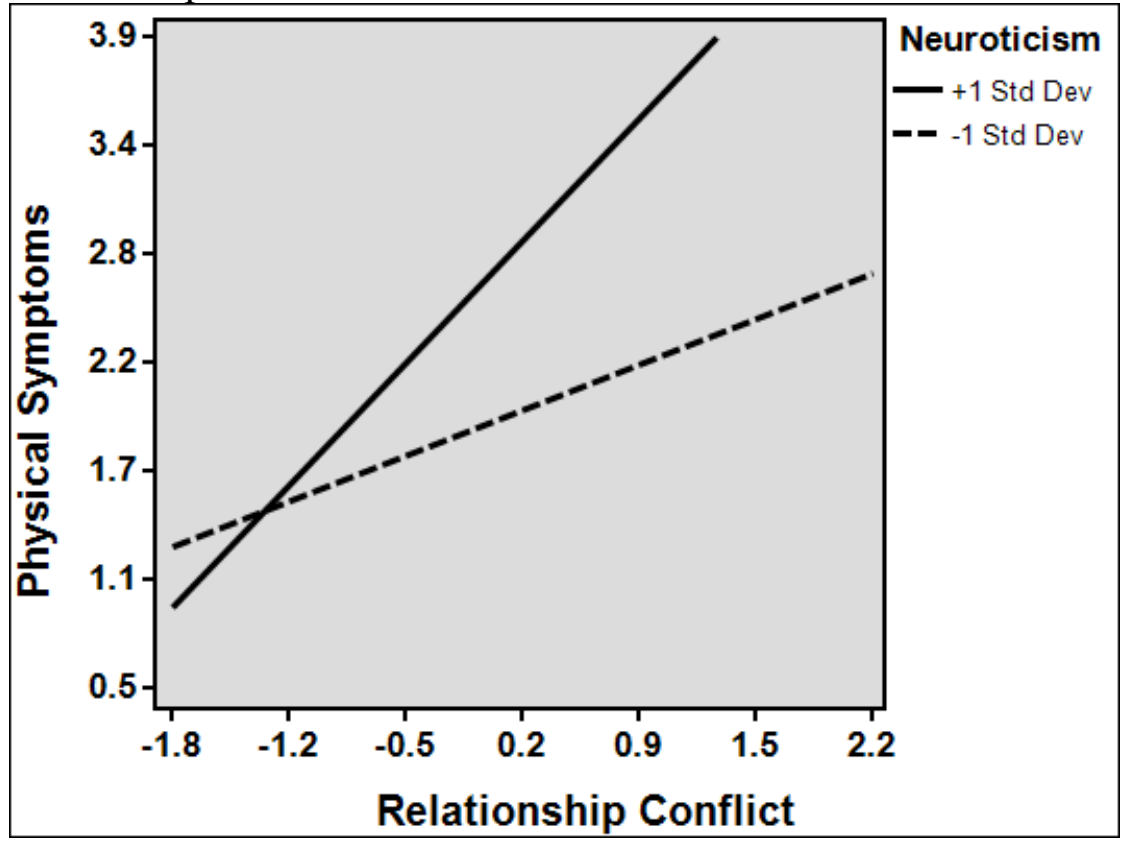

Note: -1 Std Dev effect size $=0.36, L L I C=0.20, U L C I=0.52,+1$ Std Dev effect size $=0.96, L L C I=0.83$, $U L C I=1.09 . \mathrm{LLCI}=$ lower limit confidence interval. $\mathrm{ULCI}=$ upper limit confidence interval. 
Figure 20: Neuroticism moderating the relationship conflict to stress relationship

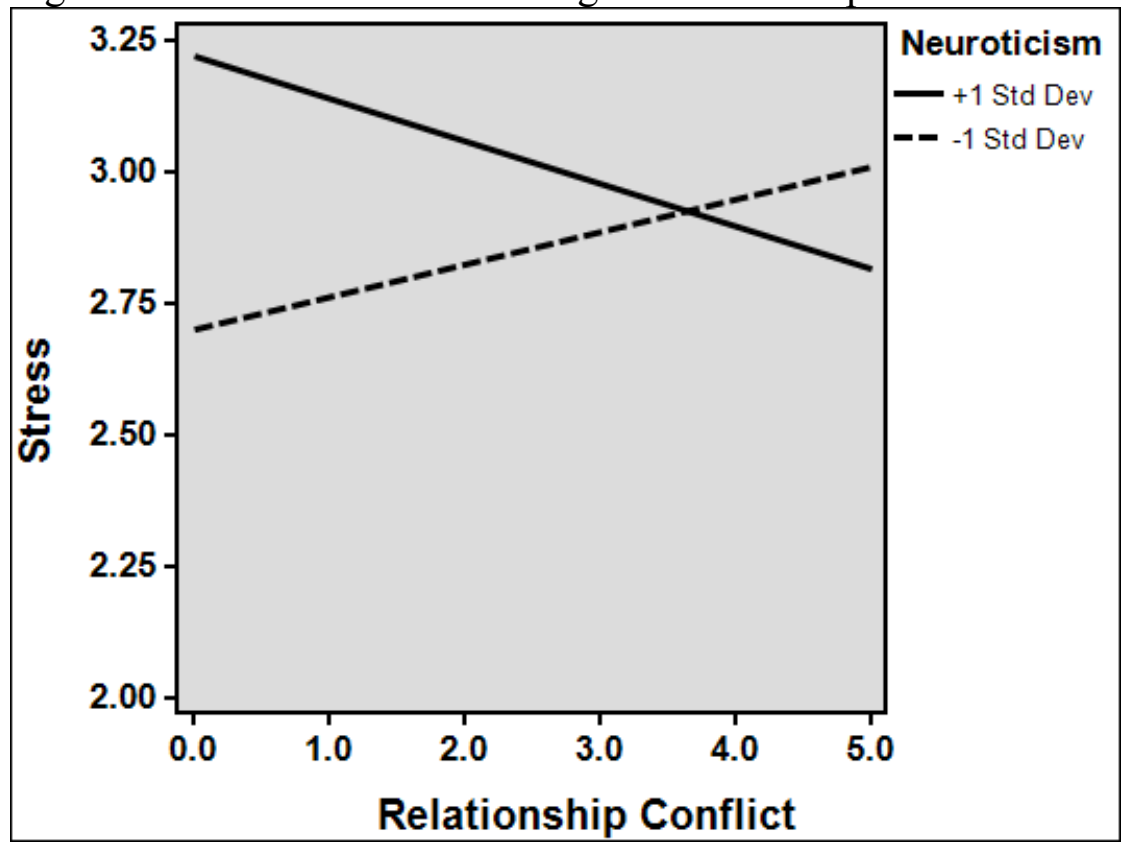

Note: -1 Std Dev effect size $=0.06, L L I C=-0.02, U L C I=0.16,+1$ Std Dev effect size $=-0.08, L L C I=$ $-0.15, U L C I=-0.01$. LLCI $=$ lower limit confidence interval. ULCI $=$ upper limit confidence interval.

Figure 21: Neuroticism moderating the relationship conflict to job satisfaction relationship

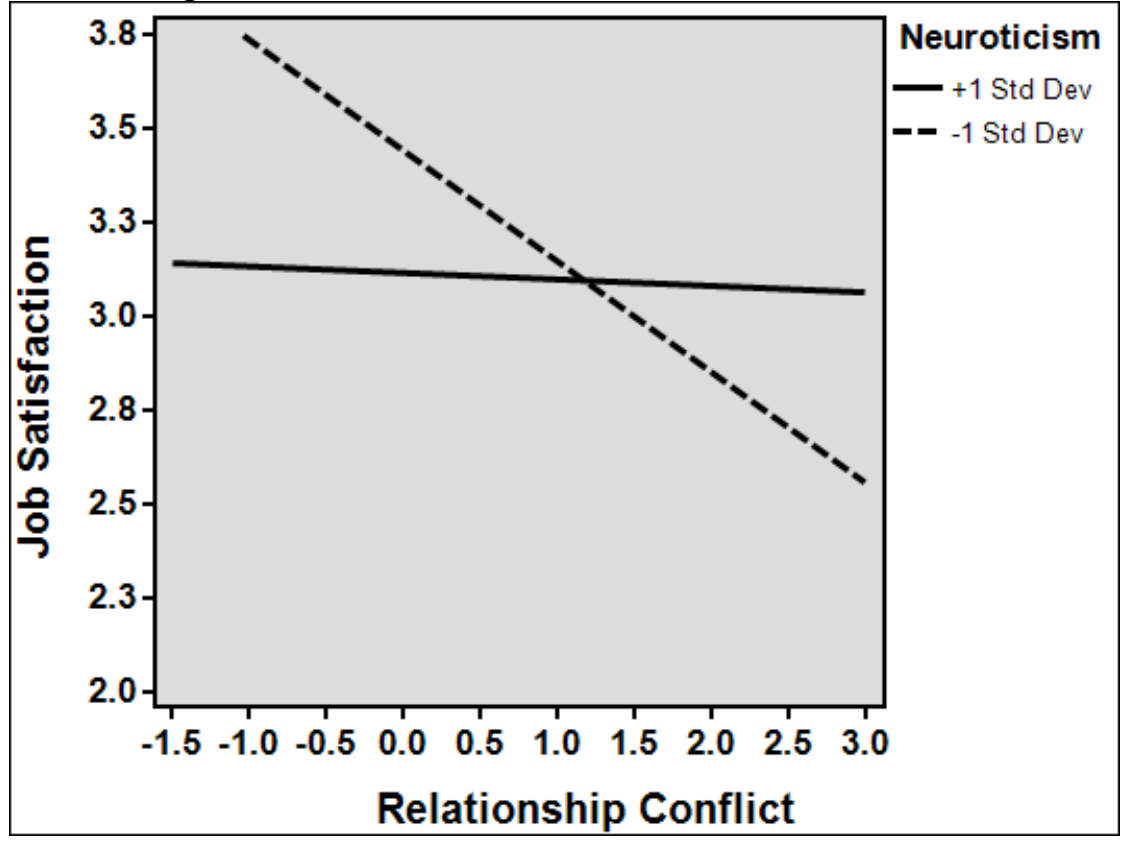

Note: -1 Std Dev effect size $=-0.29, L L I C=-0.48, U L C I=-0.11,+1$ Std Dev effect size $=-0.02, L L C I=$ $-0.17, U L C I=0.13$. LLCI $=$ lower limit confidence interval. ULCI $=$ upper limit confidence interval. 
Figure 22: Neuroticism moderating the relationship conflict to life satisfaction relationship

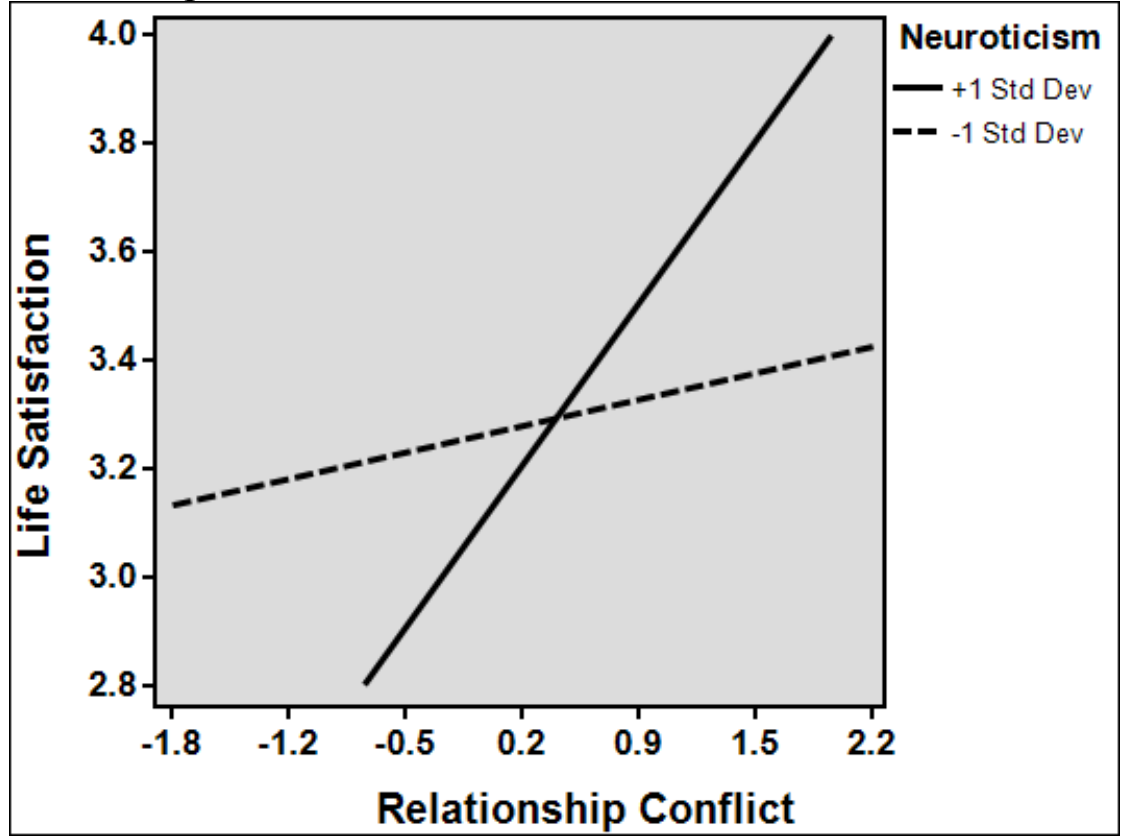

Note: -1 Std Dev effect size $=0.08, L L I C=0.08, U L C I=0.24,+1$ Std Dev effect size $=0.47, L L C I=0.34$, $U L C I=0.60 . \mathrm{LLCI}=$ lower limit confidence interval. $\mathrm{ULCI}=$ upper limit confidence interval.

Figure 23: Neuroticism moderating the task conflict to depression relationship

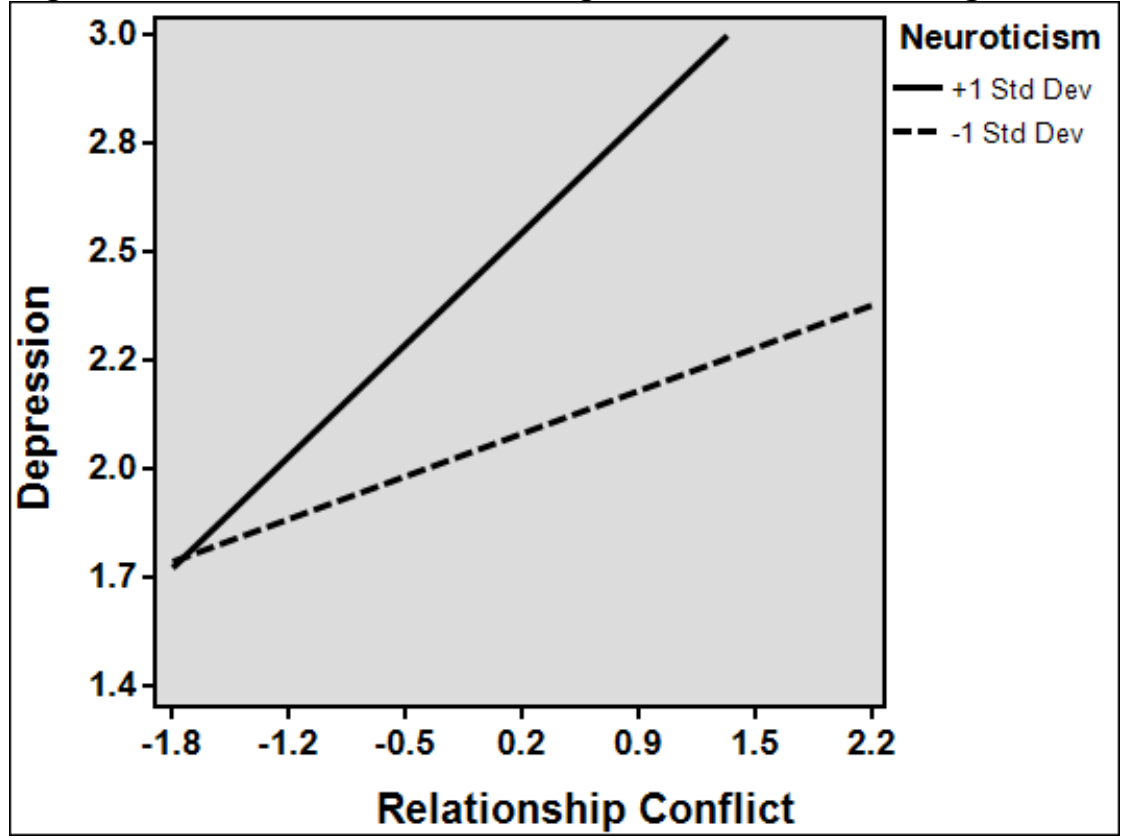

Note: -1 Std Dev effect size $=0.16, L L I C=0.08, U L C I=0.23,+1$ Std Dev effect size $=0.43, L L C I=0.36$, $U L C I=0.49 . \mathrm{LLCI}=$ lower limit confidence interval. $\mathrm{ULCI}=$ upper limit confidence interval. 
Figure 24: Neuroticism moderating the task conflict to physical symptoms relationship

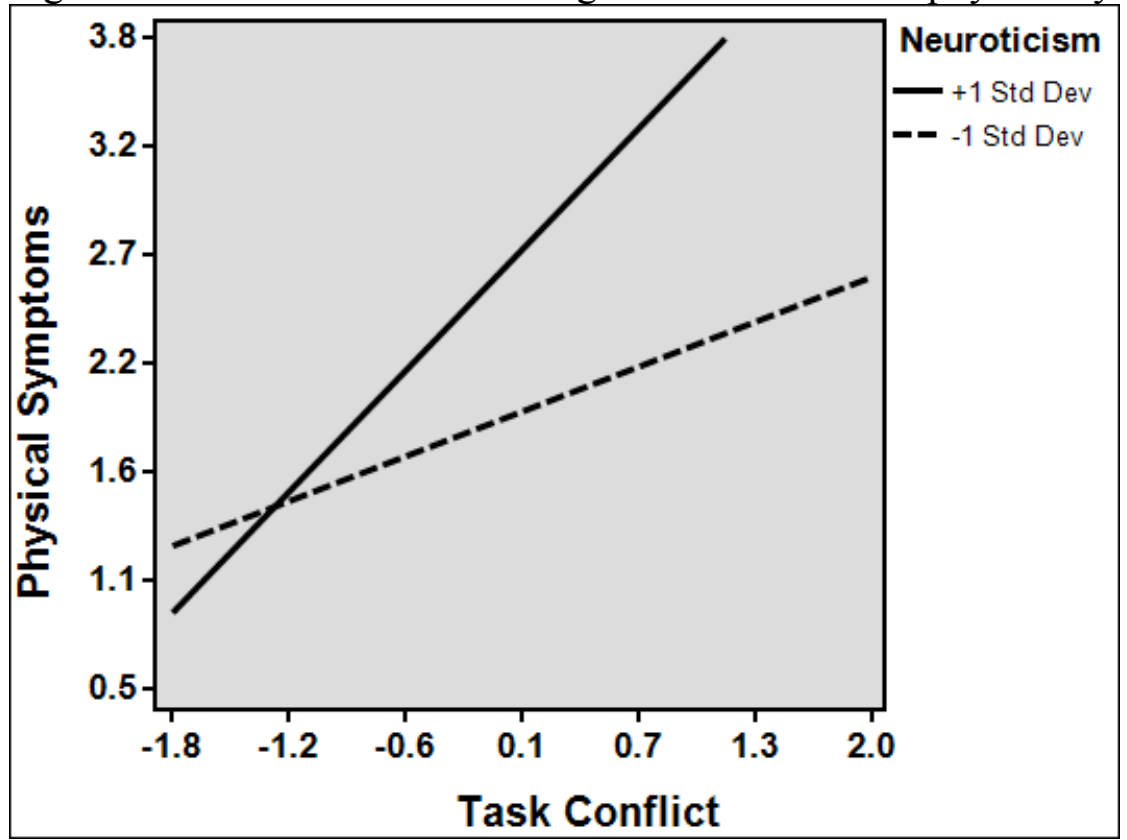

Note: -1 Std Dev effect size $=0.35, L L I C=0.20, U L C I=0.51,+1$ Std Dev effect size $=0.96, L L C I=0.80$, $U L C I=1.09 . \mathrm{LLCI}=$ lower limit confidence interval. $\mathrm{ULCI}=$ upper limit confidence interval.

Figure 25: Neuroticism moderating the task conflict to stress relationship

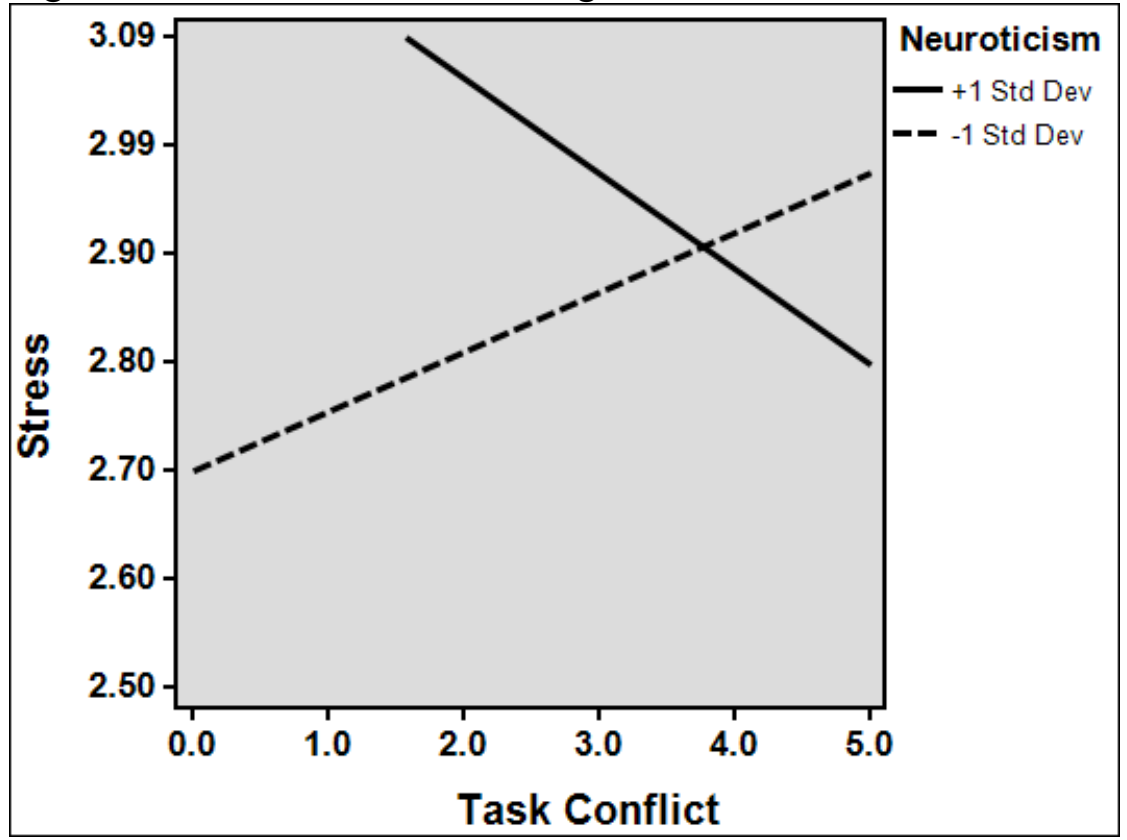

Note: $-1 \mathrm{Std}$ Dev effect size $=0.05, L L I C=-0.03, U L C I=0.13,+1$ Std Dev effect size $=-0.09, L L C I=$ $-0.16, U L C I=-0.02 . \mathrm{LLCI}=$ lower limit confidence interval. $\mathrm{ULCI}=$ upper limit confidence interval. 
Figure 26: Neuroticism moderating the task conflict to job satisfaction relationship

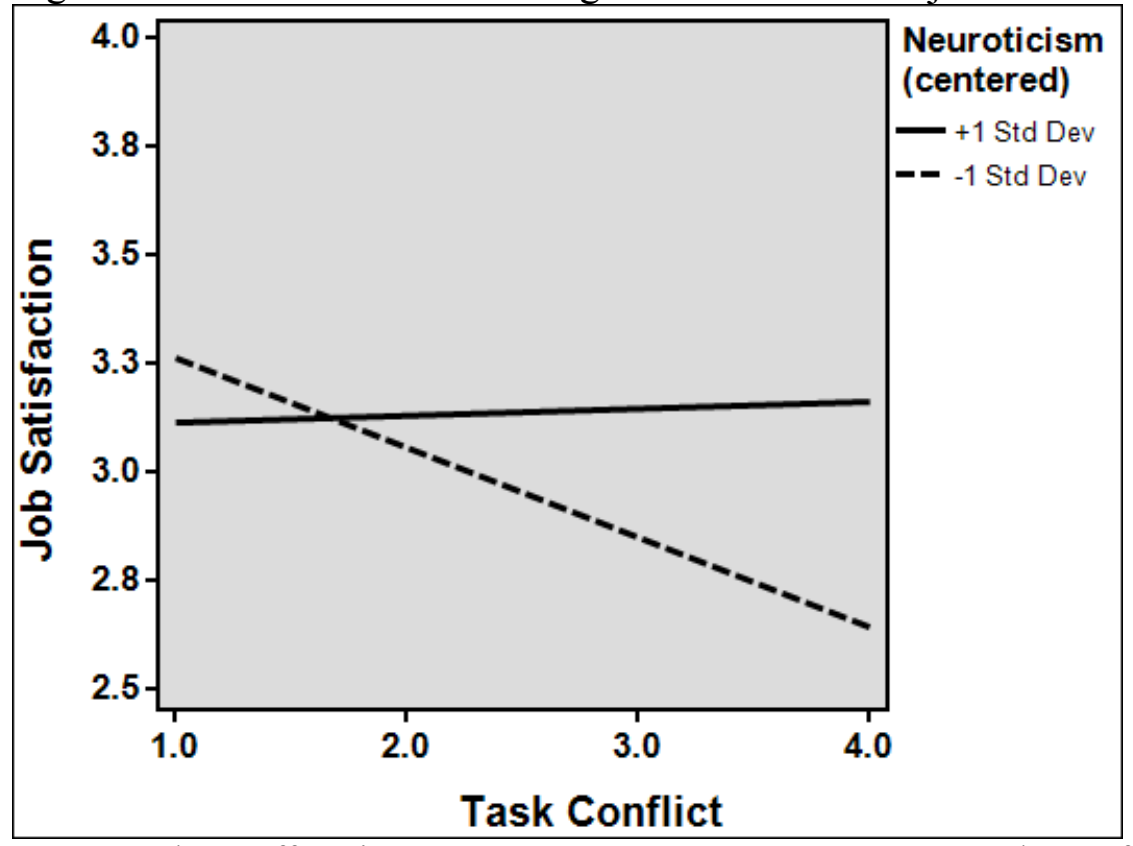

Note: -1 Std Dev effect size $=-0.21, L L I C=-0.38, U L C I=-0.04,+1$ Std Dev effect size $=0.01, L L C I=$ $-0.13, U L C I=0.17 . \mathrm{LLCI}=$ lower limit confidence interval. $\mathrm{ULCI}=$ upper limit confidence interval.

Figure 27: Neuroticism moderating the task conflict to life satisfaction relationship

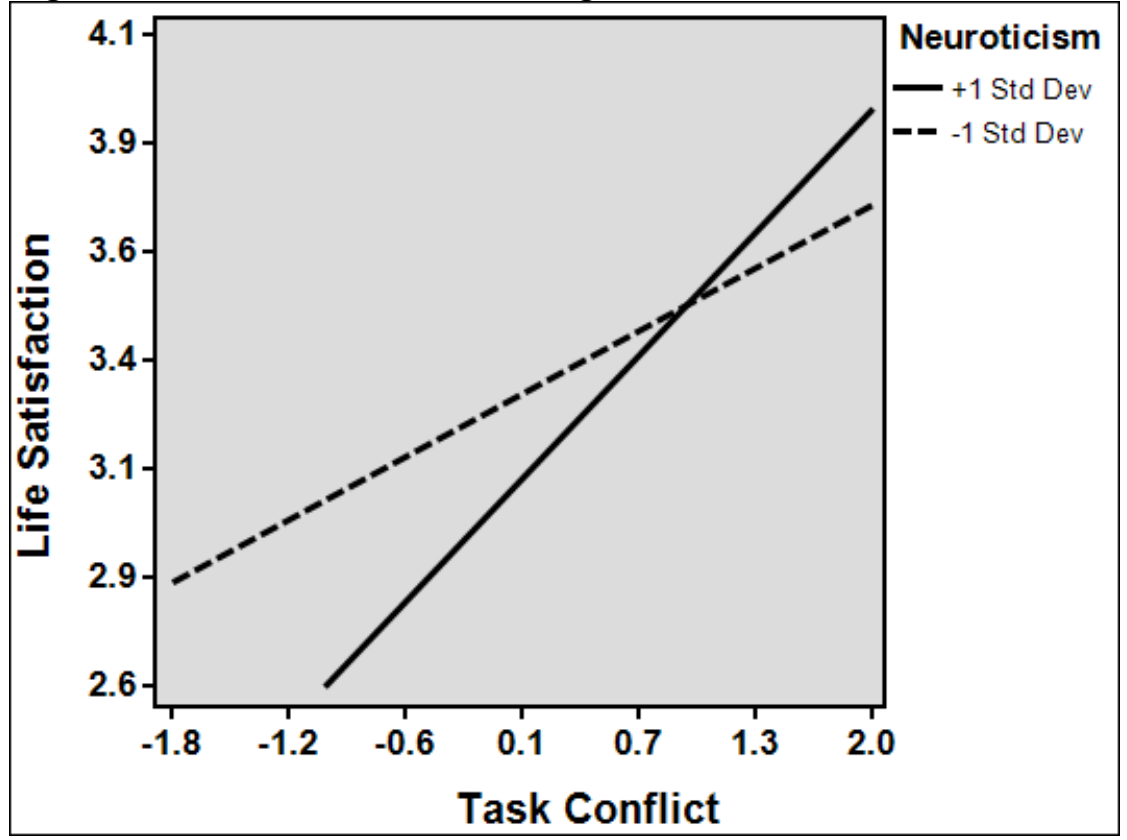

Note: -1 Std Dev effect size $=0.23, L L I C=0.08, U L C I=0.38,+1$ Std Dev effect size $=0.45, L L C I=0.32$, $U L C I=0.58 . \mathrm{LLCI}=$ lower limit confidence interval. $\mathrm{ULCI}=$ upper limit confidence interval. 
Figure 28: Agreeableness moderating the incivility to negative emotions relationship

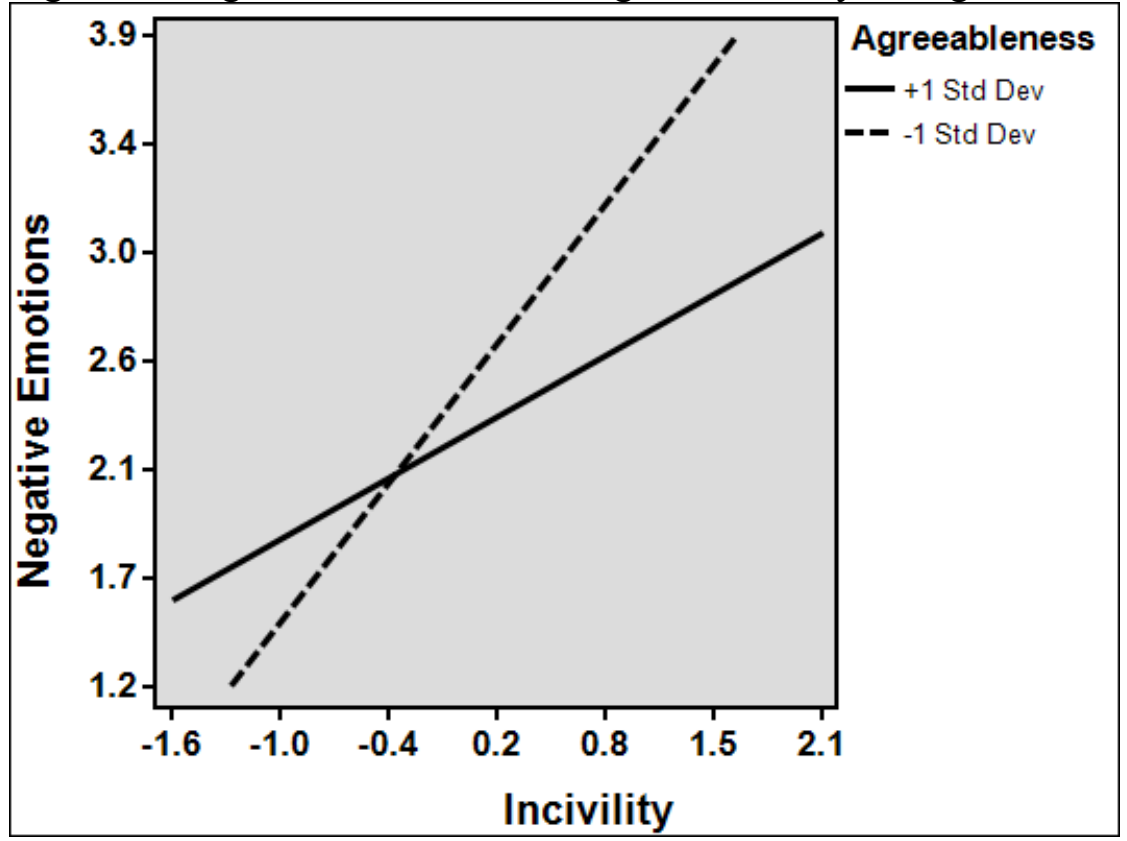

Note: -1 Std Dev effect size $=0.91, L L I C=0.80, U L C I=1.02,+1$ Std Dev effect size $=0.40, L L C I=0.28$, $U L C I=0.52 . \mathrm{LLCI}=$ lower limit confidence interval. $\mathrm{ULCI}=$ upper limit confidence interval.

Figure 29: Agreeableness moderating the relationship conflict to negative emotions relationship

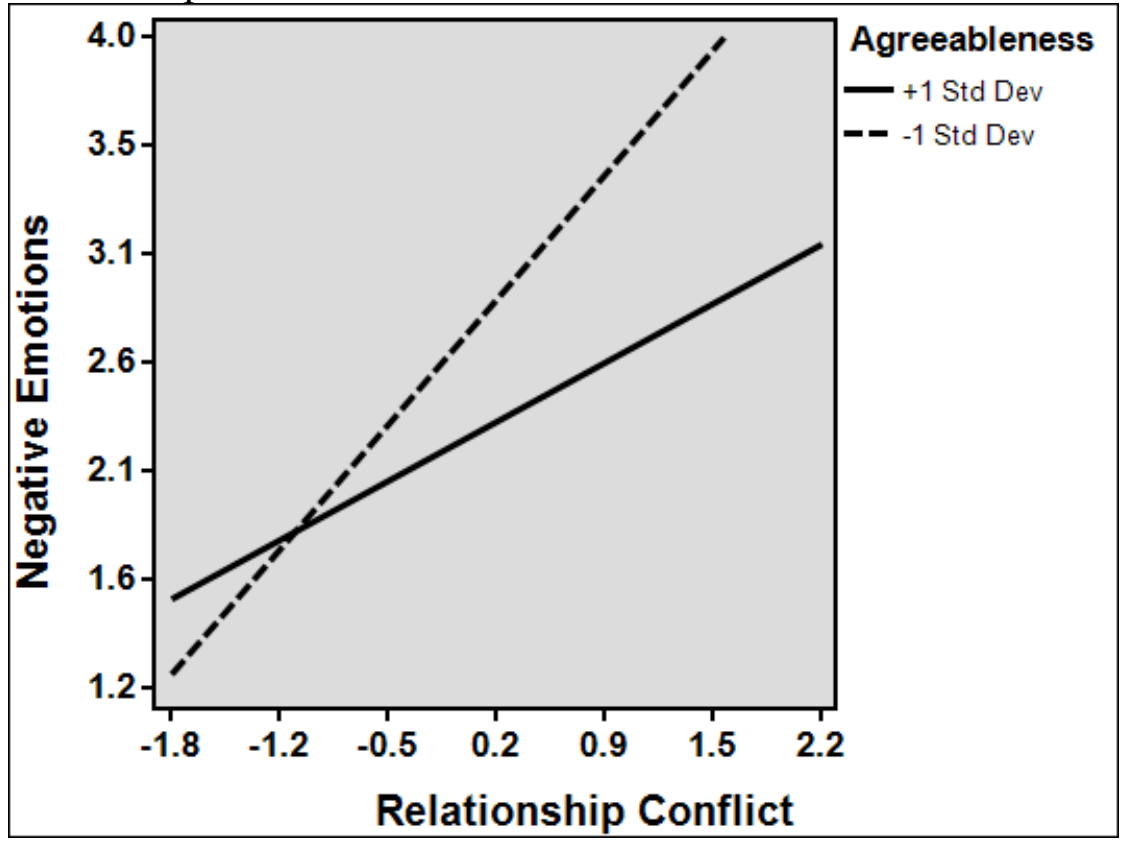

Note: -1 Std Dev effect size $=0.81, L L I C=0.69, U L C I=0.93,+1$ Std Dev effect size $=0.38, L L C I=0.25$, $U L C I=0.52 . \mathrm{LLCI}=$ lower limit confidence interval. $\mathrm{ULCI}=$ upper limit confidence interval. 
Figure 30: Agreeableness moderating the task conflict to negative emotions relationship

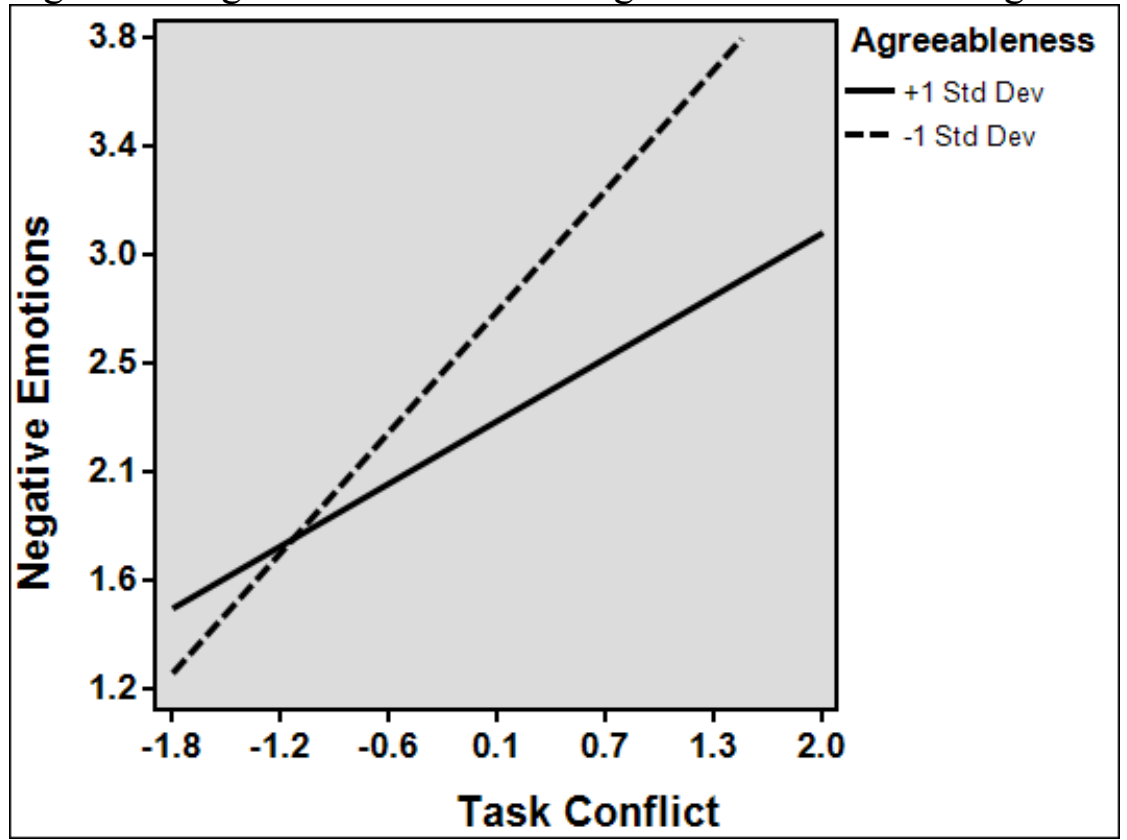

Note: -1 Std Dev effect size $=0.78, L L I C=0.66, U L C I=0.90,+1$ Std Dev effect size $=0.40, L L C I=0.27$, $U L C I=0.54 . \mathrm{LLCI}=$ lower limit confidence interval. $\mathrm{ULCI}=$ upper limit confidence interval.

Figure 31: Agreeableness moderating the incivility to depression relationship

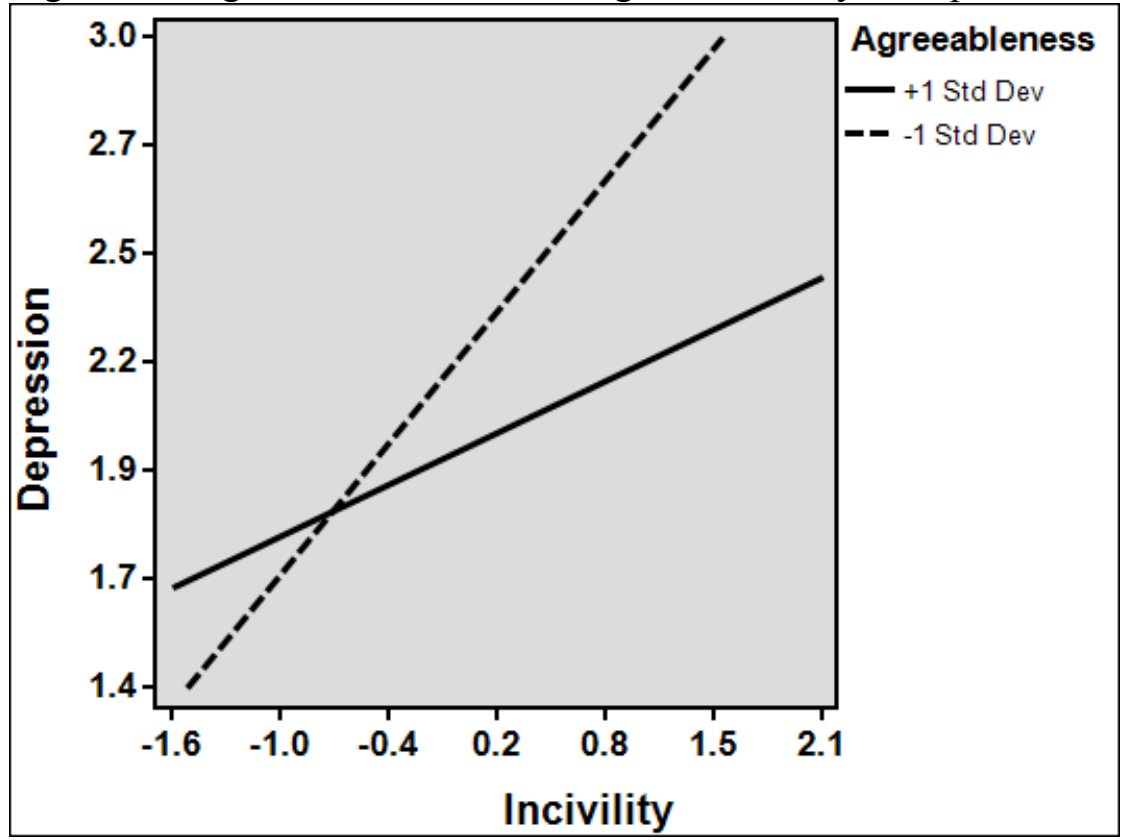

Note: -1 Std Dev effect size $=0.53, L L I C=0.47, U L C I=0.59,+1$ Std Dev effect size $=0.21, L L C I=0.15$, $U L C I=0.27 . \mathrm{LLCI}=$ lower limit confidence interval. ULCI $=$ upper limit confidence interval. 
Figure 32: Agreeableness moderating the incivility to physical symptoms relationship

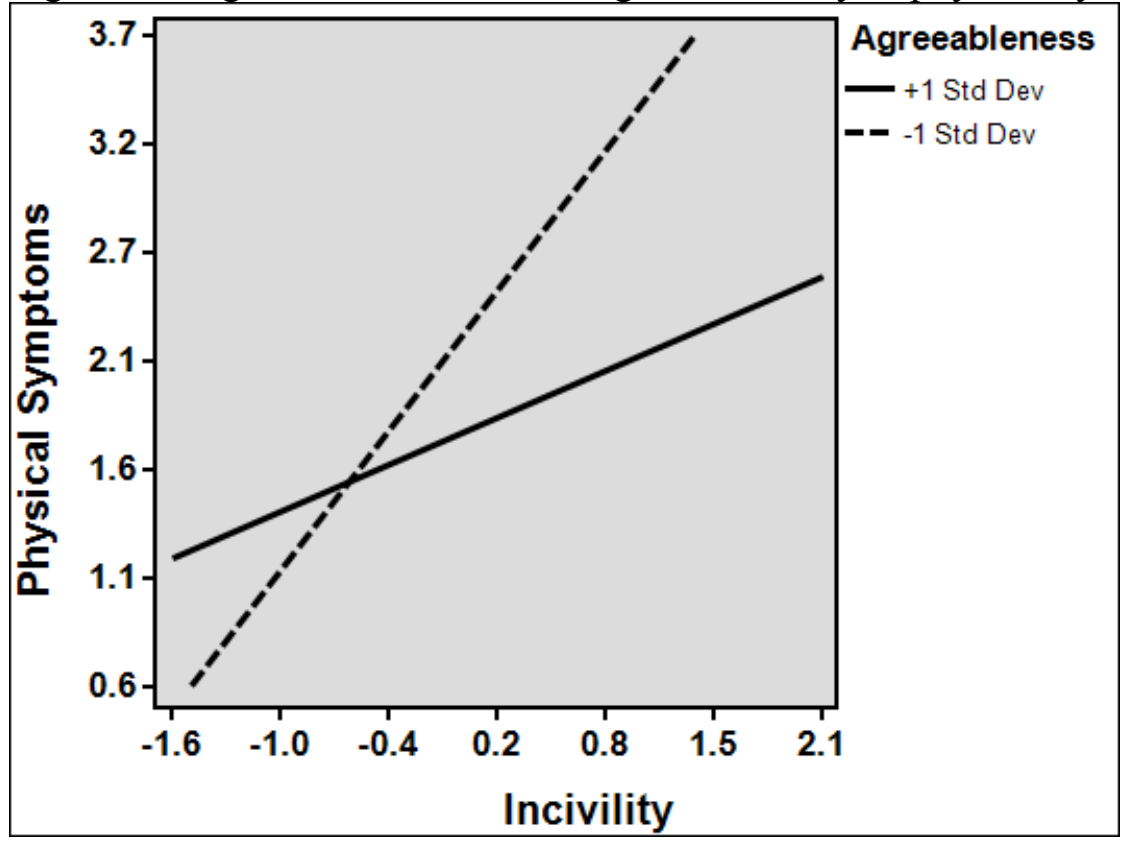

Note: -1 Std Dev effect size $=1.08, L L I C=0.96, U L C I=1.21,+1$ Std Dev effect size $=0.36, L L C I=0.23$, $U L C I=0.50 . \mathrm{LLCI}=$ lower limit confidence interval. $\mathrm{ULCI}=$ upper limit confidence interval.

Figure 33: Agreeableness moderating the incivility to stress relationship

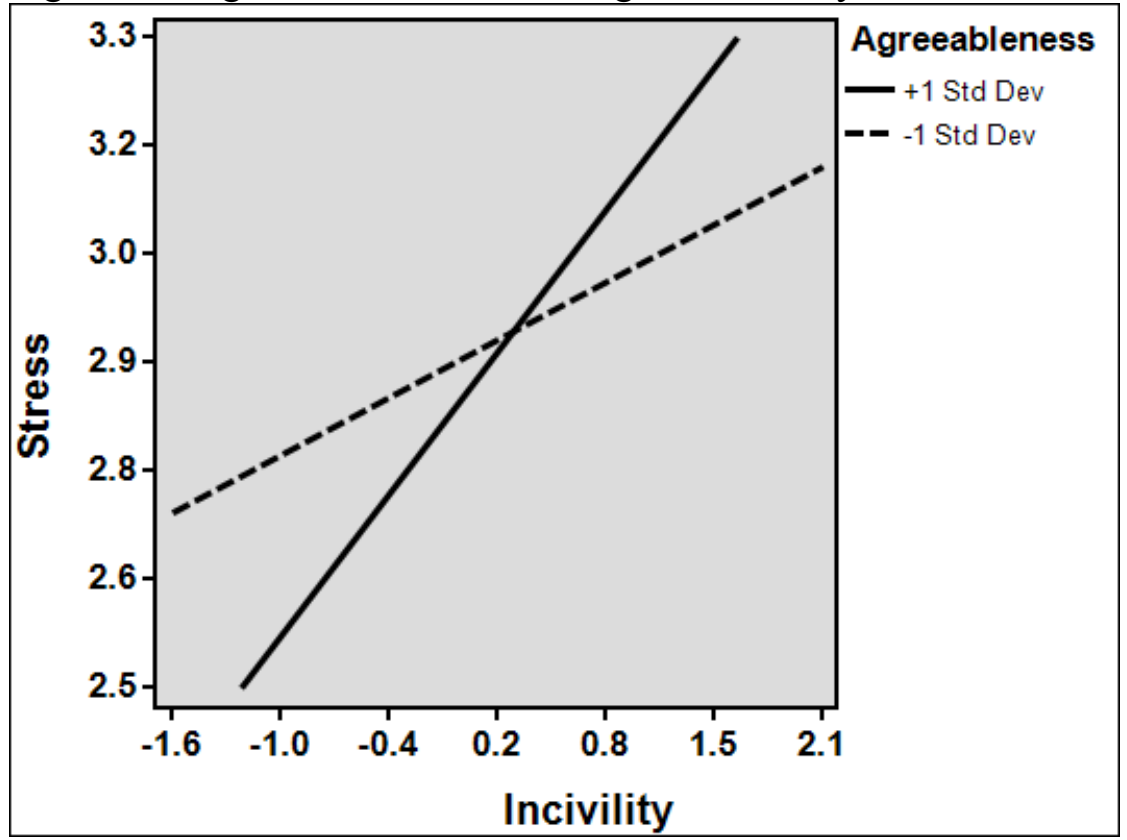

Note: -1 Std Dev effect size $=0.12, L L I C=0.05, U L C I=0.20,+1$ Std Dev effect size $=0.30, L L C I=0.21$, $U L C I=0.38 . \mathrm{LLCI}=$ lower limit confidence interval. $\mathrm{ULCI}=$ upper limit confidence interval. 
Figure 34: Agreeableness moderating the incivility to life satisfaction relationship

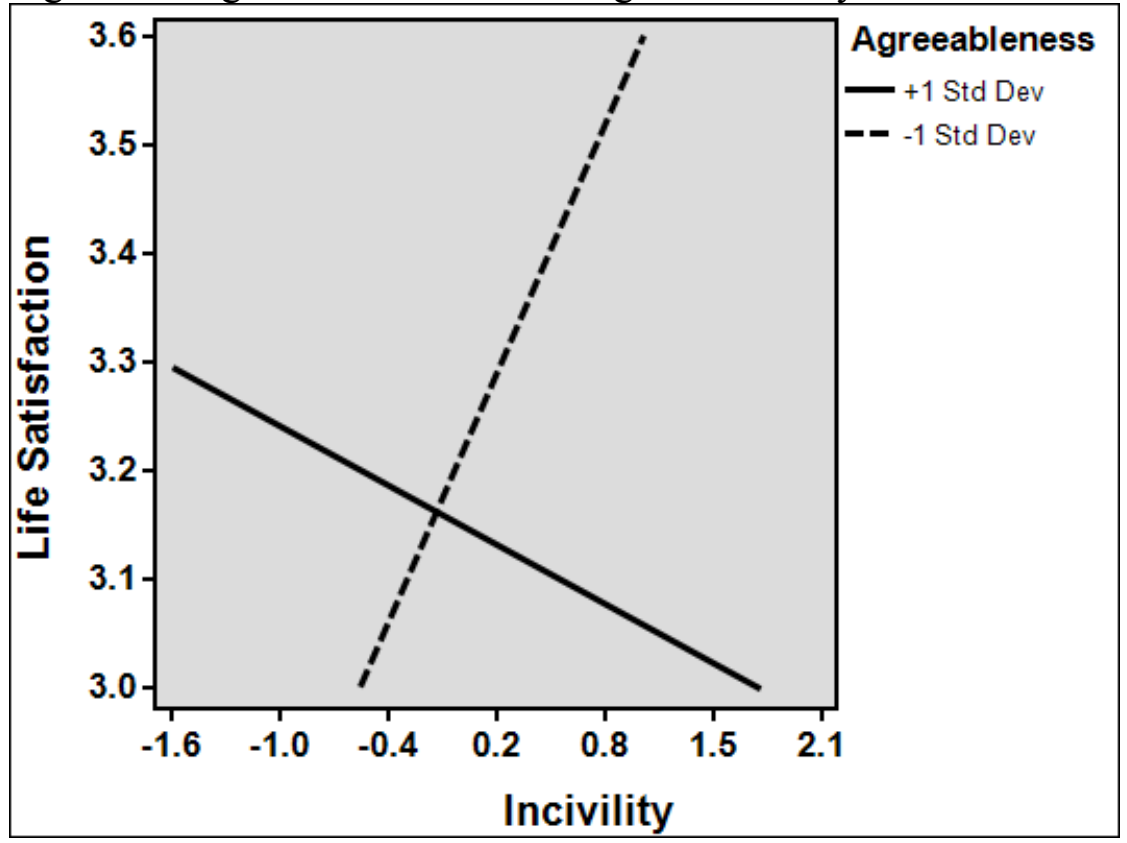

Note: -1 Std Dev effect size $=0.40, L L I C=0.27, U L C I=0.54,+1$ Std Dev effect size $=-0.10, L L C I=$ $-0.24, U L C I=0.05 . \mathrm{LLCI}=$ lower limit confidence interval. $\mathrm{ULCI}=$ upper limit confidence interval.

Figure 35: Agreeableness moderating the relationship conflict depression relationship

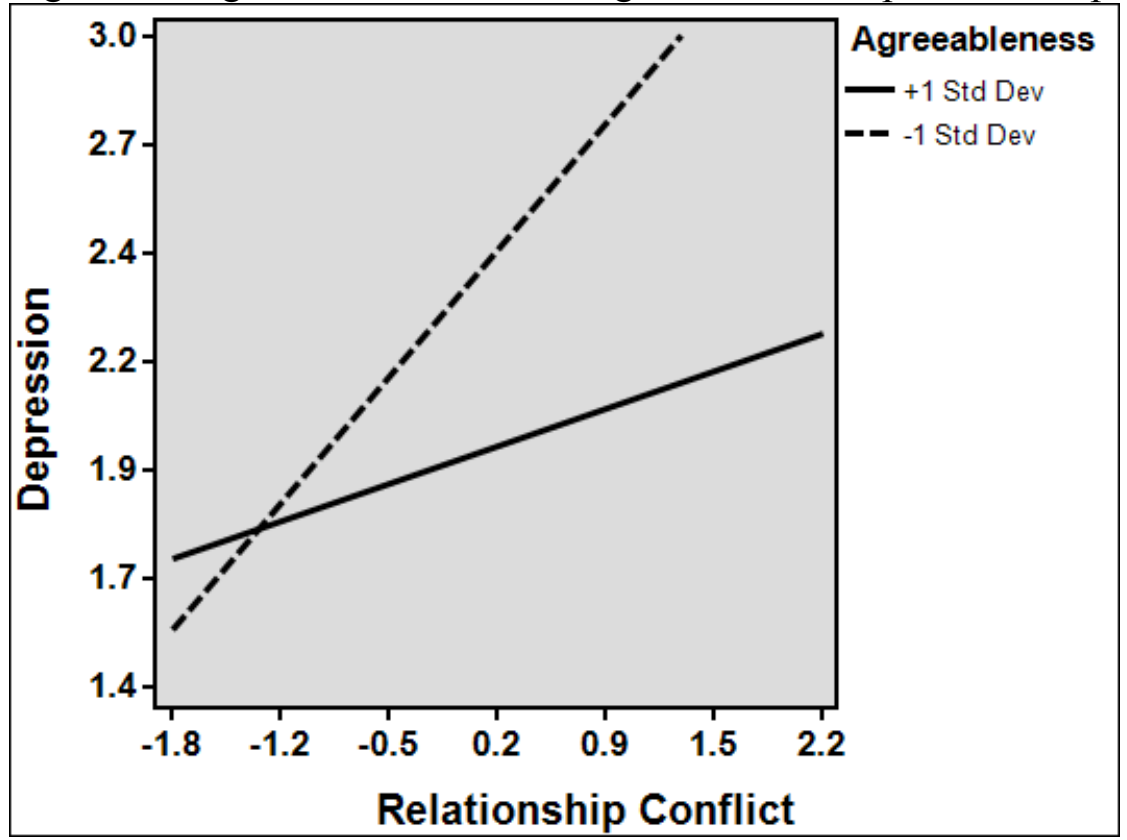

Note: -1 Std Dev effect size $=0.45, L L I C=0.39, U L C I=0.52,+1$ Std Dev effect size $=0.13, L L C I=0.06$, $U L C I=0.21 . \mathrm{LLCI}=$ lower limit confidence interval. $\mathrm{ULCI}=$ upper limit confidence interval. 
Figure 36: Agreeableness moderating the relationship conflict to physical symptoms relationship

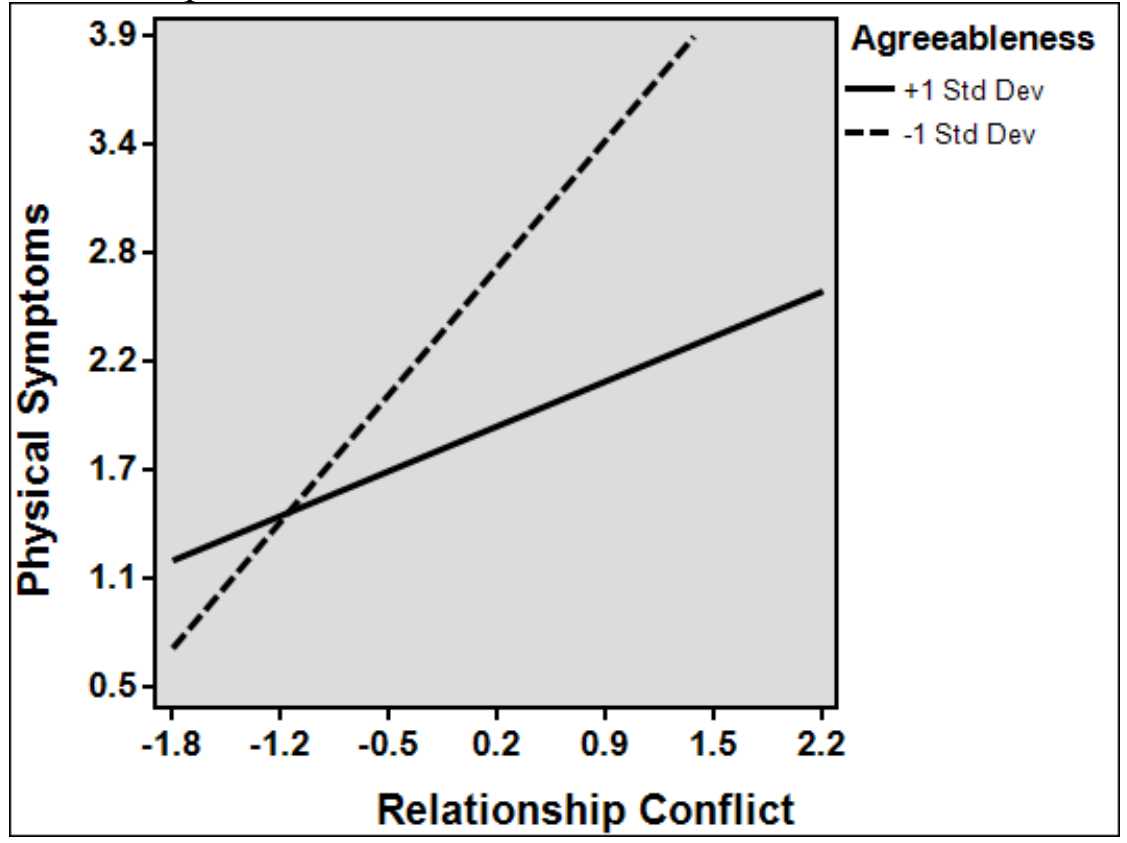

Note: -1 Std Dev effect size $=0.99, L L I C=0.86, U L C I=1.12,+1$ Std Dev effect size $=0.35, L L C I=0.20$ $U L C I=0.50 . \mathrm{LLCI}=$ lower limit confidence interval. $\mathrm{ULCI}=$ upper limit confidence interval.

Figure 37: Agreeableness moderating the relationship conflict to job satisfaction relationship

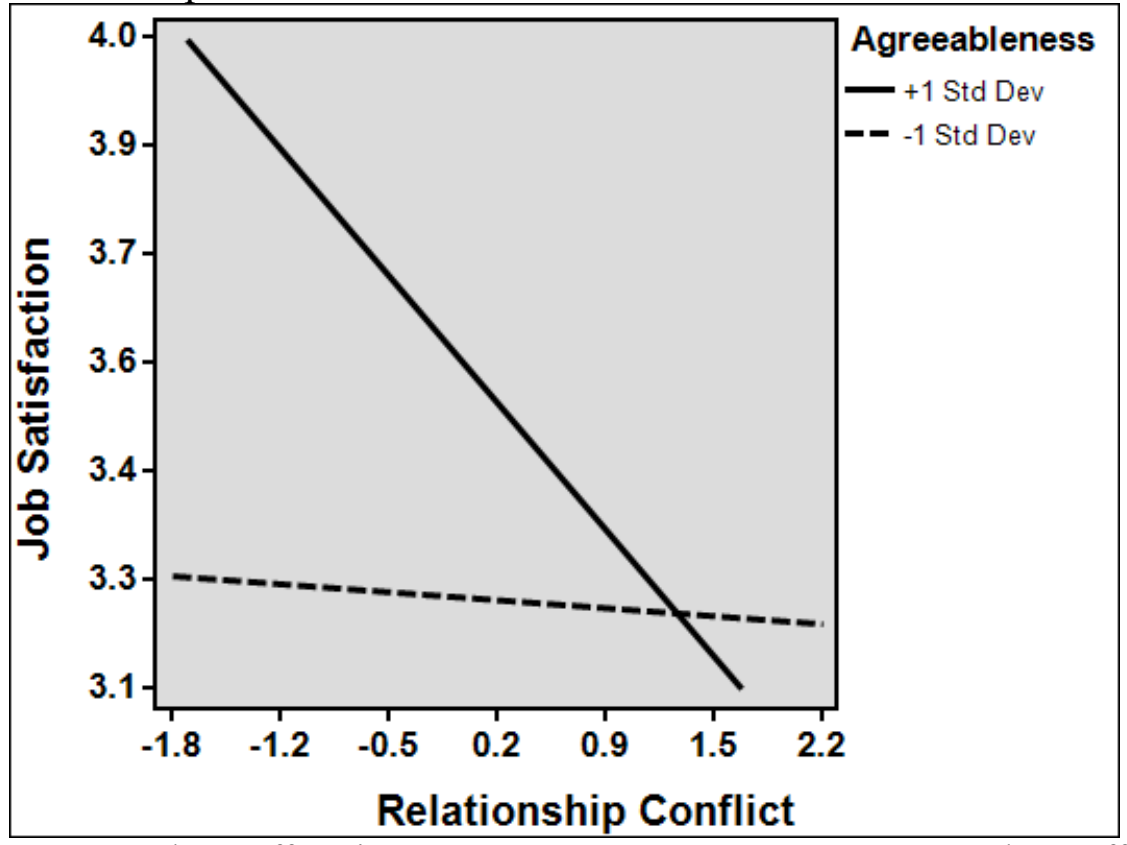

Note: -1 Std Dev effect size $=-0.02$, LLIC $=-0.16$, ULCI $=0.10,+1$ Std Dev effect size $=-0.26, L L C I=$ $-0.43, U L C I=-0.09 . \mathrm{LLCI}=$ lower limit confidence interval. $\mathrm{ULCI}=$ upper limit confidence interval. 
Figure 38: Agreeableness moderating the relationship conflict to life satisfaction relationship

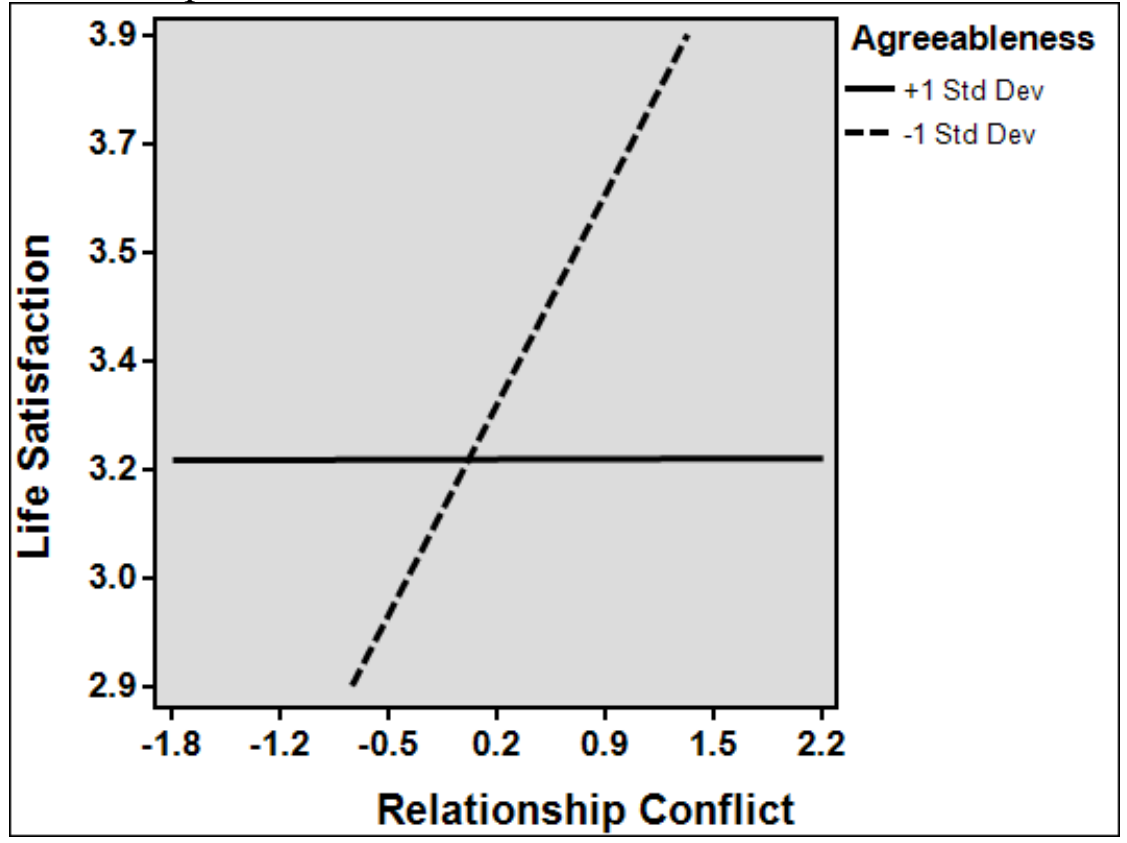

Note: -1 Std Dev effect size $=0.49, L L I C=0.36, U L C I=0.62,+1$ Std Dev effect size $=0.00, L L C I=-0.14$ $U L C I=0.15 . \mathrm{LLCI}=$ lower limit confidence interval. $\mathrm{ULCI}=$ upper limit confidence interval.

Figure 39: Agreeableness moderating the task conflict to depression relationship

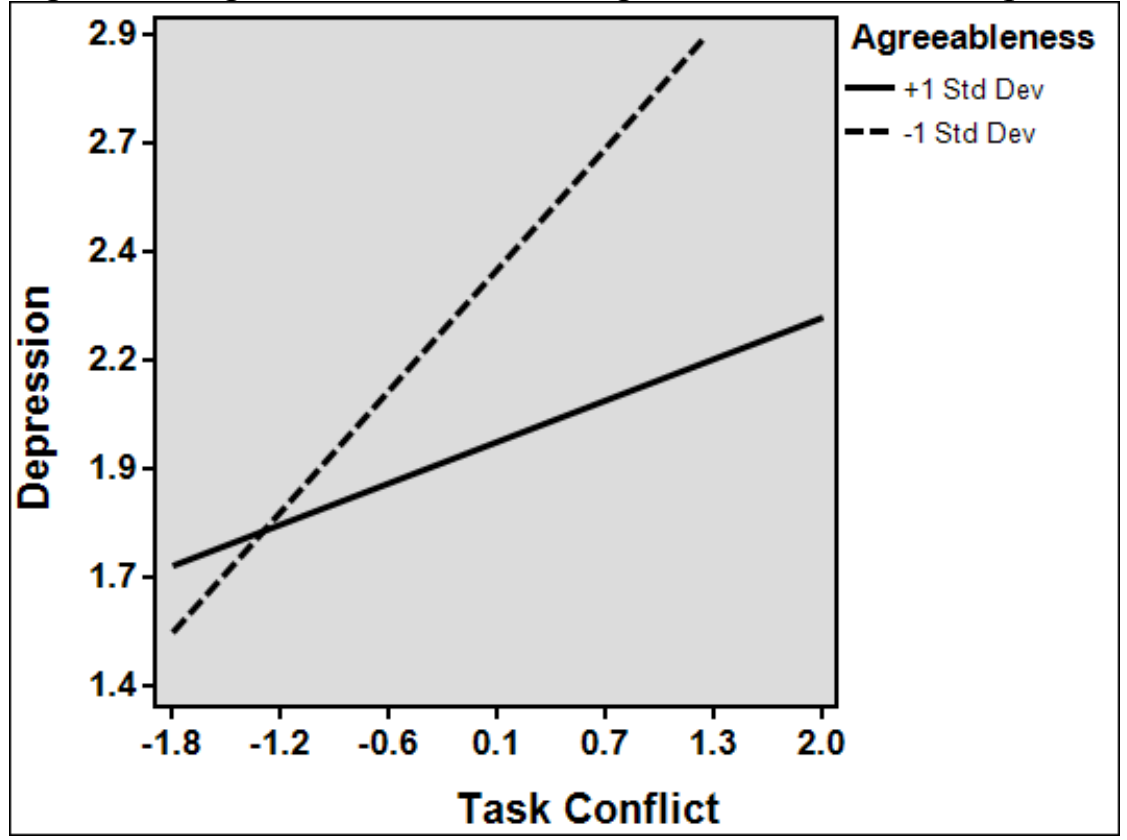

Note: -1 Std Dev effect size $=0.44, L L I C=0.38, U L C I=0.51,+1$ Std Dev effect size $=0.15, L L C I=0.08$, $U L C I=0.23 . \mathrm{LLCI}=$ lower limit confidence interval. $\mathrm{ULCI}=$ upper limit confidence interval. 
Figure 40: Agreeableness moderating the task conflict to physical symptoms relationship

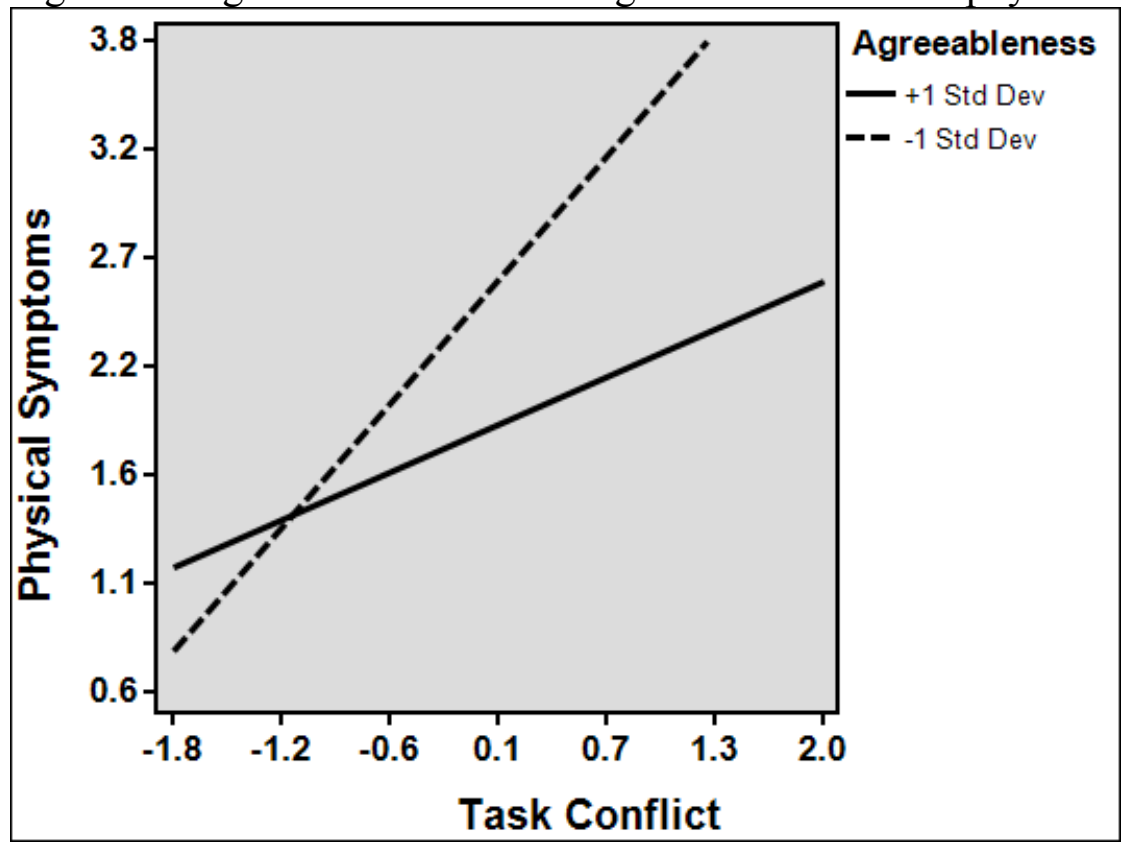

Note: -1 Std Dev effect size $=0.96, L L I C=0.82, U L C I=1.09,+1$ Std Dev effect size $=0.37, L L C I=0.22$, $U L C I=0.52$. LLCI $=$ lower limit confidence interval. ULCI $=$ upper limit confidence interval.

Figure 41: Agreeableness moderating the task conflict to life satisfaction relationship

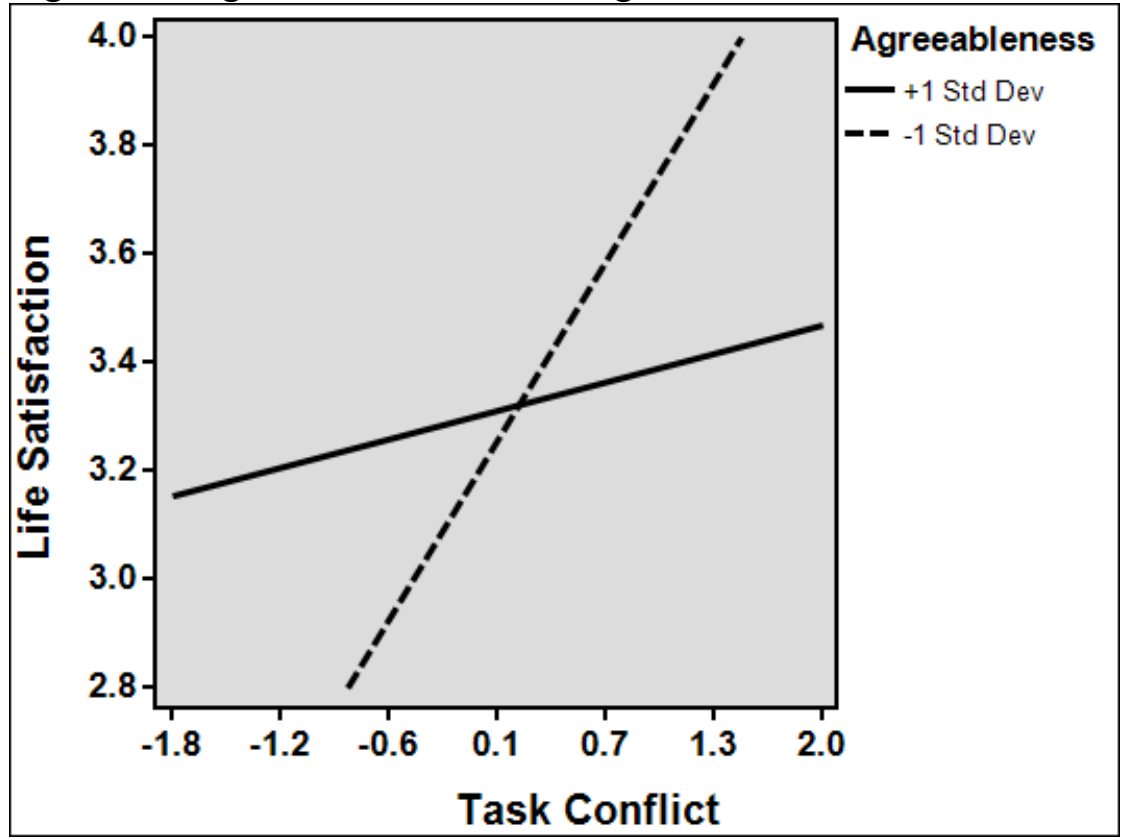

Note: -1 Std Dev effect size $=0.52, L L I C=0.39, U L C I=0.65,+1$ Std Dev effect size $=0.08$, LLCI -0.06 , $U L C I=0.23$. LLCI $=$ lower limit confidence interval. ULCI $=$ upper limit confidence interval. 
Figure 42: Conscientiousness moderating the incivility to physical symptoms relationship

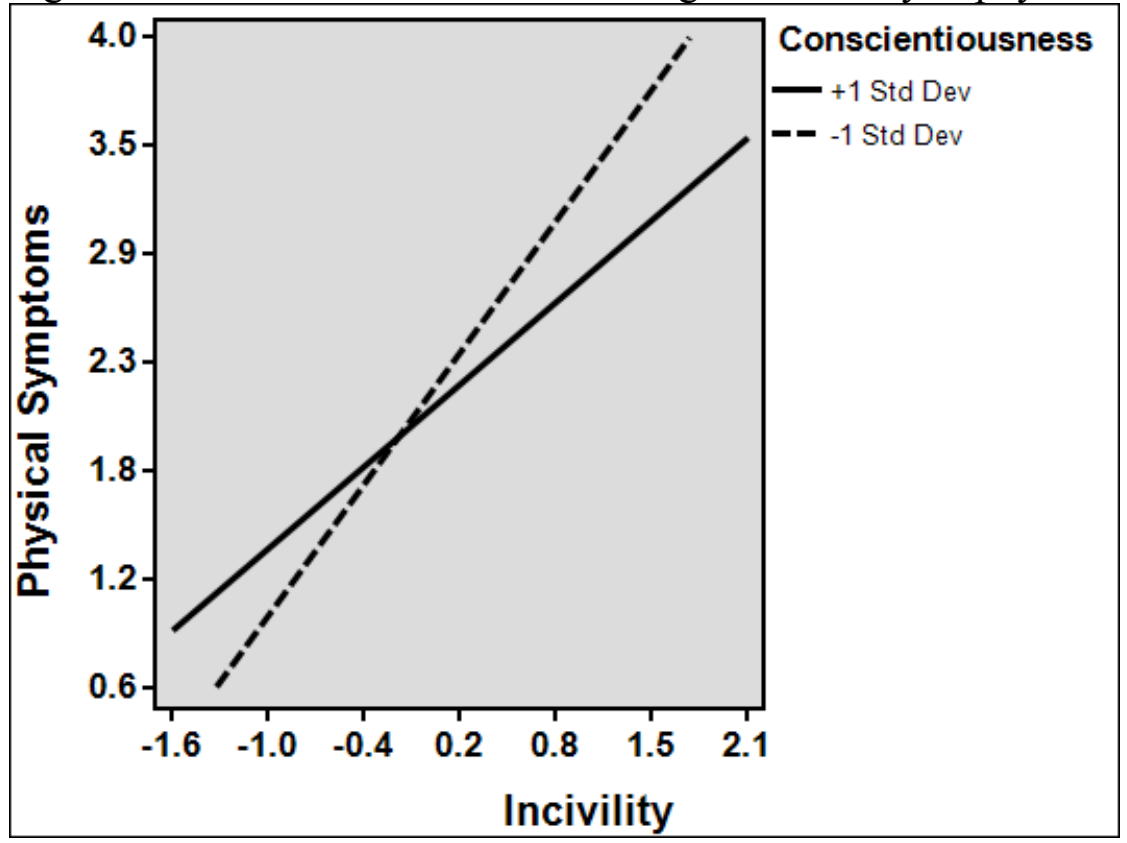

Note: -1 Std Dev effect size $=1.11, L L I C=0.95, U L C I=1.27,+1$ Std Dev effect size $=0.69, L L C I=0.58$, $U L C I=0.81$. LLCI $=$ lower limit confidence interval. $\mathrm{ULCI}=$ upper limit confidence interval.

Figure 43: Conscientiousness moderating the incivility to stress relationship

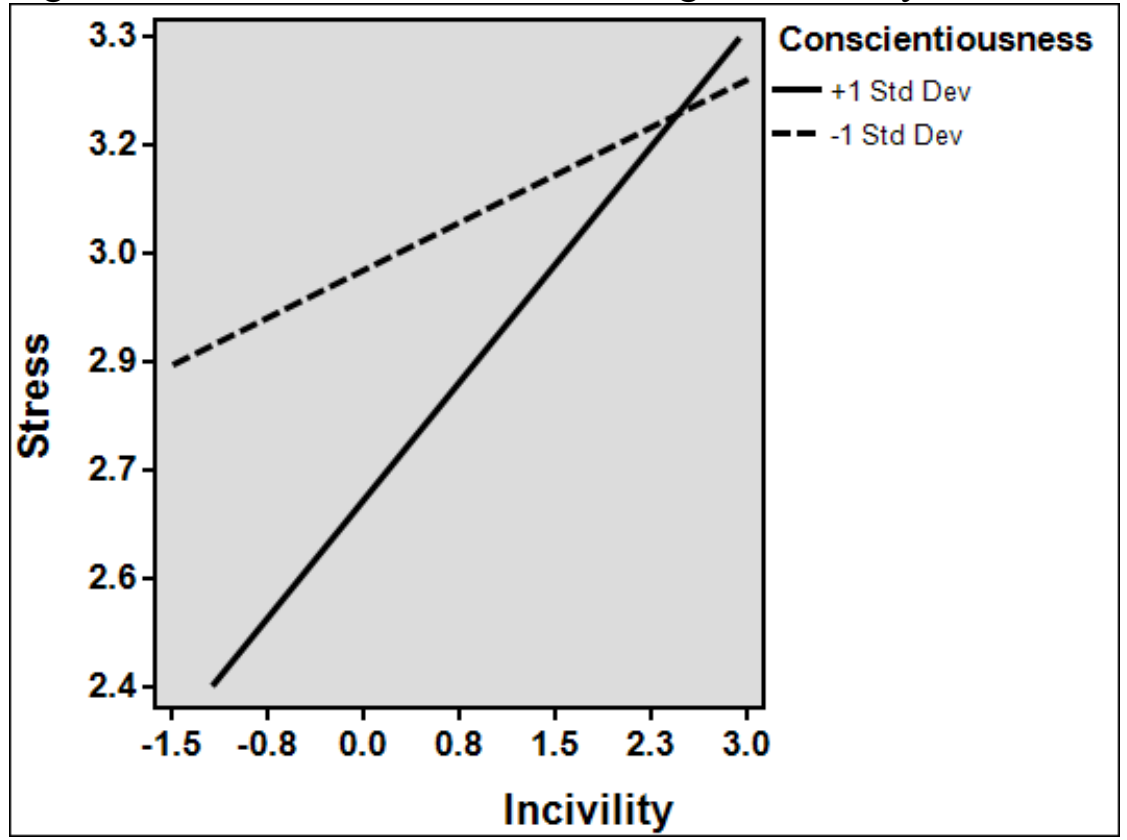

Note: -1 Std Dev effect size $=0.09, L L I C=0.01, U L C I=0.17,+1$ Std Dev effect size $=0.22, L L C I=0.16$, $U L C I=0.27$. LLCI $=$ lower limit confidence interval. $\mathrm{ULCI}=$ upper limit confidence interval. 
Figure 44: Conscientiousness moderating the incivility to job satisfaction relationship

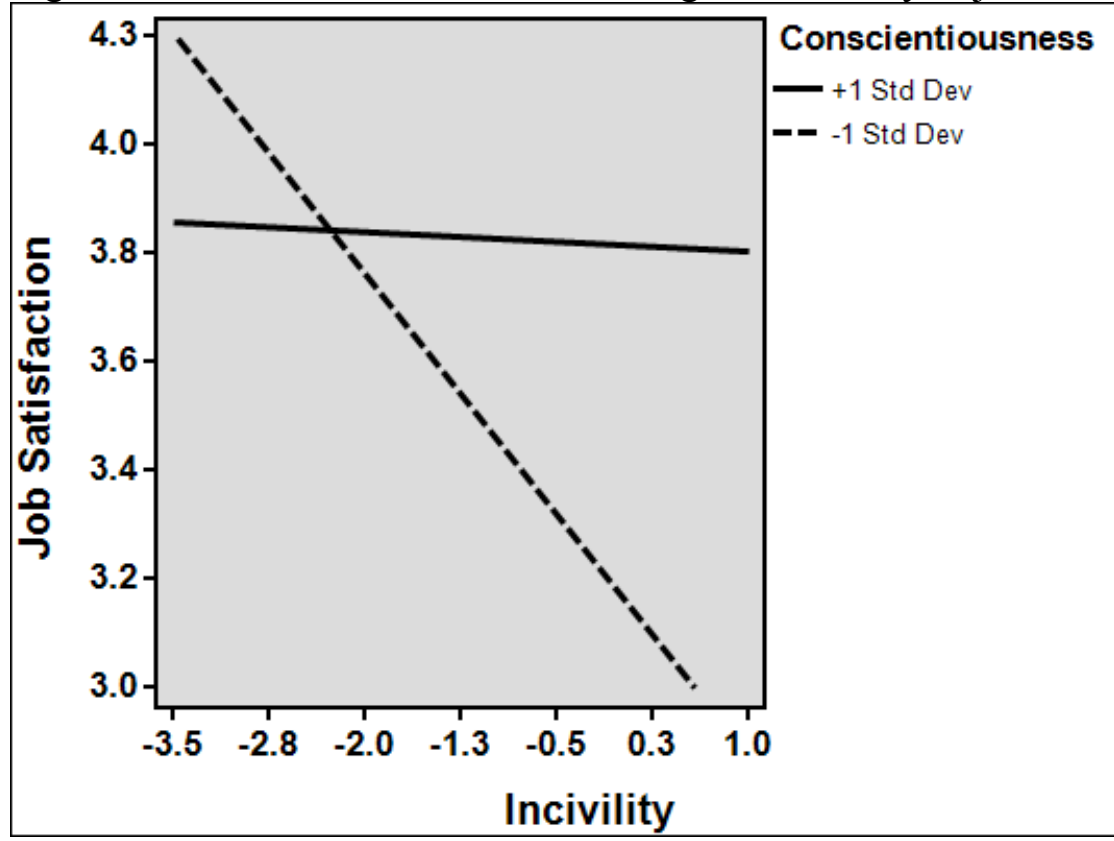

Note: -1 Std Dev effect size $=-0.31, L L I C=-0.47, U L C I=-0.15,+1$ Std Dev effect size $=-0.01, L L C I=$ $-0.13, U L C I=0.10 . \mathrm{LLCI}=$ lower limit confidence interval. ULCI $=$ upper limit confidence interval.

Figure 45: Conscientiousness moderating the task conflict to physical symptoms relationship

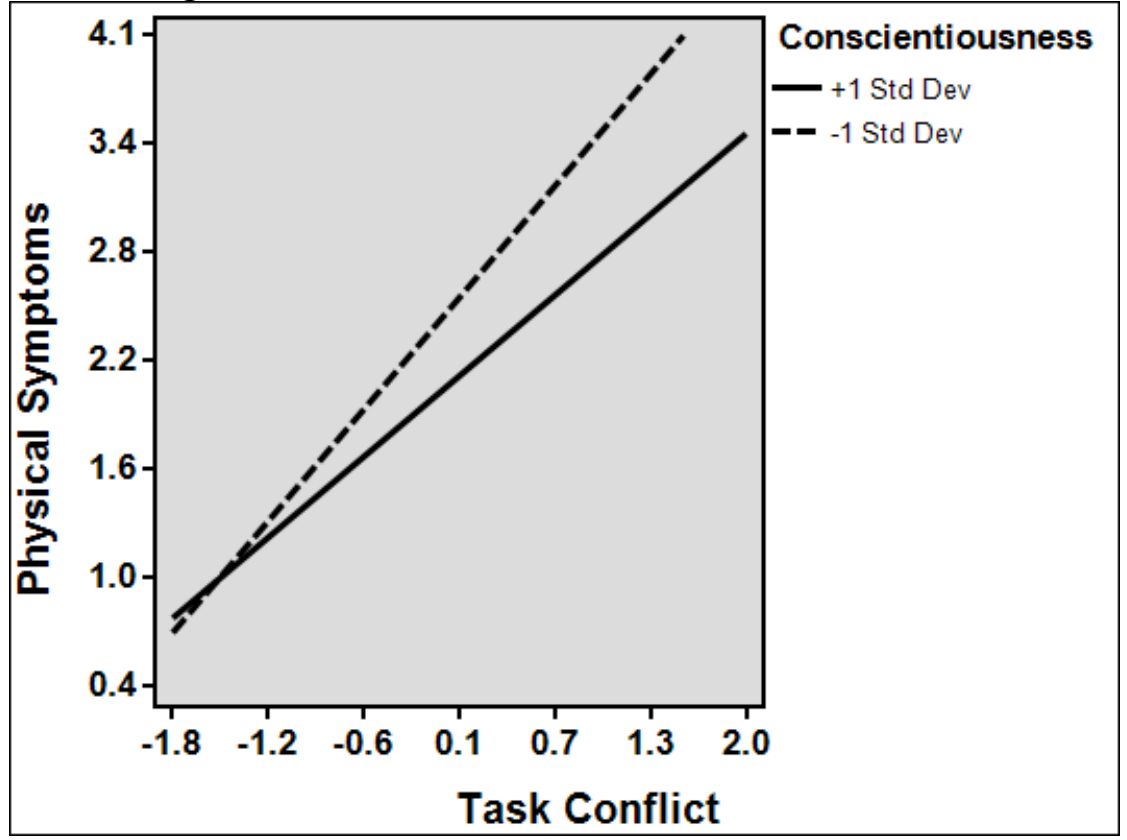

Note: -1 Std Dev effect size $=1.00, L L I C=0.83, U L C I=1.17,+1$ Std Dev effect size $=0.72, L L C I=0.58$, $U L C I=0.86 . \mathrm{LLCI}=$ lower limit confidence interval. $\mathrm{ULCI}=$ upper limit confidence interval. 
Figure 46: Trait anger moderating the incivility to negative emotions relationship

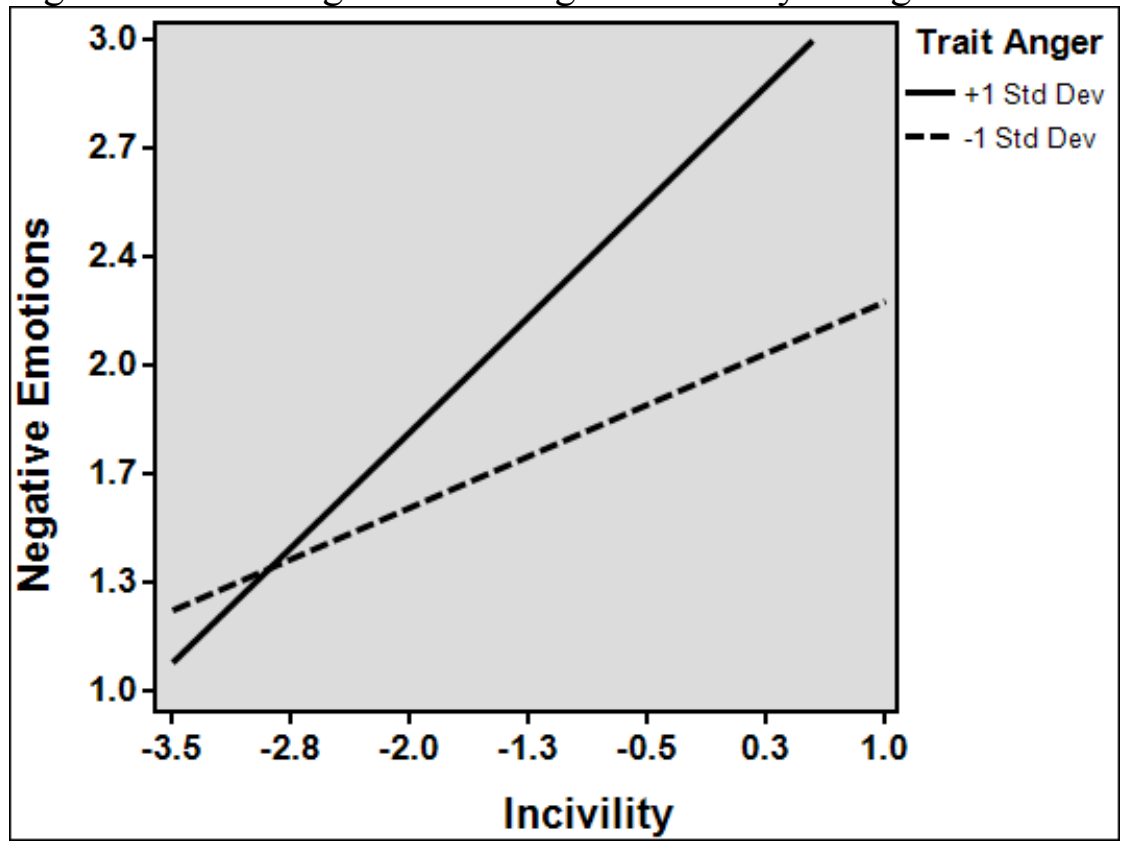

Note: -1 Std Dev effect size $=0.21, L L I C=0.12, U L C I=0.31,+1$ Std Dev effect size $=0.48, L L C I=0.37$, $U L C I=0.59 . \mathrm{LLCI}=$ lower limit confidence interval. $\mathrm{ULCI}=$ upper limit confidence interval.

Figure 47: Trait anger moderating the relationship conflict to negative emotions relationship

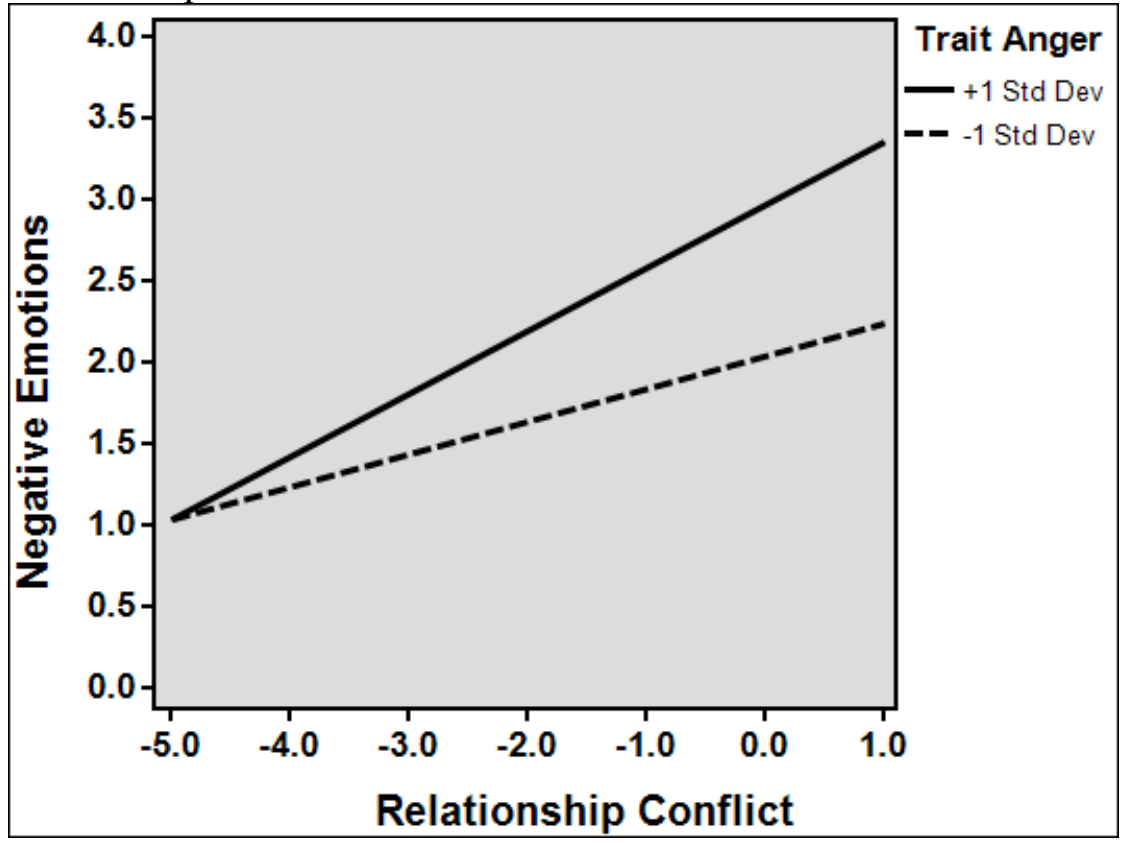

Note: -1 Std Dev effect size $=0.20, L L I C=0.08, U L C I=0.32,+1$ Std Dev effect size $=0.39, L L C I=0.27$, $U L C I=0.50 . \mathrm{LLCI}=$ lower limit confidence interval. $\mathrm{ULCI}=$ upper limit confidence interval. 
Figure 48: Trait anger moderating the incivility to depression relationship

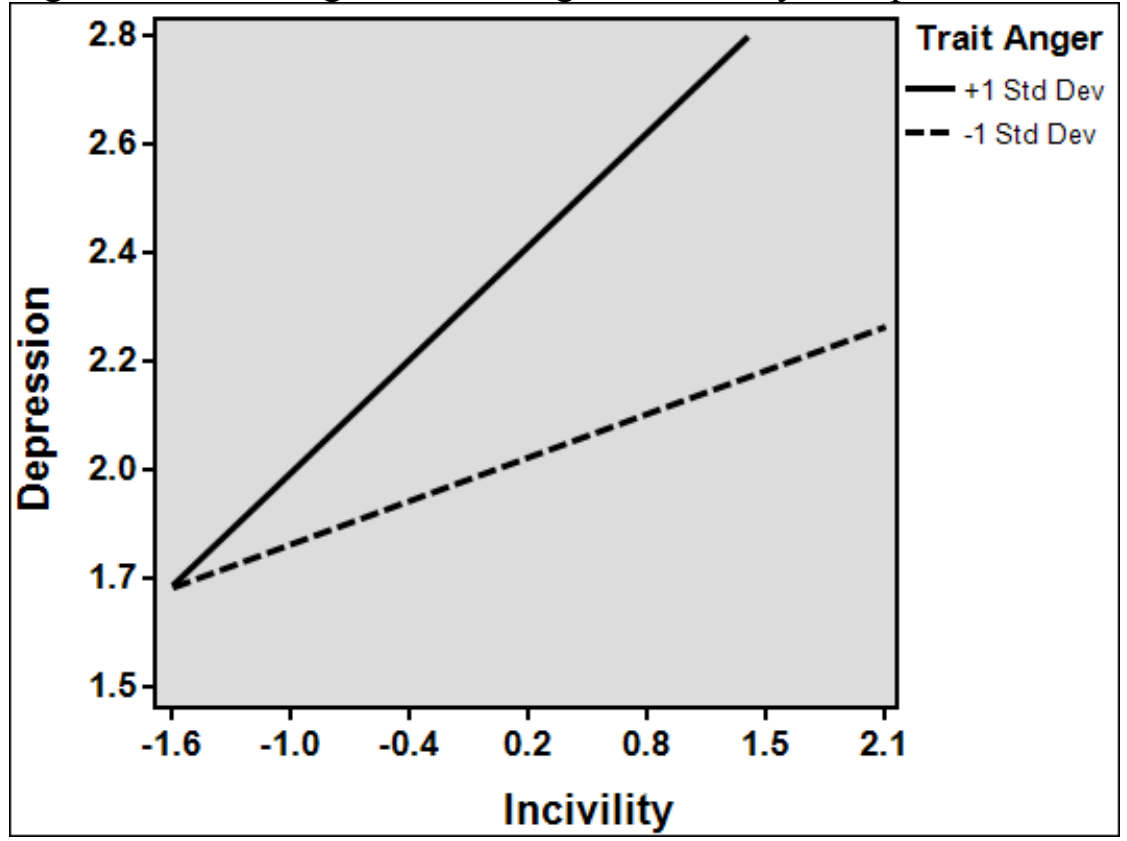

Note: -1 Std Dev effect size $=0.14, L L I C=0.09, U L C I=0.19,+1$ Std Dev effect size $=0.37, L L C I=0.31$, $U L C I=0.43 . \mathrm{LLCI}=$ lower limit confidence interval. $\mathrm{ULCI}=$ upper limit confidence interval.

Figure 49: Trait anger moderating the incivility to physical symptoms relationship

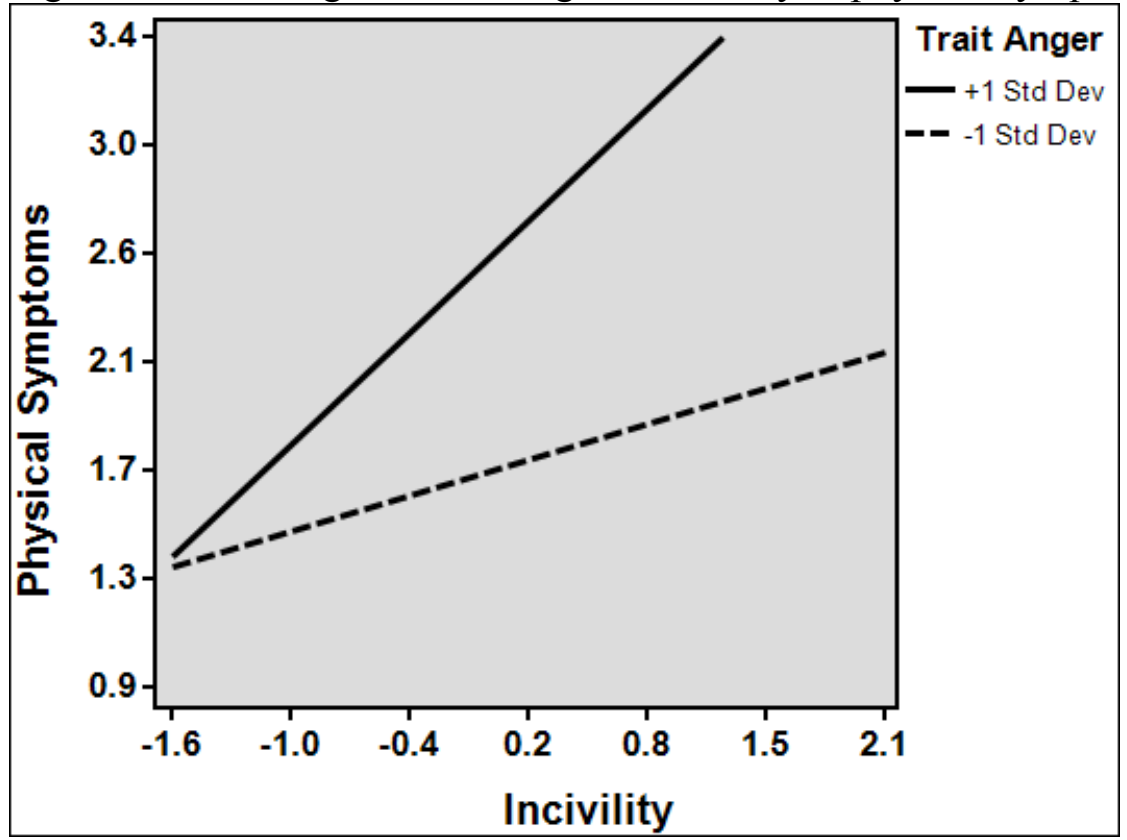

Note: -1 Std Dev effect size $=0.22, L L I C=0.12, U L C I=0.33,+1$ Std Dev effect size $=0.70, L L C I=0.58$, $U L C I=0.82 . \mathrm{LLCI}=$ lower limit confidence interval. $\mathrm{ULCI}=$ upper limit confidence interval. 
Figure 50: Trait anger moderating the incivility to stress relationship

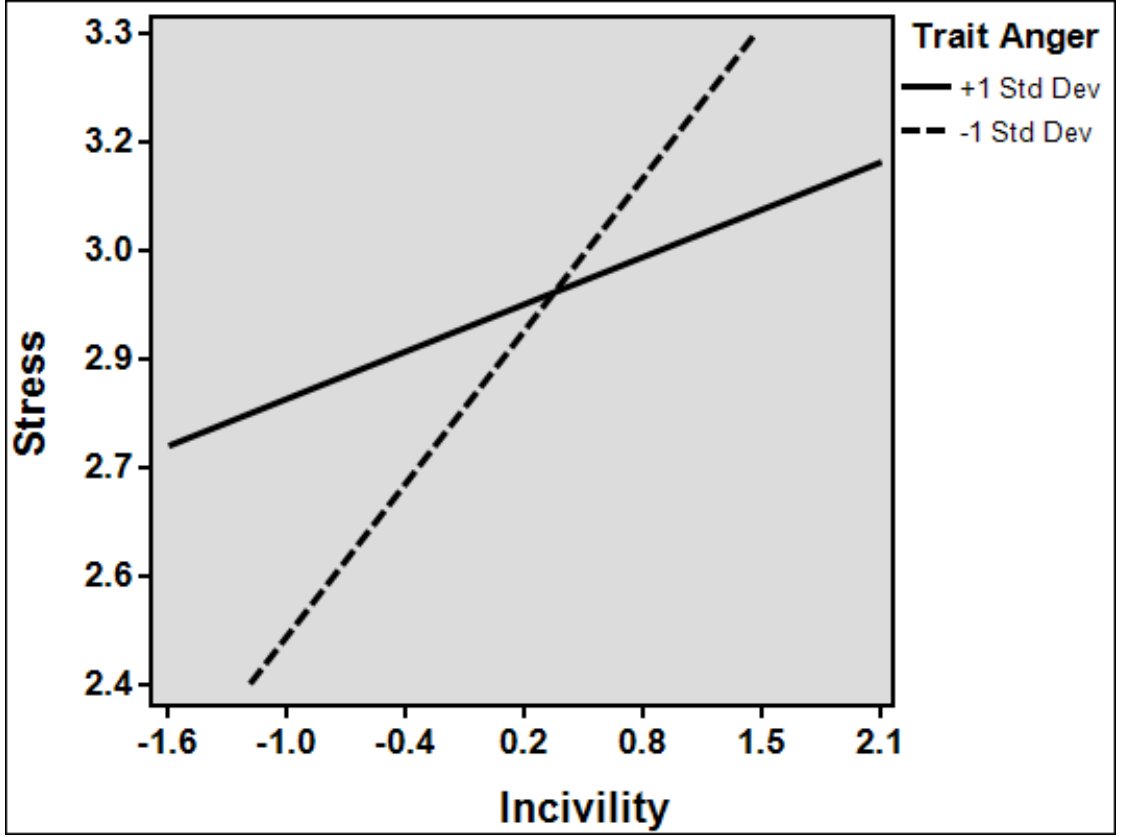

Note: -1 Std Dev effect size $=0.34, L L I C=0.27, U L C I=0.41,+1$ Std Dev effect size $=0.11, L L C I=0.02$, $U L C I=0.19 . \mathrm{LLCI}=$ lower limit confidence interval. $\mathrm{ULCI}=$ upper limit confidence interval.

Figure 51: Trait anger moderating the incivility to job satisfaction relationship

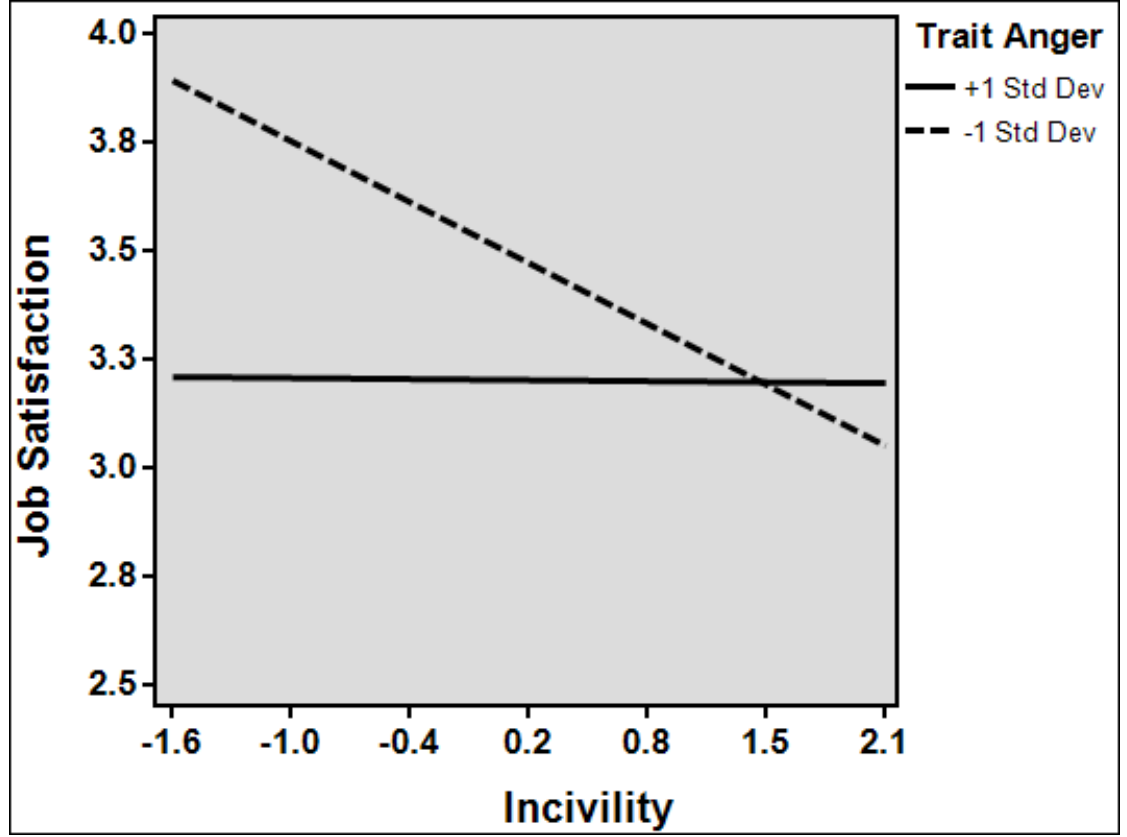

Note: $-1 \mathrm{Std}$ Dev effect size $=-0.23$, LLIC $=-0.38$, ULCI $=-0.08,+1$ Std Dev effect size $=0.00, L L C I=$ $-0.17, U L C I=0.16 . \mathrm{LLCI}=$ lower limit confidence interval. $\mathrm{ULCI}=$ upper limit confidence interval. 
Figure 52: Trait anger moderating the incivility to life satisfaction relationship

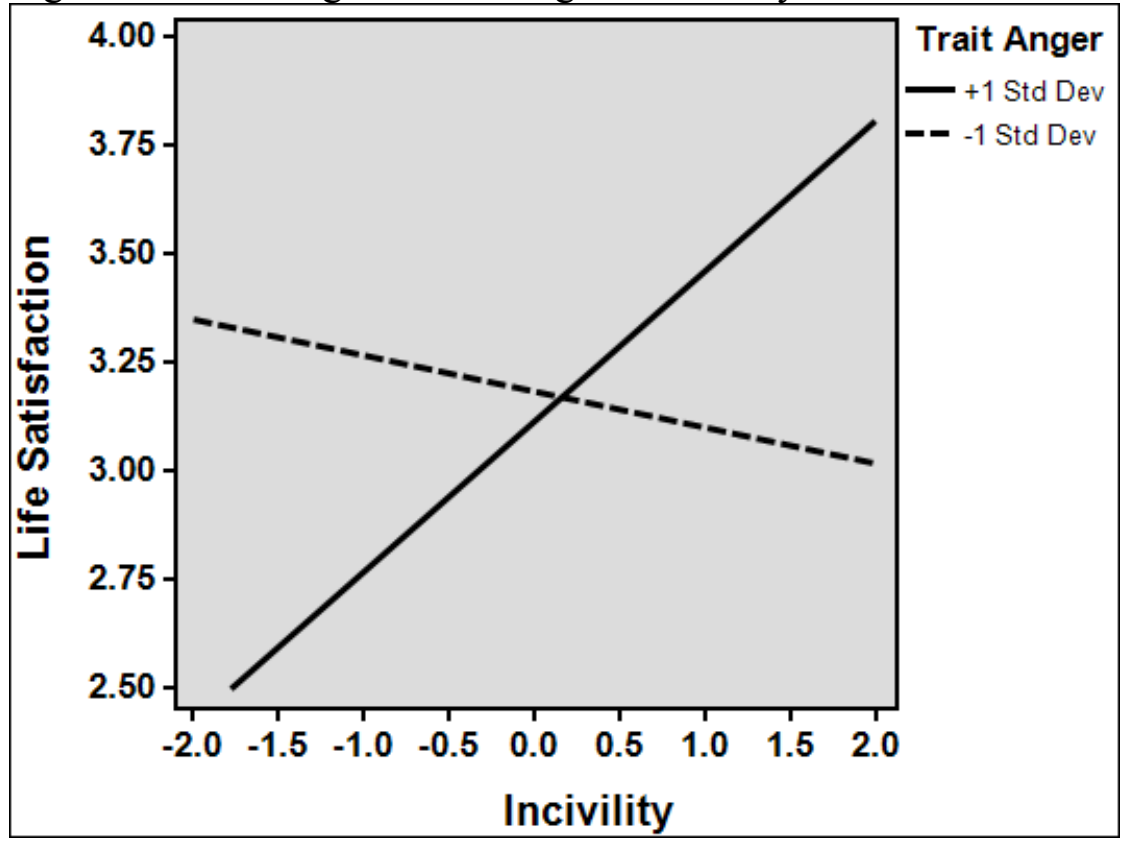

Note: -1 Std Dev effect size $=-0.08, L L I C=-0.22$, ULCI $=0.05,+1$ Std Dev effect size $=0.35, L L C I=$ $0.20, U L C I=0.49$. LLCI $=$ lower limit confidence interval. ULCI $=$ upper limit confidence interval.

Figure 53: Trait anger moderating the relationship conflict to depression relationship

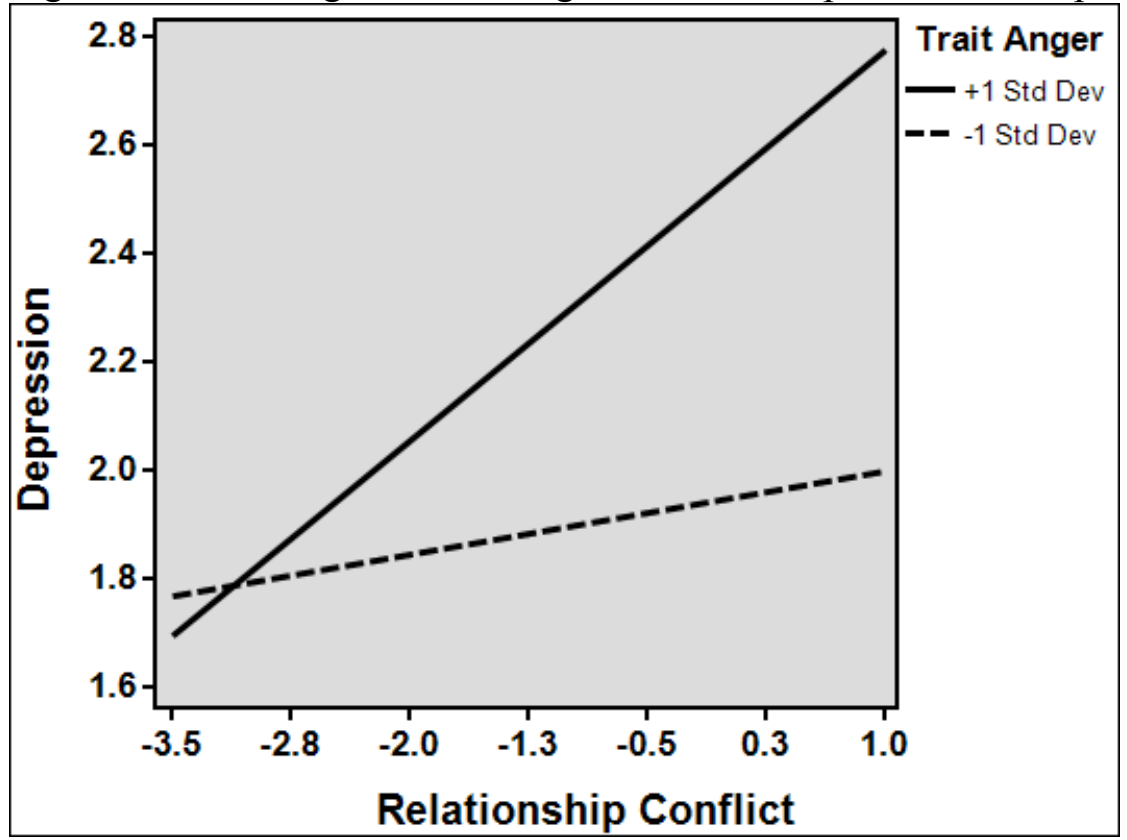

Note: -1 Std Dev effect size $=0.05, L L I C=-0.02, U L C I=0.12,+1$ Std Dev effect size $=0.23, L L C I=$ $0.16, U L C I=0.29 . \mathrm{LLCI}=$ lower limit confidence interval. ULCI $=$ upper limit confidence interval. 
Figure 54: Trait anger moderating the relationship conflict to physical symptoms relationship

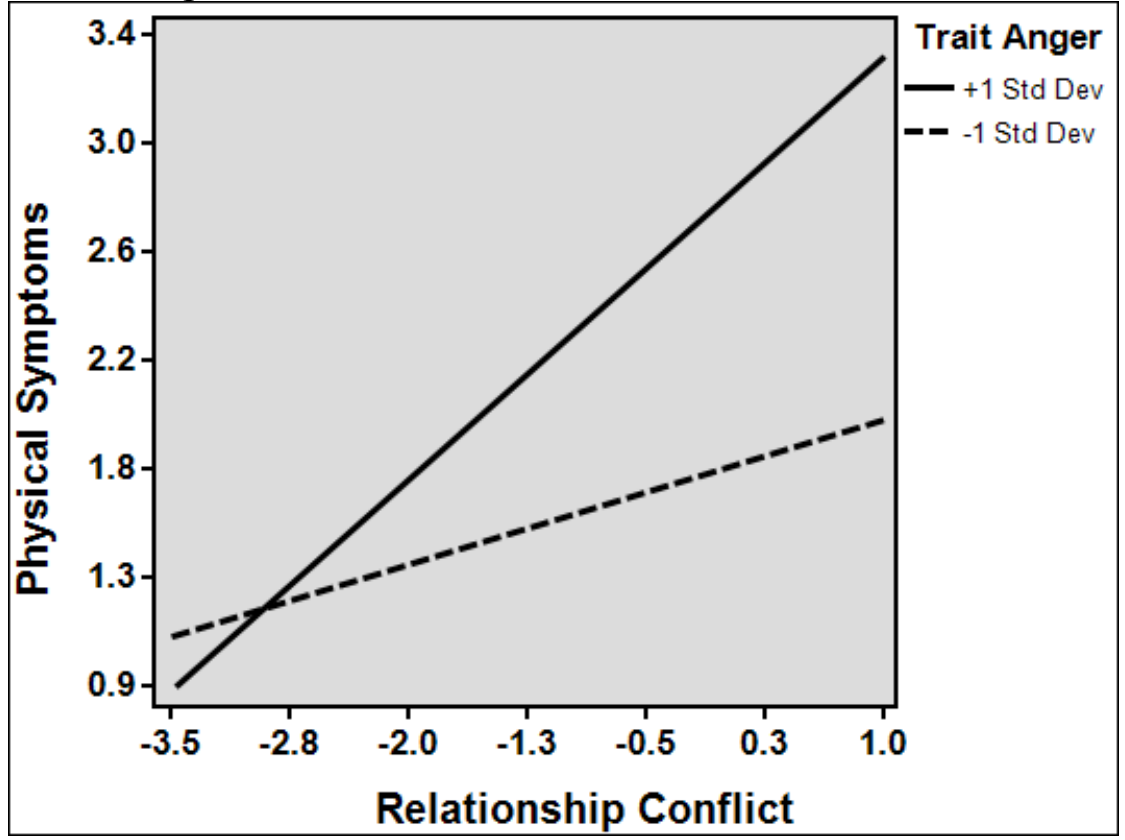

Note: -1 Std Dev effect size $=0.19, L L I C=0.04, U L C I=0.33,+1$ Std Dev effect size $=0.55, L L C I=0.41$, $U L C I=0.68 . \mathrm{LLCI}=$ lower limit confidence interval. $\mathrm{ULCI}=$ upper limit confidence interval.

Figure 55: Trait anger moderating the relationship conflict to stress relationship

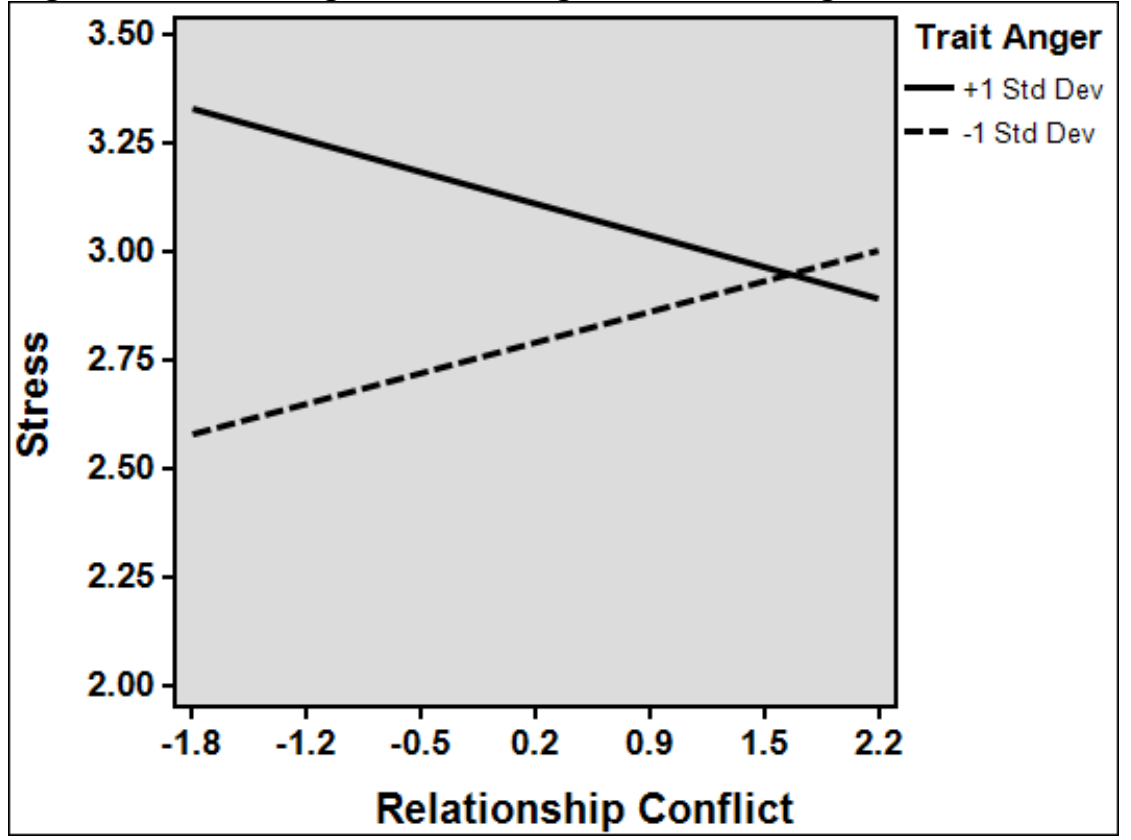

Note: -1 Std Dev effect size $=0.11, L L I C=0.01, U L C I=0.21,+1$ Std Dev effect size $=-0.11, L L C I=$ $-0.20, U L C I=-0.02$. LLCI $=$ lower limit confidence interval. ULCI $=$ upper limit confidence interval. 
Figure 56: Trait anger moderating the relationship conflict to job satisfaction relationship

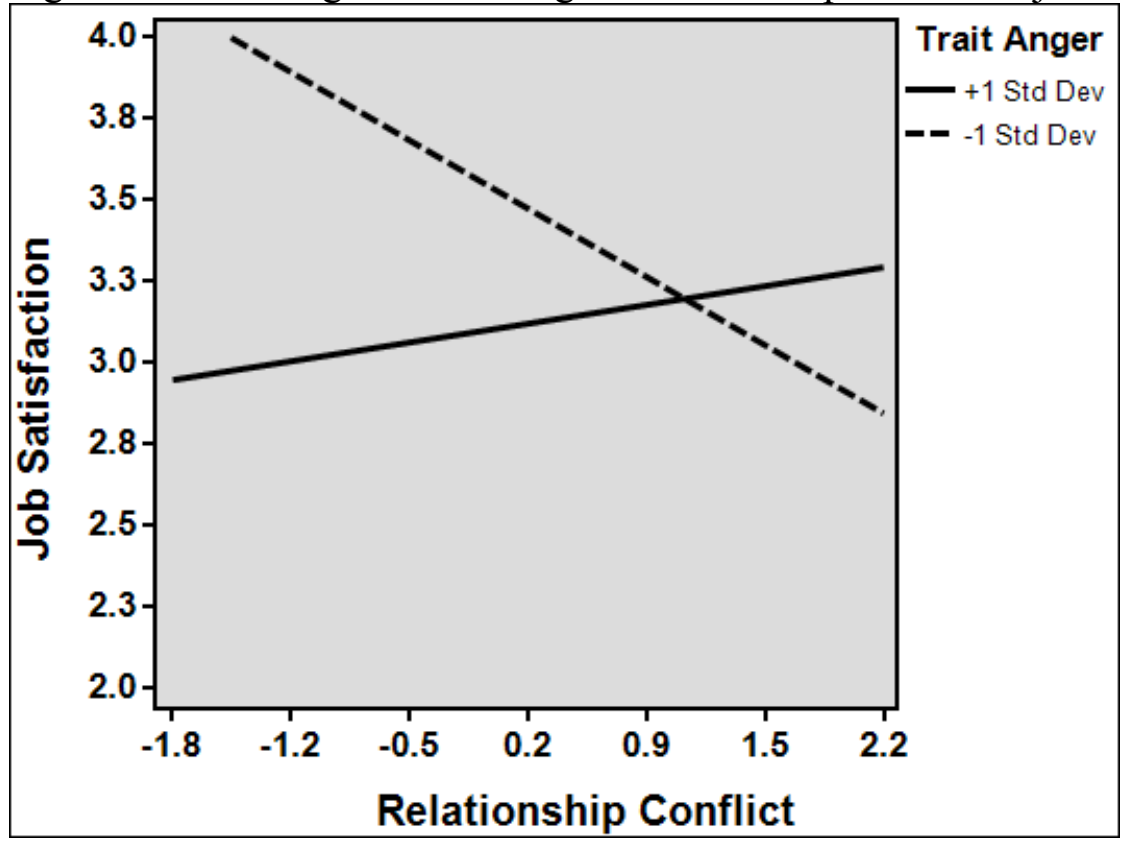

Note: -1 Std Dev effect size $=-0.31, L L I C=-0.49, U L C I=-0.13,+1$ Std Dev effect size $=0.09, L L C I=$ $-0.08, U L C I=0.25 . \mathrm{LLCI}=$ lower limit confidence interval. ULCI $=$ upper limit confidence interval.

Figure 57: Trait anger moderating the relationship conflict to life satisfaction relationship

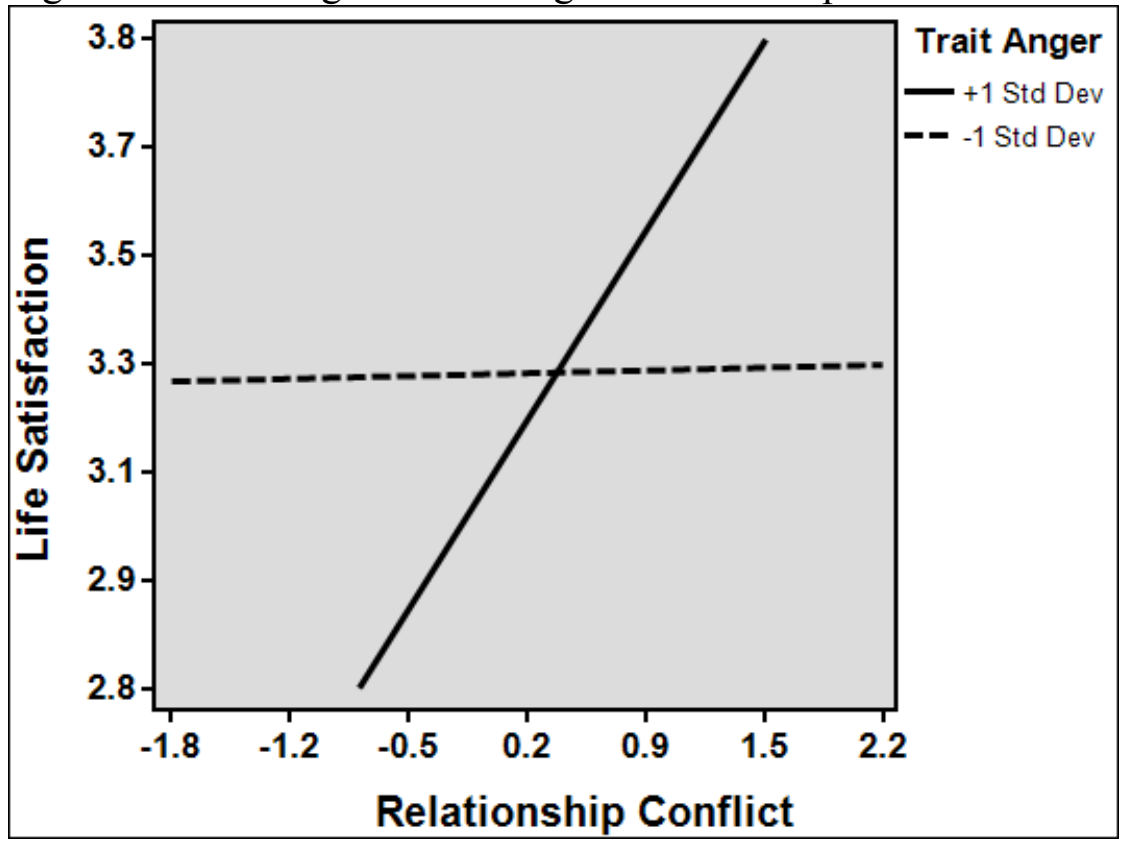

Note: -1 Std Dev effect size $=0.01, L L I C=-0.15, U L C I=0.17,+1$ Std Dev effect size $=0.47, L L C I=$ $0.32, U L C I=0.62 . \mathrm{LLCI}=$ lower limit confidence interval. ULCI $=$ upper limit confidence interval. 
Figure 58: Trait anger moderating the task conflict to depression relationship

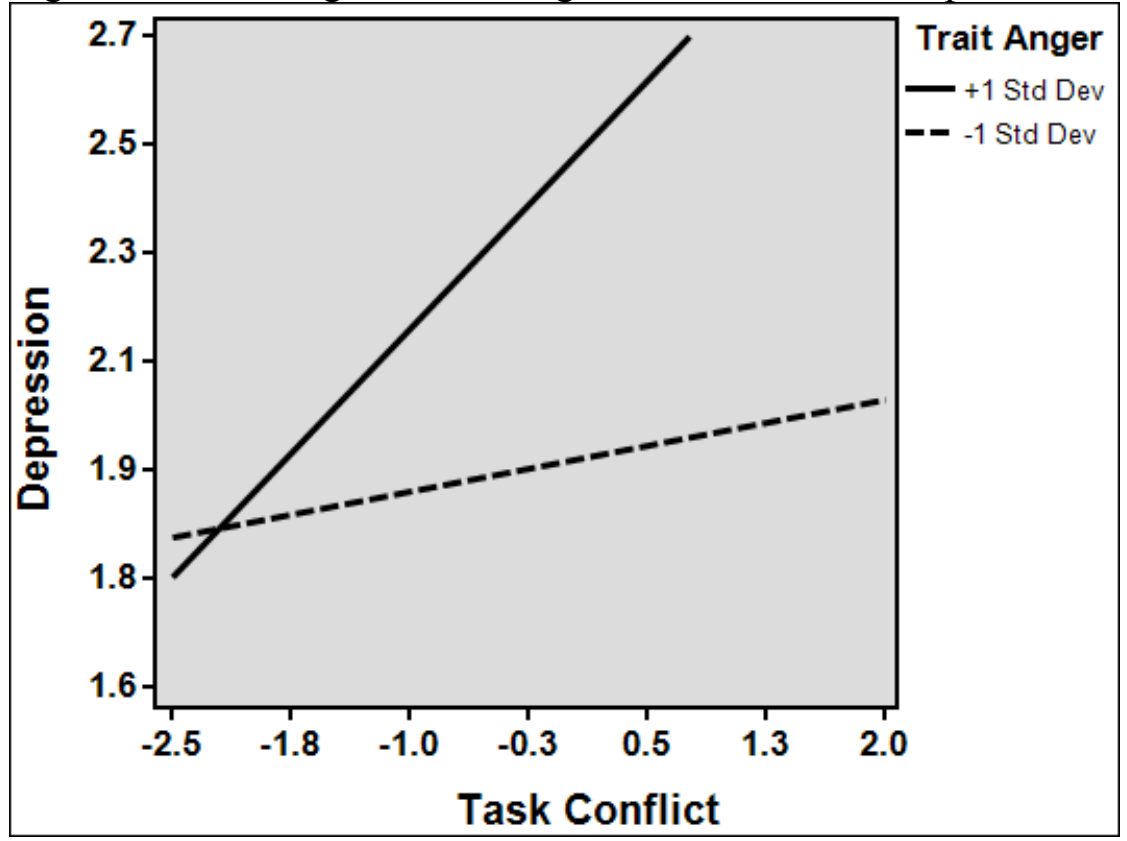

Note: -1 Std Dev effect size $=0.05, L L I C=-0.01, U L C I=0.12,+1$ Std Dev effect size $=0.29, L L C I=$ $0.23, U L C I=0.35 . \mathrm{LLCI}=$ lower limit confidence interval. $\mathrm{ULCI}=$ upper limit confidence interval.

Figure 59: Trait anger moderating the task conflict to physical symptoms relationship

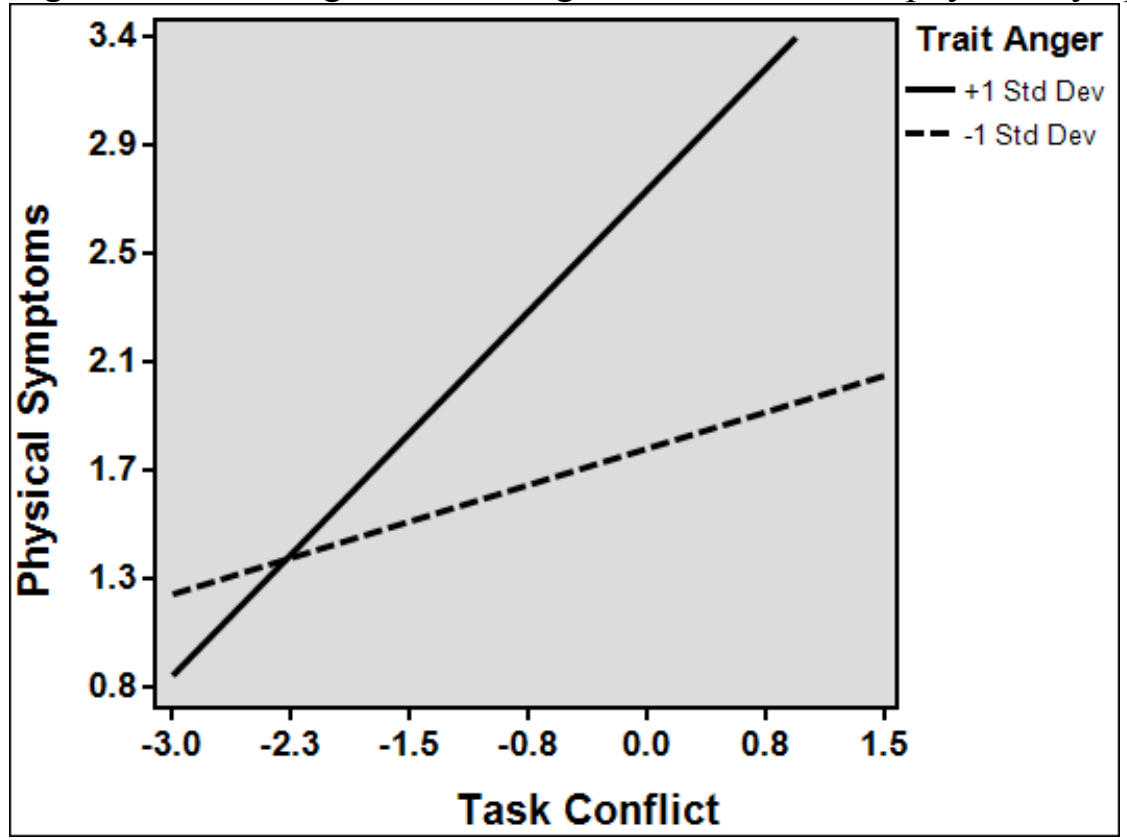

Note: -1 Std Dev effect size $=0.19, L L I C=0.06, U L C I=0.32,+1$ Std Dev effect size $=0.63, L L C I=0.50$, $U L C I=0.76 . \mathrm{LLCI}=$ lower limit confidence interval. $\mathrm{ULCI}=$ upper limit confidence interval. 
Figure 60: Trait anger moderating the task conflict to stress relationship

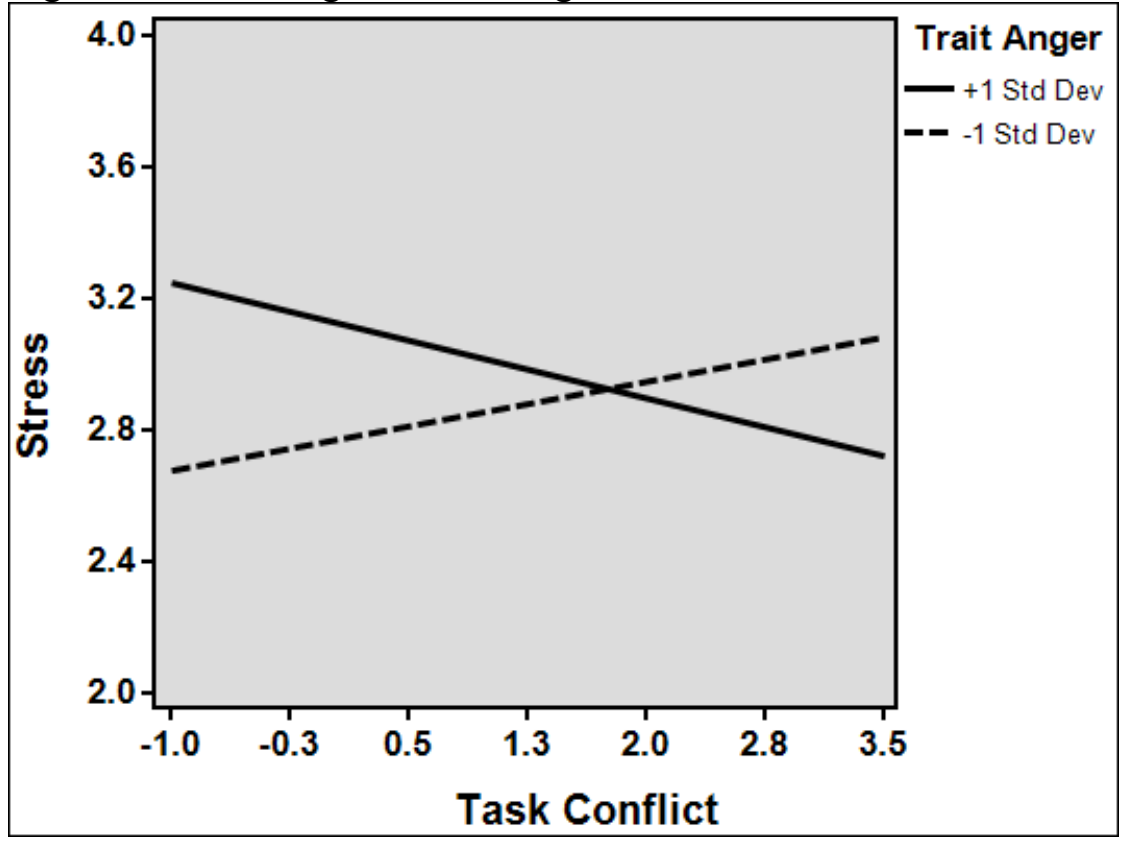

Note: -1 Std Dev effect size $=0.09, L L I C=0.00, U L C I=0.18,+1$ Std Dev effect size $=-0.12, L L C I=$ $-0.21, U L C I=-0.02 \mathrm{LLCI}=$ lower limit confidence interval. $\mathrm{ULCI}=$ upper limit confidence interval.

Figure 61: Trait anger moderating the task conflict to job satisfaction relationship

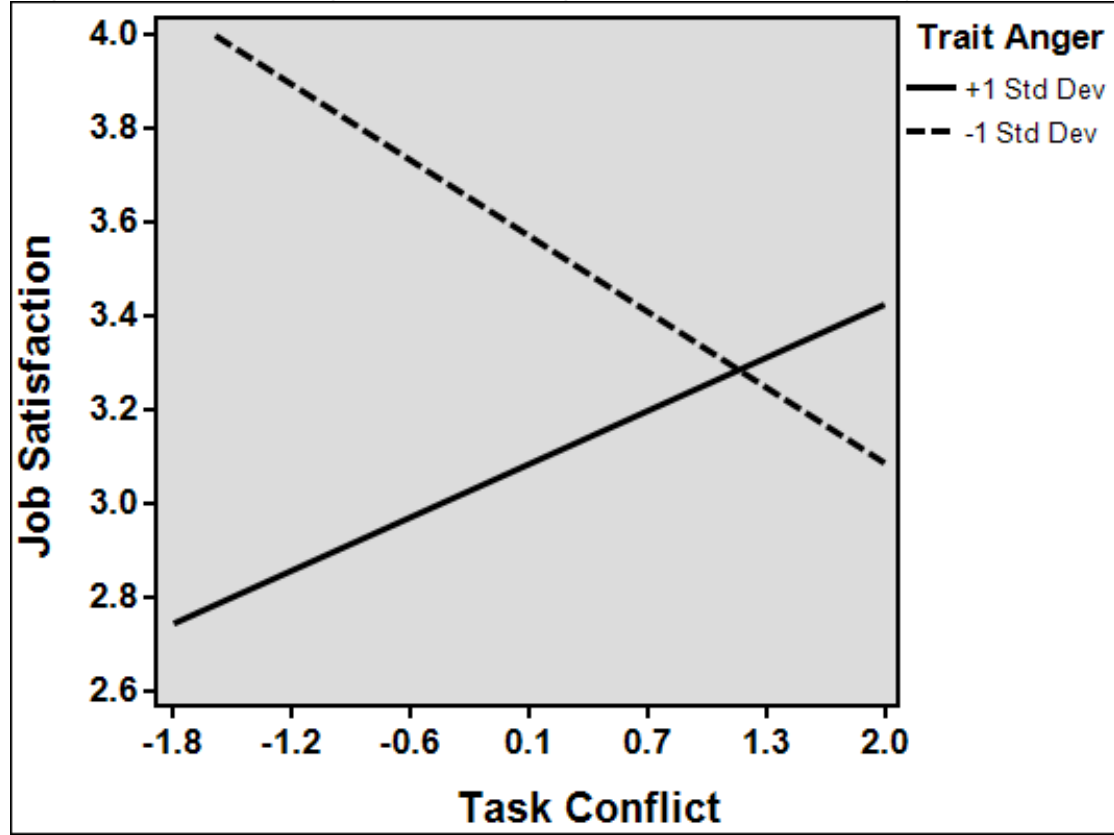

Note: $-1 \mathrm{Std}$ Dev effect size $=-0.26$, LLIC $=-0.43$, ULCI $=-0.09,+1$ Std Dev effect size $=0.18, L L C I=$ $0.01, U L C I=0.35 . \mathrm{LLCI}=$ lower limit confidence interval. $\mathrm{ULCI}=$ upper limit confidence interval. 
Figure 62: Trait anger moderating the task conflict to life satisfaction relationship

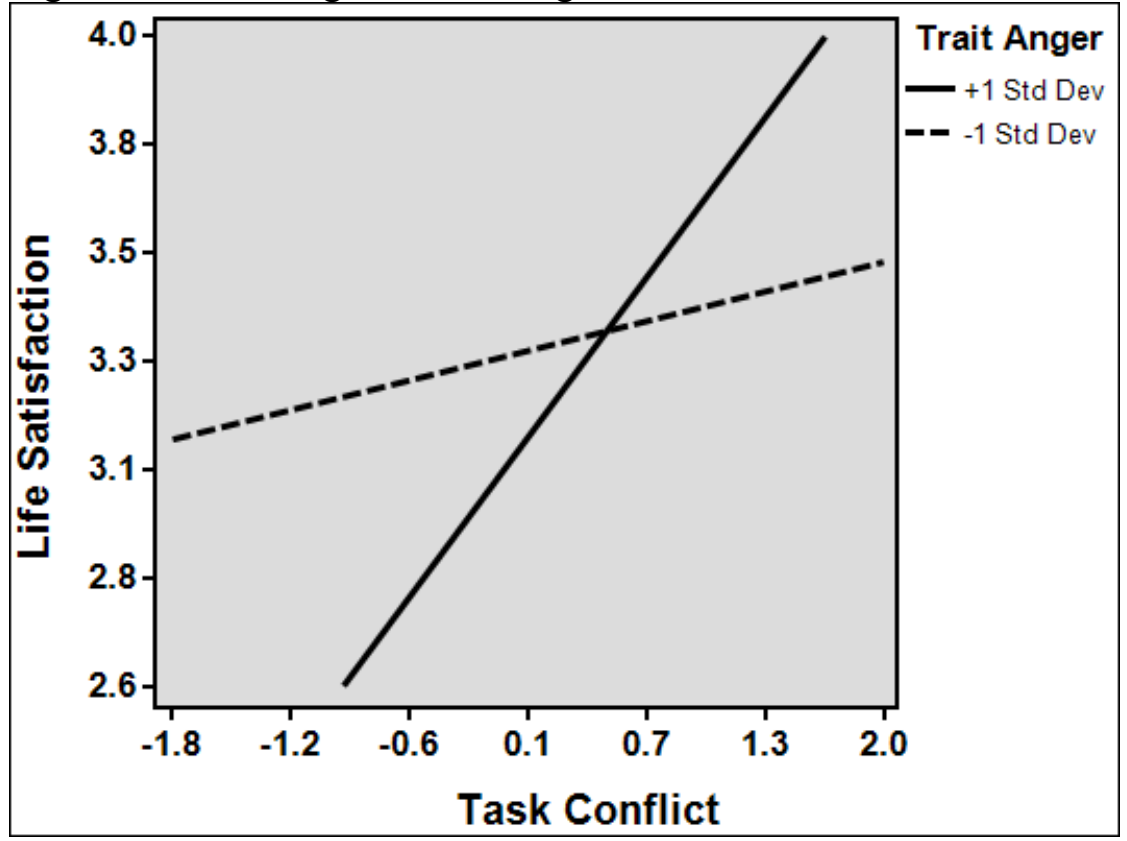

Note: -1 Std Dev effect size $=0.10, L L I C=-0.05, U L C I=0.25,+1$ Std Dev effect size $=0.54, L L C I=$ $0.39, U L C I=0.69 . \mathrm{LLCI}=$ lower limit confidence interval. ULCI $=$ upper limit confidence interval.

Figure 63: Locus of control moderating the incivility to negative emotions relationship

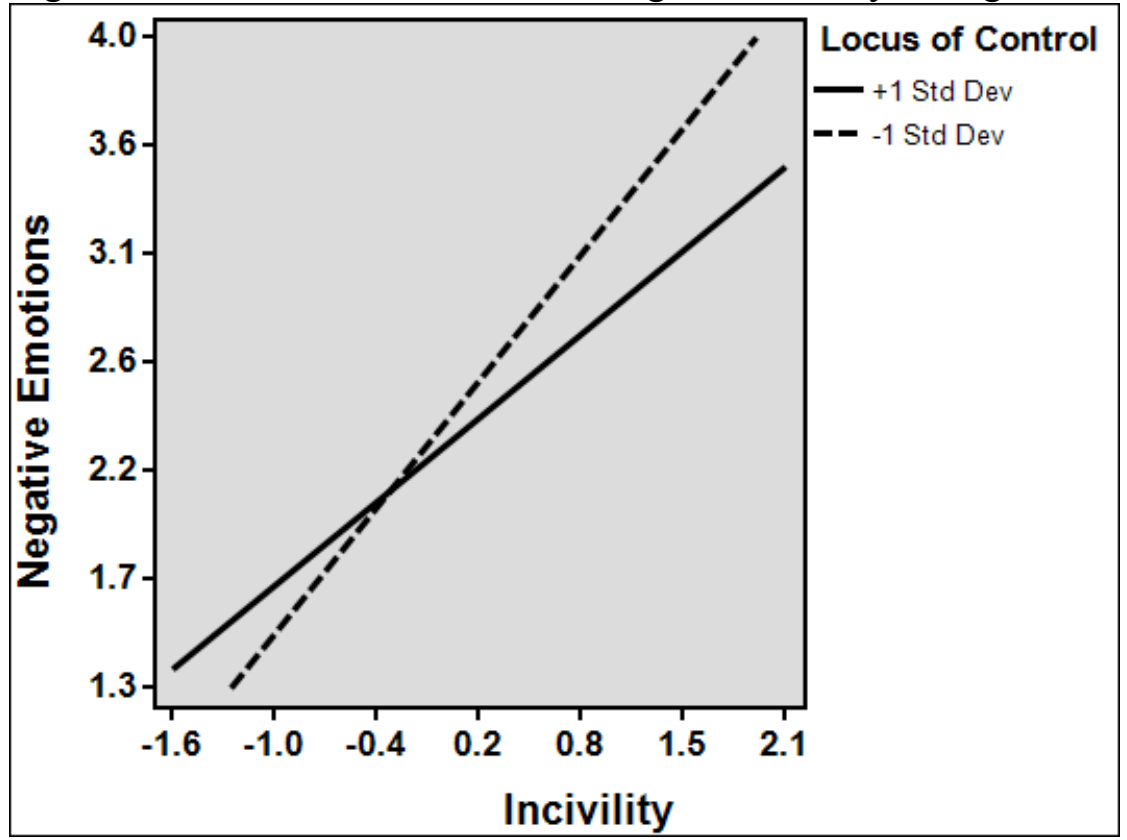

Note: -1 Std Dev effect size $=0.86, L L I C=0.72, U L C I=1.00,+1$ Std Dev effect size $=0.57, L L C I=0.46$, $U L C I=0.69 . \mathrm{LLCI}=$ lower limit confidence interval. ULCI $=$ upper limit confidence interval. 
Figure 64: Locus of control moderating the relationship conflict to negative emotions relationship

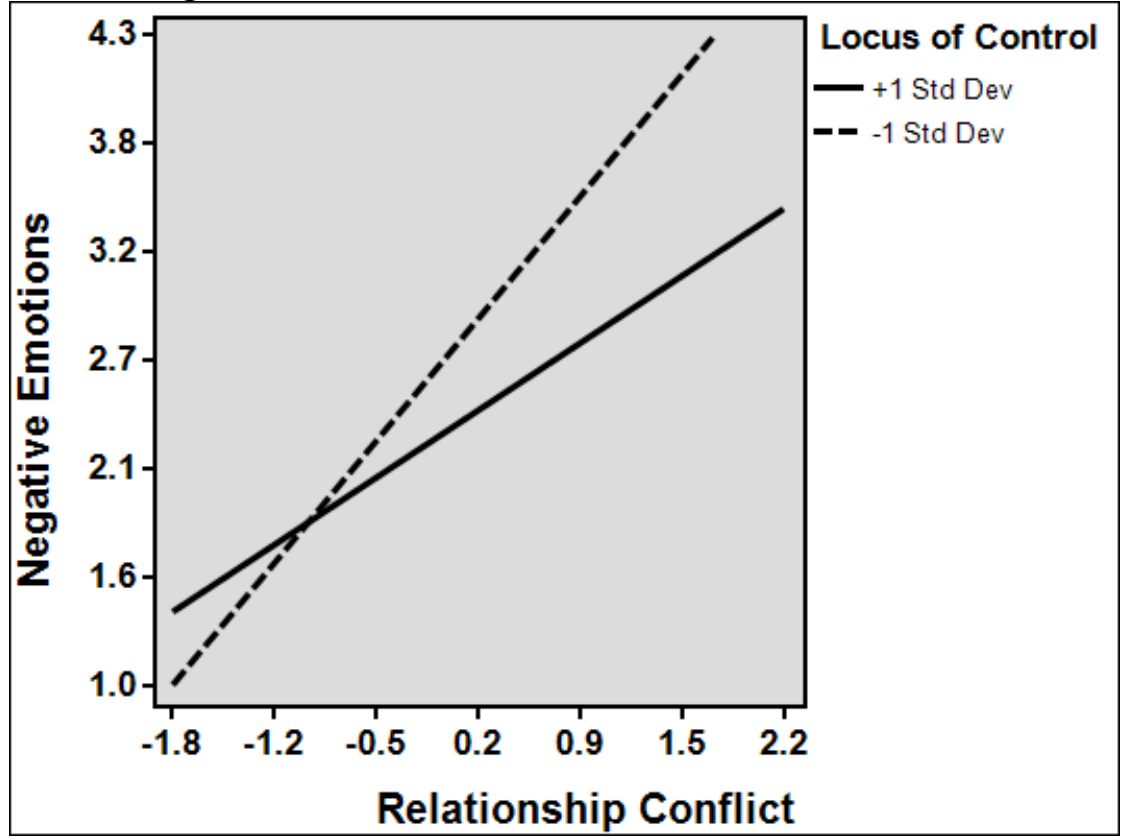

Note: -1 Std Dev effect size $=0.93, L L I C=0.78, U L C I=1.08,+1$ Std Dev effect size $=0.51, L L C I=0.38$, $U L C I=0.64 . \mathrm{LLCI}=$ lower limit confidence interval. $\mathrm{ULCI}=$ upper limit confidence interval.

Figure 65: Locus of control moderating the task conflict to negative emotions relationship

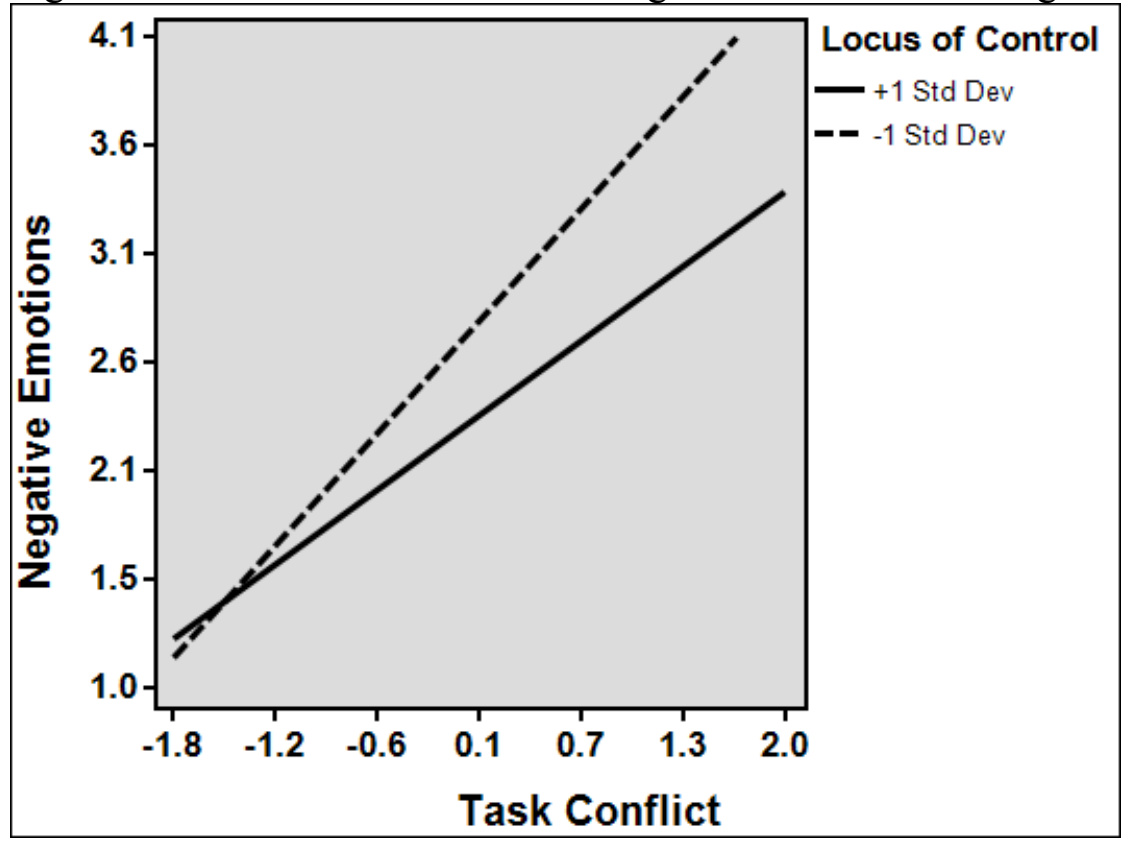

Note: -1 Std Dev effect size $=0.84, L L I C=0.71, U L C I=0.97,+1$ Std Dev effect size $=0.56, L L C I=0.43$, $U L C I=0.68 . \mathrm{LLCI}=$ lower limit confidence interval. $\mathrm{ULCI}=$ upper limit confidence interval. 
Figure 66: Locus of control moderating the incivility to depression relationship

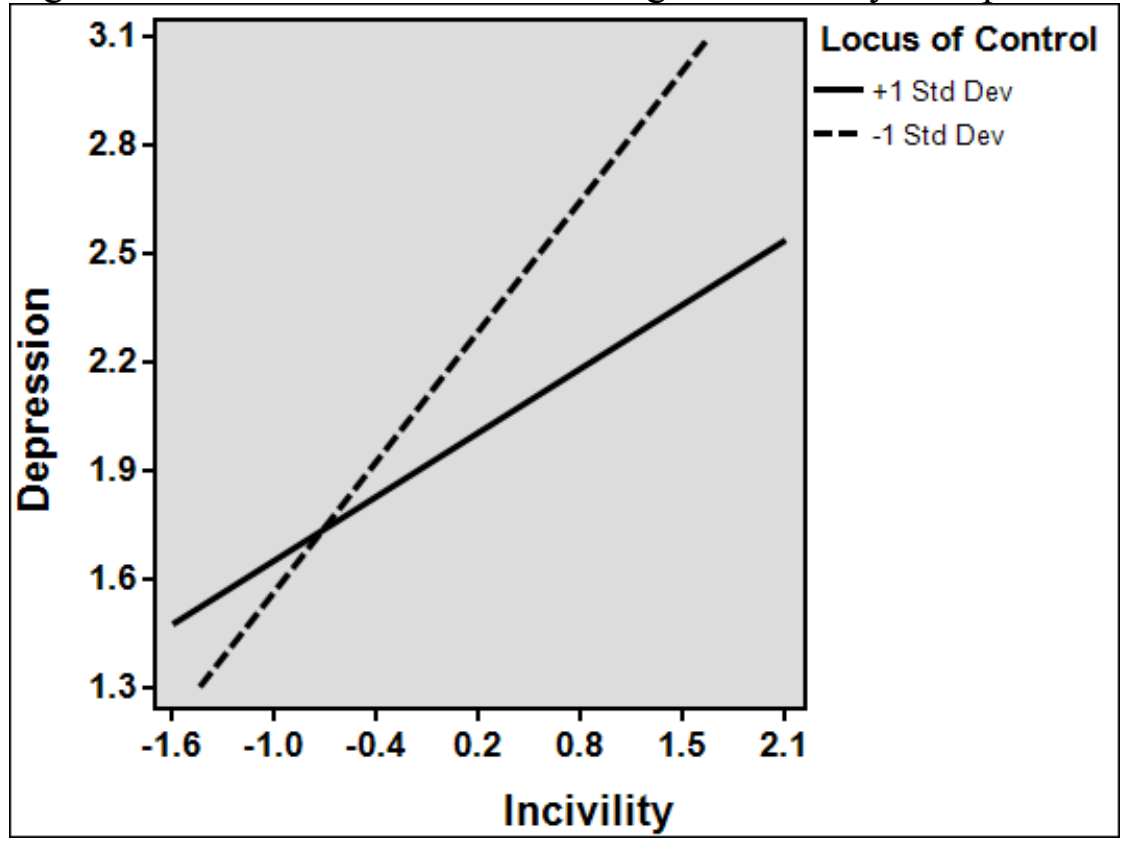

Note: -1 Std Dev effect size $=0.58, L L I C=0.51, U L C I=0.65,+1$ Std Dev effect size $=0.28, L L C I=0.22$, $U L C I=0.35 . \mathrm{LLCI}=$ lower limit confidence interval. $\mathrm{ULCI}=$ upper limit confidence interval.

Figure 67: Locus of control moderating the incivility to physical symptoms relationship

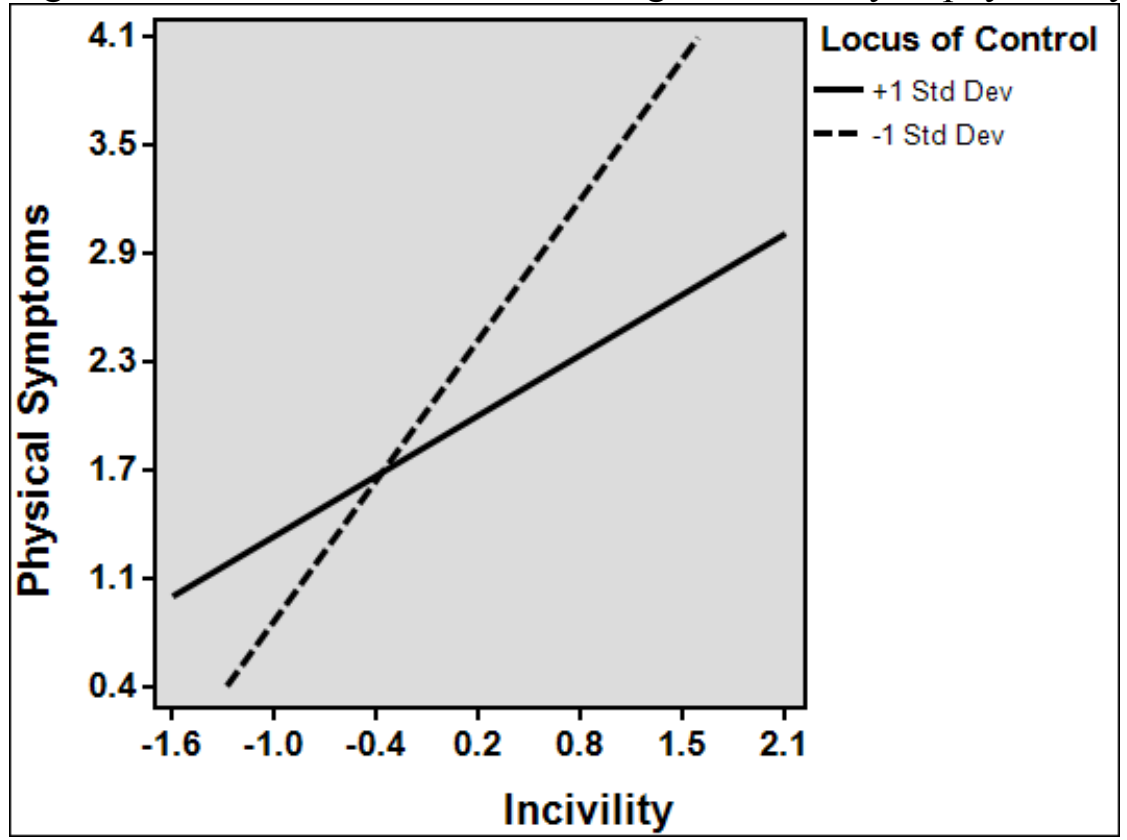

Note: -1 Std Dev effect size $=1.27, L L I C=1.2, U L C I=1.42,+1$ Std Dev effect size $=0.55, L L C I=0.42$, $U L C I=0.68 . \mathrm{LLCI}=$ lower limit confidence interval. $\mathrm{ULCI}=$ upper limit confidence interval. 
Figure 68: Locus of control moderating the incivility to stress relationship

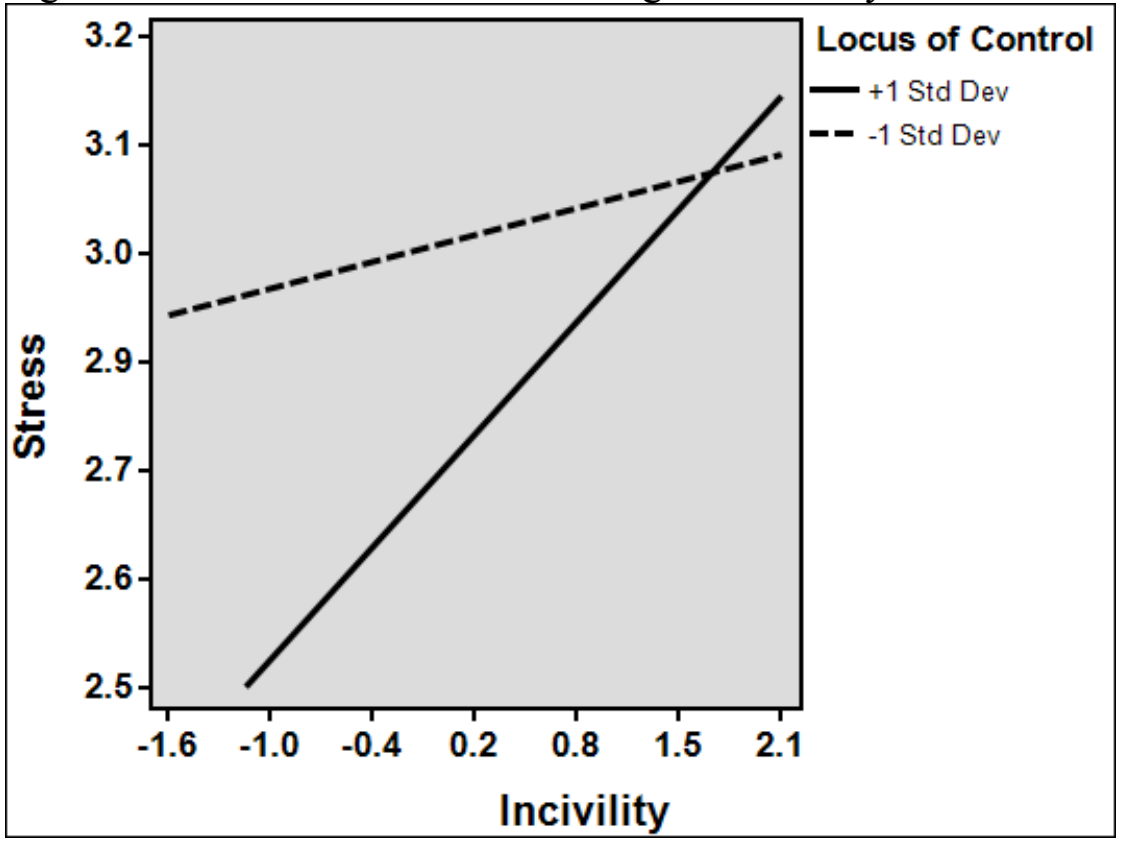

Note: -1 Std Dev effect size $=0.05, L L I C=-0.03, U L C I=0.13,+1$ Std Dev effect size $=0.22, L L C I=$ $0.15, U L C I=0.29 . \mathrm{LLCI}=$ lower limit confidence interval. $\mathrm{ULCI}=$ upper limit confidence interval.

Figure 69: Locus of control moderating the incivility to life satisfaction relationship

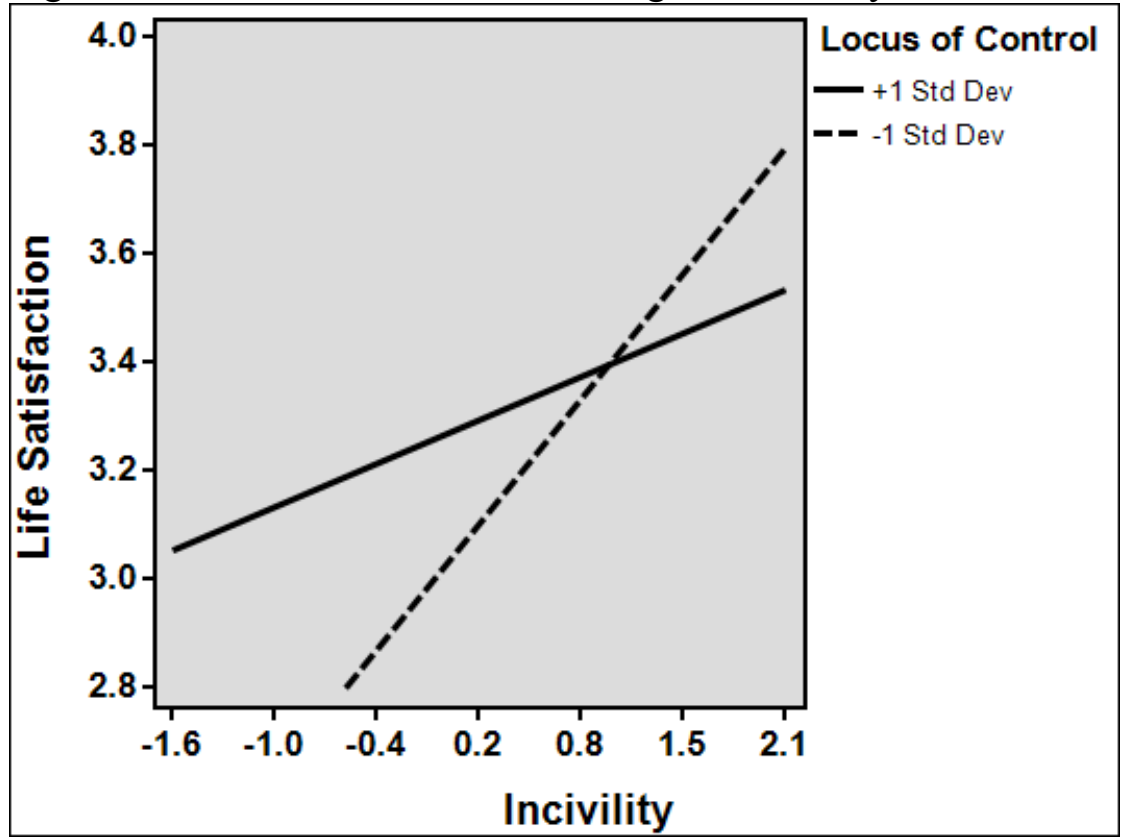

Note: -1 Std Dev effect size $=0.37, L L I C=0.22, U L C I=0.53,+1$ Std Dev effect size $=0.13, L L C I=$ $-0.01, U L C I=0.26 . \mathrm{LLCI}=$ lower limit confidence interval. $\mathrm{ULCI}=$ upper limit confidence interval. 
Figure 70: Locus of control moderating the relationship conflict to depression relationship

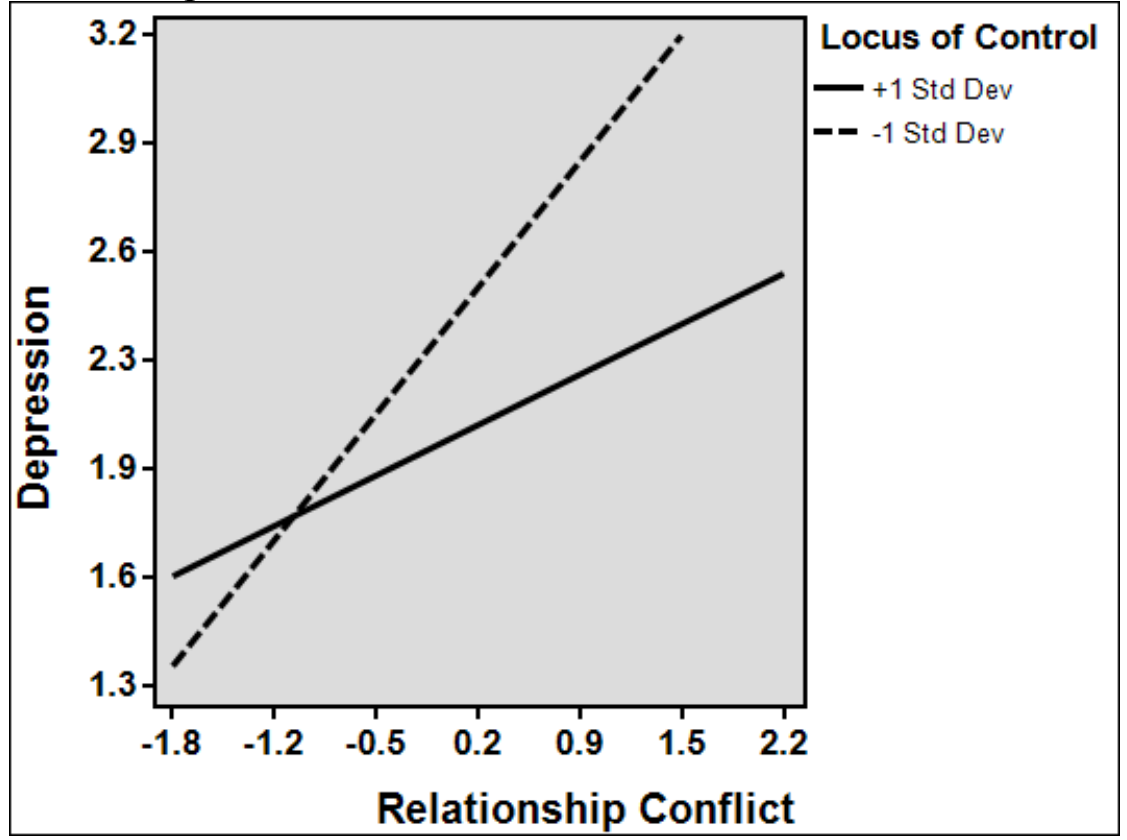

Note: -1 Std Dev effect size $=0.58, L L I C=0.49, U L C I=0.66,+1$ Std Dev effect size $=0.23, L L C I=0.15$, $U L C I=0.30 . \mathrm{LLCI}=$ lower limit confidence interval. $\mathrm{ULCI}=$ upper limit confidence interval.

Figure 71: Locus of control moderating the relationship conflict to physical symptoms relationship

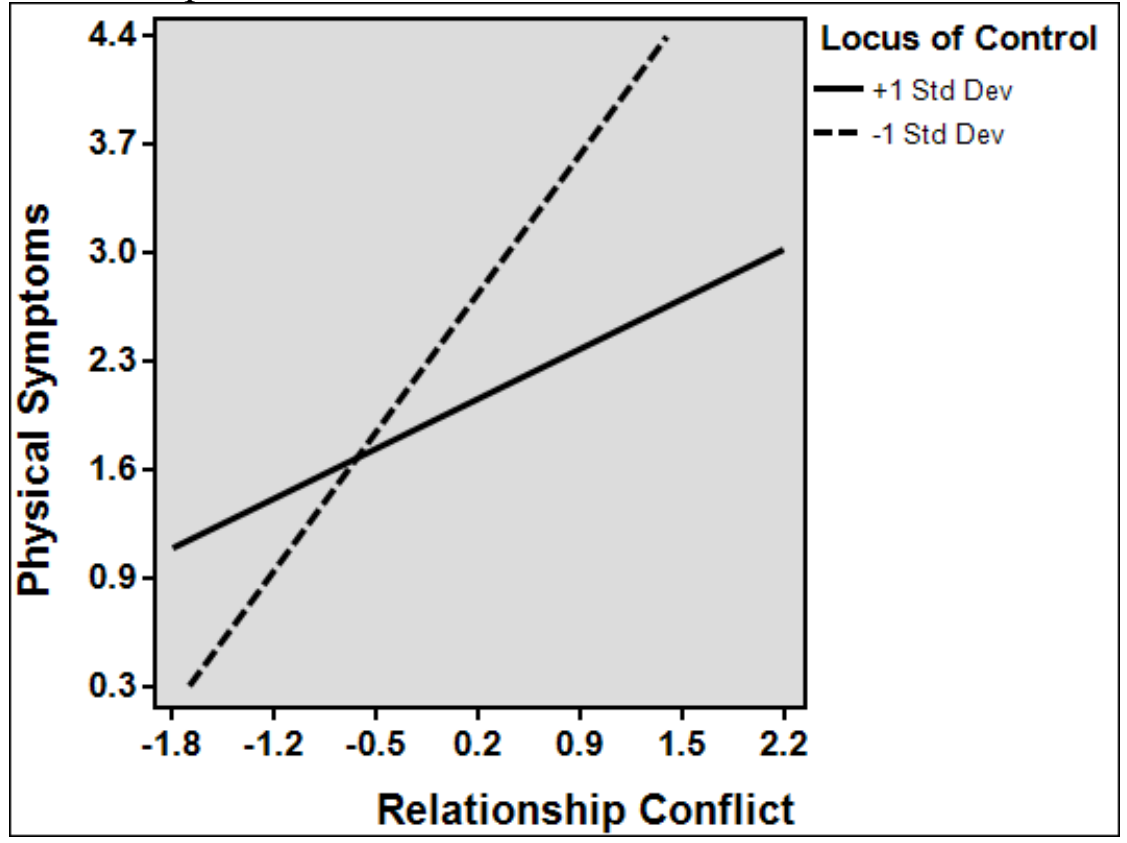

Note: -1 Std Dev effect size $=1.32, L L I C=1.16, U L C I=1.49,+1$ Std Dev effect size $=0.47, L L C I=0.33$, $U L C I=0.62 . \mathrm{LLCI}=$ lower limit confidence interval. $\mathrm{ULCI}=$ upper limit confidence interval. 
Figure 72: Locus of control moderating the relationship conflict to job satisfaction relationship

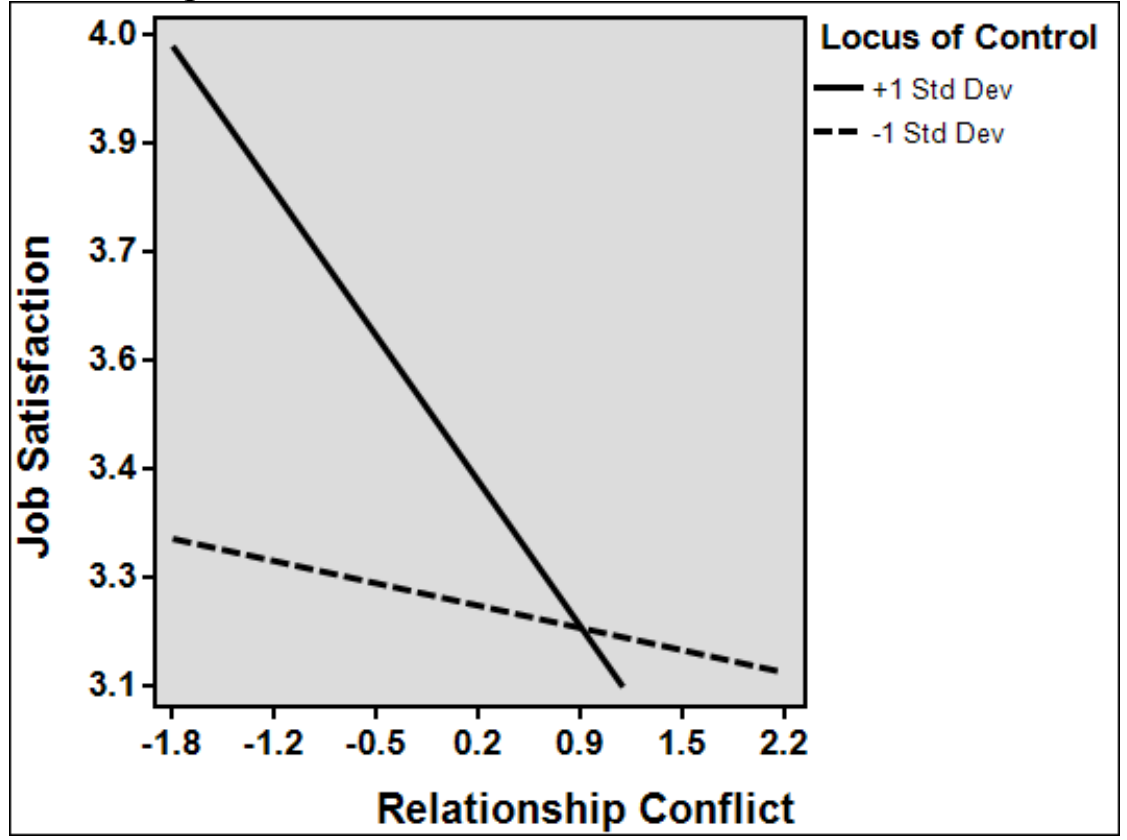

Note: -1 Std Dev effect size $=-0.05$, LLIC $=-0.23, U L C I=0.14,+1$ Std Dev effect size $=-0.30, L L C I=$ $-0.46, U L C I=-0.14 . \mathrm{LLCI}=$ lower limit confidence interval. $\mathrm{ULCI}=$ upper limit confidence interval.

Figure 73: Locus of control moderating the relationship conflict to life satisfaction relationship

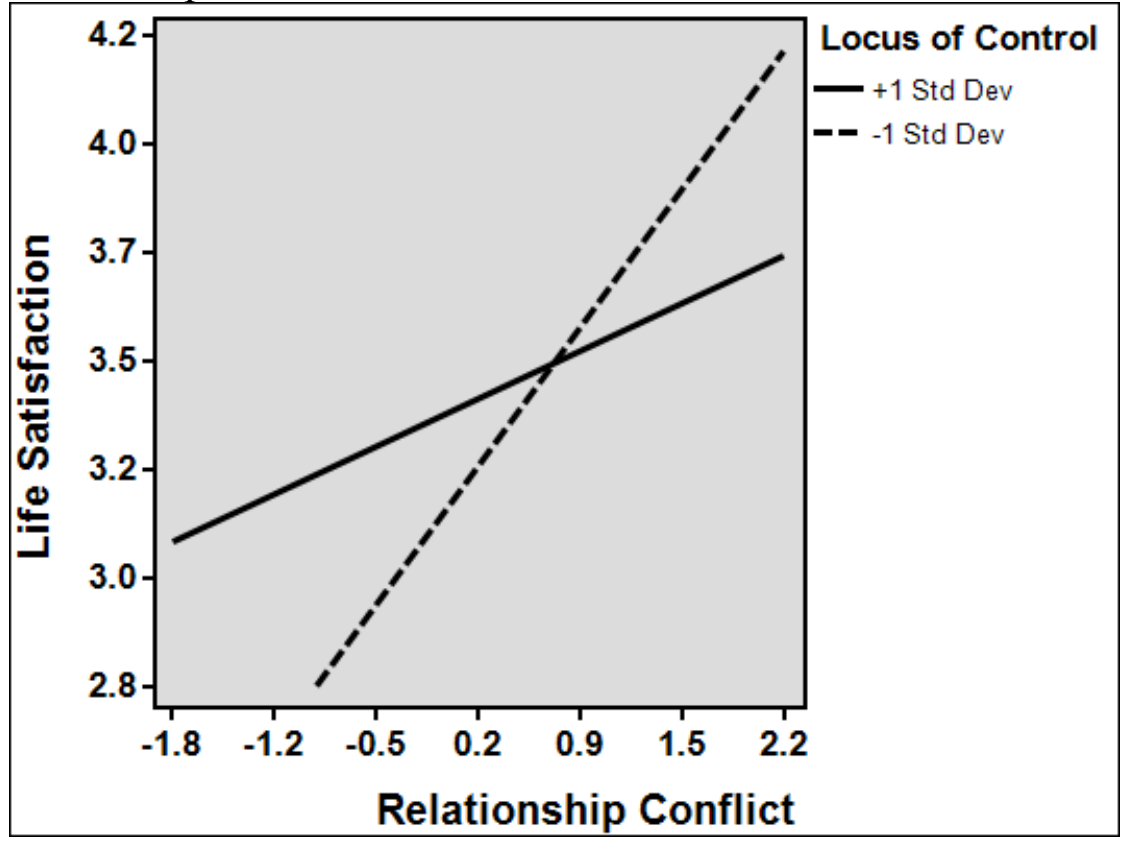

Note: -1 Std Dev effect size $=0.46, L L I C=0.30, U L C I=0.62,+1$ Std Dev effect size $=0.16, L L C I=0.02$, $U L C I=0.30 . \mathrm{LLCI}=$ lower limit confidence interval. $\mathrm{ULCI}=$ upper limit confidence interval. 
Figure 74: Locus of control moderating the task conflict to depression relationship

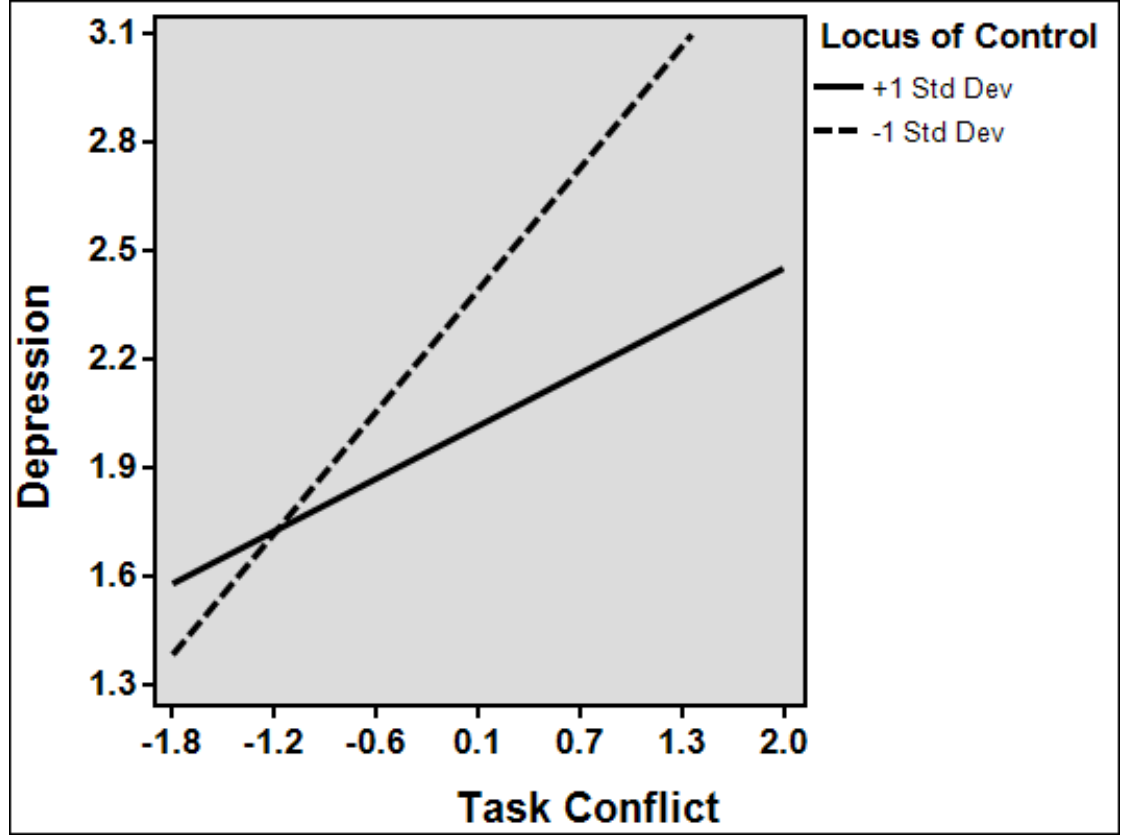

Note: -1 Std Dev effect size $=0.55, L L I C=0.48, U L C I=0.63,+1$ Std Dev effect size $=0.24, L L C I=0.17$, $U L C I=0.31$. LLCI $=$ lower limit confidence interval. $\mathrm{ULCI}=$ upper limit confidence interval.

Figure 75: Locus of control moderating the task conflict to physical symptoms relationship

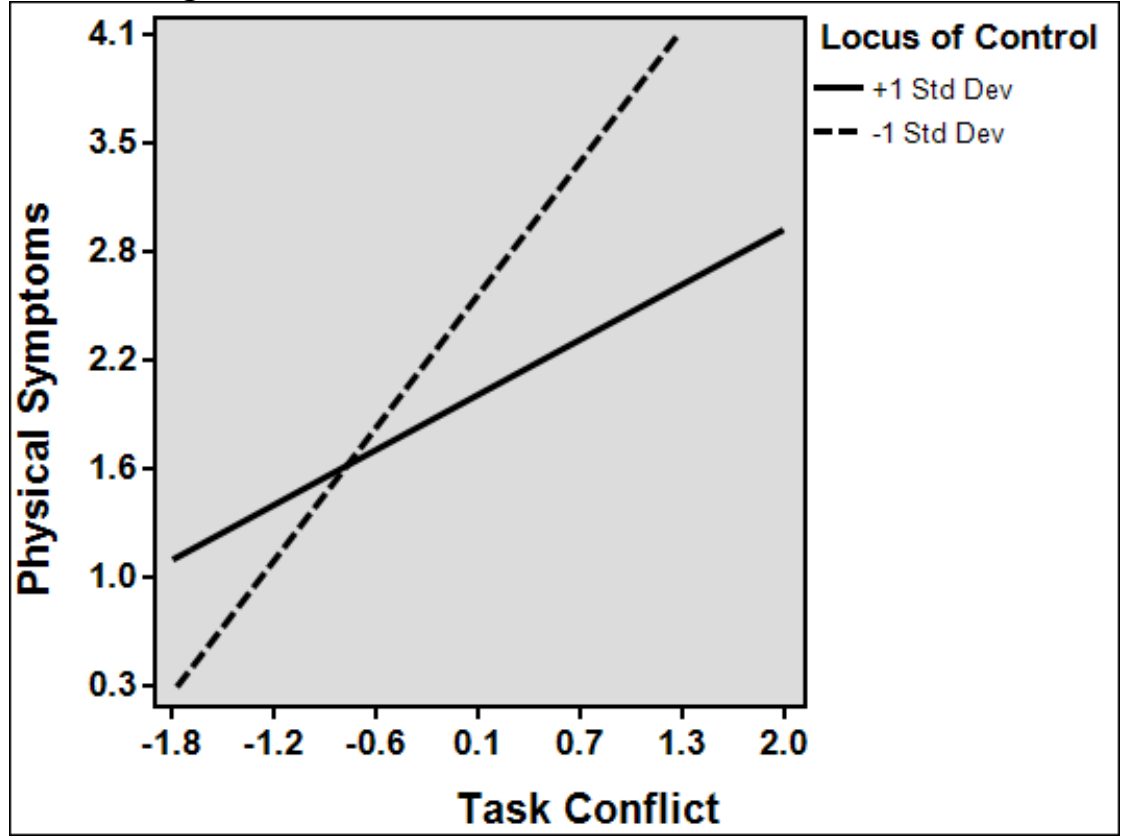

Note: -1 Std Dev effect size $=1.21, L L I C=1.06, U L C I=1.36,+1$ Std Dev effect size $=0.50, L L C I=0.36$, $U L C I=0.64 . \mathrm{LLCI}=$ lower limit confidence interval. $\mathrm{ULCI}=$ upper limit confidence interval. 